$\checkmark$ Library, N.W. BJ.dg UUN i 1963

\title{
TABULATION OF DATA ON RECEIVING TUBES
}

Handbook 83

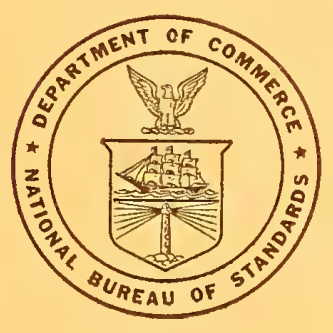

United States Department of Commerce National Bureau of Standards 

UNITED STATES DEPARTMENT OF COMMERCE • Luther H. Hodges, Secretary NATIONAL BUREAU OF STANDARDS - A. V. Astin, Director

\title{
Tabulation of Data on Receiving Tubes
}

\author{
C. P. Marsden and J. K. Moffitt
}

The National Bureau of Standards

Electron Devices Data Service

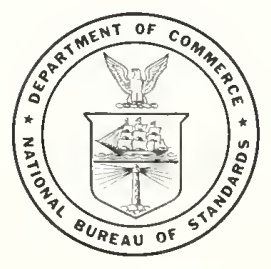

National Bureau of Standards Handbook 83

Issued May 23, 1963

Supersedes Handbook 68 
Library of Congress Catalog Card Number: 63-60063 


\section{Foreword}

This tabulation of data on receiving tubes currently in use has been prepared as part of the National Bureau of Standards Electron Devices Data Service. Established in 1948 to provide technical data on radio tubes to members of the Bureau staff, the service has since been extended to other scientists in government and in industry. In the course of the program, a large volume of information on domestic and foreign tubes has been accumulated on punched cards from which it could be automatically printed. It was felt desirable to make these data available in a single reference source as an aid to circuit designers in selecting tube types for particular uses.

The engineer should find this manual useful in narrowing down the choice of tubes to one or a few types. However, it is not practical to give all possible operating conditions nor to provide the characteristic curves for each tube in a tabulation such as this. It will still be necessary to consult the tube manufacturer's literature for such detailed information.

All information appearing in this publication was taken from manufacturers' published specifications and every effort has been made to ensure accuracy and completeness. However, the Bureau cannot assume responsibility for omissions nor for results obtained with these data.

Additional NBS prepared tabulations which are also available include the following: "Tabulation of Data on Microwave Tubes" NBS Handbook 70 (1961), which represents a listing of foreign and domestic microwave tubes; "Diode Source Book" (published by Semiconductor Products magazine, 1961), which contains charts giving the characteristics of semiconductor diodes, and "Electron Tube Interchangeability Chart" (published by Electronic Industries, $1962)$.

A. V. Astin, Director. 


\section{Contents}

Foreword

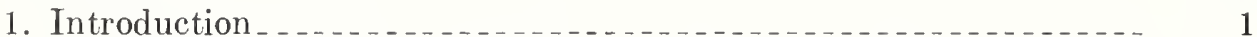

2. Organization of the tabulation

3. Sorting and terminology used in the tabulation

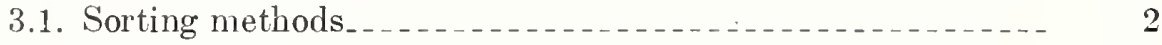

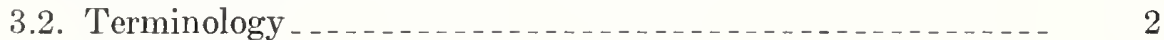

3.3. Unit symbols $\ldots \ldots \ldots \ldots \ldots \ldots$

4. Numerical listing of data on receiving tubes_._.

5. Characteristic listing of data on receiving tubes $\ldots 56$

6. List of similar types of receiving tubes._._. 109

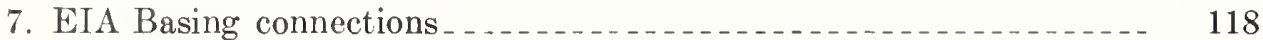




\title{
Tabulation of Data on Receiving Tubes
}

\begin{abstract}
A tabulation of Receiving-Type Electron Tubes with some characteristics of each type has been prepared in the form of two major listings, a Numerical Listing in which the tubes are arranged by type number, and a Characteristic Listing in which the tubes are arranged by tube type and further ordered on the basis of one or two important parameters. The tabulation is accompanied by a listing of similar tube types and basing connections for the listed tubes.
\end{abstract}

\section{Introduction}

The Electron Devices Section of the National Bureau of Standards has developed over the past several years an Electron Devices Data Service. This service attempts to obtain and maintain a file of data on all electron devices, i.e., tubes, transistors, and semiconductor diodes, manufactured in the United States and other countries. In an effort to make this service more readily available to engineers applying electronics in laboratories throughout the country, it was decided to develop a method of tabulating the essential information on these devices in handbook form for ready reference. For this publication on Receiving Tubes, an easily decipherable code and format for the tube characteristics was developed which would be suitable for a punched card system allowing automatic transfer to the printed page. The sources of information were the manufacturers' published handbooks and data sheets. The accuracy of the printed information is reasonably assured by verifying tabulations, by various sortings, and cross checking with manufacturers' publications.

This tabulation includes only the information normally furnished by the manufacturers in their handbooks or data sheets, and includes those tubes generally known as "Receiving Tubes." These include tubes to be found in home entertainment devices, military equipment, general purpose electronic laboratory equipment, etc. The tabulation is limited to tubes with not more than 25 watts plate dissipation and with maximum operating frequency less than 1,000 megacycles per second. One further restriction is that the tubes are currently active types, most of which have been registered with EIA and are produced by foreign or United States manufacturers. These tubes appear in the manufacturers' "New Equipment Price Lists" or are those on which a new or revised data sheet has been issued since 1956 . Types listed by manufacturers as "For Replacement Only" or as "Discontinued" types are tabulated only in the Numerical Listing.

The user of this tabulation should be reminded that industry has used various letter suffixes to designate improved versions of a tube type. For example the letter " $W$ " indicates that the type has been improved for military end-use and "WA" and/or "WB" indicate further improvements. Thus the " $6 \mathrm{AL} 5 \mathrm{~W}$ " is an improved version of the "6AL5" and this is continued to the ultimate improved type designation " $5726 /$ 6AL5W/6097".

To a void these complex designations, this tabulation lists only the type numbers by which a type is most commonly designated. The user should be cautioned that these versions of a tube may not be bilaterally interchangeable as the improved versions may differ in some physical dimensions or in one or more electrical characteristics.

\section{Organization of the Tabulation}

The Receiving Tube Tabulation comprises four principal sections as follows:

1. Numerical Listing. In this, the tubes are arranged by type number in the numericalalphabetical sequence which is standard in the industry.

2. Characteristics Listing. Here the current tubes are grouped according to the number of electrodes, and within the group they are arranged by increasing value of one or two pertinent characteristics.

3. Similar Tube Types. Following each tube listed is one or more types similar to it. Here are found those tubes from sections 1 and 2 which are coded as having similar types available, together with some older tubes not included in sections 1 and 2 but which are similar to a current listed tube.

Tubes which are identical in all respects except heater ratings, e.g., $3 \mathrm{BE} 6,4 \mathrm{BE} 6,12 \mathrm{BE} 6$, etc., have been omitted from the similar tubes list since they are obviously similar types and may be found by turning to the characteristics listing where they will be found in a group or in close proximity to one another.

4. Electronic Industries Association (EIA) Base Connections. This section shows the base connections in tabular form for the EIA Base Numbers shown in the Numerical and Characteristic Listings. This tabular form contains all the information shown in the normal basing diagram and specifically indicates the use for each base pin. Initial confusion at this method of display will be more than compensated by the ready applicability of the specific information contained in this tabular form.

The format has column headings of the base pin numbers up to twelve and one column for a top cap or external connection. Under these headings, is printed the symbol for the tube element or elements corresponding to the pin number for 
each base number. The code for the symbols is shown below:

$\begin{array}{ll}\text { H } & \text { Heater } \\ \text { F } & \text { Filament } \\ \text { HCT } & \text { Heater Center Tap } \\ \text { KCT } & \text { Filament Center Tap } \\ \text { G1, G2, etc. } & \text { Cathode } \\ \text { P } & \text { Plate Number } \\ \text { D } & \text { Deflector } \\ \text { T } & \text { Target } \\ \text { IC } & \text { Internal Connection } \\ \text { IS } & \text { Internal Shield } \\ \text { SH } & \text { Shell, Sleeve, etc. }\end{array}$

A prefixed number is used before the code letter to indicate the section number of the tube (e.g., the two sections in a twin triode) and a postfixed number to indicate the number of the element in a section. In those cases in which an element is common to more than one section, no prefixed number is used (e.g., a single common screen grid, G2 in a twin pentode).

A blank in the column of a pin number indicates that there is no pin in the base or that the pin has no internal or external connection.

\section{Sorting and Terminology of the Tabulation}

To assist the user in understanding and applying the tabulation, the method of sorting and the definition of terms and abbreviations are explained in this section.

\subsection{Sorting Methods}

The Numerical Listing is arranged in numericalalphabetical sequence by tube type number. In the Characteristics Listing the tubes are arranged in 46 groups by tube structure. Within these groups the tubes are arranged according to increasing value of one or two important parameters and finally by tube type number.

Given below are the groups into which the tubes are arranged and the characteristics by which the tubes are sorted within a group, e.g., all of the single triodes are grouped together, and are arranged in order of increasing value of " $\mu$ ". Where two or more tubes have the same $\mu$, these are then arranged by increasing value of "gm". Tubes with identical values of both $\mu$ and gm are then sorted by type number.

\begin{tabular}{|c|c|c|c|}
\hline \multirow{2}{*}{ Group heading } & \multicolumn{3}{|c|}{ Characteristics sorted on } \\
\hline & Primary & Secondary & Tertiary \\
\hline $\begin{array}{l}\text { 1. Regulator, Single Diode, Cold } \\
\text { Cathode. } \\
\text { 2. Regulator, Single Diode, Fila- } \\
\text { mentary Cathode. } \\
\text { 3. Reference, Single Diode, Cold } \\
\text { Cathode. }\end{array}$ & $E_{b}{ }^{*} \ldots \ldots$ & $\mathbf{I}_{\mathrm{b}}{ }^{*}-\ldots \ldots$ & Type No. \\
\hline
\end{tabular}

\begin{tabular}{|c|c|c|c|}
\hline \multirow{2}{*}{ Group heading } & \multicolumn{3}{|c|}{ Characteristics sorted on } \\
\hline & Primary & Secondary & Tertiary \\
\hline 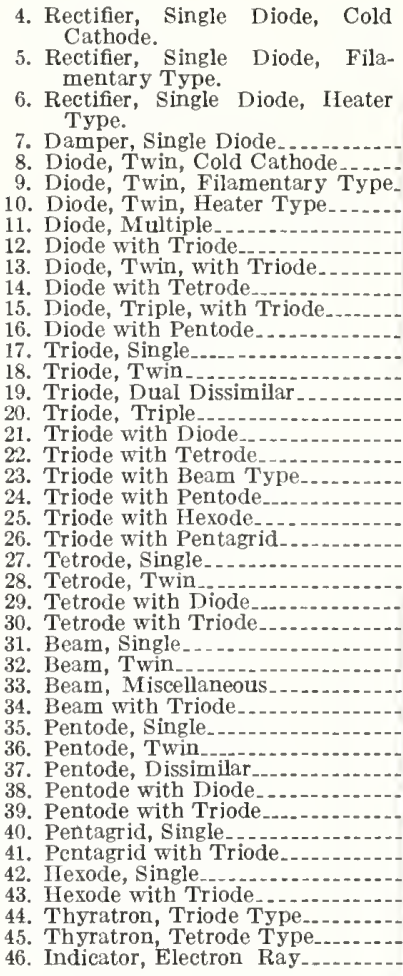 & $\left\{\begin{array}{l}\mathrm{gm} \\
\mathrm{gm}_{\mathrm{Dx} \ldots \ldots} \ldots \ldots \\
\mathrm{E}_{\mathrm{b} \ldots \ldots} \ldots\end{array}\right.$ & $\begin{array}{l}r_{1} \ldots \ldots \\
\text { Type No } \\
I_{b} \ldots \ldots \\
I_{b} \ldots \ldots\end{array}$ & $\begin{array}{l}\text { Type No. } \\
\text { Type No. }\end{array}$ \\
\hline
\end{tabular}

- $E_{b}$ and $E_{D x}$ used for sorting are the maximum values, $I_{b}$ is the typical value.

\subsection{Terminology}

The Numerical and Characteristic Listings are in tabular form containing 22 columns. The headings of these columns and their meanings are given below.

A blank in any column indicates that the characteristic designated by the column is not applicable to the tube in question or that no value was given in the available data.

\section{Definitions}

Type Number. This column lists the numericalalphabetical designation assigned to the tube type by the manufacturer.

Code. A letter " $\mathrm{S}$ " indicates that this tube is similar to some other type. Such a tube will be found in the Similar Tubes List on pages 109 through 117 with its similar types. It is to be noted that these tubes are similar, not necessarily equivalent or directly interchangeable

An asterisk $\left(^{*}\right)$ in this column indicates that the tube is on the Military Preferred List issued by the Department of Defense as "Military Standard Electron Tubes; Selection and use of", MIL-STD-200F, 15 March 1962.

A plus sign $(+)$ is used to designate a tube not on the Military Preferred List but which the 
manufacturer refers to as a ruggedized, reliable, or premium type.

In the Numerical List the letters "OBS" have been used to indicate that these tube types were not found on any manufacturers current price list and are thus considered as "replacement only" types and as such should not be considered in the design of new equipment. These will not appear in the Characteristics Listing but have been included in the Numerical List for reference only.

Kind. An easily decipherable three letter symbol is used here showing the tube to be a diode, triode, beam pentode, etc.

$\begin{array}{ll}\text { BEA } & \text { Beam } \\ \text { DIO } & \text { Diode } \\ \text { DWD } & \text { Double Diode } \\ \text { GTB } & \text { Gated Beam } \\ \text { HEX } & \text { Hexode } \\ \text { PDD } & \text { Pentode-Diode } \\ \text { PND } & \text { Pentode } \\ \text { PTG } & \text { Pentagrid } \\ \text { SHB } & \text { Sheet Beam } \\ \text { TDI } & \text { Triode Dissimilar } \\ \text { TET } & \text { Tetrode } \\ \text { TRD } & \text { Triple Diode } \\ \text { TRI } & \text { Triode } \\ \text { TRT } & \text { Triple Triode } \\ \text { TTR } & \text { Twin Triode } \\ \text { TWP } & \text { Twin Pentode }\end{array}$

Type. A three-letter symbol is used to amplify the characterization under "Kind." Thus a tube is designated as single, twin, or combined with some other type in a multiple structure, in one envelope.

Note: A tube containing two or more different structures in one envelope will be listed once for each such structure in the Numerical Listing and once in each appropriate group in the Characteristic Listing, e.g., the $6 \times 8$ is listed as a triode with a pentode section and also as a pentode with a triode section. The data given on any one line refers to the section of the tube as designated in the column headed "Kind."

$\begin{array}{ll}\text { DIO } & \text { With Diode } \\ \text { DIS } & \text { Dissimilar (as applied to Dual } \\ & \text { Triodes) } \\ \text { DSD } & \text { Dissimilar with Diode } \\ \text { DTR } & \text { With Dissimilar Dual Triode } \\ \text { DWD } & \text { With Double Diode } \\ \text { GTB } & \text { With Gated Beam } \\ \text { PDD } & \text { With Pentode-Diode } \\ \text { PND } & \text { With Pentode } \\ \text { QUA } & \text { Quadruple } \\ \text { SIN } & \text { Single-Type } \\ \text { SXD } & \text { Sextuple } \\ \text { TDI } & \text { With Triode Dissimilar } \\ \text { TET } & \text { With Tetrode } \\ \text { TRD } & \text { With Triple Diode } \\ \text { TRI } & \text { With Triode }\end{array}$

Bulb. Designates the type, size, and shape of the bulb by an alphabetical-numerical code defined as follows:

A. Initial Letter

MT-Metal Tubular or Cylindrical Shape

$\mathrm{S}$-Indicates the "ST" design, i.e., the domedconical-body glass bulb

T-Glass tubular or cylindrical shape

B. Number-this number multiplied by oneeighth (1/8) inch gives the bulb diameter. Only the whole number is used, thus a T6 $1 / 2$ bulb is designated T6.

C. Descriptive terms are used for the following:

$\begin{array}{ll}\text { ACO } & \text { Acorn Design } \\ \text { CM } & \text { Ceramic-Metal Design } \\ \text { LIT } & \text { Lighthouse Design } \\ \text { PC } & \text { Printed Circuit Design } \\ \text { PEN } & \text { Pencil Design } \\ \text { ROK } & \text { Rocket Design }\end{array}$

Use. Gives the application for which the tube was developed or is most useful as stated in the manufacturer's data sheet. If a tube is particularly suited to some band of frequencies such as audio, intermediate, very high, etc., it is so designated in this column by AFA, IFA, VHF, etc. Such designation is the only reference to the frequency of operation of tubes in this Tabulation.

AFA

AFD

$\mathrm{CA}$

$\mathrm{CON}$

DA

DET

DIS

EL

GA

GEN

GGA

HDA

HF

IFA

IND

MIX

ONA

OSC

PA

REC

REF

REG

RFA

SEM

THY

TRG

UHF

VA

VDA

VDO

VHF
Audiofrequency amplifier

Audiofrequency Driver

Cascode Amplifier

Converter

Damper

Detector

Discriminator

Electrometer

Gating Amplifier

General Purpose

Grounded Grid Amplifier

Horizontal Deflection Amplifier

High Fidelity

Intermediate-frequency Amplifier

Indicator (Electron Ray)

Mixer

On-Off Applications (Computer Service)

Oscillator

Power Amplifier

Rectifier

Voltage Reference

Voltage Regulator

Radio Frequency Amplifier

Secondary Emission Tube

Thyratron

Trigger

Ultra-high Frequency Amplifier

Voltage Amplifier

Vertical Deflection Amplifier

Vertical Deflection Oscillator

Very-high Frequency Amplifier 
Char. Refers to a specific characteristic of the given tube.

GAS Gas-filled (as applied to rectifiers, regulators, etc.)

HIP High Perveance

RCO Remote Cut-off i.e., more tha 17 volts SCO Sharp Cut-off i.e., 7 volts or less

SRC Semi-remote Cut-off i e., more than 7 to 17 volts

VAC Vacuum (as applied to rectifiers)

Reg. Indicates the manufacturer who registered the type with the EIA. In some cases a manufacturer may no longer make a tube which he registered but it was impractical to try to list all companies making a given tube type so the present system was adopted as being fair to all manufacturers.

The not equal sign $(\not \neq)$ is the symbol used to indicate that the original registrant is no longer producing receiving tubes, but the type is currently being manufactured by another company or companies.

$\begin{array}{ll}\text { AM } & \text { Amperex Electronic Corp. } \\ \text { BE } & \text { Bendix Electron Tube Products } \\ \text { CG } & \text { Canadian General Electric Co. Ltd. } \\ \text { CH } & \text { Chatham Electronics } \\ \text { CI } & \text { Compagnie Industrielle Francaise } \\ \text { GE } & \text { General Electric Co. } \\ \text { HI } & \text { Hitachi Ltd. } \\ \text { HY } & \text { CBS Hytron } \\ \text { LR } & \text { Standard Elektrik Lorenz } \\ \text { MI } & \text { Marconi Italiama } \\ \text { MU } & \text { Mullard Ltd. } \\ \text { NU } & \text { National Union Electric Corp. } \\ \text { PL } & \text { Philco (Lansdale) } \\ \text { RA } & \text { Raytheon Manufacturing Co. } \\ \text { RC } & \text { Radio Corporation of America } \\ \text { RE } & \text { Rogers Electronic Tubes Ltd. } \\ \text { RV } & \text { Radio Valve Co. Ltd. } \\ \text { SH } & \text { Siemens \& Halske } \\ \text { SO } & \text { Sonotone Corp. } \\ \text { ST } & \text { Standard Telephones \& Cables Ltd. } \\ \text { SY } & \text { Sylvania Electric Products, Inc. } \\ \text { TA } & \text { Thorn AEI Radio Valves \& Tubes Ltd. } \\ \text { TE } & \text { Telefunken G.M.B.H. } \\ \text { TO } & \text { Tokyo Shibaura Electric Co. Ltd. } \\ & \text { (Toshiba) } \\ \text { TS } & \text { Tungsol Electric Inc. } \\ \text { VI } & \text { Victoreen Instrument Co. } \\ \text { WE } & \text { Western Electric Co., Inc. } \\ \text { WH } & \text { Westinghouse Electric Corp. } \\ & \end{array}$

\footnotetext{
Cath. K. Designates the type of cathode. C Cold Cathode

F Filamentary Cathode

H Heater type (i.e., unipotential cathode)

$\mathbf{E}_{f}$. Specifies the nominal heater or filament voltage in volts. In the case of tubes whose heater or filament is center tapped to allow series
}

or parallel operation of the sections, the value given is for series connection.

If $_{\text {f }}$ Typical heater or filament current in milliamperes.

Max. $\mathbf{E}_{\mathrm{b}}$ or $\mathbf{E}_{\mathrm{px}}$. Maximum plate voltage permissible in the tube. In the case of diodes and thyratrons the value is the peak inverse voltage which can be applied to the tube.

Max. $\mathbf{I}_{b}$. Maximum plate current in milliamperes which the tube may pass.

$\mathbf{P}_{\mathrm{p}}$. Maximum plate dissipation of the tube in watts. In the case of twin tubes the dissipation is for one section only, e.g., the 6SN7GTB is listed at a dissipation of 5 watts. The manufacturer gives this as the value for each plate, but with both units operating the total for both plates must not exceed 7.5 watts. For this reason multiple tubes should be checked in the manfacturer's data before operating the tube with maximum dissipation in each section.

$\mathbf{E}_{\mathrm{b}}$. Typical value for the d-c plate or operating voltage in volts.

$\mathbf{I}_{\mathrm{b}}$ - Typical d-c anode current in milliamperes for the operating voltage in the preceding column.

Gm. Typical value of grid-plate transconductance of the tube in micromhos.

$\mu$. Typical tube amplification factor.

$\boldsymbol{r}_{\mathbf{p}}$. Typical value for plate resistance in ohms.

Capacity in: Typical value for input capacitance of the tube, i.e., between grid \#1 and all other electrodes.

Capacity out: Typical value for the output capacitance of the tube, i.e., between the anode and all other electrodes.

Note: These capacity values are measured without an external, grounded shield.

EIA Base No. This column designates the number assigned by the EIA to the base connections of the tube. These Base Numbers will be found in the last section of the Tabulation beginning on page 119. The designation "FL" is used to indicate flexible or flying leads on the miniature or subminiature tubes. The column is left blank where no Base Number is applicable as in lighthouse and ceramic-metal tubes.

\subsection{Unit Symbols}

While the normally used electrical unit is printed at the top of each column, it will be noted that letter symbols are used following some numbers to indicate a change of unit.

\begin{tabular}{|c|c|c|}
\hline Symbol & Column heading & Unit \\
\hline $\begin{array}{l}\mathbf{K} \\
\mathbf{U} \\
\mathbf{A}^{\prime} \\
\mathbf{K} \\
\mathbf{M}\end{array}$ & $\begin{array}{l}\operatorname{Max} E_{b} \text { or } E_{p r} \ldots \ldots \\
M a x I_{b} \text { and } l_{b-\ldots} \ldots \\
\operatorname{Max} l_{b} \text { and } l_{b \ldots} \ldots \\
I_{p} \ldots \ldots\end{array}$ & $\begin{array}{l}\text { Kilovolts. } \\
\text { Microamperes. } \\
\text { Amperes. } \\
\text { Kilohms. } \\
\text { Megohms. }\end{array}$ \\
\hline
\end{tabular}




\section{Numerical Listing of Data on Receiving Tubes}




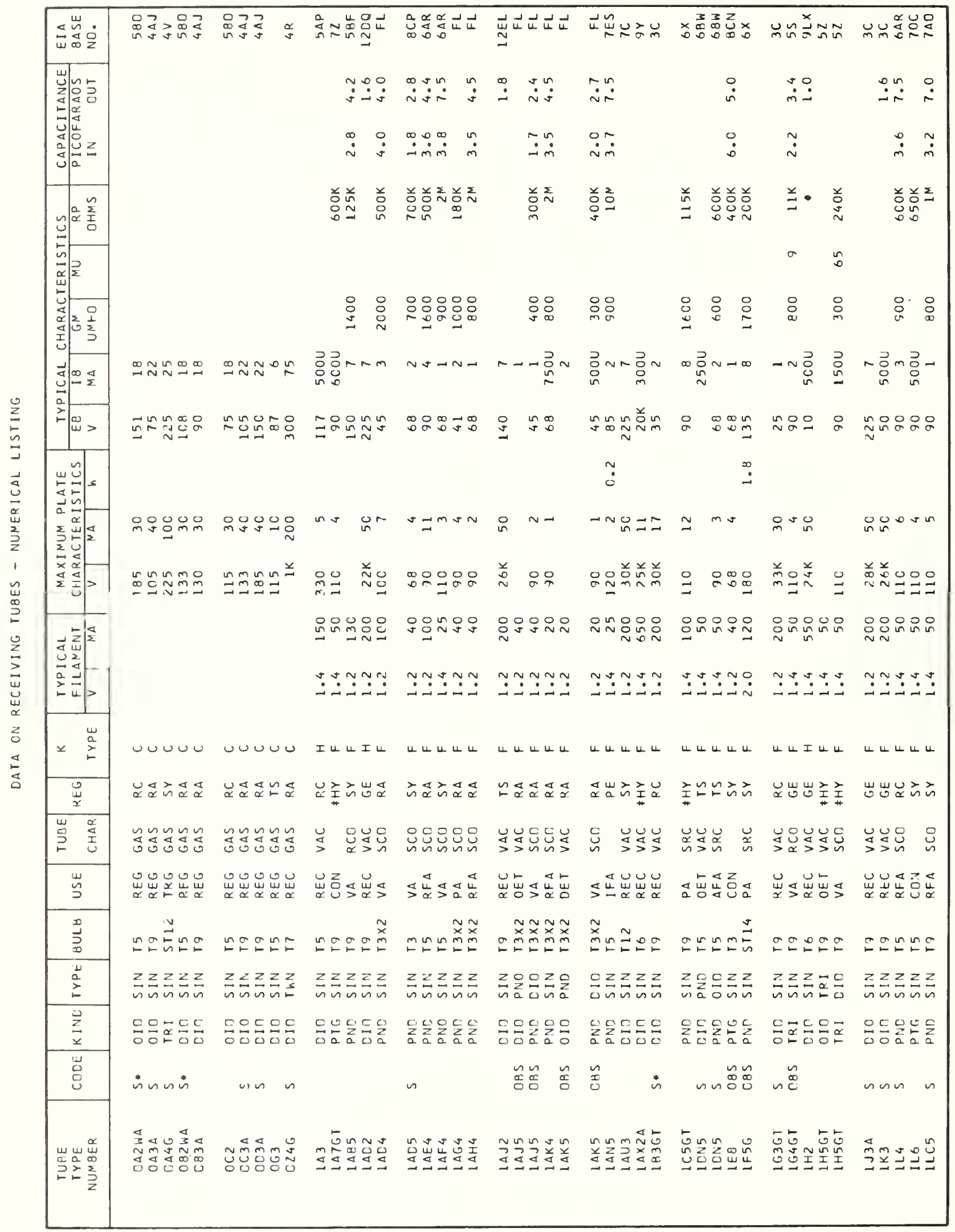




\begin{tabular}{|c|c|c|c|c|c|c|c|c|c|}
\hline 造㟒号 & 东乔若是山 & 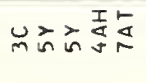 & 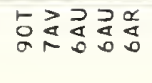 & 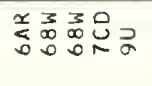 & 山コっううa & $\underset{\sim}{\mathcal{O}}$ & 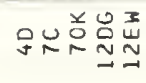 & $\underset{\infty}{\breve{I}} \underset{\sim}{\stackrel{U}{N}}$ & 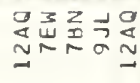 \\
\hline 武能号 & 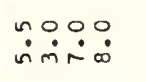 & 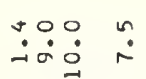 & $\stackrel{\infty}{\dot{\sim}} \quad \dot{\sim} \dot{\sim}$ & 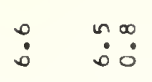 & $\ddot{\sigma} \dot{\sim} \dot{\sim} \dot{\circ}$ & & 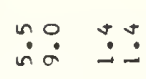 & $\stackrel{m}{\because} \stackrel{\circ}{-}$ & 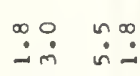 \\
\hline $\begin{array}{ll} & 0 \\
0 \\
0\end{array}$ & $\because \cong \dot{m}$ & $\dot{\sim} \dot{\sim}$ & $\stackrel{\sim}{\sim} \dot{m}$ & $\stackrel{0}{\dot{m}} \quad \stackrel{\dot{\sim}}{ }$ & $\ddot{ن} \dot{m}$ & & $\stackrel{\sim}{\sim} \dot{0}$ & $\stackrel{\sim}{\dot{n}}$ & $\ddot{j} \dot{j} \ddot{r} \dot{j}$ \\
\hline 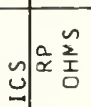 & 总 & $\underset{\infty}{\sum_{0}^{2}}$ & 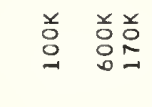 & $\begin{array}{l}0 \\
\text { 응 } \\
\text { o용 }\end{array}$ & $\Sigma$ & & 웅요 & 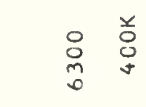 & 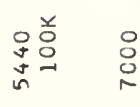 \\
\hline 氙 & \pm & & & & & & $\checkmark n$ & 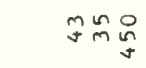 & $\infty$ \\
\hline \begin{tabular}{l|l}
0 \\
0
\end{tabular} & 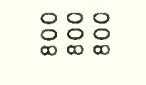 & 品品 & 용요 & $\begin{array}{l}\circ \\
\circ\end{array}$ & & & $\begin{array}{l}O \\
\stackrel{D}{D} \\
\end{array}$ & 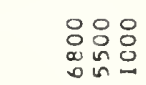 & $\begin{array}{l}8 \\
8 \\
0\end{array}$ \\
\hline - & 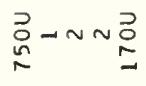 & 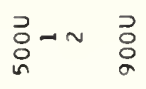 & $\sim \underset{\sim}{D} \sim v$ & N $\underset{\sim}{\vec{\rho}} \sim{ }_{0} \vec{O}$ & 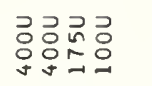 & N & dagr & 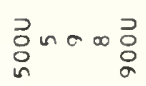 & nOgñ \\
\hline 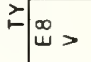 & 응양ㅇㅇㅇ & 양ㅇㅇㅇ & $\underset{\sim}{\infty} \quad \underbrace{\infty}_{0} \circ$ & 용요 & 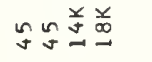 & $\stackrel{\infty}{-}$ & 운용ㅇㅁㅇㅇㅁ & 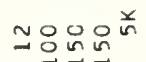 & 옷용요 \\
\hline . & & $\overrightarrow{0}$ & & $\stackrel{\sim}{0}$ & & & $\ddot{\dot{n}} \dot{\sim} \dot{\sim}$ & $\because \dot{\sim} \dot{\sim} \dot{\sim}$ & 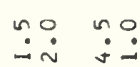 \\
\hline$\frac{a}{x}$ & $m$ in & on & $0=$ & $\sim m v 0$ & $\sim \sim-n \in$ & $\omega$ & $\checkmark \infty \cup 0$ & $0 \sim \infty 0$ & 00 \\
\hline 政 & $\mathrm{m}$ & & & & & & & & \\
\hline 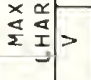 & 읔ㅇㅇㅡ & 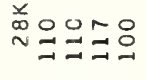 & $\stackrel{\searrow}{\sim}$ 용요 & 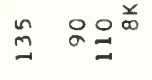 & 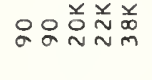 & $\stackrel{r}{\sim}$ & 品品品売齐 & 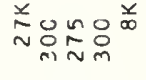 & $\begin{array}{l}n \\
N_{\infty}^{\infty} \\
\sim\end{array}$ \\
\hline$\frac{z_{w}^{2}}{2}$ & 음요요요 & 융용욤요 & 용음요요요 & 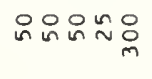 & 온 & $\stackrel{n}{N}$ & $\begin{array}{l}: \\
0\end{array}$ & 옷용요 & 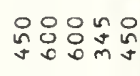 \\
\hline 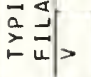 & 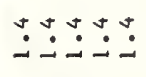 & 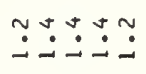 & $\stackrel{\Delta}{\sim} \stackrel{\Delta}{\circ}$ & 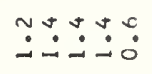 & 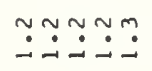 & $\stackrel{\sim}{\check{\sim}}$ & $\tilde{\sim} \dot{\sim} \dot{\sim} \dot{\sim} \dot{\sim} \dot{\sim}$ & $\dot{\dot{i}} \dot{\sim} \dot{\sim} \dot{0} \dot{0}$ & $\dot{\sim} \dot{\sim} \dot{i} \dot{\sim} \dot{\sim}$ \\
\hline$× \stackrel{\vec{a}}{\Sigma}$ & 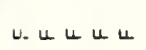 & $u U u I u$ & エレルル & 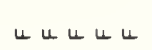 & UUルUル & $u$ & UIIII & $\| I I I I$ & IIIUI \\
\hline$\underset{\alpha}{\stackrel{u}{山}}$ & えええ的高 & 的主主的品 & 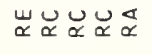 & 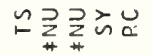 & 幽文主动 & $\sum_{2}$ & 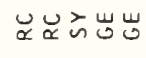 & 岁 & 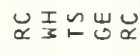 \\
\hline 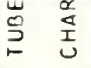 & 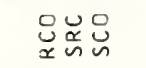 & 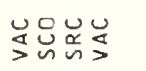 & 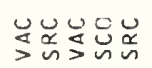 & 号㢟号 & 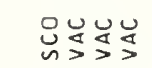 & $\stackrel{\square}{>}$ & $\begin{array}{l}\text { U } \\
\propto \\
\sim\end{array}$ & 岁重踪兑 & 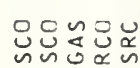 \\
\hline$\stackrel{u}{s}$ & 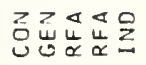 & 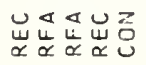 & 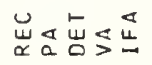 & 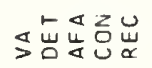 & ڤñ & $\underset{\sim}{\breve{\sim}}$ & 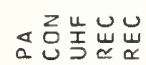 & 岀出堊忌出 & 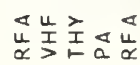 \\
\hline$\stackrel{D}{D}_{\infty}^{\infty}$ & 욤ำ & 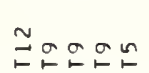 & ํำณnュ & 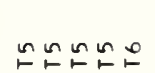 & 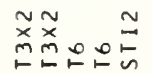 & $\approx$ & 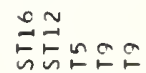 & のコュュの & 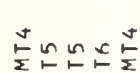 \\
\hline $\begin{array}{l}\omega \\
a \\
\vdots\end{array}$ & 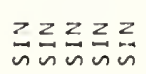 & 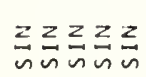 & 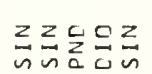 & 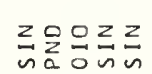 & $\sum_{a} \underset{\alpha}{\alpha} \leq z z$ & $\frac{z}{n}$ & 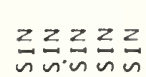 & 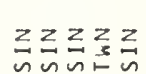 & 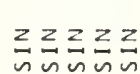 \\
\hline$\frac{0}{\underline{x}}$ & 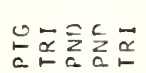 & 을름음염 & 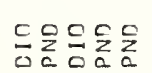 & 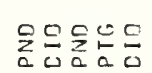 & 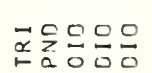 & $\stackrel{5}{0}$ & 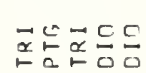 & 듬몸ㅁㅁㅁ & 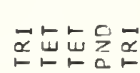 \\
\hline 岁 & $n \backsim n$ & 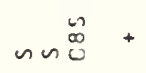 & $\backsim \backsim \dot{t}$ & $\dot{\Delta} \backsim n$ & $\tilde{n}$ & & 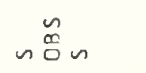 & 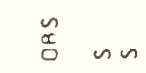 & nuñ \\
\hline 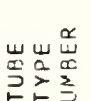 & 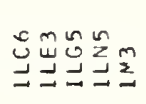 & 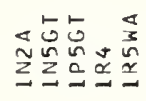 & 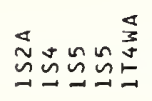 & 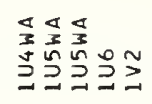 & 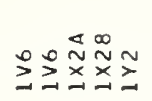 & $\cong$ & 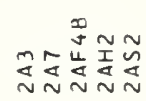 & 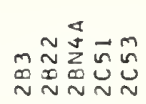 & 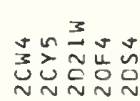 \\
\hline
\end{tabular}




\begin{tabular}{|c|c|c|c|c|c|c|c|c|c|}
\hline 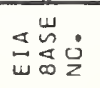 & 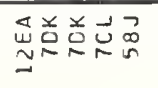 & 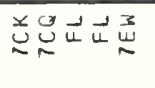 & 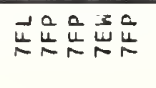 & 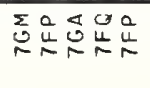 & $\underset{0}{0} \vec{u} \vec{u} \vec{u} \vec{u}$ & 言导总 & 兑虫 & 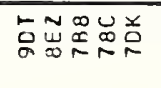 & 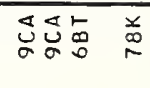 \\
\hline 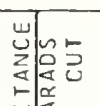 & 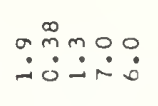 & $\ddot{r} \dot{0} \dot{v} \dot{\sim} \dot{\sim}$ & $\ddot{\dot{v}} \ddot{\sim} \dot{\sim} \dot{\sim}$ & $\begin{array}{l}\dot{\sim} \dot{\sim} \dot{\sim} \dot{m} \dot{m} \\
\end{array}$ & $\ddot{m} \dot{m} \dot{m} \dot{m}$ & $\begin{array}{l}\because \sim 0 \\
\dot{m} \dot{m} \dot{S}\end{array}$ & $\ddot{0}$ & 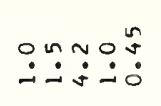 & $\ddot{\sim} \ddot{\sim} \dot{\sim} \dot{\sim} \quad \dot{n}$ \\
\hline \begin{tabular}{l|l}
0 \\
0
\end{tabular} & 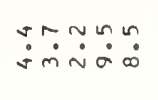 & $\ddot{\sim} \dot{\sim} \dot{\sim} \dot{\sim} \dot{\sim}$ & $\ddot{m} \dot{\sim} \dot{m} \dot{\sim} \dot{m}$ & 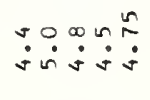 & $\dot{m}^{\infty} \dot{m} \dot{m} \dot{m} \dot{m}$ & $\ddot{0} \dot{\sim} \dot{n}$ & $\dot{\sim}$ & $\stackrel{\infty}{\dot{\sigma}} \dot{0} \dot{\sim}$ & $\stackrel{\varphi}{\dot{v}} \quad \stackrel{n}{n}$ \\
\hline$\checkmark=\frac{n}{2}$ & 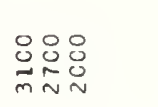 & 弟总兑兑 & 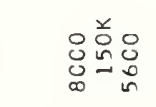 & 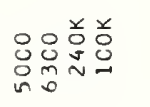 & & 总㥈 & $\begin{array}{l}0 \\
\stackrel{0}{\infty} \\
\stackrel{0}{-}\end{array}$ & 으욣ㅇ & $2 \quad 2$ \\
\hline 点 & m & & O্ $_{\infty}^{n}$ & $\approx \pi \quad 0$ & & $\stackrel{\infty}{\sim} \sim$ & $=$ & $\approx \pm$ & $\stackrel{\sim}{N}$ \\
\hline 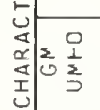 & 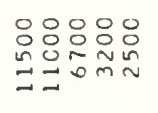 & $\begin{array}{l}0 O O \\
0\end{array}$ & $\begin{array}{l}0 \\
0\end{array}$ & 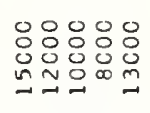 & & 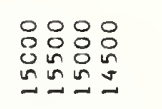 & : & 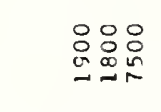 & $\underset{0}{0}$ \\
\hline 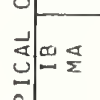 & 윽욤안 & 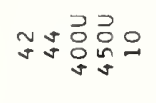 & ㅇニニ & $\simeq \infty 0=$ & 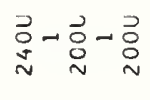 & $\simeq O \simeq \simeq$ & $\stackrel{\infty}{\sim}-$ & $\sim \sim \mathscr{\sim} \checkmark \stackrel{\sim}{\sim}$ & $\Xi ナ \sigma \sim \infty$ \\
\hline$\infty>$ & 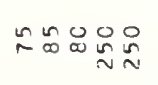 & 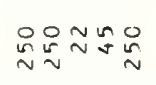 & 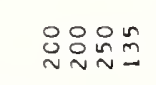 & $\stackrel{n}{m} \stackrel{n}{\sim} \underset{\sim}{\sim} \stackrel{\sim}{N} \stackrel{n}{\sim}$ & $\stackrel{D}{\sim} \sim \sim N N$ & 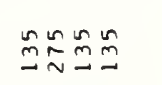 & $\stackrel{\circ}{\infty}$ & 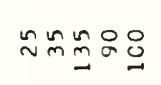 & 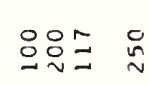 \\
\hline 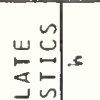 & 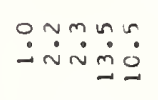 & $\begin{array}{ll}\ddot{0} & \dot{m} \\
\dot{0} & \dot{m}\end{array}$ & $\begin{array}{l}\sim \sim \sim N \\
\sim \dot{\sim} \dot{\sim}\end{array}$ & $m \ddot{n} \sim \ddot{\sim} \dot{\sim} \dot{\sim} \dot{\sim}$ & & $\ddot{\sim} \dot{\sim} \dot{\sim} \dot{\sim} \dot{\sim}$ & $\tilde{m}$ & $\dot{\sim} \dot{\sim} \dot{\sim}$ & $\stackrel{\infty}{\dot{0}-\dot{m}} \quad \dot{m}$ \\
\hline 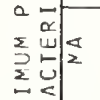 & $\mathscr{\sim} \underset{\sim}{\mathcal{N}} \mathfrak{\sim} \sim \mathfrak{\sim}$ & $\stackrel{\sim}{\sim}-\underset{\sim}{0}$ & $\sim \underset{\sim}{\sim} \underset{N}{\sim} \sim$ & 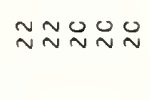 & $\sim \sim \sim N$ & $\sim \mathcal{N} N \mathbb{N}$ & OO & $\bigcup_{\infty} \cup_{\infty}^{\infty} \sim \sim \infty$ & $0 \simeq \underbrace{\infty}_{\infty}$ \\
\hline 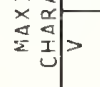 & 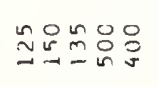 & 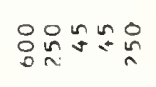 & 品品孞足 & 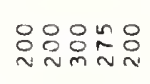 & 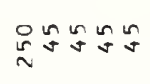 & OO & 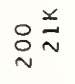 & 㒸兑品设品 & 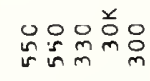 \\
\hline 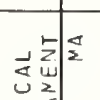 & 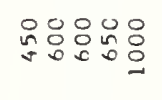 & 郒品㶽品品 & 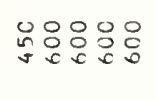 & 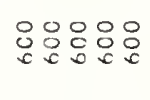 & 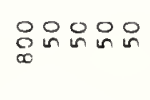 & 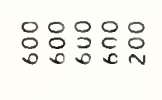 & :O & 웅요 & $\begin{array}{l}\circ \circ: 00 \\
\text { 용용 }\end{array}$ \\
\hline 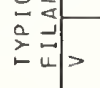 & $\ddot{\sim} \dot{\sim} \dot{\sim} \dot{\varphi} \dot{\varphi}$ & $\begin{array}{l}m \cup \sim m \\
\dot{0} \dot{\sim} \dot{\sim}\end{array}$ & $\ddot{\sim} \dot{\sim} \dot{\sim} \dot{\sim} \dot{\sim}$ & $\dot{\sim} \dot{\sim} \dot{\sim} \dot{\sim} \dot{\sim} \dot{\sim}$ & 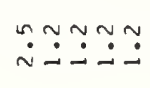 & $\dot{m} \dot{\sim} \dot{\sim} \dot{\sim} \dot{\sim} \dot{\sim}$ & $\stackrel{\sim}{\sim} \dot{\sim}$ & $\because \sim \infty \infty \sim m$ & $\begin{array}{l}\dot{m} \mathscr{m} \dot{m} \sim \\
\dot{m}\end{array}$ \\
\hline $\begin{array}{r}u \\
\times \quad \stackrel{a}{z}\end{array}$ & $I I I U U$ & IயUルI & $I I I I I$ & IIIII & エйuU & IIIII & $=u$ & IエиルI & IIIII \\
\hline$\underset{\sim}{u}$ & 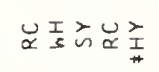 & 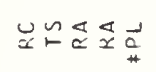 & 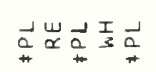 & 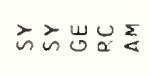 & 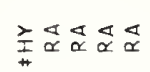 & え岕え迆 & え゙ & $u_{\alpha} u_{\alpha} u_{\alpha} \dot{z}_{i}$ & 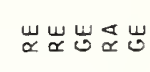 \\
\hline 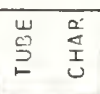 & 品 & 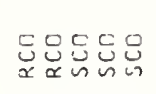 & 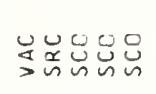 & ت्ن & & 号怘怘 & $\dot{\underline{\alpha}}$ & 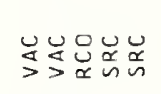 & 呈导号 \\
\hline$\stackrel{\breve{s}}{\leftrightharpoons}$ & 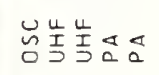 & 过台崖这堊 & 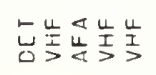 & 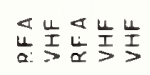 & 呈号爻号品 & 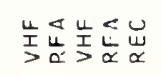 & $\begin{array}{l}\dot{\Delta} \\
\Delta \\
\vec{x}\end{array}$ & 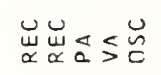 & 芭号出出出 \\
\hline$\underset{0}{D}$ & 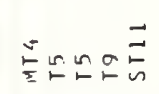 & 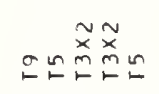 & ロே゚ロ上ロ & ピロロロロ & 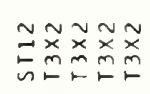 & ヘロロロ゚ & $\curvearrowleft \Xi$ & レ゚ロロロ & レ゚ロレロロ \\
\hline $\begin{array}{l}u \\
0 \\
2 \\
2 \\
⺊\end{array}$ & 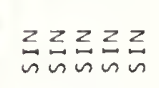 & 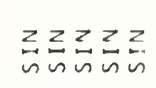 & 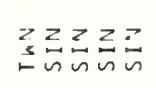 & 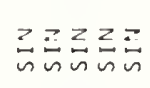 & 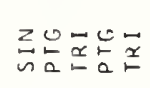 & 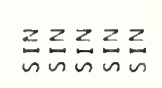 & 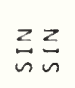 & 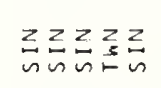 & 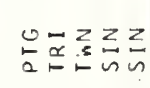 \\
\hline$\frac{u}{z}$ & 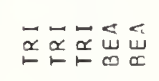 & 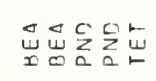 & 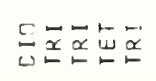 & 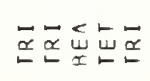 & 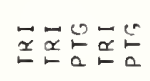 & 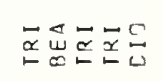 & $\underset{\sim}{\square}$ & 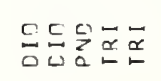 & 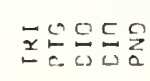 \\
\hline 岕 & 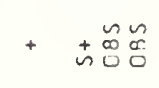 & 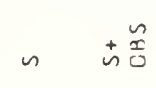 & $\dot{n} \backsim \backsim u$. & $\backsim n n$ & $\stackrel{\infty}{\infty} \backsim \backsim \backsim n n$ & $n$ & $n$ & $\sim$ & $n$ \\
\hline 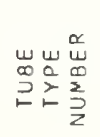 & 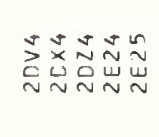 & 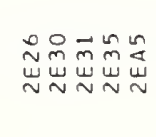 & 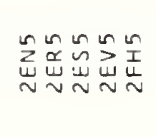 & 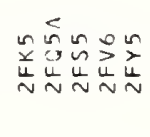 & 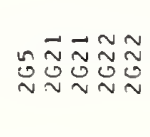 & 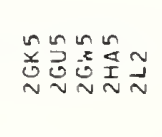 & $\stackrel{\sim}{\sim} \underset{N}{N}$ & 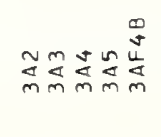 & 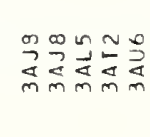 \\
\hline
\end{tabular}




\begin{tabular}{|c|c|c|c|c|c|c|c|c|c|}
\hline 岀峞远 & 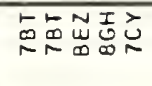 & 崫弟号总怘 & 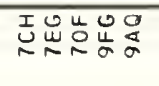 & 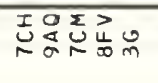 & 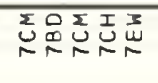 & 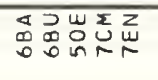 & 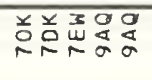 & 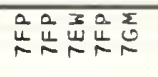 & 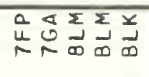 \\
\hline 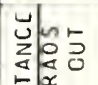 & 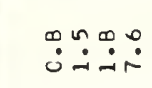 & $\stackrel{\infty}{\dot{-}} \quad \stackrel{0}{\circ} \stackrel{\infty}{ }$ & $\ddot{\infty} \dot{\sim} \dot{m} \dot{m}$ & $\dot{i} \dot{\sim}$ & 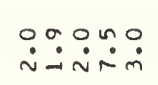 & $\ddot{n} \quad \dot{\sim}$ & ஸैm? & 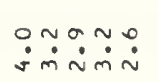 & 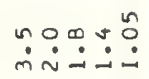 \\
\hline 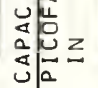 & $\stackrel{\dot{\sim}}{\dot{j}}$ & $\dot{\square} \quad$ in & 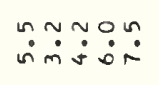 & $\dot{n} \dot{r}$ & 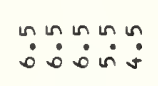 & $\stackrel{n}{r} \quad \dot{0} \dot{n}$ & $\ddot{m} \dot{\sim} \dot{m}$ & 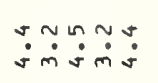 & 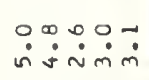 \\
\hline$\backsim=\underbrace{}_{0}=\frac{n}{\alpha}$ & $\underset{\sim}{\stackrel{x}{U}}$ & $\begin{array}{rl}2 & 0 \\
0 \\
0\end{array}$ & 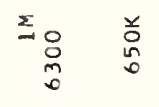 & 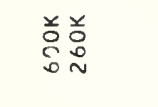 & 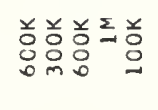 & $\begin{array}{l}\text { 兑 } \\
\text { 总 } \\
\text { n }\end{array}$ & 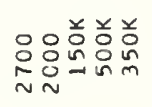 & 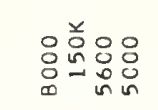 & 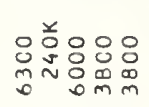 \\
\hline 占 & ¿ & $\stackrel{\circ}{\sim}$ & $\stackrel{m}{5}$ & & & & 品 & $\operatorname{lon}_{\infty} \stackrel{n}{\sim}$ & $\stackrel{0}{N} \mathrm{~m} m$ \\
\hline \begin{tabular}{l|l}
0 \\
0 \\
0
\end{tabular} & 号 & 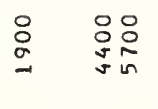 & 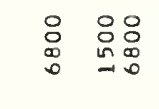 & 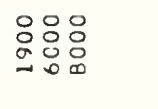 & 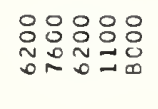 & 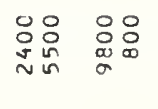 & 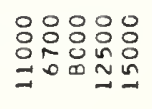 & 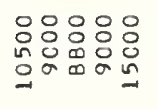 & 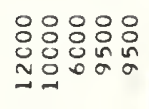 \\
\hline 能整 & $-\backsim \sim \sim \curvearrowleft$ & =욤요 & $m=\underset{\substack{O \\
\\
j}}{a} \sim 0$ & - $v-\underset{O}{\circ}$ & 으우음 & 음윰욜ㅁ & 오음ㅇ & 으ニニ & $\sigma O r \sigma \sigma$ \\
\hline$=\infty$ & $\stackrel{\circ}{\sim}$ 品品 & 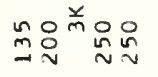 & 怘品元品怘 & $\stackrel{\circ}{\sim} \cong$ & 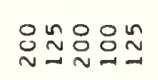 & 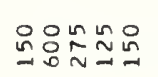 & 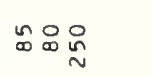 & 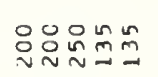 & $\underset{m}{n} \underset{\sim}{n}$ 웅ㅇㅇㅇ \\
\hline س & $\stackrel{n}{\dot{0}} \quad \dot{m}$ & $\ddot{\dot{\sim}} \quad \dot{m} \dot{\sim}$ & $\ddot{\sim} \ddot{\sim} \quad \ddot{i}$ & $\dot{\sim} \dot{\sim} \dot{\sim}$ & $\dot{\sim} \dot{\sim} \dot{\sim} \dot{\sim} \dot{\sim}$ & $\ddot{\dot{v}} \dot{\sim} \dot{\sim} \dot{\sim}$ & $\ddot{\sim} \dot{\sim} \dot{\sim} \sim \tilde{\sim} \dot{\sim} \dot{\sim}$ & $\tilde{\dot{\sim}} \dot{\sim} \tilde{m} \dot{\sim} \dot{\sim}$ & $\ddot{\sim} \dot{\sim} \quad \tilde{m}$ \\
\hline S & 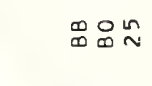 & உO욤요 & $\Xi \approx \simeq \simeq$ & 용 & 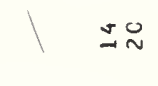 & 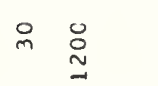 & 융 & 워요 $\sim \sim ⿻$ & 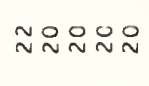 \\
\hline 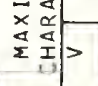 & 总总总品 & 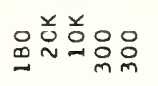 & 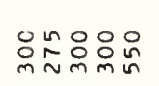 & 品㶽品剪 & 윰윰윰요 & 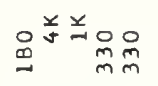 & 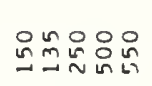 & 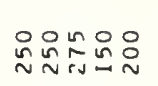 & 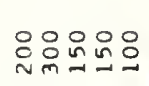 \\
\hline$\frac{\sum_{w}}{2}$ & 음요요묘 & 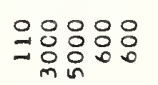 & 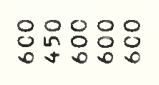 & 응용ㅇㅇㅇㅁㅇ & 음응응 & 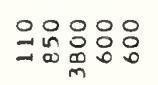 & 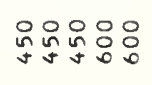 & 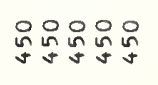 & $\begin{array}{l}0 \\
\text { ñ. } \\
\text { v }\end{array}$ \\
\hline 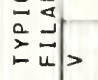 & $\dddot{m} \ddot{m} \ddot{m} \dot{m} \dot{\sim}$ & $\dot{\infty} \dot{\sim} \dot{\sim} \tilde{\sim} \dot{m} \dot{m}$ & $\ddot{m} \ddot{m} \dot{m} \dot{m} \dot{m}$ & $\ddot{m} \dot{m} \dot{m} \sim \tilde{m} \dot{\sim}$ & 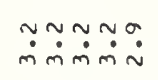 & $\begin{array}{l}\dot{\sim} \dot{\sim} \dot{m} \sim \dot{m} \\
\dot{m}\end{array}$ & $\dot{m} \dot{m} \dot{m} \dot{m} \dot{m}$ & $\dot{\sim} \dot{\sim} \dot{\sim} \dot{\sim} \dot{m} \dot{\sim} \dot{ }$ & 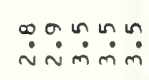 \\
\hline$\times \sum_{\Sigma}^{\frac{u}{\Sigma}}$ & IIIIU & UルUII & IIIII & エエエルU & IIIII & レIUII & IIIII & IIIII & IIIII \\
\hline$\underset{\sim}{\underset{\sim}{u}}$ & えええひひ主 & え岕出岕岕 & سِّ يِّ & 岕岕え岕出 & 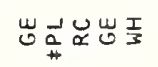 & 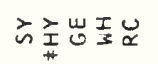 & 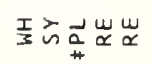 & 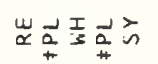 & 的岕吕吕吕 \\
\hline 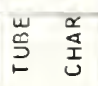 & 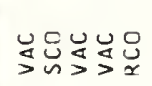 & 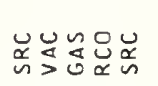 & 号 总怘 & 芯 & 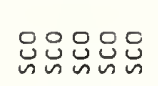 & 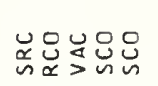 & 容怘 & 总号怘怘 & 号号误品品 \\
\hline$\stackrel{u}{s}$ & 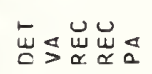 & 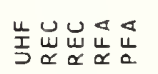 & 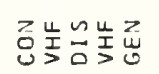 & 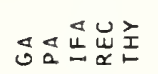 & 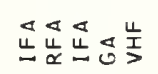 & 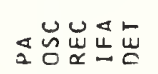 & 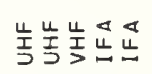 & 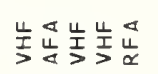 & 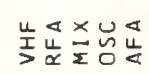 \\
\hline$\sum_{\infty}^{\infty}$ & ロ & のゴュュ & レロレロ゚゚ & ロ゚ッュュ゚ & 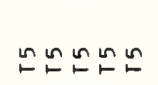 & の苞こにュ & ヘロロッ゚。 & ロロレロロロ & 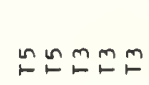 \\
\hline$\stackrel{w}{a}$ & 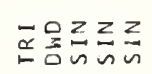 & 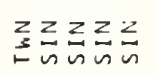 & 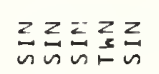 & 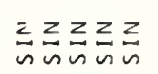 & 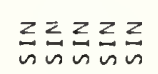 & 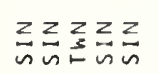 & 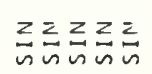 & 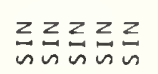 & 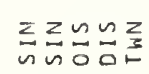 \\
\hline$\frac{0}{2}$ & 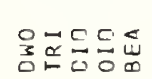 & 똔응드음음 & 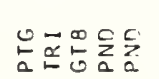 & 음름음뭄 & 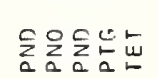 & 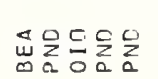 & $\vec{x} \vec{a} \leftarrow \underline{口}$ & 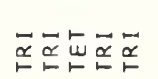 & $\vec{\alpha} \underset{\sim}{\underline{w}} \vec{\alpha} \underline{\underline{\alpha}} \overrightarrow{\underline{\alpha}} \overrightarrow{\underline{L}} \overrightarrow{\underline{\alpha}}$ \\
\hline 岕 & $n n \tilde{x}$ & ins & $n$ & $n$ & 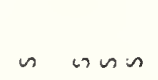 & $n^{*}$ & $n \backsim n$ & nnun & $\backsim$ \\
\hline 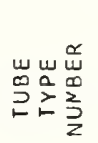 & 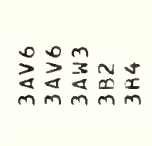 & 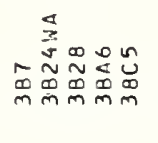 & 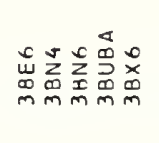 & 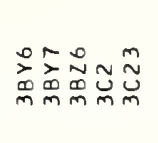 & 造出苔总号 & 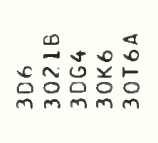 & 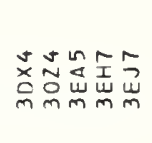 & 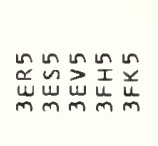 & 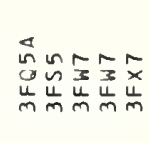 \\
\hline
\end{tabular}




\begin{tabular}{|c|c|c|c|c|c|c|c|c|c|}
\hline 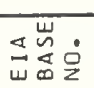 & 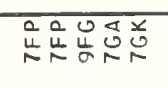 & 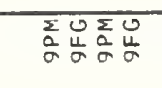 & $\begin{array}{l}0 \\
0 \\
0 \\
0\end{array}$ & 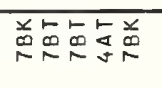 & 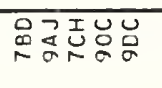 & 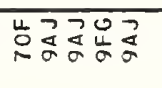 & 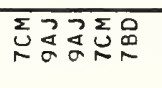 & 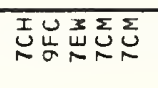 & 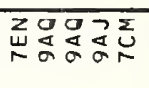 \\
\hline 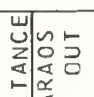 & $\dot{m} \ddot{m} \tilde{m} \dot{m} \dot{m}$ & $\vec{i} \quad \dot{m}$ & $\stackrel{n}{\dot{n}} \dot{m}$ & $\begin{array}{lll}0 & \infty & 0 \\
\dot{n} & \dot{0} & \dot{n}\end{array}$ & 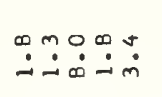 & $\stackrel{+}{\because}: \stackrel{\sim}{\sim} \dot{\sim}$ & $\begin{array}{l}\because \stackrel{0}{\sim} \\
\dot{\sim}\end{array}$ & 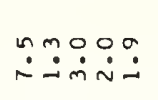 & $\stackrel{0}{\dot{m}} \dot{\dot{s}}$ \\
\hline $\begin{array}{ll}\vec{y} \\
\overrightarrow{0} \\
0 \\
0\end{array}$ & 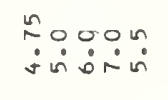 & $\because \quad \dot{0}$ & $\begin{array}{l}0 \\
\dot{\infty}\end{array}$ & 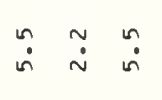 & 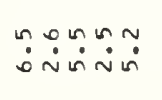 & $\begin{array}{l}\sim \\
\dot{\sim} \\
\sim\end{array} \dot{\sim} \dot{\sim} \dot{\sim} \dot{\sim}$ & $\ddot{\dot{r}} \dot{\sim} \quad \stackrel{n}{0} \dot{0}$ & 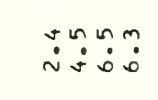 & $\begin{array}{lll}\infty & 0 & 0 \\
\dot{0} & \dot{0} & 0\end{array}$ \\
\hline$=0$ & 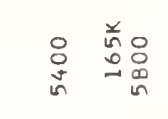 & $\stackrel{\stackrel{0}{0}}{\stackrel{m}{ \pm}}$ & 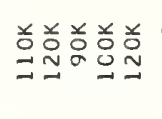 & $\stackrel{\Sigma}{\sim} \underset{0}{x} \geq$ & 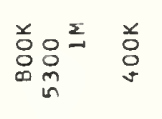 & $\begin{array}{l}\text { 品 } \\
\text { 品兑 }\end{array}$ & 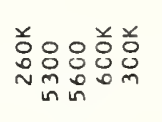 & 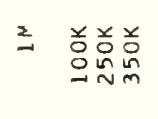 & 兑关兑品兑 \\
\hline 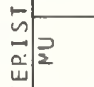 & $\stackrel{\infty}{r} \stackrel{\circ}{r}$ & $\approx$ & & $\stackrel{0}{0}$ & $\stackrel{n}{m} \stackrel{\sim}{N}$ & $\stackrel{\infty}{m} \stackrel{0}{n} \stackrel{n}{\sim}$ & 品 & m & \\
\hline 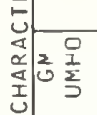 & 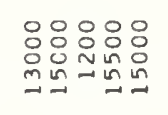 & 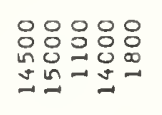 & 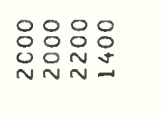 & $\begin{array}{lll}0 & 0 & 0 \\
0 & 0 & 0 \\
0 & 0 & 0\end{array}$ & $\begin{array}{l}\text { 요 } \\
\text { 욤 } \\
\text { in } \\
\text { in }\end{array}$ & 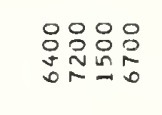 & 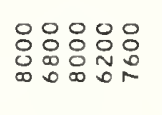 & 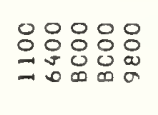 & 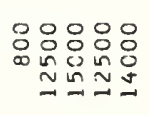 \\
\hline 我 & $=\simeq \infty 0 \simeq$ & $\simeq \cong \sim n m$ & $\infty \infty \bigcirc$ & $\infty-\underset{\stackrel{n}{N}=}{\beth}$ & $\infty O m \pm 0$ & 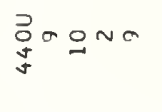 & $\pm 0 ㅇ=$ & $-\infty 00 \simeq$ & $-\quad$ 욤든 \\
\hline w > & 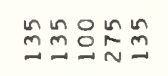 & 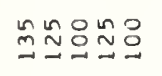 & 용용 & $\stackrel{\circ}{\sim} \stackrel{\circ}{\sim} \stackrel{x}{\sim} \stackrel{\circ}{\sim}$ & 品品品吕只 & 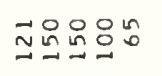 & 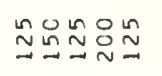 & 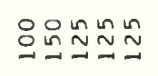 & 용요 \\
\hline 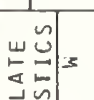 & $\dot{\sim} \dot{\sim} \ddot{\sim} \dot{\sim} \dot{m} \dot{\sim}$ & $\dot{\sim} \dot{\sim} \dot{\sim} \dot{\sim} \dot{\sim}$ & & $\dot{m}: \dot{0} \quad \dot{m}$ & 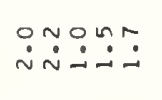 & 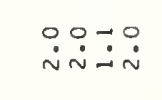 & mơmo & :̊무 & $\because \ddot{\sim} \dot{\sim} \dot{\sim} \dot{\sim} \dot{m}$ \\
\hline 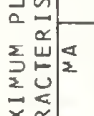 & $\underset{N}{\sim} \sim \mathcal{N}$ & $\sim \stackrel{\sim}{\sim} \simeq \sim$ & $\simeq \simeq \simeq \simeq \infty$ & $\begin{array}{l}8 \\
8 \\
\text { in }\end{array}$ & $\sim \pm$ & $\simeq \underset{N}{ } \underset{N}{ } \simeq \underset{N}{ }$ & $\underset{N}{O N}$ & ON & $\stackrel{\sim}{\sim}$ \\
\hline 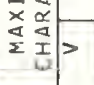 & 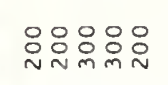 & 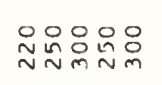 & 으=얌음양 & 品 兽兰: & 品品品品品 & 品品品品品 & 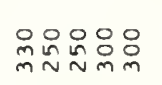 & 总品品品品 & 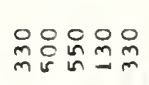 \\
\hline 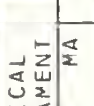 & 品品品品品 & $\begin{array}{l}0 \\
\text { in: } \\
\checkmark\end{array}$ & 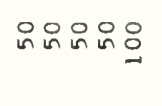 & 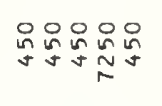 & 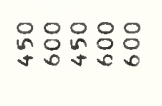 & 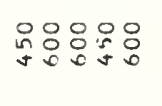 & 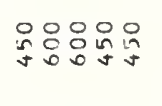 & 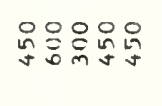 & 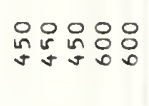 \\
\hline 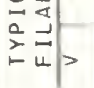 & 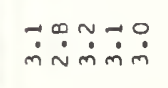 & 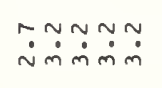 & $\ddot{\sim} \ddot{\sim} \dot{\sim} \dot{\sim} \dot{\sim} \dot{\sim}$ & 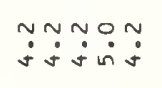 & 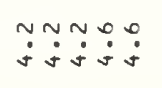 & 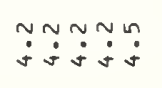 & 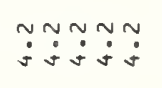 & 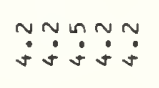 & 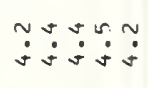 \\
\hline 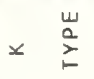 & IIIII & $I I I I I$ & レレயレL & IIIUI & $I I I I I$ & $I I I I I$ & IIIII & IIIII & IIIII \\
\hline$\underset{\Upsilon}{\breve{x}}$ & そうええ゙岕ゔ & $\sum_{\alpha} \frac{I}{3} U \frac{I}{3} ه$ & 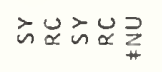 & & 岕え岕亗 & 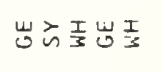 & 惢方虽嵌 & ええ゙ & 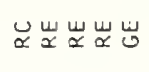 \\
\hline 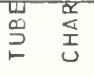 & 号怘怘怘 & 号怘怘怘 & 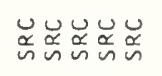 & 号导总芯怘 & $\underset{\mathscr{\alpha}}{\mathscr{\alpha}}$ & 号频怘 & 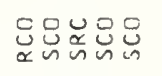 & 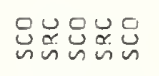 & 炭怘 \\
\hline$\vec{u}$ & 莖堊 㸚峚 & 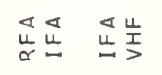 & 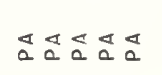 & 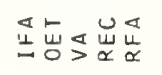 & 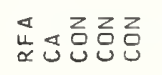 & 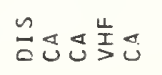 & 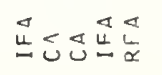 & 的堊范出 & 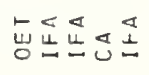 \\
\hline$\stackrel{\infty}{3}$ & 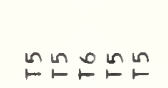 & ヒேェ゚ロ & 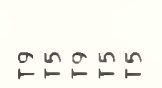 & 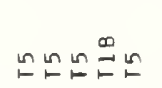 & 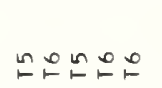 & உ゚ロ゚゚ & 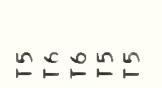 & 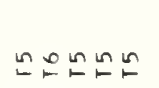 & 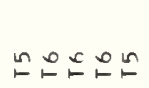 \\
\hline$\frac{11}{2}$ & 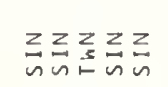 & 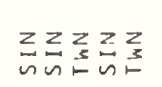 & 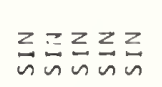 & 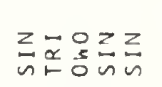 & 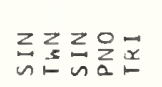 & 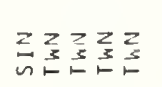 & 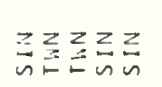 & 를ㄹㄹ를 & 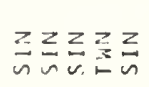 \\
\hline 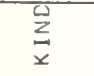 & 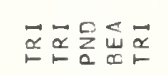 & 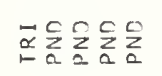 & 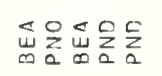 & 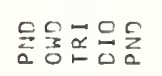 & 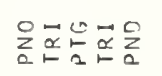 & 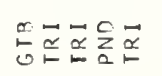 & 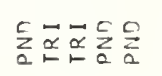 & 乩告踥 & 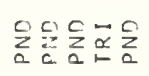 \\
\hline 岁 & $n n n$ & $u \backsim$ & $n n \dot{n}$ & $\ddot{n} n$ & $n$ & $n \backsim n$ & $\backsim \backsim \tilde{\mathscr{D}} \backsim \tilde{\mathscr{D}}$ & $n$ & $n$ \\
\hline 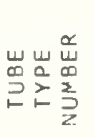 & 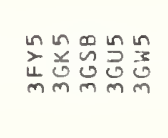 & 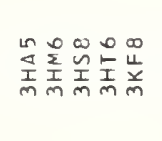 & 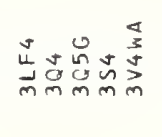 & 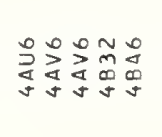 & 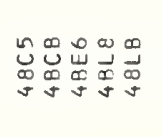 & 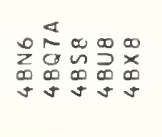 & 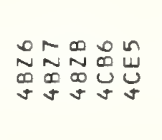 & 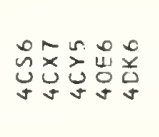 & \\
\hline
\end{tabular}




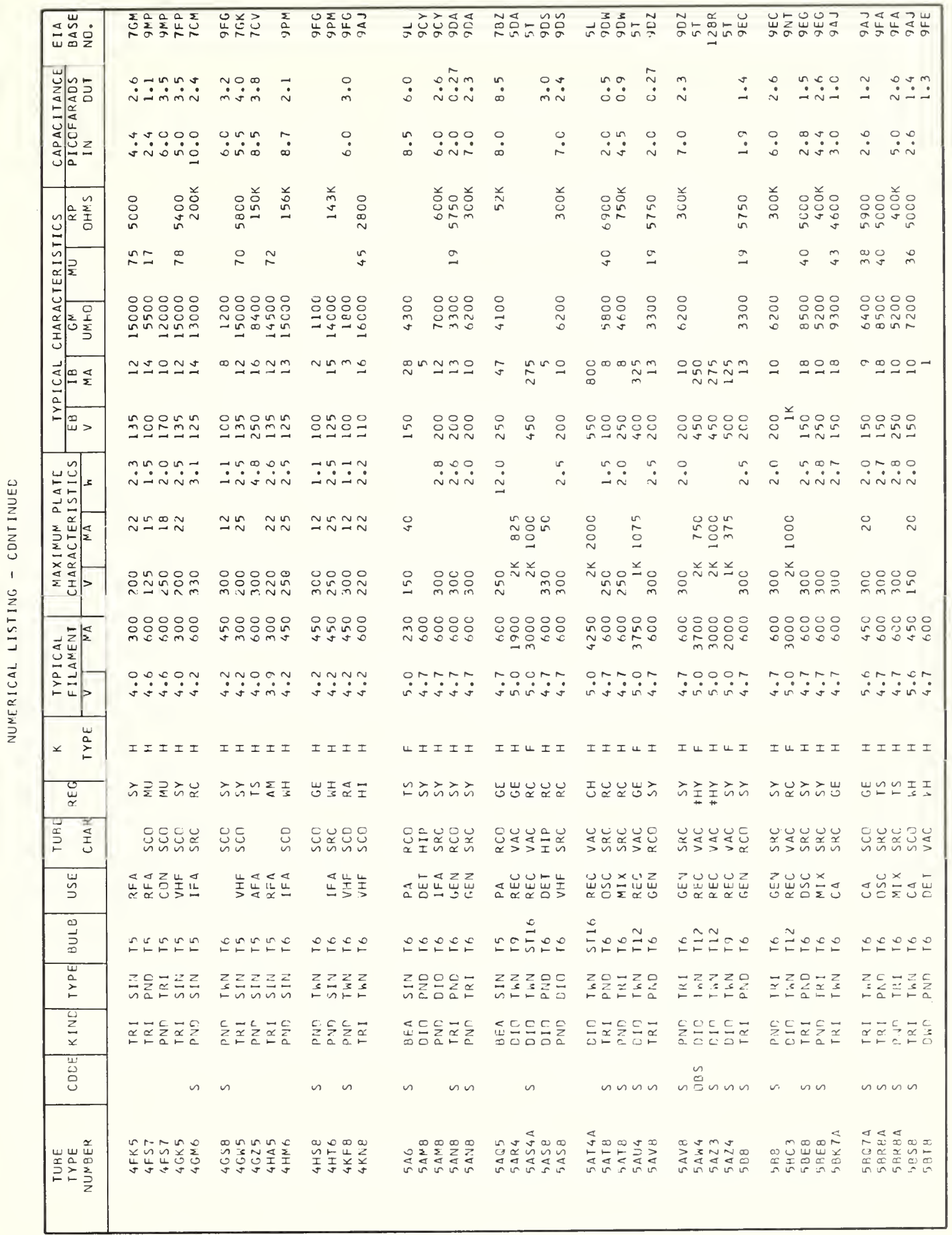




\begin{tabular}{|c|c|c|c|c|c|c|c|c|c|}
\hline 悹岕岕 & 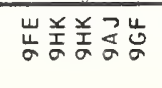 & 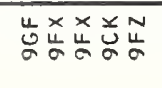 & 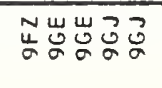 & 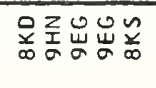 & 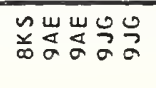 & 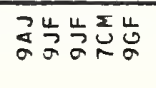 & 岕岕岕岕岩宸 & 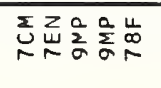 & 岁岕品品呫 \\
\hline 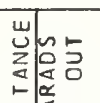 & $\dot{\sim} \dot{\sim} \dot{\sim} \dot{\sim}$ & 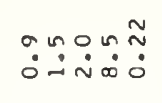 & $\dot{\sim} \quad \stackrel{\dot{\infty}}{\dot{\sim}}$ & $\dot{0} \dot{\sim} \dot{\sim}$ & $\dot{m} \dot{\sim} \dot{\sim} \dot{\sim}$ & 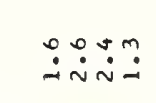 & $\dot{\sim} \dot{\sim} \dot{\sim} \dot{\sim} \dot{\sim} \dot{m} \dot{\sim}$ & $\dot{\sim} \quad \ddot{i} \dot{\sim} \dot{0}$ & $\ddot{\sim} \dot{\sim} \dot{\sim} \dot{\sim} \dot{\sim}$ \\
\hline 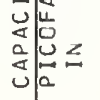 & $\begin{array}{l}0 \\
i\end{array}$ & 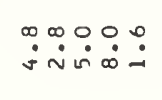 & $\begin{array}{ll}\dot{0} & \dot{\sim} \\
\dot{i}\end{array}$ & $\dot{0} \dot{\sim} \dot{0}$ & $\ddot{m} \dot{\sim} \dot{\sim} \dot{\sim} \dot{v}$ & ற்றே் & 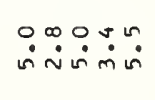 & $\dot{0} \dot{\sim} \dot{\sim} \dot{\sim}$ & 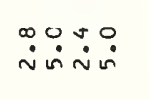 \\
\hline 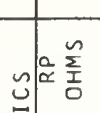 & 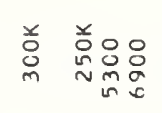 & 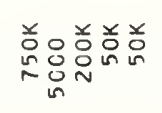 & 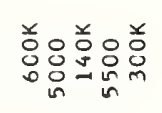 & 总兰兑 & 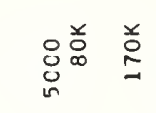 & 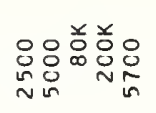 & 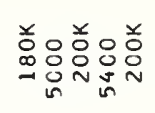 & 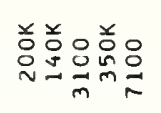 & 응요 \\
\hline 点 & 웅 & $\begin{array}{ll}0 & 0 \\
\checkmark & 0\end{array}$ & $i^{4} N$ & $n$ & $\begin{array}{ll}\text { O } & 0 \\
\end{array}$ & $\stackrel{9}{9} \quad \stackrel{m}{9}$ & $\stackrel{9}{q}$ & ニำ & $\begin{array}{ll}0 & 0 \\
\text { s } & \end{array}$ \\
\hline 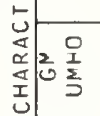 & 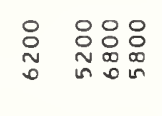 & 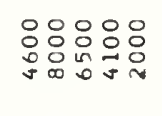 & $\begin{array}{l}0 \\
0 \\
0 \\
: 00 \\
0 \\
0\end{array}$ & \begin{tabular}{l}
0 \\
\hdashline \\
0
\end{tabular} & 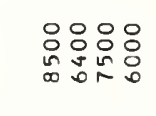 & 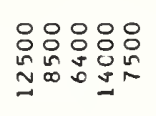 & 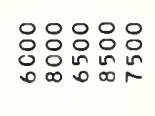 & 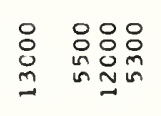 & $\begin{array}{l}\circ O \\
\circ:\end{array}$ \\
\hline$=0 \frac{1}{2}$ & $\varrho^{\circ} \bigcirc 0^{\infty}$ & $\infty \simeq \mathfrak{s}^{N}$ & 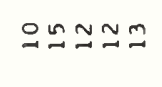 & 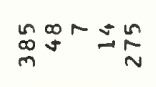 & $\ln _{m}^{\infty} \simeq \simeq \simeq$ & 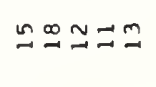 & $\Xi \Xi \simeq \pm \cong$ & 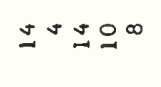 & ป요 \\
\hline w > & 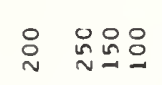 & 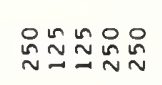 & 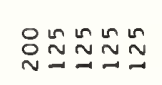 & 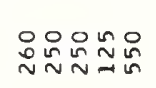 & 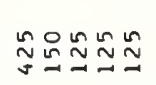 & 요ㅁㅛㅛㅛ $\cong$ & 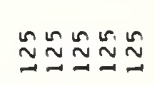 & 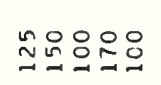 & $\stackrel{n}{\simeq \cong} \cong \cong$ \\
\hline 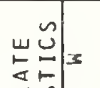 & $\stackrel{\circ}{\dot{N}} \dot{m} \dot{\sim} \dot{\sim}$ & 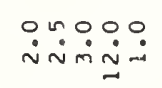 & $\stackrel{\circ \sim \infty}{\dot{\sim} \dot{\sim} \dot{\sim} \dot{\sim} \dot{\sim}}$ & $\begin{array}{l}\dot{0} \sim \stackrel{\sim}{\sim} \\
\stackrel{\sim}{*}\end{array}$ & $\ddot{m} \dot{m} \dot{\sim} \dot{\sim}$ & $\stackrel{\infty}{\dot{m} \dot{m} \dot{m} \ddot{m} \dot{\sim}}$ & 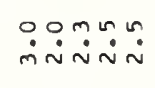 & 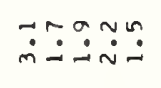 & $\dot{\sim} \dot{m}$ \\
\hline 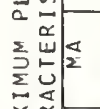 & $\stackrel{\circ}{\sim}$ & & & $\stackrel{n}{\sim} \quad \stackrel{\circ}{\circ}$ & 品 & $\approx$ & $\stackrel{i}{\sim}$ & $=0$ 品 & 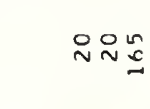 \\
\hline 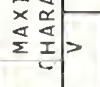 & 율 & 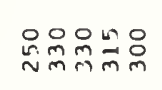 & 임임일 & 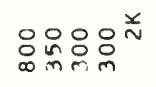 & 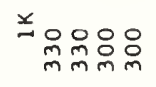 & 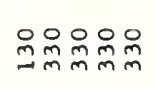 & 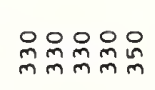 & 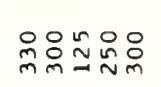 & 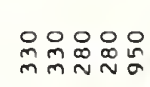 \\
\hline 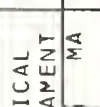 & 용용요 & $\begin{array}{l}\circ \\
\circ \\
0\end{array}$ & 응ㅇㅇㅇㅇㅇ & 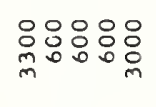 & 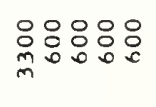 & 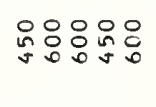 & 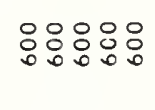 & 品品品怘品品 & 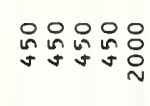 \\
\hline 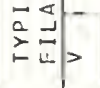 & 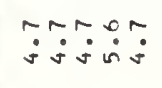 & $\dddot{j} \dot{j} \vec{j} \dot{j} \dot{s}$ & $\ddot{j} \dot{j} \dot{s} \dot{q}$ & 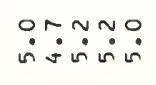 & 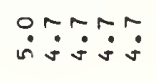 & $\ddot{ن}$ & 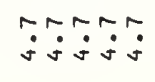 & 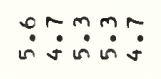 & نُ \\
\hline $\begin{array}{r}\frac{\omega}{2} \\
\times \quad \frac{a}{2}\end{array}$ & IIIII & $I I I I I$ & $I I I I I$ & IIIIU & $4 I I I I$ & IIIII & IIIII & IIIII & IIIIU \\
\hline$\underset{\vec{u}}{\vec{u}}$ & دِ سِ نِ & 岩岕岕方公 & 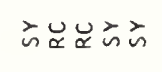 & 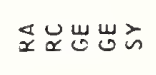 & 㟧岕岕え & $\underset{\alpha}{u} \underset{\alpha}{\alpha} \underset{\alpha}{u}$ & 岕ええ゙す & ひ乞えええひ & 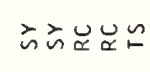 \\
\hline $\begin{array}{ll} \\
\stackrel{y}{2}\end{array}$ & 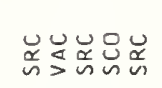 & 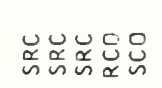 & 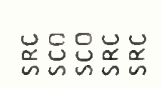 & 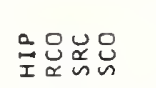 & 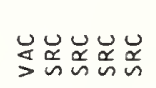 & 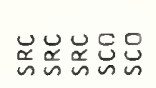 & 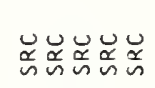 & 岁总总 点 & 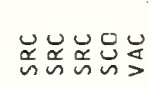 \\
\hline 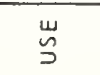 & 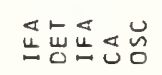 & $\begin{array}{l}x u x \\
\Sigma \\
\Sigma\end{array}$ & 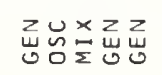 & 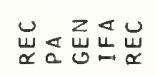 & 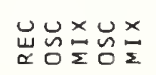 & 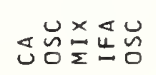 & 希品范品 & 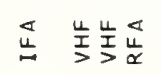 & 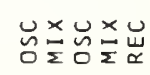 \\
\hline$\stackrel{\infty}{\supset}$ & レ゚゚゚ロ & 논요 & 오ェ요 & こ゚ะ゚ュ & こュレュュ & ゚゚์도 & ピロェ & ロロロロヒ & ゚ㅗュ \\
\hline$\frac{a}{a}$ & 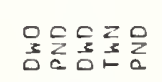 & 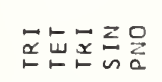 & 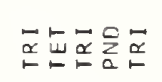 & 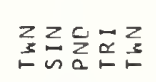 & $\sum_{3} \sum_{0} z_{0}$ & 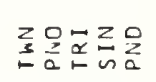 & 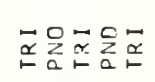 & 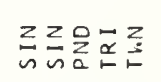 & 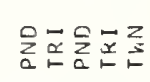 \\
\hline $\begin{array}{l}0 \\
\underline{z} \\
\underline{x}\end{array}$ & 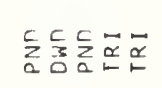 & 记采出岕吕 & 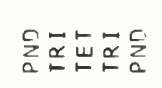 & 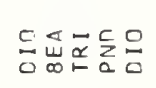 & 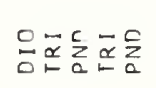 & 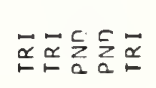 & 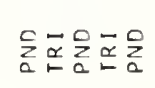 & $\sum_{a} \sum_{a} \bar{\alpha} \sum_{1} \sum_{a} \bar{\alpha}$ & 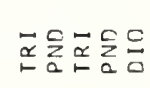 \\
\hline 岂 & $\stackrel{\sim}{\infty}$ & sinnun & 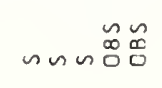 & $n$ & nununo & $n n$ & nnnn & & ++ \pm \\
\hline 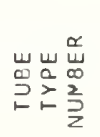 & 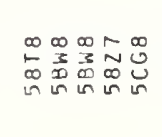 & 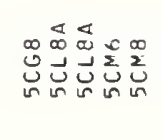 & 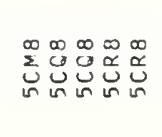 & 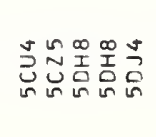 & 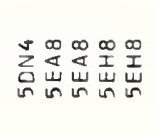 & 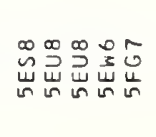 & 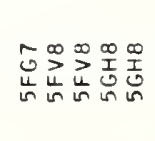 & 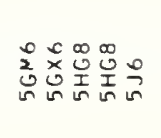 & 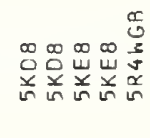 \\
\hline
\end{tabular}




\begin{tabular}{|c|c|c|c|c|c|c|c|c|c|}
\hline 崫崖 & 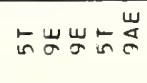 & 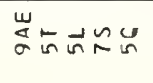 & 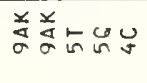 & $\vec{n}$ & Q & 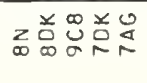 & 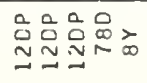 & 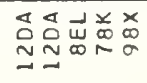 & 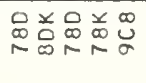 \\
\hline 矛徐吉 & $\ddot{\dot{0}}$ & $\stackrel{n}{\sim} \stackrel{\sim}{r}$ & $\ddot{0}$ & & $\begin{array}{l}00 \text { in } \\
\dot{\sim} \dot{\sim} 0 \dot{\text { in }}\end{array}$ & 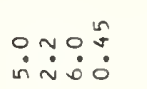 & $\stackrel{\infty}{\dot{n}} \dot{n}$ & 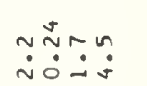 & $\because \ddot{\sim} \dot{0} \dot{\sim} \dot{\sim} \dot{\sim}$ \\
\hline 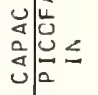 & $\stackrel{n}{\circ}$ & $\stackrel{\circ}{\dot{n}} \quad \stackrel{0}{\circ}$ & $\ddot{\sim} \dot{q}$ & & $\ddot{\sim} \dot{\sim} \dot{\sim} \dot{\sim}$ & 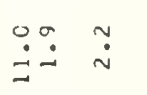 & $\begin{array}{l}n \circ \\
\dot{m}\end{array}$ & $\dot{m} \dot{m} \dot{0} \dot{0}$ & 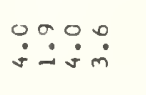 \\
\hline$\tilde{u}$ & 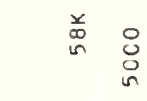 & 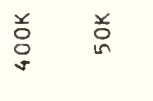 & 总兑 & & 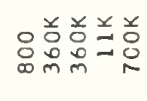 & $\stackrel{2}{2} \stackrel{0}{n} \underset{m}{\sim}$ & 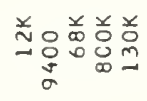 & 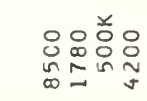 & 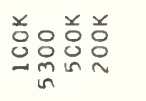 \\
\hline 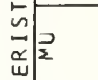 & $\stackrel{0}{\sim}$ & & $\stackrel{g}{q}$ & & $\checkmark \quad 0$ & $\stackrel{0}{\sim}$ & $\tilde{D}_{0} \vec{v}$ & ๑ & $\stackrel{\circ}{N}$ \\
\hline 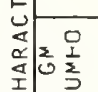 & 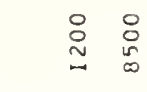 & $\begin{array}{ll}\circ & 0 \\
\sim & 0 \\
\sim & 0\end{array}$ & 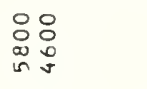 & & $\begin{array}{ll} & \text { OD } \\
\text { N } & \text { D } \\
\text { N }\end{array}$ & $\begin{array}{l}\text { :오 } \\
\text { 융 }\end{array}$ & 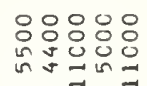 & 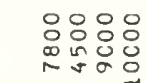 & 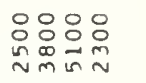 \\
\hline 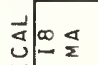 & $\stackrel{n}{\sim} \stackrel{\mathcal{N}^{n}}{\sim}-$ & 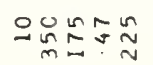 & $\infty \infty \stackrel{\sim}{\simeq} \underset{\sim}{\sim} \stackrel{\sim}{\sim}$ & $\stackrel{n}{\simeq}$ & 언으 & 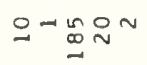 & $-\sigma \underset{\sim}{\sim} O_{m}$ & $\infty$ 임오요 & $m 0^{\infty} \simeq \underset{N}{\sim}$ \\
\hline 光 & 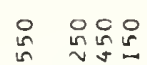 & 虽争墭虽品 & 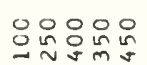 & in & 品品品品: & 일웜윰 & 욤욤요 & $\stackrel{\sim}{\sim} \stackrel{\sim}{\sim}: \stackrel{\sim}{\sim} \underset{\sim}{\sim}$ & 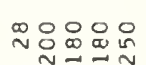 \\
\hline 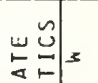 & $\stackrel{i}{\dot{\nu}}$ & $\stackrel{\infty}{\dot{\sim}} \quad \stackrel{0}{\sim}$ & & & $\because \stackrel{\circ}{\sim} \stackrel{\infty}{\sim} \dot{m}$. & OMO & 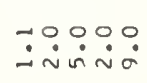 & $\dot{\sim} \ddot{\sim} \dot{m} \dot{m}$ & $\because \ddot{\sim} \dot{\sim} \dot{\sim} \dot{\sim}$ \\
\hline 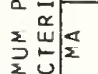 & $\stackrel{n}{n} \quad \vec{c}$ & 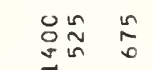 & 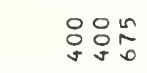 & $\stackrel{n}{n}$ & $\pm \Xi$ & $\sim \underset{\sim}{\sim} \stackrel{\infty}{\sim}$ & & $\stackrel{\infty}{\infty} \stackrel{\infty}{\sim} \stackrel{0}{\sim}$ & $\stackrel{\infty}{\sim} \underset{\sim}{\infty} \stackrel{0}{n}$ \\
\hline 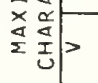 & $\stackrel{x}{\sim} \stackrel{\sim}{\sim} \stackrel{D^{\circ}}{D_{m}}$ & $\stackrel{\stackrel{x}{\sim}}{\sim} \underset{m}{\sim} \stackrel{x}{\sim}$ & $\stackrel{\circ}{\sim} \stackrel{x}{\sim} \underset{\sim}{\sim}$ & $\Xi$ & 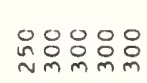 & 윰요 & 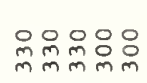 & 일욤요 & 응요 \\
\hline 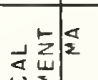 & 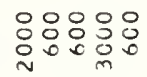 & 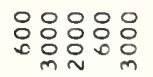 & 영융유 & : & 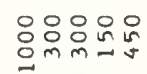 & 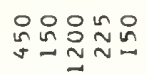 & 영요 & 品品品品先 & 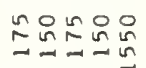 \\
\hline$\therefore \leq 5$ & ONRON & NOONO & $\sim \sim 000$ & $\circ$ & $\mathrm{mmmmm}$ & $\mathrm{mmmmm}$ & $\mathrm{mmmmm}$ & & $\mathrm{mmmmm}$ \\
\hline ここる & $\dot{n} \dot{0} \dot{0} \dot{0}$ & 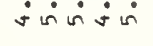 & 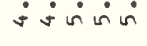 & $\dot{n}$ & $\dot{0} \dot{0} \dot{0} \dot{0}$ & $\dot{0} \dot{0} \dot{0} \dot{0}$ & $\dot{0} \dot{0} \dot{0} \dot{0}$ & $\dot{0} \dot{0} \dot{0} \dot{0}$ & $\dot{0} \dot{0} \dot{0} \dot{0}$ \\
\hline$\times \stackrel{0}{2}$ & UIIUI & $I \perp I I U$ & IIレUU & I & UIIII & $I I I I I$ & IIIII & IIIII & IIIII \\
\hline$\underset{\alpha}{\stackrel{u}{u}}$ & Uِ لّ & யேこえ岕う & 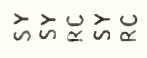 & $\underset{\propto}{u}$ & え & 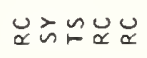 & Uِ & U山心 & \\
\hline$\sum_{0}^{m} \frac{a}{2}$ & $\begin{array}{l}U_{1} \\
> \\
>\end{array}$ & 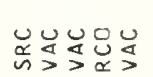 & 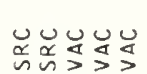 & $\ddot{\square}$ & 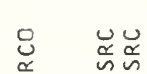 & 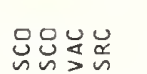 & 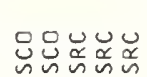 & 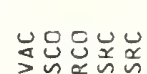 & 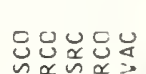 \\
\hline$\stackrel{u}{\sim}$ & 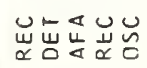 & 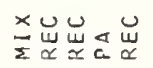 & 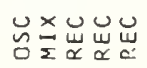 & $\underset{\varpi}{\ddot{w}}$ & 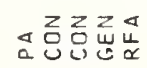 & 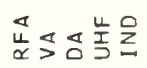 & 品出崖品 & 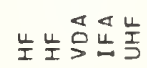 & 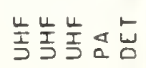 \\
\hline 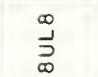 & ㅇㅡㄹㅀㅛ & 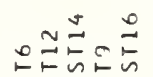 & ะのミご & $\frac{\infty}{2}$ & 决 & 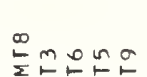 & 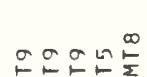 & 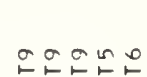 & 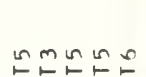 \\
\hline$\frac{\omega}{a}$ & 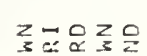 & $q_{x} z_{3} z$ & $Q_{z} z_{s} z_{s}$ & $z$ & $z \geq z \geq z$ & $z \geq z \geq n$ & ஜ气するz & $\stackrel{\alpha}{1} x^{3}$ & $z \geq z \geq z$ \\
\hline$\frac{r}{0}$ & & & & & & & & & $\backsim \backsim \backsim n \backsim$ \\
\hline$\frac{\vec{z}}{x}$ & 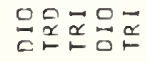 & 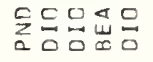 & 똔동음음 & O & 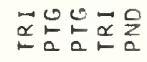 & 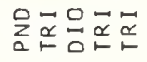 & 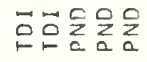 & 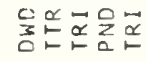 & 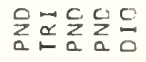 \\
\hline 号 & $n n$ & $\backsim \backsim \backsim \backsim \backsim$ & $\backsim \backsim \backsim \backsim \backsim$ & $n$ & $\mathscr{D}_{\square}^{\infty} \backsim \backsim \backsim \sim$ & $n \stackrel{\sim}{\infty} n n$ & $n n$ & $\stackrel{t}{\sim} \backsim$ & $n$ \\
\hline 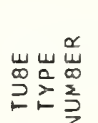 & 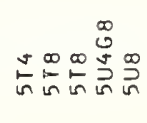 & 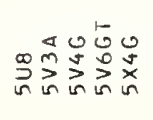 & 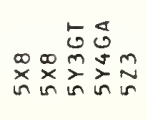 & $\stackrel{N}{N}$ & 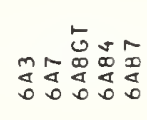 & 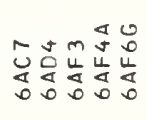 & 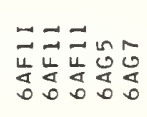 & 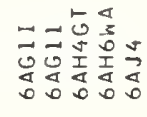 & 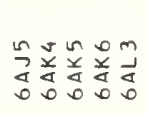 \\
\hline
\end{tabular}




\begin{tabular}{|c|c|c|c|c|c|c|c|c|c|}
\hline 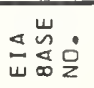 & 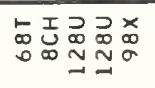 & 乙ૅૅ & 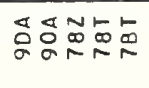 & 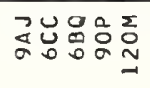 & 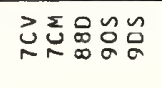 & 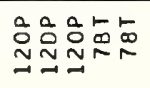 & 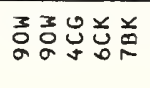 & 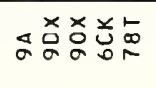 & 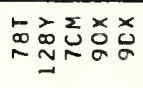 \\
\hline 気鵌言 & $\ddot{\sim} \quad \stackrel{\dot{\sim}}{\sim}$ & 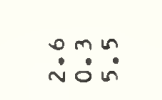 & $\stackrel{\tilde{N} m \tilde{\sim}}{\dot{\sim} \dot{\sim}}$ & $\ddot{\dot{r}} \dot{0} \dot{\sim}$ & 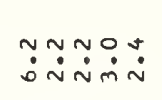 & $\ddot{\sim} \dot{\sim} \dot{\sim} \dot{0}$ & 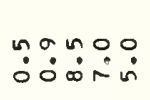 & 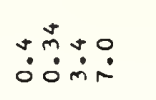 & 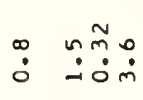 \\
\hline 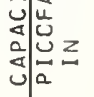 & $\stackrel{\dot{\vdots}}{=}$ & $\because \dot{0} \dot{0}$ & 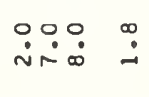 & $\stackrel{\circ}{\vdots}$ & $\dot{\sim} \dot{\sim} \dot{n} \dot{0}$ & $\ddot{\sim} \dot{\sim} \dot{\sim} \sigma \dot{\sim}$ & 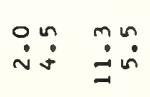 & 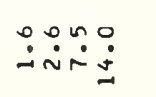 & 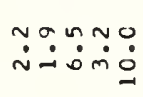 \\
\hline$y$ & 둥ㅎㅇㅇㅇㅁㅇ & 홍 & 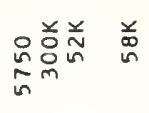 & 睪竞 & 羌。 & 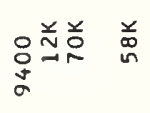 & 号总 : & 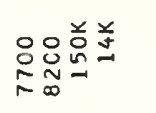 & 关。兑苾兑 \\
\hline 뇰 & $\stackrel{\infty}{\infty}$ & $\stackrel{\circ}{r}$ & $\stackrel{2}{r}$ & n & $\sim$ & ず & o & 웅 & 品 \\
\hline 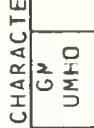 & 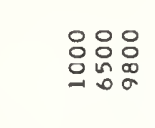 & $\begin{array}{l}\text { ㅇㅇㅇㅇ } \\
\text { 융용 }\end{array}$ & 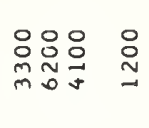 & 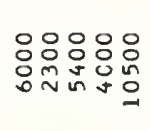 & 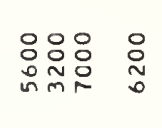 & 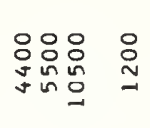 & 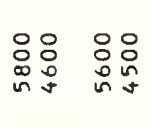 & 颌品品吕 & $\begin{array}{l}\text { 응ㅇㅇㅇㅇ } \\
\text { 융용ㅇㅇ }\end{array}$ \\
\hline 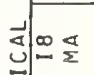 & $\sigma-\sigma o$ & $\backsim \simeq \mathcal{I}=m$ & mo5 & 음ㄷㅇㅇ & 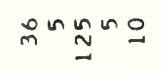 & $\alpha \operatorname{Nan}^{2}$ & $\infty \infty \underset{\sim}{\infty} \underset{\sim}{\sim} 0^{\infty}$ & Oanñ & ror a \\
\hline 悉 > & 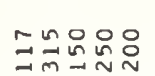 & 엉윰요 & 윰요 $\stackrel{0}{N}$ & 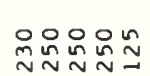 & 윩요 & 잇유 & 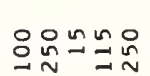 & 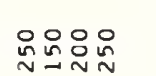 & 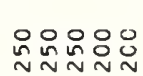 \\
\hline س & ¿̊요 & $\begin{array}{l}\infty \\
\dot{\sim}\end{array}$ & 品品 & $\ddot{\infty} \ddot{0} \dot{\sim} \dot{\sim} \dot{\sim}$ & $\ddot{n} \ddot{\sim} \dot{m} \tilde{\sim}$ & $\ddot{\sim} \dot{\sim} \dot{\sim} \dot{0} \quad \dot{0}$ & 埚品品 & $\begin{array}{l}\infty \sim 00 \\
\dot{\sim} \dot{\sim} \dot{m}\end{array}$ & 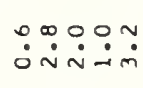 \\
\hline 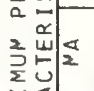 & in & 음 in & - & $\stackrel{n}{=}=$ & $\stackrel{\infty}{\sim} \underset{\text { N }}{n}$ & & 范号 & O & $\stackrel{\text { N }}{\sim}$ \\
\hline 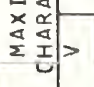 & 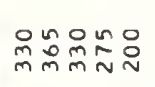 & 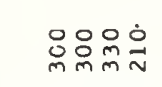 & 啹品 品 & 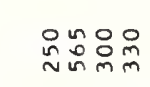 & 음욤욤욤 & 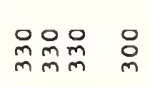 & 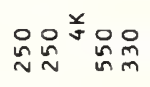 & 总总品品 & 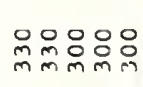 \\
\hline य $3 \frac{5}{4} \frac{\pi}{2}$ & 윰용요요N & 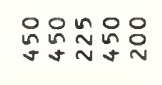 & 品品品品品 & 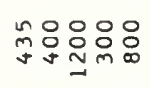 & 品资总品品 & 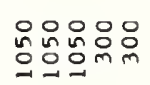 & 只品品员品 & 임잉용욤요 & 있앙융용 \\
\hline 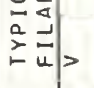 & 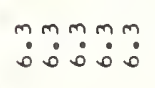 & 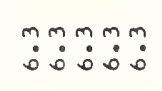 & $m m m m m$ & $\ddot{\dot{0}} \dot{m} \dot{0} \dot{0} \dot{0}$ & 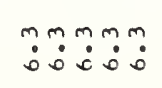 & mmmm & mmmm & mmmmm & mm:m \\
\hline$\times \sum_{\substack{n \\
\Sigma}}^{u}$ & IIIII & IIIII & IIIII & IIIII & IIIII & IIIII & IIIII & IIIII & IIIII \\
\hline$\underset{\alpha}{\stackrel{U}{\sim}}$ & سّ سّ سّ & え゙えゔさう & 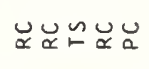 & 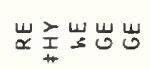 & 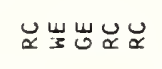 & 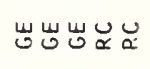 & 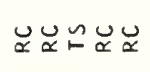 & 嵌岀岁 & 张岁主えう \\
\hline 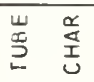 & a 号品品 & 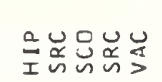 & 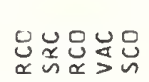 & 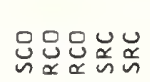 & 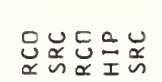 & 怘怘怘导品 & 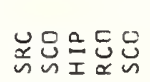 & 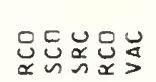 & 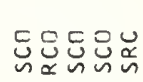 \\
\hline$\stackrel{u}{n}$ & 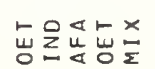 & 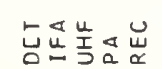 & 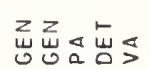 & 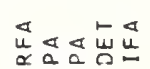 & 品号岂岩崖 & 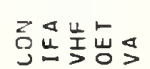 & 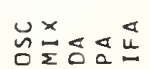 & 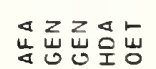 & 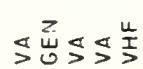 \\
\hline$\stackrel{\infty}{\vec{J}}$ & 욤요 & ะำก & ํำณn & ェッシ゚。 & ๓ュュュュ。 & 욤는 & ะ゚゚ロ & ゚゚ュゴ & 욤ํㄴㅇㅛ \\
\hline $\begin{array}{l}w \\
a \\
2\end{array}$ & 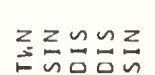 & 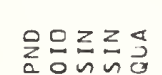 & 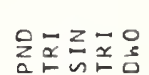 & 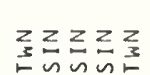 & 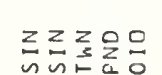 & 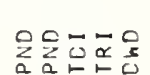 & $\sum_{z}^{0} \bar{a} z z z$ & 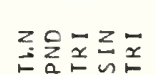 & 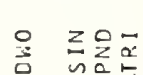 \\
\hline$\frac{0}{2}$ & 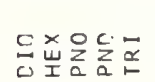 & 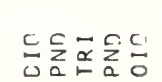 & 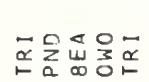 & 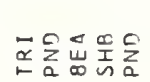 & 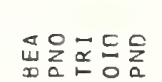 & 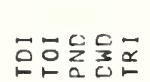 & 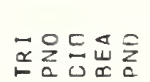 & 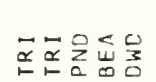 & 品高足家足 \\
\hline 岑 & $\backsim$ & 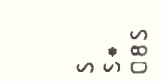 & $\backsim \backsim \backsim \backsim n$ & ヘレッn & $\backsim n$ & $n n$ & nus $\stackrel{+}{\sim}$ & ヘッn๐ & 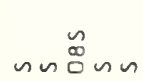 \\
\hline 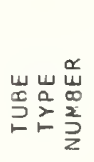 & 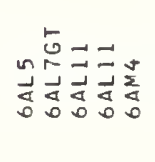 & 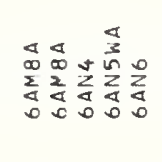 & 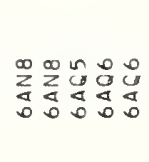 & 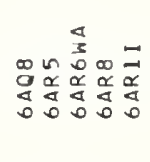 & 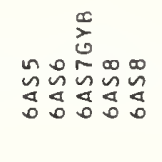 & 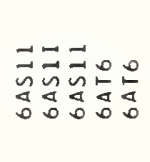 & 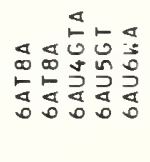 & 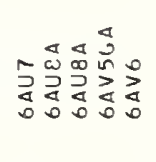 & 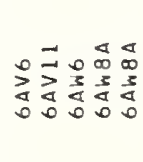 \\
\hline
\end{tabular}




\begin{tabular}{|c|c|c|c|c|c|c|c|c|c|}
\hline 岕岕递 & 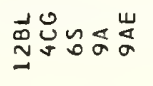 & 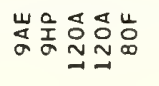 & 吠品 & 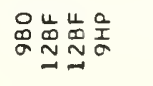 & 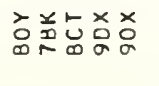 & 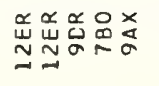 & 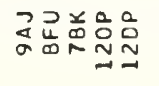 & 总志忈怘出出 & 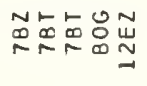 \\
\hline 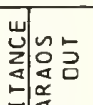 & 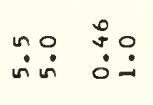 & $\because \tilde{n}$ & $\stackrel{\sim}{i}$ & $\stackrel{m}{n} \quad \dot{j}$ & 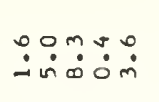 & 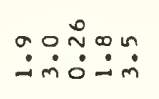 & 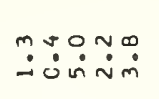 & 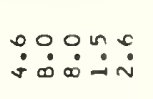 & $\dot{0}: \stackrel{n}{0}$ \\
\hline 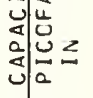 & $\ddot{n} \quad \stackrel{0}{i} \dot{\sim}$ & $\dot{n} \quad \dot{i}:$ & $\ddot{\sim} \ddot{\sim}$ & & 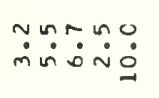 & $\dot{\sim} \dot{0} \dot{\sim} \dot{0}$ & $\ddot{\sim} \dot{\sim} \dot{m} \dot{v} \dot{m} \dot{N}$ & $\stackrel{\dot{\Xi}}{=} \dot{n} \dot{\sim} \dot{v}$ & $\stackrel{\infty}{\dot{\perp}} \dot{\sim}$ \\
\hline ș & $\begin{array}{l}\text { J. } \\
\text { vo } \\
\text { in }\end{array}$ & $\begin{array}{ll}\frac{y}{0} & \text { m } \\
\text { 의 }\end{array}$ & 号兑 & $\stackrel{\stackrel{ }{N}}{\sim}$ & 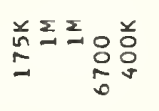 & $\begin{array}{l}\text { 음 } \\
\text { 임 } \\
\text { s. }\end{array}$ & 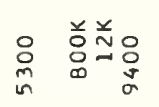 & 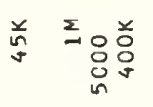 & 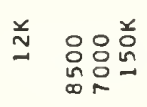 \\
\hline 氛运 & 웅 & 음 & 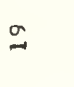 & $\cong 0$ & $\stackrel{\infty}{\sim}$ & $\stackrel{\infty}{\sim}$ & $\stackrel{n}{\sim} \sum_{0}^{\infty} \vec{s}$ & $\rho^{2}$ & $\stackrel{n}{m}$ \\
\hline 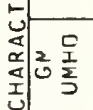 & 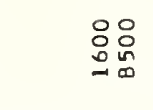 & $\begin{array}{ll}\circ & \circ \\
& \circ \\
\checkmark & \circ\end{array}$ & 욤응 & 怘 & 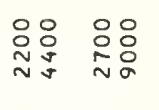 & 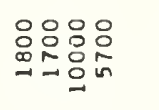 & 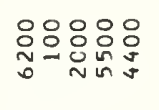 & 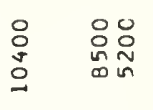 & 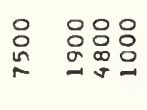 \\
\hline 幽 & $\stackrel{\sim}{0} \cong \underset{工}{\simeq} \cong-\infty$ & $\stackrel{0}{=}$ & mo & 옥 으용으 & $0=+\infty m$ & in $\quad \infty \infty$ & $0-\sigma \sim a$ & $=m \Phi 0$ & $\stackrel{\alpha}{m}-0 \infty-$ \\
\hline 常 > & 洋品品品 & 怘 $\quad \stackrel{D}{\sim}$ & : 윰 & 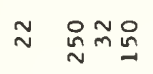 & 음용용ㅇㅇㅇ & 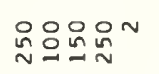 & 음 용유유 & $\stackrel{n}{m} \stackrel{i}{\sim} \stackrel{0}{\sim} \underset{n}{\sim}$ & 욤욤요 \\
\hline ع & 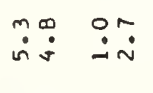 & $\stackrel{\infty}{\dot{\sim}} \dot{\sim} \dot{0}$ & $\dot{\sim} \dot{\sim}$ & $\dot{m} \dot{m}$ & $\because 000 \stackrel{ }{\circ \dot{\sim}}$ & $\stackrel{\operatorname{Ln}}{\sim} \ddot{\sim} \dot{\sim} \dot{\sim}$ & $\stackrel{\sim}{\sim} \underset{\sim}{\dot{n}} \dot{m} \dot{\sim} \dot{\sim}$ & $\ddot{v} \dot{0} \dot{\sim} \dot{\sim} \dot{\sim} \dot{\sim}$ & 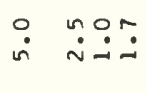 \\
\hline 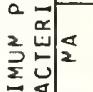 & 蕴足 & $\stackrel{O}{\Xi}^{n} \stackrel{\sim}{\sim}$ & & 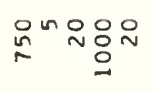 & $\approx$ & $\stackrel{N}{N \sim n}$ in & $\sim \sim v$ & $\stackrel{0}{\stackrel{D}{\beth}}$ & $\stackrel{\circ}{\simeq}$ \\
\hline 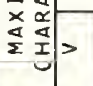 & 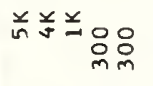 & 弟 & 兽品 & v & 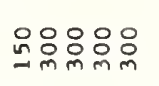 & 品品品品品 & 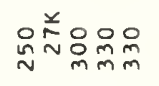 & 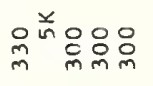 & 品 $: 000$ \\
\hline 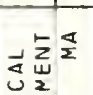 & 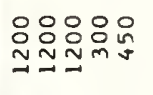 & 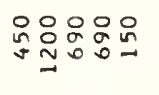 & 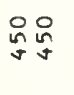 & 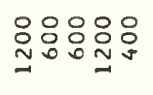 & 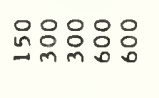 & 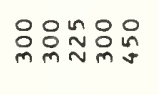 & 응응융용요 & 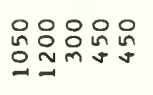 & 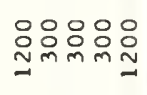 \\
\hline 造势> & $m m m m m$ & $m m m m m$ & $\ddot{m} \ddot{0}$ & $m \ddot{m}: \ddot{m}: m m$ & mmmm.: & $\ddot{0} \dot{0} \dot{0} \dot{0} \dot{0} \dot{0}$ & m & 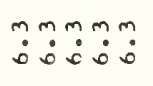 & 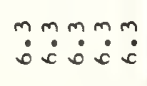 \\
\hline 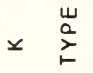 & IIIII & IIIII & $I I$ & IIIII & IIIII & IIIII & IエII & IIIII & IIIII \\
\hline$\underset{\sim}{\stackrel{\Psi}{x}}$ & 岕乞ひうる & 重え岕嵌公 & $\underset{\alpha}{\alpha}$ & 甹岕岕 & 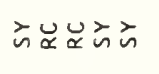 & $\backsim \backsim \ddot{\sim} \bar{a}$ & 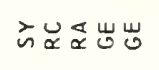 & 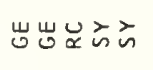 & $\vec{a}_{\alpha} u_{\propto} u_{\omega}$ \\
\hline $\begin{array}{ll} \\
\end{array}$ & 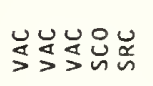 & 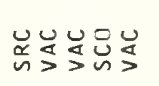 & 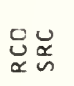 & 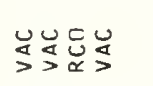 & 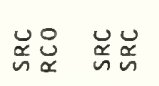 & 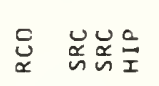 & 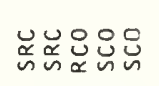 & 号某 芯选 & 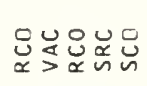 \\
\hline$\stackrel{u}{s}$ & 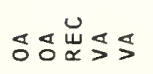 & 崩占占造忌 & uñ & 㟧岁呫岌 & 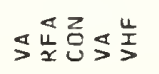 & 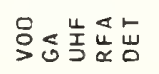 & 过岂造出导 & 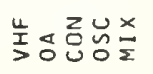 & 吕出出出出 \\
\hline$\sum_{\infty}^{\infty}$ & ேேロレ゚ & 뭄ำ & 욘 & レロロロ告 & 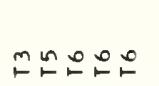 & ロロ゚ロ゚ & レシュレロ & こテロレ゚ & 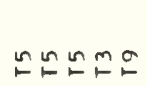 \\
\hline $\begin{array}{l}4 \\
\vdots \\
2 \\
亡 \\
\end{array}$ & 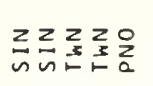 & 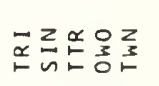 & $\sum_{a} \underset{\sim}{\alpha}$ & 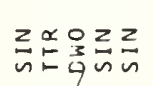 & 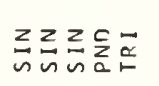 & 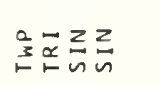 & 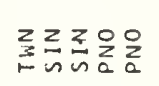 & 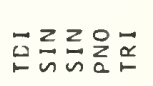 & 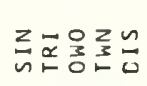 \\
\hline$\frac{0}{2}$ & 음응듬뭄 & 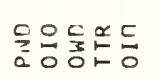 & $\underset{\alpha}{\sim} \sum_{a}^{c}$ & 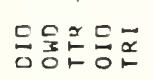 & 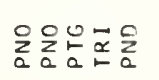 & 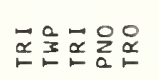 & 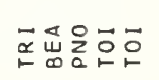 & 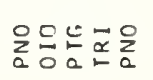 & 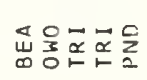 \\
\hline $\begin{array}{l}\text { 山े } \\
\text { ठ }\end{array}$ & ńฺn & $n$ & $n n$ & $\tilde{\infty}$ & 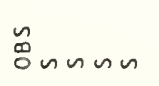 & $n n$ & $n n$ & ヘnทn & レレ๐ \\
\hline 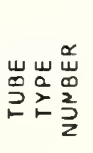 & 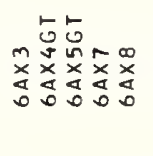 & 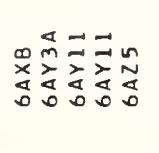 & 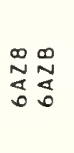 & 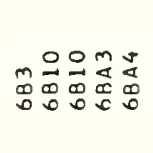 & 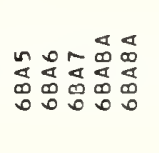 & 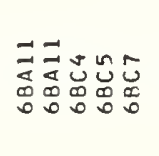 & 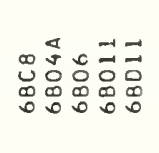 & 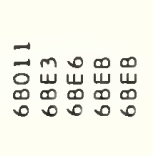 & 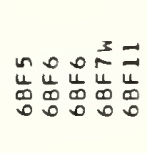 \\
\hline
\end{tabular}




\begin{tabular}{|c|c|c|c|c|c|c|c|c|c|}
\hline 㟧苫号 & 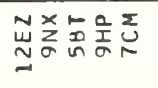 & 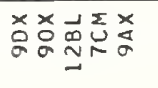 & 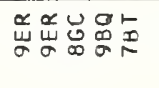 & 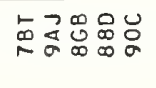 & 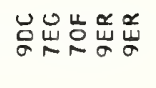 & 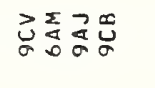 & 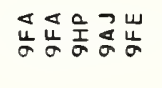 & 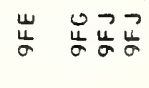 & 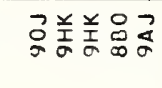 \\
\hline 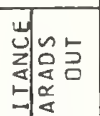 & $\ddot{\dot{\theta}} \dot{0} \dot{0} \dot{0}$ & 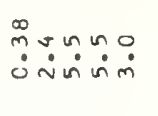 & $\vec{m} \circ: 0$ & 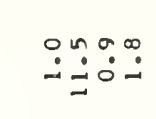 & $\stackrel{\infty}{m} \stackrel{\because}{\sim} \stackrel{n}{\sim}$ & 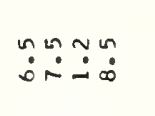 & 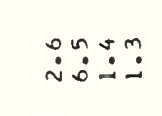 & $\dot{\sim} \dot{\sim} \dot{m} \dot{\sim} \dot{0}$ & $\dot{2} \dot{\sim} \dot{\sim}$ \\
\hline 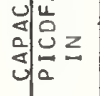 & $\stackrel{\dot{\Xi}}{\dot{\Xi}} \dot{\sim}$ & $\stackrel{0}{\sim} \stackrel{0}{\sim}$ & 品品 & $\dot{m} \stackrel{\sim}{\sim} \dot{\sim}$ & $\dot{n} \tilde{m} \tilde{m} \dot{m}$ & $\begin{array}{l}\infty \\
\dot{0} \dot{\sim} \dot{\sim} \\
\dot{\sim}\end{array}$ & $\dot{0} \quad \dot{\sim}$ & $\ddot{i} \dot{m} \dot{0} \dot{m}$ & $\stackrel{\infty}{\dot{v}} \dot{\sim} \dot{\sim}$ \\
\hline 어워 & 弟 $\stackrel{x}{\sim}$ & 品兑 & 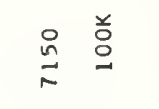 & 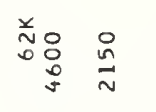 & 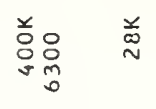 & 兹 훙요 & 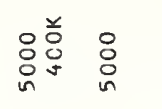 & 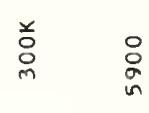 & $\begin{array}{l}\text { 兑品 } \\
\text { N }\end{array}$ \\
\hline 웠 & & $=$ & $\stackrel{\stackrel{x}{N}}{N}$ & 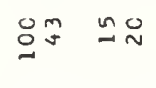 & 3 & $\stackrel{\infty}{m}$ & $\stackrel{0}{*} \quad \stackrel{m}{\xi}$ & $\stackrel{m}{m}$ & $\cong \approx$ \\
\hline \begin{tabular}{l|l}
0 \\
0
\end{tabular} & $\begin{array}{lll}0 & 0 & 0 \\
0 & 0 & 0 \\
0 & 0 & 0\end{array}$ & $\begin{array}{ll}\circ & 0 \\
0 & 0 \\
m & 0 \\
m & 0 \\
\end{array}$ & 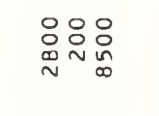 & $\begin{array}{l}\text { 品 } \\
\text { 品: } \\
\text { 品 }\end{array}$ & 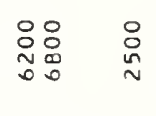 & $\begin{array}{l}0 \\
0 \\
0\end{array}$ & 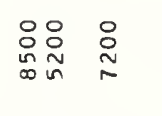 & $\begin{array}{l}0 \\
0 \\
\\
0\end{array}$ & 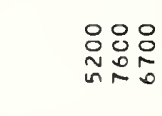 \\
\hline $40 \frac{5}{2}$ & $\stackrel{0}{m}_{m}^{n} \underset{\sim}{n} r$ & 요용 & $\sigma \infty-\hat{m}-$ & - & Oの & 㶽 in $\sigma$ 品克 & $\cong$ ㅇㅇㅂㅇㅛ - & 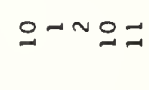 & $\Xi^{\sim n} O \mathbb{N}^{\circ}$ \\
\hline$r^{2}$ & $\stackrel{n}{\sim} \stackrel{\circ}{\sim} \stackrel{\circ}{\sim}$ & 䠐只 $\vec{\sim}$ & mo $\stackrel{i}{\sim}$ & 虽品 $\simeq \underset{\sim}{\sim}$ & 只品 $\vec{\beth}^{m} \stackrel{⿱}{\sim}$ & 虽忠品品 & 克怘 $\simeq$ & 只兑品 导 & $\stackrel{n}{\sim} \stackrel{\sim}{\sim} \underset{\sim}{\sim}{ }^{n} 0$ \\
\hline 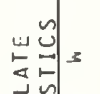 & 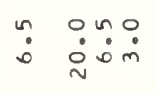 & $\ddot{\sim} \dot{\sim} \dot{m} \dot{j} \dot{j} \dot{m}$ & $\because \stackrel{\sim}{\sim} \dot{0}$ & 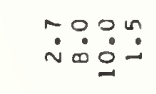 & $\stackrel{\sim}{-} \stackrel{\sim}{-}$ & $\begin{array}{l}\dot{0}: \stackrel{\sim}{\sim} \dot{\sim} \dot{\sim} \\
\sim\end{array}$ & خ $\dot{\sim} \dot{\sim} \dot{0} \dot{\sim}$ & $\dot{\sim} \dot{\sim} \dot{\sim}-\dot{\sim}$ & $\dot{m} \dot{0} \dot{\sim}$ \\
\hline 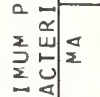 & 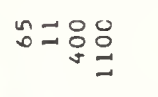 & 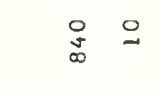 & $\backsim \sim N$ & $\stackrel{ }{\simeq} \underset{\sim}{N}$ & $\Xi \approx \simeq \Xi$ & ñ & 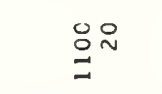 & $\sim \simeq$ & 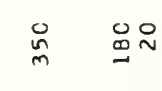 \\
\hline 这㖕> & 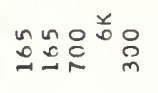 & 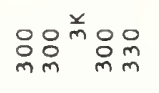 & 足 & 品品 落品 & 욜요 & 윰요요 & 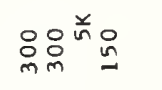 & 㒸兑品 & 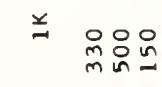 \\
\hline & 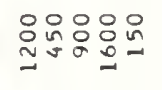 & $\begin{array}{l}0 \\
0 \\
0\end{array}$ & 용용요 & 品品品品 & 品品品: & 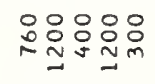 & 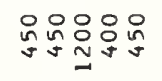 & in & 品品品品品 \\
\hline 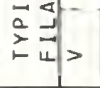 & $\ddot{\circ} \dot{0} \dot{0} \dot{0} \dot{0}$ & $\ddot{0} \ddot{0} \ddot{0} \ddot{0} \ddot{0}$ & 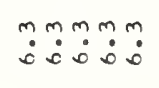 & $\ddot{0} \ddot{0} \ddot{0} \ddot{0} \ddot{0}$ & 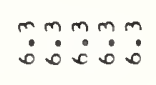 & $\ddot{0}: \ddot{0}: \ddot{0}^{m}$ & $\ddot{0}_{\dot{0}}^{m} \dot{m} \dot{0} \dot{0}$ & 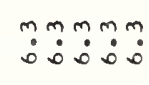 & m:m : \\
\hline 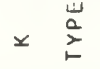 & IIIII & IIIII & IIIII & IIIII & IIIII & IIIII & IIIII & IIIII & IIIII \\
\hline 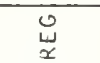 & U山山 & 岕岕出乞岂 & 旅岕岕方 & え岕岕えら & こ岁岕えうう & 公主岩口立 & 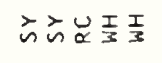 & I I & え岕岕え责 \\
\hline 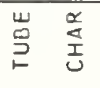 & 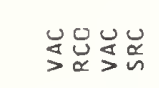 & 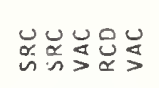 & 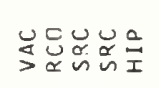 & 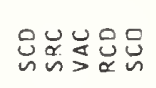 & 品 & 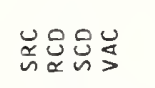 & 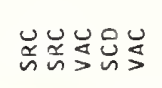 & 造总总过品 & 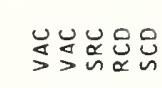 \\
\hline 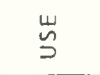 & 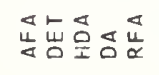 & 忌垲范范出 & 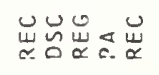 & 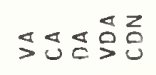 & 总堊路岂芳 & 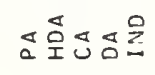 & 㟔彭顿出 & 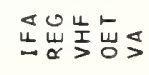 & 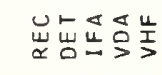 \\
\hline$\stackrel{\infty}{5}$ & 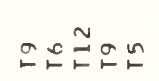 & レ゚のにた & ピュュュ & ピュ゙ロレ & ピュュ゚゚ & ト゚ロ゚トレ & ト゚ト゚ト゚ & ヒミュ゚゚゚ & レ゚ェ゚゚ \\
\hline 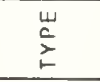 & 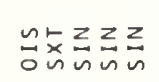 & 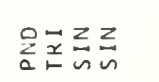 & 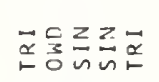 & 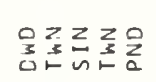 & 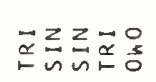 & 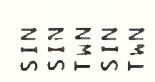 & 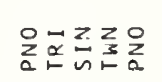 & 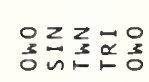 & 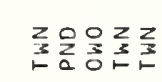 \\
\hline$\frac{\tilde{z}}{\underline{z}}$ & 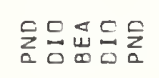 & 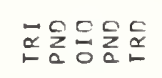 & 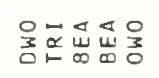 & 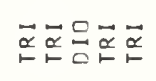 & 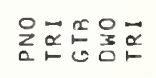 & 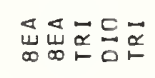 & 좀응음 $\overrightarrow{0}$ & 虽出足呈金 & 등오음뭄뭄 \\
\hline $\begin{array}{l}\text { 㟔 } \\
\text { ப }\end{array}$ & n & $n \backsim \backsim n$ & & $\mathscr{c}_{\Delta} n n n$ & $n$ & $n \backsim \backsim$ & $\backsim \backsim \sim \tilde{\mathscr{D}}$ & 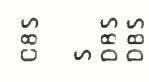 & $\backsim \tilde{E}$ \\
\hline 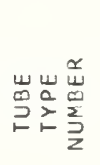 & 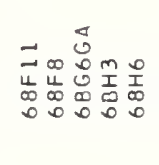 & 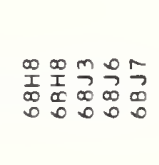 & 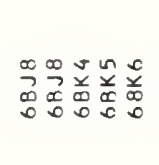 & 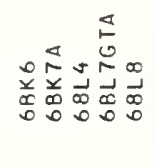 & 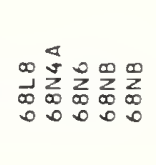 & 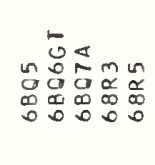 & 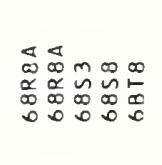 & 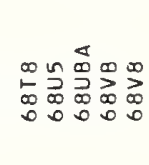 & 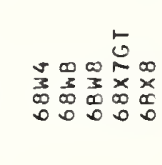 \\
\hline
\end{tabular}




\begin{tabular}{|c|c|c|c|c|c|c|c|c|c|}
\hline 崫岕员 & 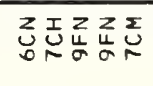 & कर & 品的范总 & そう出怘怘 & 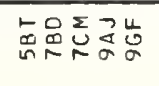 & 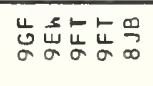 & 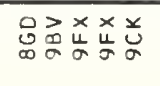 & 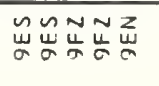 & Z \\
\hline 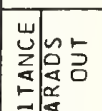 & $\begin{array}{l}0 \infty 00 \\
\dot{\sim} \\
\dot{\sim}\end{array}$ & $\stackrel{\sim}{\sim}$ & $\because \stackrel{0}{\because}:$ & $\stackrel{\circ}{\dot{\alpha}} \underset{\dot{0}}{\dot{\alpha}} \dot{\sim}$ & 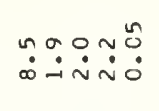 & 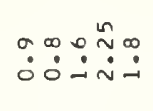 & 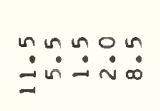 & 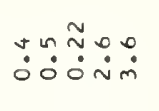 & 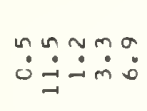 \\
\hline 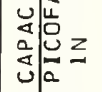 & 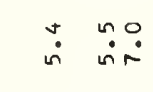 & $\stackrel{\circ}{\sim}$ & 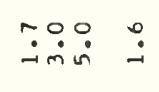 & $\dot{\sim} \dot{\sim} \dot{0}$ & $\ddot{\sim} \dot{\sim} \dot{0} \dot{\sim} \dot{\sim} \dot{\sim}$ & $\begin{array}{l}\infty \\
\dot{v} \dot{\sim} \dot{\sim} \dot{\sim} \dot{\infty}\end{array}$ & 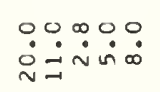 & 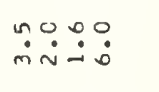 & $\ddot{\sim} \ddot{\infty} \sim \dot{\sim} \dot{\sim} \dot{\sim}$ \\
\hline 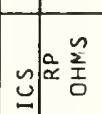 & $\begin{aligned} & \Sigma 0 \\
& 0 \\
& 0\end{aligned}$ & $\begin{array}{l}\text { O: } \\
\text { 品 } \\
\text { in }\end{array}$ & 兑응 & 芯芯。兑 & 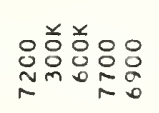 & 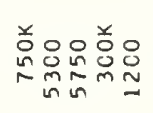 & 总品兑兑 & 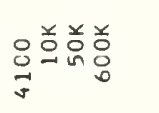 & 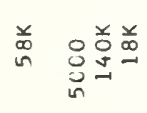 \\
\hline 占新 & & $\stackrel{0}{m} \stackrel{n}{v}$ & $=\stackrel{\circ}{ }$ & & 웅 & 吕 & $\stackrel{9}{9}$ & $\stackrel{\infty}{\sim} \overrightarrow{0}$ & $\stackrel{0}{\circ}$ \\
\hline 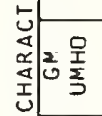 & $\begin{array}{l}\circ \\
\circ\end{array}$ & $\begin{array}{l}: 0 \\
\therefore: \\
\infty \\
0 \infty\end{array}$ & 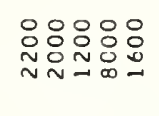 & 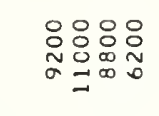 & 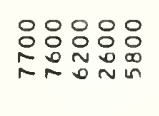 & 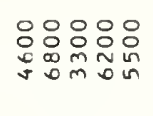 & 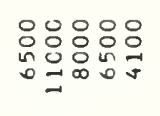 & 욤요 & $\begin{array}{l}\circ \\
\therefore\end{array}$ \\
\hline 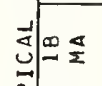 & $\stackrel{n}{\simeq} \stackrel{\text { in }}{=} \Xi \pm$ & 으우 & $0^{\infty} \sim 0^{-1}$ & 음응응으 & $\stackrel{n}{\sim}=0 \sigma \infty$ & 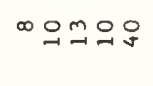 & 佂さェテ & $i^{n} \sim O^{n}$ & 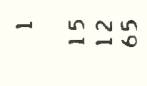 \\
\hline > & $\stackrel{\circ}{\sim} \stackrel{0}{N} \stackrel{n}{\sim}$ & $\stackrel{P}{\sim} \stackrel{\curvearrowleft}{\simeq}$ & 品品怘 $\underset{\sim}{\sim} \underset{\sim}{\sim}$ & 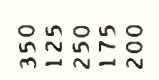 & 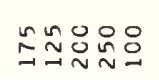 & 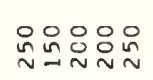 & $\stackrel{n}{=} \stackrel{\sim}{\sim} \stackrel{n}{\approx} \cong \stackrel{n}{\sim}$ & 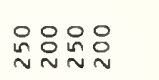 & $\stackrel{\circ}{\sim} \cong \stackrel{\sim}{\sim} \underset{\sim}{\sim}$ \\
\hline 世气 & $\stackrel{\dot{\sim}}{\dot{\sim}} \dot{\sim} \dot{\sim}$ & $\ddot{\sim} \dot{\sim}$ & 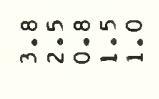 & ம் & $\dot{0} \underset{\sim}{\sim} \dot{\sim} \dot{\sim} \dot{m}$ & $\dot{\sim} \dot{\sim} \dot{\sim} \dot{\sim} \dot{\sim} \dot{\sim}$ & $\stackrel{\sim}{\sim} \dot{\sim} \sim \dot{\sim} \dot{\sim}$ & $\because \sim \dot{\sim} \dot{\sim} \dot{\sim}$ & $\dot{\dot{0}} \dot{\sim} \sim \dot{\sim} \dot{\sim}$ \\
\hline 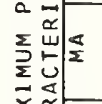 & $\stackrel{n}{\approx} \underset{\infty}{\infty}$ & 욤 & 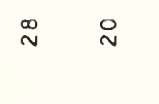 & 욤 总号 & $\stackrel{\circ}{\circ}$ & $\stackrel{O}{\sim} \quad \stackrel{0}{n}$ & $\underset{\substack{0 \\
\infty}}{0}$ & 웃 & $\begin{array}{ll}\stackrel{0}{0} & \circ \\
\end{array}$ \\
\hline 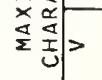 & m & $\stackrel{\circ}{\sim} \stackrel{\circ}{\sim}$ & 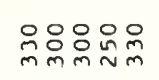 & 壬O & 움임윰요 & 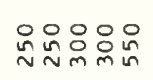 & 울요 & 웅욤요 & : \\
\hline 过氙密 & 응ㅇㅇㅇㅇㅛ & 家家 & 品品: & 음오욤요 & 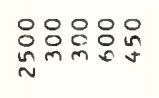 & 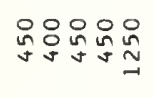 & 员品品品品 & 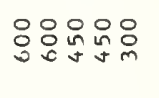 & 을 \\
\hline 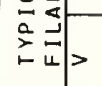 & $\ddot{0} \dot{0} \dot{0} \dot{0} \dot{0} \dot{0}$ & $\ddot{m} \ddot{m}$ & mm & $\dot{0} \dot{0} \dot{0} \dot{0} \dot{0}$ & 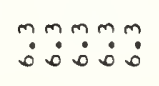 & 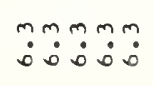 & $\ddot{0} \dot{0} \dot{0} \dot{0} \dot{0}$ & m: & :mmmm \\
\hline 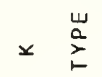 & IIIII & $I I$ & IIIII & IIIII & IIIII & IIIII & IIIII & IIIII & IIIII \\
\hline$\underset{\alpha}{\underset{\sim}{\Psi}}$ & 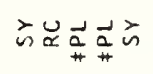 & $\underset{\vec{a}}{\vec{a}}+\vec{a}$ & 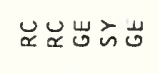 & $\underset{\propto}{u} \tilde{u} \tilde{\sim} \breve{\alpha}$ & 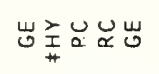 & 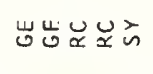 & 方嵌岕出方 & 幽えゔ岕 & 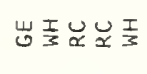 \\
\hline 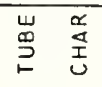 & 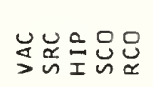 & $\begin{array}{l}D_{\tilde{x}} \\
\text { ñ }\end{array}$ & 号号怘怘 & 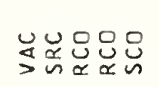 & 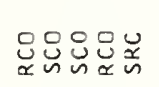 & 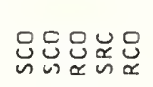 & 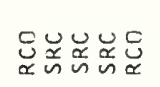 & 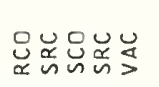 & 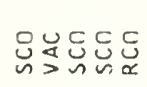 \\
\hline 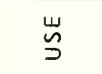 & 吕怘岕范 & త్రత్ & 㟔出出堊出 & 岀区迨呈品 & 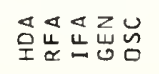 & 原导出出号 & 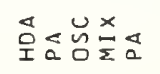 & 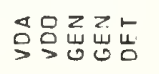 & 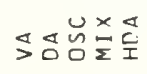 \\
\hline$\stackrel{\infty}{3}$ & ユュュ゚ロロ & $\stackrel{2}{2}$ & に点こた。 & レッロニュ & こュュロ゚゚ & ゚ロ요 & そ゚゚ュュ & レ゚゚゚ュ & ピレェレ \\
\hline $\begin{array}{l}\omega \\
\frac{a}{2} \\
2 \\
\end{array}$ & 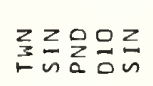 & $\begin{array}{l}2 \\
3 \\
3 \\
1\end{array}$ & 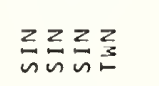 & 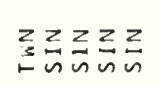 & 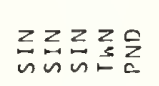 & 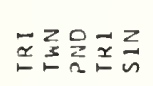 & 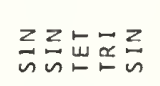 & 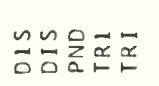 & 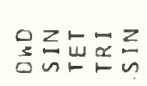 \\
\hline$\underset{\underline{z}}{\underline{\underline{z}}}$ & 은응응 & $\vec{\alpha} \overrightarrow{\underline{\alpha}}$ & 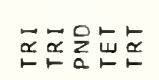 & 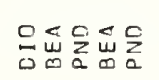 & 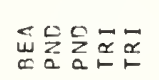 & 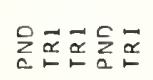 & 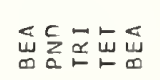 & 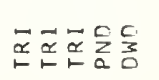 & 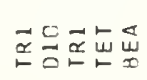 \\
\hline 岂 & $n$ & $n n$ & sinns & $n n$ & 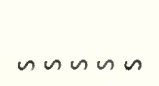 & 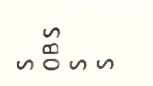 & n๐nnnu & $n n n$ & $\operatorname{nnn} \tilde{E}$ \\
\hline 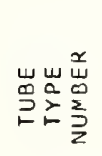 & 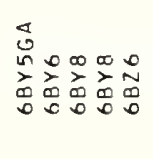 & 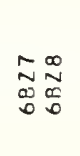 & 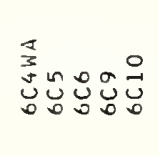 & 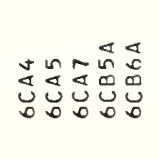 & 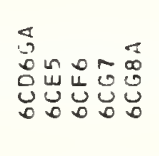 & 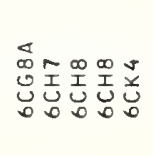 & 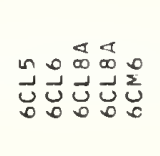 & 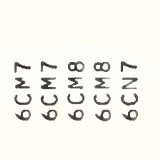 & 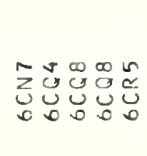 \\
\hline
\end{tabular}




\begin{tabular}{|c|c|c|c|c|c|c|c|c|c|}
\hline 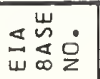 & 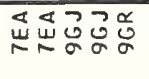 & 甹岕岕凯造岕 & 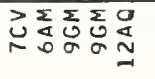 & 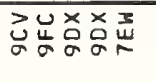 & 岀岀党 & 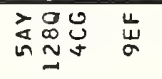 & 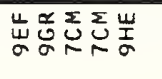 & 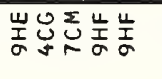 & 乞承资是导 \\
\hline 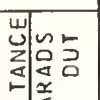 & $\begin{array}{l}: \infty 0 \\
\dot{\sim} \dot{\sigma}\end{array}$ & 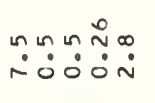 & $\stackrel{n}{\infty} \dot{\sim} \dot{\sim} \stackrel{\sim}{\sim} \dot{\sim} \dot{\sim}$ & 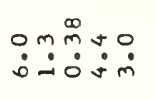 & $\ddot{\square}: \dot{0}$ & 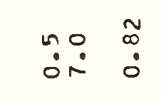 & 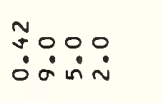 & 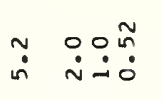 & $\stackrel{\circ}{\circ} \stackrel{\square}{-} \stackrel{\infty}{0}$ \\
\hline $\begin{array}{lll} & \\
0\end{array}$ & : & 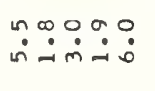 & 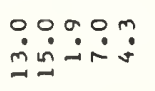 & 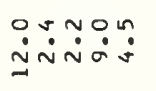 & 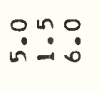 & ஸo in & $\dot{\sim} \dot{\sim} \dot{0} \dot{0}$ & 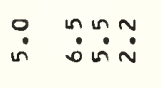 & $\stackrel{9}{\dot{0}}$ \\
\hline 气ِ & 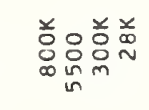 & 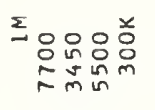 & 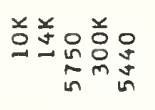 & 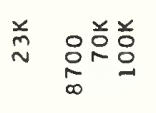 & 㱏总 & $\begin{array}{l}\stackrel{x}{J} \\
-\end{array}$ & 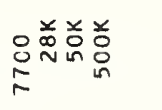 & 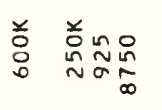 & 兼 \\
\hline 気这 & $\approx$ & $\simeq \approx \approx$ & $\sigma \quad \infty$ & oro & $n \infty$ & in & 요 & $\mathscr{0}$ & $m$ \\
\hline \begin{tabular}{l|l} 
& \\
& 5
\end{tabular} & $\begin{array}{l}\text { 요요 } \\
\text { 品足: } \\
\text { N }\end{array}$ & 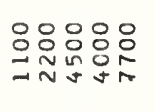 & 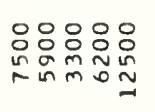 & $\begin{array}{l}\circ \circ 800 \\
\circ 0 \\
\circ \\
\circ\end{array}$ & 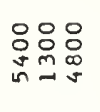 & 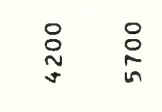 & 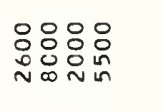 & 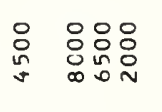 & 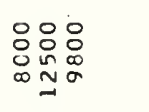 \\
\hline 嵌 & NOำ & -0워 $\simeq$ & 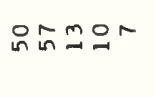 & 우 $\approx 0$ & $\stackrel{p}{-\infty}$ & 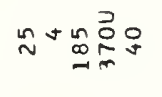 & aテ & $\beth \stackrel{n}{=} 2 \underset{m}{0}$ & $\exists \cong \simeq$ \\
\hline D > & 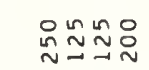 & 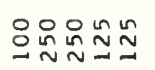 & 옴 윰윰유 & 움욤윰묘 & 点虽虽 & 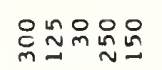 & 克윳용ㅇㅁ & 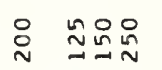 & 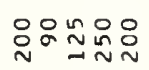 \\
\hline 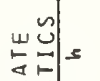 & 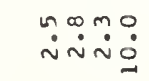 & 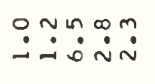 & 足: $\dot{\sim} \dot{\sim} \dot{\sim}$ & $\begin{array}{l}\text { ப̊口: } \\
\text { ป் }\end{array}$ & 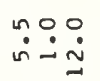 & $\dot{\sim}: \dot{0}: \dot{0}$ & 家品品 & ن̊m & 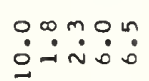 \\
\hline 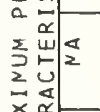 & & v요 & : & $\stackrel{O}{=} \stackrel{\circ}{\sim}$ & $\stackrel{\circ}{\cong}$ & $\stackrel{\circ}{=} \check{g}^{m o}$ & 욤 in & $\stackrel{0}{=} \stackrel{n}{I}$ & $\stackrel{\sim}{\sim} \stackrel{n}{\sim} \underset{\sim}{\mathcal{D}}$ \\
\hline 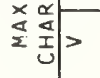 & 品品品品 & 品品总品品 & 丘: & 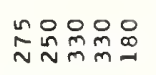 & 虽品品品 & 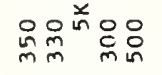 & 맘밈윰유 & 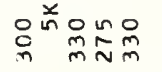 & 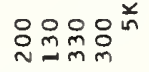 \\
\hline 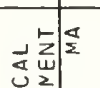 & 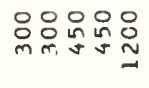 & 品品品品品 & 总品员品品 & 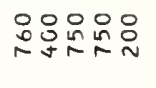 & 员怘怘 & 虽员品品品品 & 品咨品品品 & 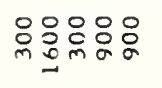 & 克预品品品 \\
\hline 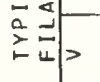 & mmmm & 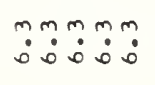 & $\ddot{\circ} \dot{0} \dot{0} \dot{0} \dot{0} \dot{0}$ & $m m m m m$ & m. & 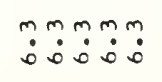 & $\ddot{\dot{0}} \dot{0} \dot{0} \dot{0} \dot{0} \dot{0}$ & $\dot{0} \dot{0} \dot{0} \dot{0} \dot{0}$ & mmmmm \\
\hline $\begin{array}{r}m \\
\times \quad \stackrel{a}{z} \\
\square\end{array}$ & IIIII & IIIII & IIIII & IIIII & $I I I$ & IIIII & IIIII & IIIII & IIIII \\
\hline$\underset{\underset{I}{\Psi}}{\mathcal{O}}$ & ここごうう立 & 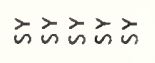 & 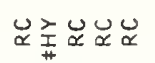 & 峎え岕岕予 & U્ & 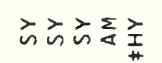 & 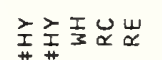 & 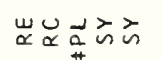 & 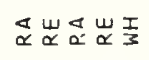 \\
\hline 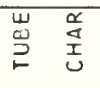 & 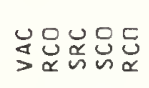 & 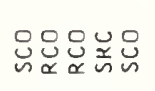 & 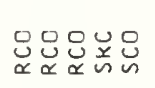 & 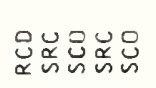 & 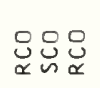 & 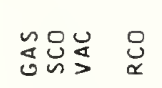 & 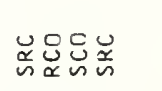 & 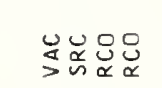 & 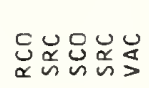 \\
\hline$\stackrel{\vec{u}}{د}$ & 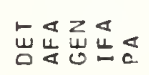 & 过㟔号出出 & 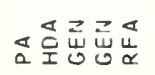 & 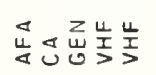 & 空号㔯 & 主出咶呈号 & 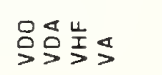 & 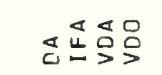 & 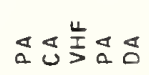 \\
\hline$\stackrel{2}{\vec{D}}$ & セロッ゚゚゚ & セ゚゚゚゚゚゚ & レコュ゚゙ & レ゚゚゚ロ上 & レ゚゚゚ & ๓ロロ゚゚ & ト゚ロヒュ゚ & レロッ゚ロ & ே゚ロュロ \\
\hline 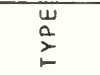 & 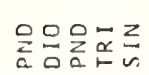 & 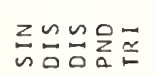 & 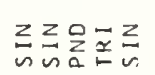 & 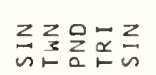 & 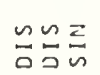 & 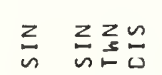 & 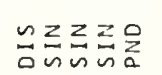 & 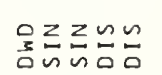 & 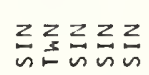 \\
\hline$\underset{x}{\stackrel{0}{2}}$ & 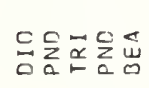 & 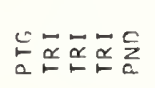 & 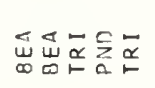 & 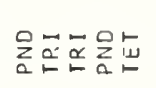 & 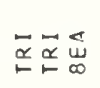 & 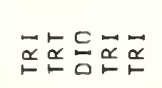 & 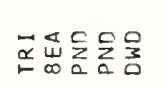 & 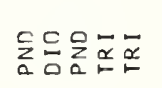 & 出金路员员 \\
\hline $\begin{array}{l} \\
\\
\\
\end{array}$ & $\begin{array}{l}\sim \sim \\
\infty \\
0 \\
0 \\
0\end{array}$ & 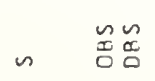 & 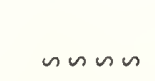 & ทnทn & $n$ & $\dot{n} \sim \stackrel{\sim}{\infty}$ & $\tilde{D}_{0}$ & ヘレッn & 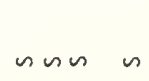 \\
\hline 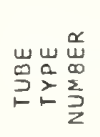 & 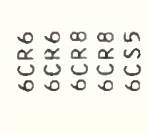 & 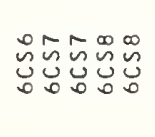 & 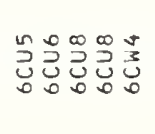 & 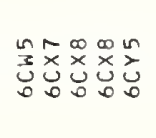 & $\begin{array}{l}\hat{z} \tilde{N} \\
000 \\
000\end{array}$ & 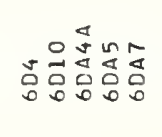 & 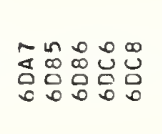 & 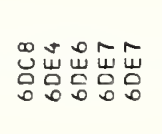 & 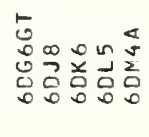 \\
\hline
\end{tabular}




\begin{tabular}{|c|c|c|c|c|c|c|c|c|c|}
\hline 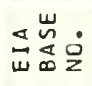 & 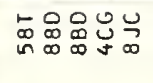 & 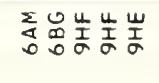 & 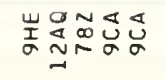 & 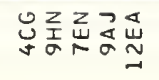 & 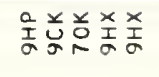 & 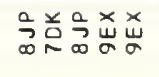 & 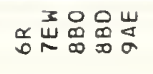 & 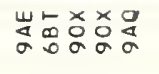 & 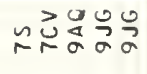 \\
\hline 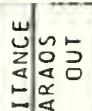 & 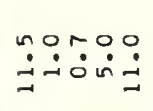 & 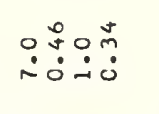 & $\stackrel{\infty}{\therefore} \dot{0}$ & 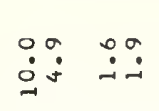 & $\ddot{\dot{0} \sigma 0 \stackrel{\infty}{\circ}}$ & $\stackrel{\text { mo }}{-}$ in & $\ddot{\sim} \dot{\sim} \dot{0} \dot{0}$ & $\stackrel{\circ}{\dot{\sim}} \stackrel{\circ}{\circ}$ & $\ddot{\sigma} \circ \dot{0} \dot{m} \dot{\sim}$ \\
\hline 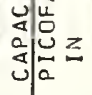 & $\ddot{\sim} \dot{\sim} \dot{\sim} \quad \dot{\sim}$ & $\ddot{n} \dot{\sim} \dot{\sim} \dot{\sim} \sim$ & $\ddot{m} \dot{n}$ & $\stackrel{n}{\dot{\sim} \dot{\sim}} \underset{\sim}{\infty} \dot{\sim} \dot{\sim} \dot{\sim} \dot{j}$ & $\dot{\dot{g}}$ & $\stackrel{\sim}{\sim} \stackrel{0}{\Xi}$ & $\begin{array}{l}\infty \\
\dot{m} \dot{0} \dot{\sim} \dot{m}\end{array}$ & $\dot{n} \stackrel{\dot{\sim}}{\dot{\sim}} \stackrel{\circ}{=}$ & 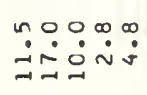 \\
\hline 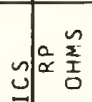 & 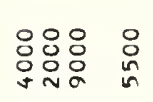 & 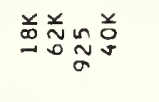 & 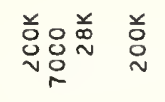 & 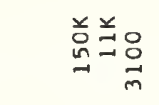 & 点。 & 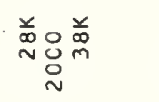 & 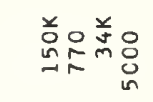 & 弟 兰首 & 兰弟 \\
\hline 勾 & $\approx \approx$ & $\stackrel{\circ}{0}$ & $\hat{0} \stackrel{0}{\sim}$ & $g \stackrel{n}{m}$ & 용 & $\simeq 8$ & $\ln \ln 0$ & $\stackrel{0}{0}$ & J \\
\hline 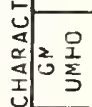 & 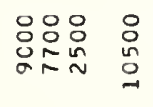 & 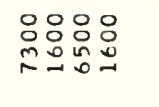 & 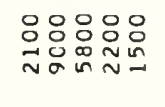 & 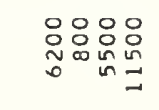 & 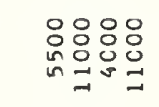 & 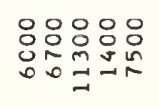 & 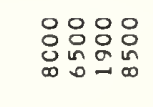 & 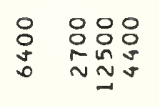 & 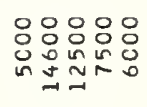 \\
\hline$=\frac{4}{\Sigma}$ & 원을 & $n n^{n}-n_{m}^{n}$ & $\sim \sim N \sim-$ & $\stackrel{\infty}{m}-0$ 오 & 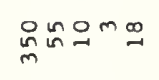 & 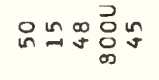 & 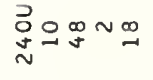 & $\simeq 0 \sim \simeq \sim$ & 足 $\simeq \simeq \simeq \simeq$ \\
\hline > & 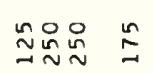 & 욤욤욤요 & $\stackrel{n}{\sim} \stackrel{0}{\sim} \stackrel{\sim}{\sim} \stackrel{\sim}{\sim} \sim$ & 只唄怘 & 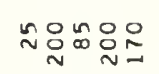 & 오N & 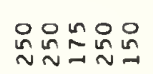 & $\stackrel{n}{\cong} \stackrel{\circ}{N}$ 足 & 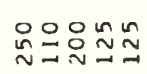 \\
\hline 世气 & 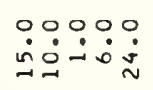 & 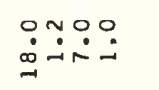 & 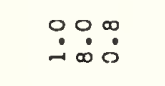 & 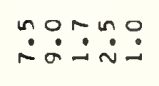 & 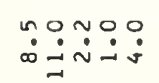 & 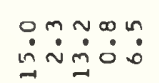 & ஸ் & $\vec{m} \dot{m} \dot{i} \dot{\sim}$ & 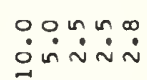 \\
\hline 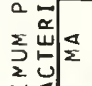 & 品 品吕 & $\underset{0}{0} \stackrel{n}{=} q^{n}$ & $\ln n$ on & 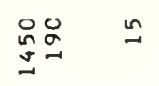 & 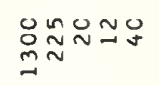 & $\stackrel{i}{\sim} \ln 0$ & 品 & $\stackrel{q}{0}^{\circ}$ & $\stackrel{O}{\infty}$ \\
\hline 希势, & 吕品品酋 & 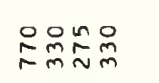 & 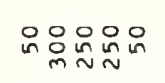 & 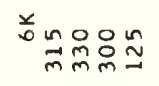 & 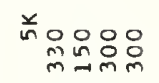 & 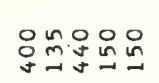 & 沜品品怘品足 & 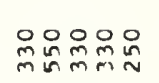 & 오N \\
\hline$\frac{\sum^{\prime}}{2}$ & 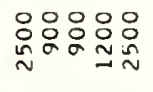 & 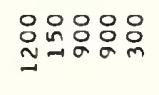 & 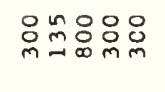 & 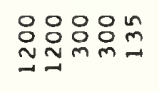 & 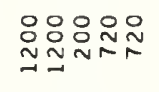 & 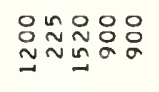 & 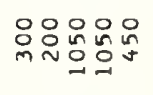 & 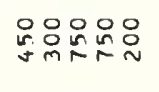 & 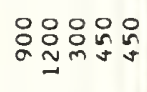 \\
\hline 려인 & $\ddot{0} \dot{0} \dot{\oplus} \dot{\oplus} \dot{0}$ & $\ddot{0} \dot{0} \dot{0} \dot{0} \dot{0}$ & $\ddot{0} \dot{0} \ddot{0} \ddot{0} \ddot{0}$ & mற்m & 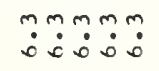 & 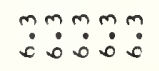 & 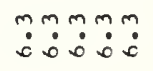 & 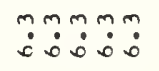 & 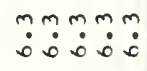 \\
\hline $\begin{array}{r}\omega \\
\times \quad \stackrel{a}{\Sigma}\end{array}$ & IIIII & $I I I I I$ & $I I I I I$ & IIIII & IIIII & IIIII & IIIII & IIIII & IIIII \\
\hline$\underset{\check{u}}{\stackrel{u}{x}}$ & え岕出 $\underset{x}{\varnothing}$ & 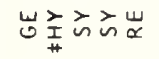 & 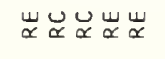 & 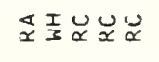 & Ư⿱ & ええ゙岕品怘 & 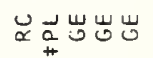 & 岕さらええむ & 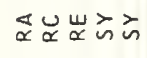 \\
\hline 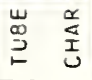 & 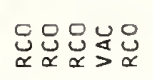 & 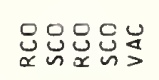 & 通 & 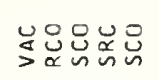 & 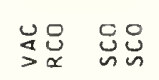 & 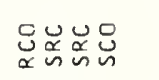 & 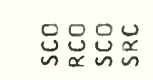 & 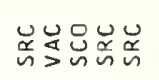 & 兽怘 \\
\hline$\tilde{n}$ & 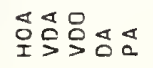 & 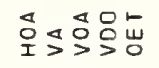 & 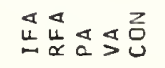 & 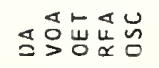 & 吅岌岗台台 & 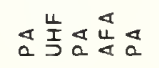 & 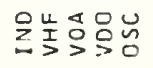 & 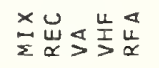 & 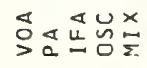 \\
\hline$\stackrel{D}{ు}_{\infty}^{\infty}$ & ニロロロュ & テュュ゚゚ロ & セ点にレ゚ & こ゚ル゚゚を & の゚ロレ゚ & きュュュュ & ロレロの゚ & ゚ヒェレ゚゚ & こロェレ゚ \\
\hline 崩 & 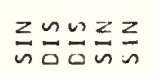 & 르믐ํ음 & 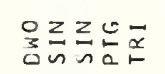 & 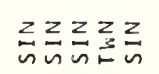 & 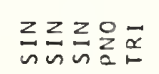 & 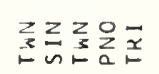 & 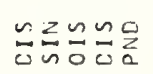 & 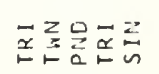 & 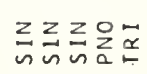 \\
\hline$\stackrel{\vec{\nu}}{\underline{\Sigma}}$ & 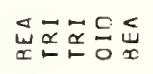 & 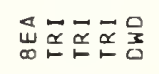 & 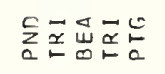 & 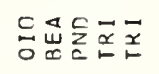 & 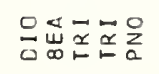 & 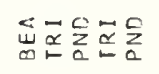 & 吕出品品品 & 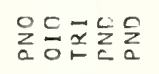 & 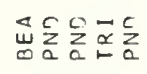 \\
\hline $\begin{array}{l}\text { U⿺ } \\
\text { 仓 } \\
\end{array}$ & $n$ & $\backsim \backsim$ & \pm & + & $n n$ nn & $\tilde{\infty} \tilde{\infty}$ & 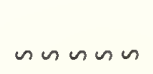 & 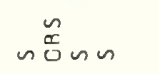 & $\tilde{\infty}$ \\
\hline 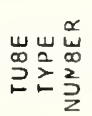 & 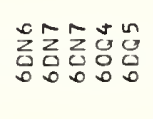 & 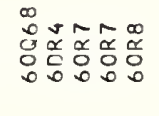 & 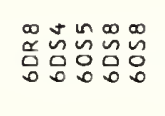 & 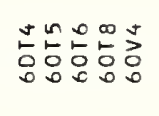 & 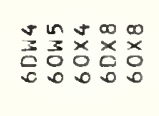 & 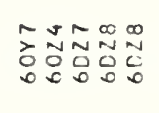 & 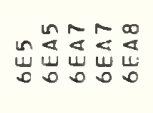 & 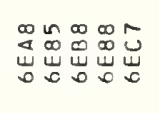 & 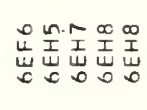 \\
\hline
\end{tabular}




\begin{tabular}{|c|c|c|c|c|c|c|c|c|c|}
\hline 崖崖虽 & 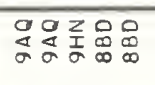 & 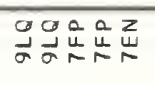 & 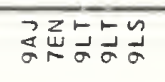 & 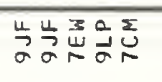 & 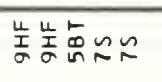 & 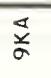 & 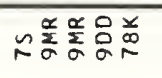 & 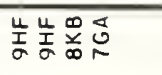 & 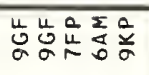 \\
\hline 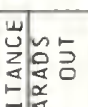 & $\dot{m} \ddot{\dot{m}} \dot{\sim} \dot{0}$ & 品 & $\stackrel{\sim}{\sim}$ & 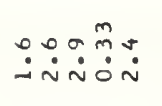 & 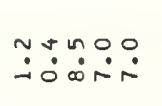 & & 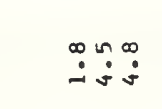 & サ & $\dot{\sim} \dot{\sim} \dot{m} \dot{\infty} \dot{\sim}$ \\
\hline 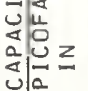 & $\because \quad \dot{0} \dot{\sim}$ & $\ddot{n} \dot{0} \dot{m}$ & $\ddot{0}:$ & $\dot{m}$ & 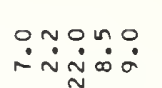 & $\dot{\sim}$ & $\ddot{m} \dot{m} \cdot n$ & טํำ & 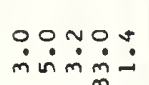 \\
\hline 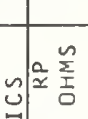 & 关 兑 & 弟 总 & 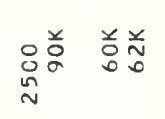 & 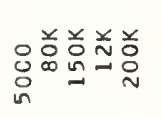 & 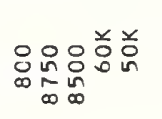 & $\underset{\sim}{\stackrel{\sim}{*}}$ & 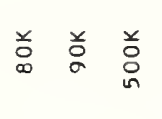 & 总总总 & 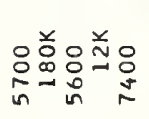 \\
\hline 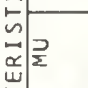 & n & $0_{\infty}^{\circ}$ & 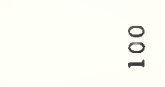 & 용 & $\stackrel{\infty}{\sim}$ & $\tilde{n}$ & & 0.0 & $\underset{j}{m} \quad$ j \\
\hline 至 & 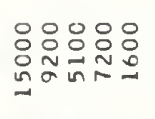 & 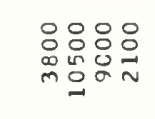 & 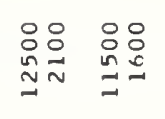 & 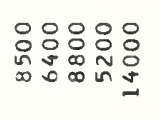 & 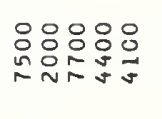 & 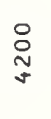 & 옹 & $\begin{array}{l}\circ 0 \\
\circ 0 \\
0\end{array}$ & 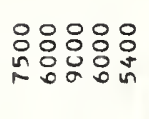 \\
\hline 象 & 오욤요 - & NaO9m & $\simeq \sim \sim \cong-$ & 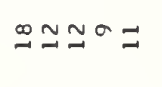 & 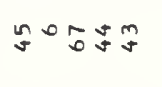 & $s$ & $\stackrel{p}{r} \leadsto-$ & $q_{f}-\prod_{\infty}^{\infty} \sigma N$ & エココピ \\
\hline 泾 & 윰옷욤욤 & 음유 & 용 윳ㅇ & 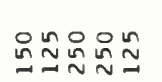 & 员吕乩品品 & $\stackrel{n}{\beth}$ & 윰욤음 & 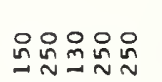 & 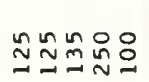 \\
\hline 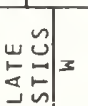 & ن & O̊N & $\stackrel{\infty}{\dot{-} 0} \quad \stackrel{0}{n}$ & $\dot{m} \dot{m} \dot{m} \dot{\sim} \dot{m}$ & 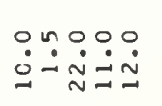 & $\dot{i}$ & 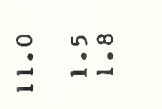 & 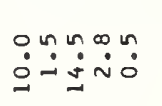 & " \\
\hline 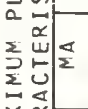 & $\stackrel{n}{\sim} \underset{\sim}{2} \tilde{\sim}$ & $\stackrel{N}{N}$ & $\approx n$ & 유N & 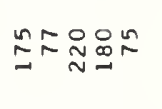 & & NO & $\stackrel{n}{=} i_{N}^{m}$ & No \\
\hline 等趁> & 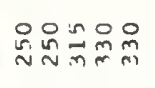 & 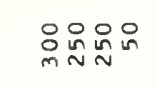 & 일 $\underset{m}{\circ}$ & 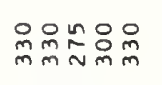 & 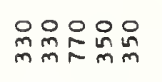 & $\stackrel{\circ}{m}$ & $\underset{m}{n} \stackrel{m}{m}$ & 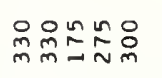 & 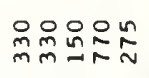 \\
\hline$\frac{1}{\Delta} \sum_{\frac{\pi}{2}}^{\frac{\pi}{2}}$ & 임임용요 & 임임욤유 & $\begin{array}{l}\text { n }: 0: 8 \\
\text { mo: }\end{array}$ & 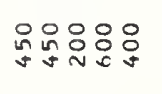 & 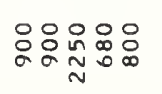 & on & 웅임요 & N & 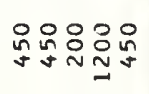 \\
\hline 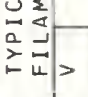 & 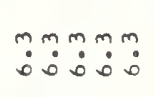 & 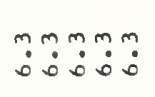 & $\ddot{b} \dot{0}: \dot{m}: \dot{m}:$ & $\ddot{\dot{0}} \dot{0} \dot{0} \dot{0} \dot{0} \dot{0}$ & 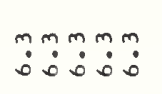 & $\ddot{m}$ & $\ddot{0} \ddot{0}: \dot{m}: \dot{m}: \dot{0}$ & 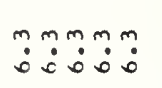 & mm:m:m \\
\hline $\begin{array}{r}\breve{a} \\
\searrow\end{array}$ & IIIII & IIIII & IIIII & IIIII & IIIII & $I$ & IIIII & IIIII & $I I I I I$ \\
\hline$\underset{\Upsilon}{\tilde{u}}$ & 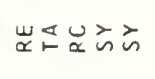 & 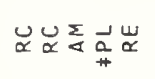 & $\underset{\propto}{u} \underset{\propto}{ }$ & 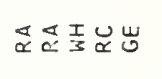 & え゙ら的岕嵌 & Ư & 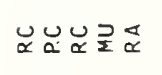 & 齿 & 嵌㟧 \\
\hline 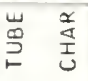 & 돓요 & 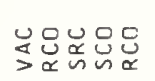 & 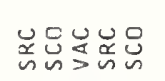 & 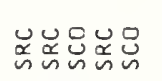 & 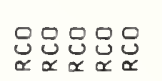 & $\dot{\ddot{\alpha}}$ & 足导导导怘 & 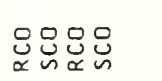 & 导品怘导导 \\
\hline$\stackrel{\uplus}{气}$ & 范 遌号号 & 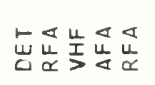 & 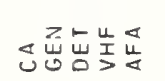 & 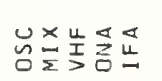 & 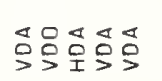 & 忌 & 造 造 & 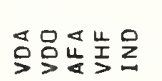 & 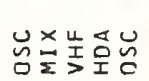 \\
\hline$\stackrel{\infty}{3}$ & 용 & ゚゚ロロロ & ๕ュュ゚ュ & ピロレッ & ๑ேュ゚゚ & 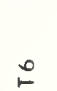 & の゚゚ロ上 & 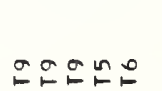 & ゚ロッュュ \\
\hline $\begin{array}{l}w \\
a \\
z \\
\imath\end{array}$ & 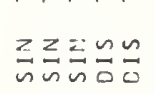 & 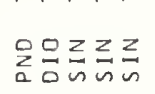 & 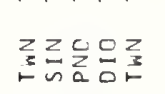 & 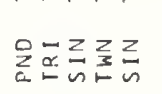 & 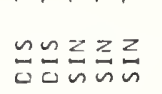 & & 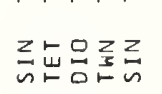 & 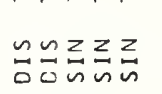 & 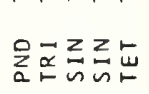 \\
\hline$\frac{0}{2}$ & 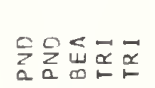 & 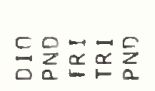 & 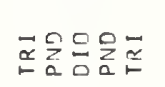 & 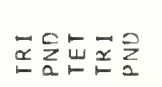 & 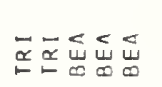 & $\underline{\alpha}$ & 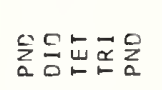 & 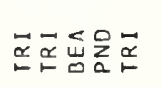 & 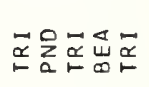 \\
\hline 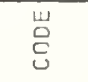 & $n n$ & nns & $n$ & $n n \quad n$ & $n n \mathscr{D}_{0} n$ & & $\backsim$ & $n n$ & $\stackrel{\sim}{\mathscr{D}}$ \\
\hline 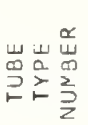 & 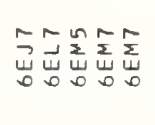 & 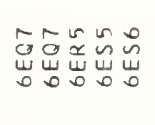 & 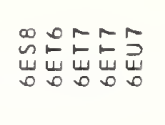 & 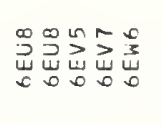 & 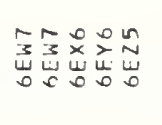 & $\stackrel{\infty}{\underset{\sim}{\tilde{~}}}$ & 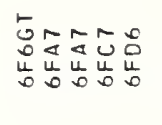 & 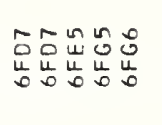 & 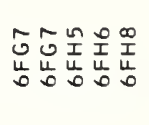 \\
\hline
\end{tabular}




\begin{tabular}{|c|c|c|c|c|c|c|c|c|c|}
\hline 岀岩员 & 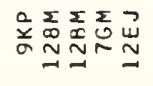 & 岂兰品关品适 & 呈堊堊造员 & 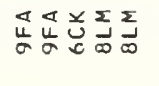 & 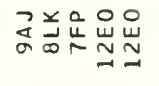 & 离多 & 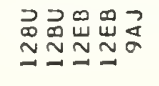 & 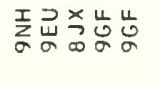 & 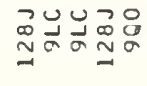 \\
\hline 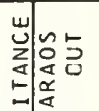 & 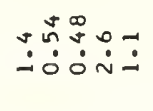 & 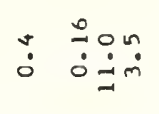 & 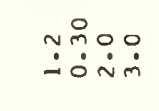 & $\ddot{\sim} \dot{\sim} \dot{\sim} \dot{\sim} \dot{\sim}$ & ப் & & $\dot{\dot{\sim}}$ & $\ddot{\sim} \dot{\sim} \dot{\sim} \dot{\sim}$ & 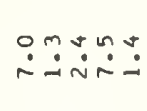 \\
\hline \begin{tabular}{l|l}
0 \\
0 \\
0 \\
0
\end{tabular} & mơ & 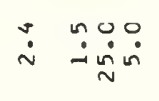 & $\ddot{\sim} \dot{\sim} \dot{v} \dot{s}$ & $\begin{array}{l}\infty \circ 000 \\
\dot{v} \dot{\sim} \dot{\sim} \dot{m}\end{array}$ & 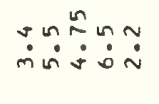 & & $\dot{\dot{I}}$ & Oீ: & $\ddot{0}$ \\
\hline v & 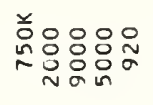 & 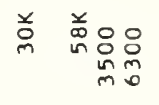 & 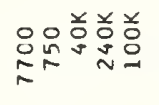 & 品 & 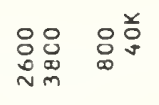 & & 诘음 음 & 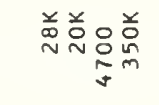 & 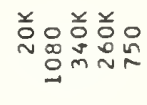 \\
\hline 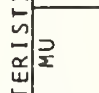 & $\tilde{\sim} \approx \sim$ & $\stackrel{0}{0}$ & $\operatorname{Sin}_{\substack{\infty \\
0}}$ & 羟 & mํำ & & $\stackrel{\infty}{=}$ & $\hat{s}$ & in \\
\hline 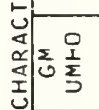 & 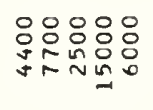 & 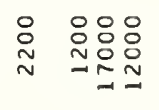 & 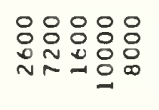 & 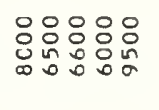 & 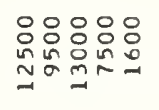 & 品品 & 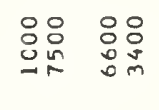 & 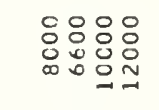 & 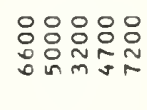 \\
\hline 包 & $\sim \neg \infty \cong$ & $\sim-\sigma$ & $\sigma$ 음 $\rightarrow 0$ 어 & $\simeq \simeq \mathscr{\sim}$ & $\cong \sigma=\underbrace{n}$ & $N$ 品 & - 요 in & 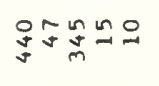 & $\stackrel{n}{n}$ 邑 \\
\hline : & 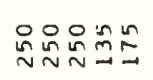 & $\stackrel{\circ}{\sim} \stackrel{\circ}{\sim}: \stackrel{n}{\sim}$ & 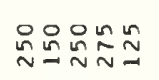 & 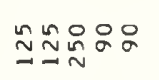 & 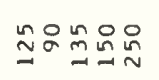 & $\stackrel{n}{\cong} \cong$ & 䠐只 & 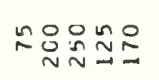 & 只是昆品昆 \\
\hline 等 & 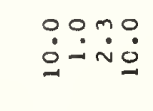 & $\stackrel{\dot{0}}{\because} \dot{0} \dot{\sim}$ & 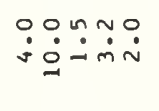 & $\dot{0} \dot{\sim} \dot{\sim}$ & $\stackrel{\sim}{\dot{\sim} \sim} \dot{\sim} \dot{\sim} \dot{\sim}$ & $\stackrel{0}{-\infty}$ & 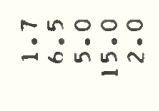 & OO̊ñ & 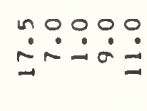 \\
\hline 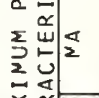 & 品 N & in $\underset{i}{\mathbb{N}}$ & $\stackrel{N}{\sim} \underset{\sim}{\sim} \sim \mathcal{N}$ & 욧 品옷 & 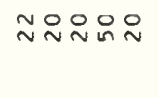 & & 经怘怘 & $\stackrel{n}{\sim}: 0 \cap 00$ & 品员 品品 \\
\hline 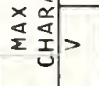 & 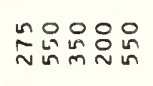 & 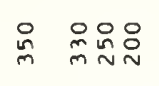 & 品品品: & 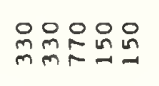 & 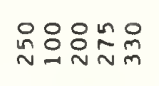 & 品品 & 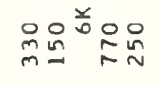 & 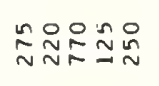 & 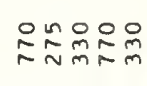 \\
\hline 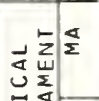 & 은영영요 & 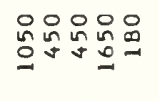 & 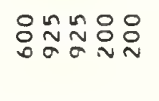 & 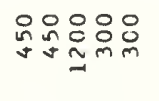 & 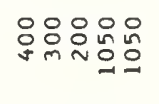 & 옳 & 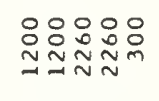 & 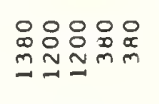 & 웅응ㅇㅇㅁㅇㅛ \\
\hline 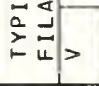 & $\ddot{0}: \ddot{0}: \ddot{0}^{m}$ & $\ddot{0} \ddot{0} \dot{0} \ddot{0} \dot{0}$ & 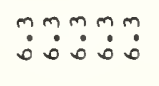 & & $\ddot{0} \ddot{0}: \ddot{0}: \dot{m}$ & $\ddot{m}:$ & mm & 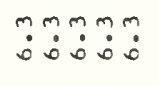 & 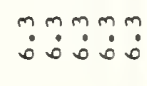 \\
\hline$\times \quad \frac{a}{2}$ & IIIII & IIIII & IIIII & IIIII & IIIII & $I I$ & IIIII & IIIII & IIIII \\
\hline$\underset{\ddot{x}}{\stackrel{u}{x}}$ & 巡岕岕え岕 & 嵌岕岕こ方 & びええ゙せ & I I & 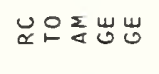 & 空辛 & 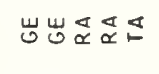 & 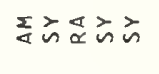 & Uु \\
\hline 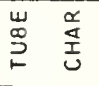 & 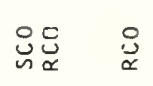 & 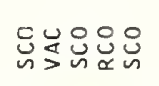 & 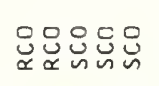 & 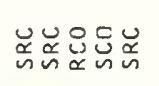 & U: & & 号芯导品 & 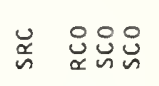 & 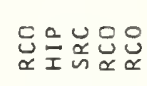 \\
\hline$\stackrel{山}{s}$ & 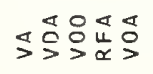 & 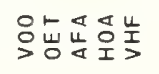 & 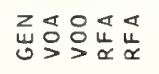 & 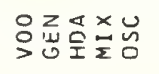 & 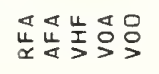 & 殅 & 近出台台出 & 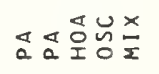 & 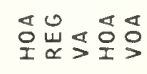 \\
\hline 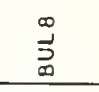 & ேのレの & の゚レこに & ロのレロ & உ゚ジロ & ロロே & 눈 & ロேミュレ & にேニュ゚ & シ゚ロにに \\
\hline $\begin{array}{l}\omega \\
0 \\
\vdots \\
\Sigma \\
\end{array}$ & 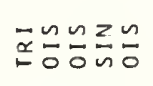 & 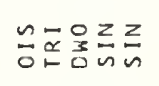 & 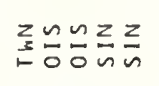 & 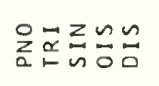 & 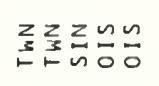 & $\sum_{a}^{\circ} \underset{\sim}{\underline{\alpha}}$ & ニニ음응존 & 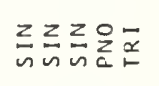 & 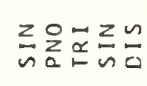 \\
\hline 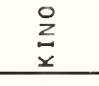 & 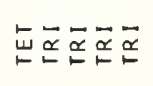 & 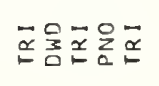 & 套吕吕出出 & 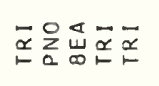 & 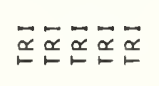 & 垔号 & 응음음음몬 & 出出出恕吕吕 & 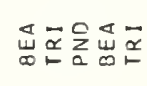 \\
\hline $\begin{array}{l}\text { Ü } \\
\text { 어 }\end{array}$ & & $n$ & & $n n$ & $n n$ & & & & $n n$ \\
\hline 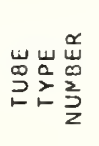 & 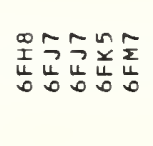 & 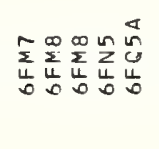 & 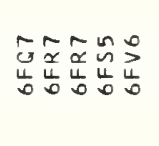 & 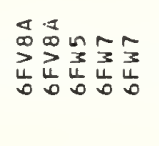 & $\begin{array}{l}\infty \\
0 \\
3 \\
3 \\
0 \\
0 \\
0\end{array}$ & 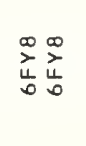 & 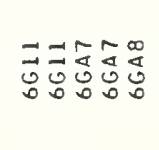 & 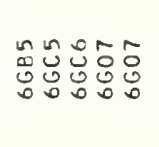 & 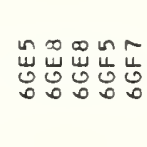 \\
\hline
\end{tabular}




\begin{tabular}{|c|c|c|c|c|c|c|c|c|c|}
\hline 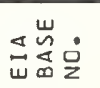 & 品岁岁岁岁 & 前岩岩岩崖兑 & 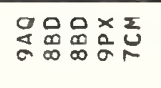 & 岁弦좃잉ㅇㅁㅇ & 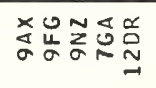 & 己う希焉 & 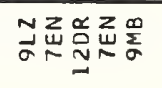 & $g \stackrel{\substack{n \\
\sim}}{\sim}$ & 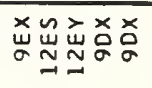 \\
\hline 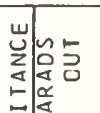 & $\stackrel{0}{\sim m} \dot{0} \dot{\sim} \dot{\sim} \dot{m}$ & $\ddot{0} \dot{\sim} \dot{\sim} \dot{\sim} \dot{m} \dot{r}$ & $\ddot{m} \dot{m} \ddot{\dot{0}} \dot{\sim} \dot{\sim}$ & 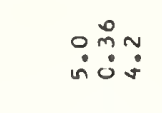 & 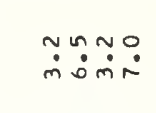 & $\stackrel{\infty}{\dot{j}}$ & $\stackrel{\curvearrowleft}{\circ} \quad \stackrel{0}{\circ}$ & $\ddot{\sigma} \dot{\infty} \dot{\sim}$ & $\ddot{\infty} \stackrel{0}{\dot{r} \dot{\sim}}$ \\
\hline 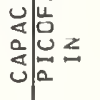 & 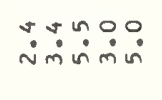 & $\dot{n} \dot{0} \dot{m} \dot{\infty} \dot{0} \dot{0}$ & $\because \because \dot{\sim} \propto \dot{0}$ & $\ddot{n} \div:$ & 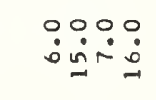 & $\ddot{n} \dot{\dot{n}}$ & $\because \stackrel{\dot{\sim}}{\dot{\sim}}$ & $\begin{array}{l}\dot{0} \dot{0} \\
\dot{\sim} \dot{n}\end{array}$ & 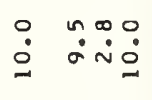 \\
\hline$\underset{\underbrace{}}{u}$ & 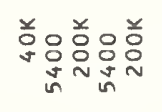 & 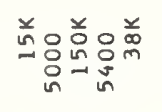 & 兑品兑㒸兑 & 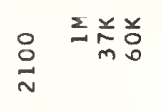 & 酋呞弟 & 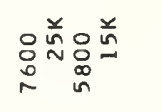 & 美㒸兰兑弟 & 兰总总 & 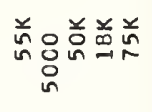 \\
\hline 包 & కొ & $\stackrel{\infty}{\sim}$ & n : & $\stackrel{0}{-1}$ & & $\stackrel{0}{\circ} \stackrel{0}{\circ}$ & & $\stackrel{\infty}{\sim}$ & $\stackrel{2}{r}$ \\
\hline 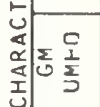 & 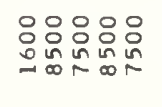 & 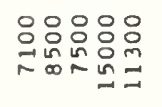 & 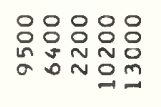 & 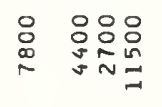 & 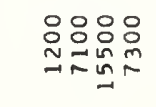 & 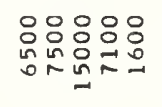 & 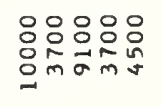 & 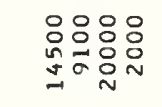 & 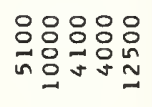 \\
\hline 矛禺 & $\neg さ \cong さ \cong$ & ニ̃ & $\infty \underset{\sim}{0} \sim D^{\circ}$ & $\infty-\beth \sim N$ & $n^{+\infty} 00$ 员 & 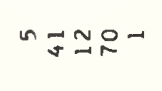 & 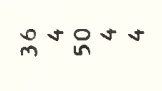 & $\infty \simeq \mathbb{N}^{\circ} \mathrm{O}^{-}$ & $\stackrel{\infty}{m} \tilde{m} \tilde{\sigma}+\stackrel{\sim}{\sim}$ \\
\hline$\sqrt[2]{\infty}$ & 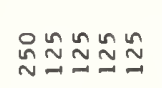 & 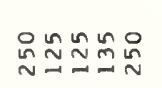 & 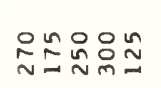 & $\stackrel{n}{\sim} \stackrel{\stackrel{N}{N} \sim}{\sim}$ & 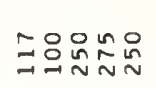 & 品只恣怘怘 & 虽怘啰品兄 & 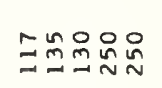 & 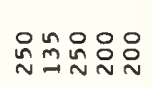 \\
\hline 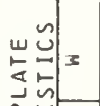 & 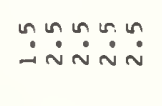 & $\stackrel{n}{\sim} \dot{\sim} \dot{\sim} \dot{\sim} \dot{\sim} \dot{m}$ & 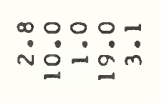 & 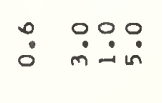 & 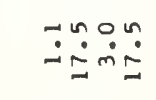 & $\ddot{\circ} \dot{\sim} \dot{\sim} \dot{\sim} \dot{0} \dot{0}$ & 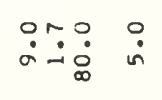 & : & 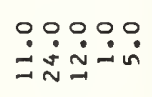 \\
\hline 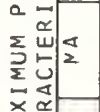 & $\stackrel{N}{\sim} \stackrel{i}{\sim}$ & in $\quad \approx n$ & in $\stackrel{\substack{n \\
\infty}}{\infty}$ & $\stackrel{\circ}{\sim}$ & $\tilde{n} \simeq$ 怘资占 & 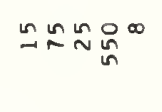 & in $\stackrel{0}{\sim}$ & 趈 N & $\stackrel{a_{\infty}}{\sim} \stackrel{n}{\sim}$ \\
\hline 希势> & 刻品品品品 & 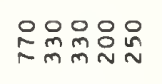 & 喔品品品品 & 일 : & 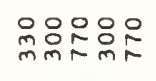 & 옹융융유 & 윰욜 & 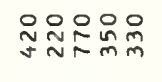 & 品只品品品 \\
\hline 过娄 & 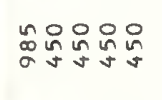 & 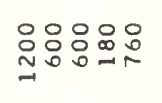 & 웅용ㅇㅇㅇㅇㅇ & 율윰윰욤 & 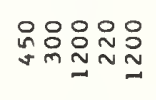 & 양요욤요 & 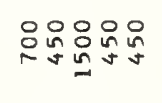 & 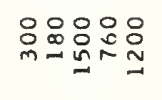 & 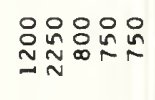 \\
\hline $\begin{array}{lll}0 & 4 \\
2 & =\end{array}$ & 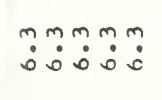 & mmmmm & $\dot{m} \ddot{0}: m \dot{m}: m \cdot \dot{m}$ & $\ddot{0} \dot{0}: m \dot{0} \dot{0}$ & $\ddot{\dot{0}} \dot{0} \dot{0} \dot{0} \dot{0} \dot{0}$ & 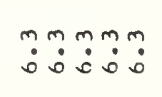 & mmmmm & 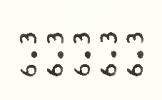 & $\ddot{\dot{0}} \ddot{\dot{0}} \ddot{\dot{0}} \dot{0} \dot{0}$ \\
\hline $\begin{array}{l}\stackrel{\omega}{a} \\
\searrow\end{array}$ & IIIII & IIIII & IIIII & IIIII & IIIII & IIIII & IIIニI & IIIII & IIIII \\
\hline$\underset{\sim}{\mathbb{\Psi}}$ & uِ uِ & 记えええええ & 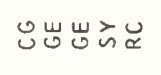 & 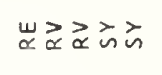 & 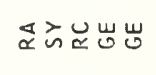 & 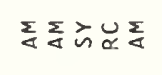 & سِّ & 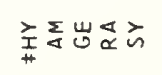 & えぇ\& \\
\hline 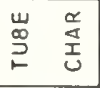 & 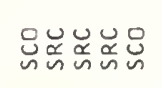 & 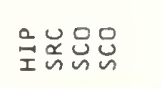 & 을요 & 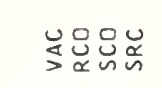 & 岁品呈品品 & $\begin{array}{l}\text { Dुg } \\
\text { in }\end{array}$ & 号怘 & 足 & 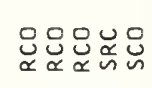 \\
\hline 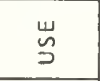 & 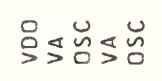 & 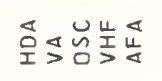 & 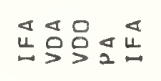 & 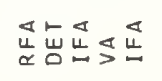 & 点 造造呈 & 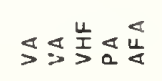 & 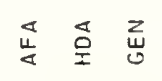 & 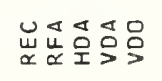 & 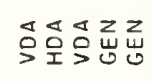 \\
\hline$\stackrel{D}{\infty}_{\infty}^{\infty}$ & ロ゚ロ゚ロ & そュ゚ロ & レ゚ロテロ & ゚ュル゚ロ & レ゚き゚ミ & ヘํュュュ & ゚ロニュ゚ & こュュュ゚ & ロュュ゚。 \\
\hline $\begin{array}{l}w \\
\stackrel{u}{2} \\
\Sigma\end{array}$ & 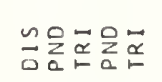 & 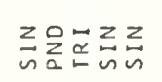 & 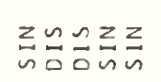 & 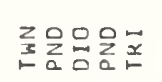 & 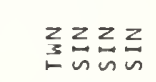 & 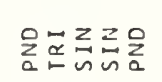 & 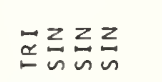 & 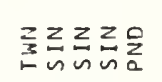 & 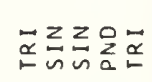 \\
\hline$\underset{2}{2}$ & 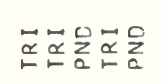 & 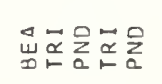 & 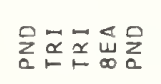 & 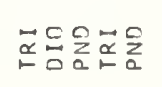 & 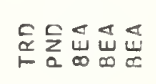 & 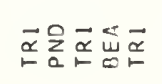 & 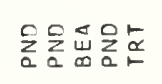 & 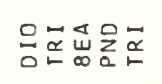 & 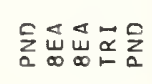 \\
\hline 号 & $n n$ & $n$ & $n n$ & sus & $n n$ & $n n$ & 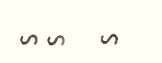 & & $n n$ \\
\hline 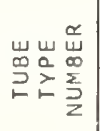 & 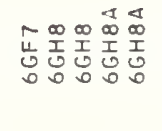 & 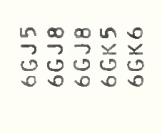 & 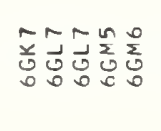 & 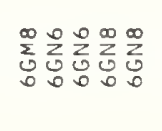 & 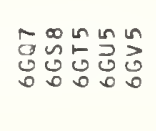 & 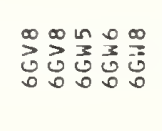 & 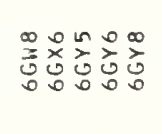 & 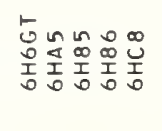 & 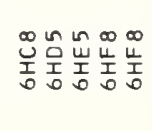 \\
\hline
\end{tabular}




\begin{tabular}{|c|c|c|c|c|c|c|c|c|c|}
\hline 通崖完 & 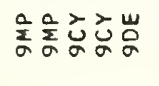 & 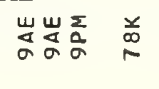 & 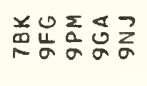 & 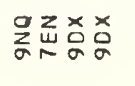 & 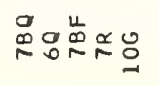 & 畐岂㟔㟔岕 & 岁念㤂吉品 & 崌 总忌 & 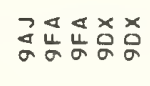 \\
\hline 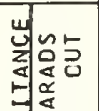 & $\dot{m} \stackrel{\sim}{n}$ & 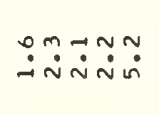 & s & 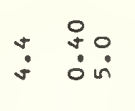 & பீ: & 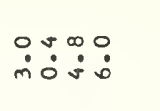 & 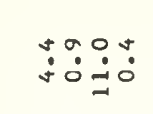 & $\dot{m}$ & 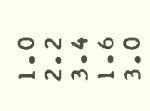 \\
\hline 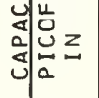 & $\dot{0} \ddot{\sim} \dot{m}$ & 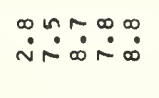 & $\stackrel{\infty}{\infty} \quad \stackrel{0}{\dot{\infty}}$ & $\sim \infty \dot{0}$ & $\ddot{\sim} \dot{v} \dot{\sim}$ & $\begin{array}{l}0 \backsim 00 \\
\dot{\Xi} \dot{\sim}=\dot{n}\end{array}$ & $\dot{\sim} \dot{\sim} \dot{\sim} \dot{\sim} \dot{\sim}$ & $\stackrel{0}{\circ}$ & 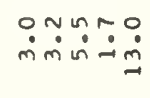 \\
\hline 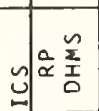 & 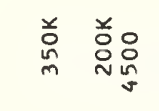 & 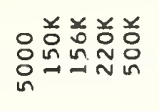 & 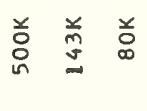 & 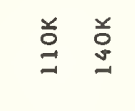 & 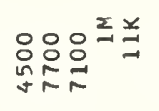 & 兑总。兑。 & 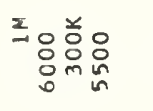 & 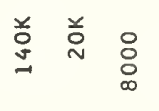 & 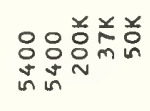 \\
\hline 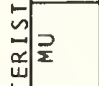 & $\beth \quad \stackrel{n}{1}$ & o & & $\stackrel{ }{r}$ & 点율 in & 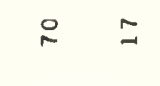 & 요 & nn & 웡 \\
\hline \begin{tabular}{l|l} 
& \\
0 & 0
\end{tabular} & 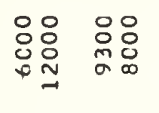 & 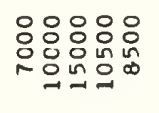 & 응요 & 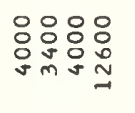 & 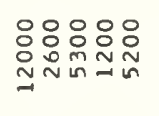 & 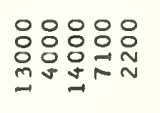 & 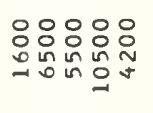 & 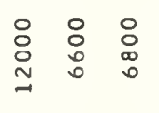 & 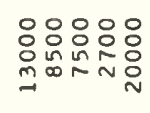 \\
\hline 勾乐 & $\pm 0 ㅇ ㅛ$ & $\mathscr{ユ} \simeq \cong$ & aN & $m m+\sigma$ & $\cong \sigma \infty \sim 0$ & $\Xi+\infty \stackrel{\infty}{\sim}$ & $\simeq \operatorname{man}_{m}^{t}$ & $\approx \stackrel{n}{\sim} \pm^{n}$ & 워 $\simeq \sim \simeq$ \\
\hline 分 & 음요으요 & 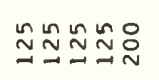 & 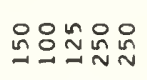 & 怘品品品 & 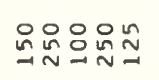 & 品咨品怘怘 & 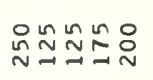 & 怘 沜怘음 & 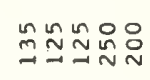 \\
\hline 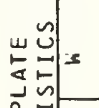 & 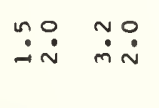 & $\ddot{\sim} \backsim \ddot{\sim} \dot{\sim} \dot{\sim} \dot{\sim} \dot{m}$ & 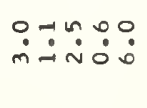 & $\ddot{\sim} \because \ddot{-} \dot{0}$ & $\begin{array}{l}\sim \infty \\
\dot{\sim} \dot{\sim} \sim \dot{\sim} \dot{\sim}\end{array}$ & $\ddot{m} \dot{\sim} \dot{0} \dot{\sim} \dot{\sim} \dot{\sim}$ & $\ddot{m} \dot{i} \dot{\sim} \underset{\sim}{\dot{j}} \dot{\circ}$ & 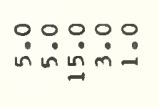 & $\dot{\sim} \dot{\sim} \ddot{i} \dot{j}$ \\
\hline 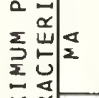 & $\stackrel{\infty}{\sim} \stackrel{\circ}{\sim}$ & $\stackrel{n}{\sim}$ & $\cong \stackrel{N}{\sim} \ln g$ & 욤 & 유요 & $\stackrel{n}{\Xi}$ & $\stackrel{n}{m}$ & $\underset{\infty}{n}{ }_{\infty}^{0} \underset{m}{m} N$ & 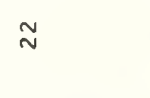 \\
\hline 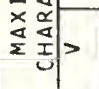 & 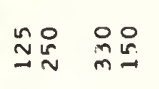 & 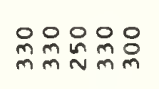 & 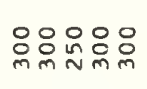 & 있임율 & 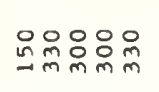 & 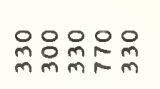 & 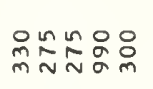 & 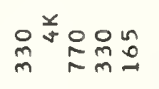 & 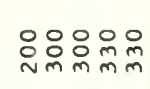 \\
\hline 过艺这文 & 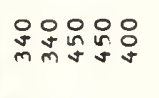 & :::윰 & 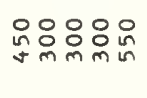 & 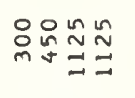 & 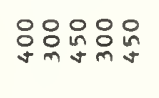 & 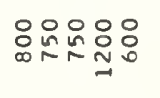 & 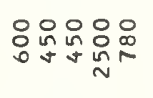 & 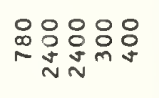 & 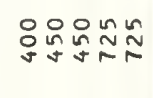 \\
\hline 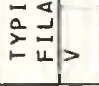 & 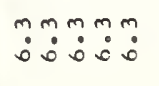 & 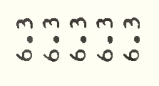 & $\ddot{0}: \ddot{0}: \ddot{0}:$ & 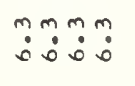 & 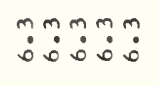 & 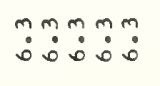 & 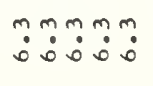 & $\ddot{0} \dot{0}: \dot{m} \dot{0}: \dot{0}$ & 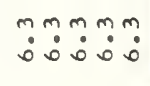 \\
\hline $\begin{array}{r}\frac{w}{a} \\
\longleftarrow\end{array}$ & IIIII & IIIII & IIIII & IIII & エエエエエ & エエエエ & IIIII & IIIII & IIIII \\
\hline$\underset{\alpha}{\stackrel{U}{\Psi}}$ & 골롤 $\frac{1}{0} \frac{1}{4}$ & 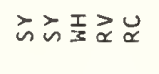 & 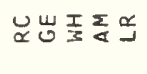 & Uِ & 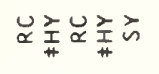 & 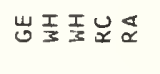 & 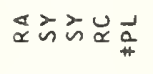 & 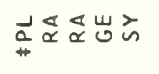 & え゙岕出えうう \\
\hline 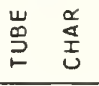 & 吠品 㶽 & 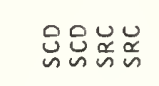 & 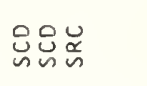 & 造总跣 & 诘导怘品 & 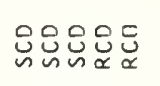 & 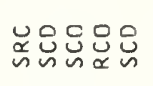 & 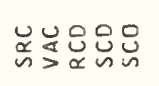 & 它虽品号导 \\
\hline$\stackrel{山}{د}$ & 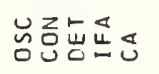 & 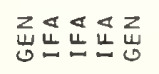 & 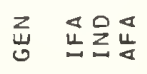 & 品出品殅 & 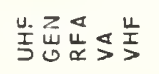 & 巡忌出选呈品 & 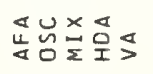 & 钫品品出品 & 造出 $₫ \Delta$ \\
\hline$\stackrel{\infty}{\supset}$ & トェレ゚ロ & ゚゚゚ロレ & ピレレト & ゚ロロミ & セロロロ゚ & こ゚ロ゚ュ゚ & ゚レュ。 & ゚ミ゙゚゚ & ゚レレロに \\
\hline $\begin{array}{l}w \\
a \\
2 \\
2 \\
\end{array}$ & 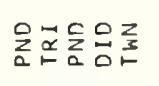 & 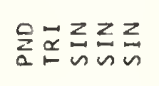 & 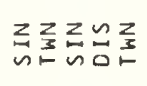 & 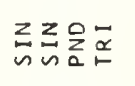 & 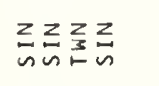 & 忐出吕忌兄 & 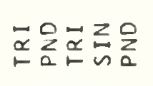 & 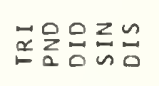 & 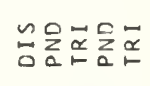 \\
\hline$\underset{z}{2}$ & 몬음음몸 & 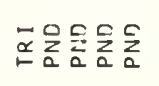 & $\sum_{a}^{c} \sum_{a} \sum_{a}^{c} \underset{\alpha}{\alpha} \frac{c}{2}$ & 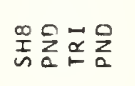 & 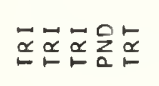 & 春喜出出出 & 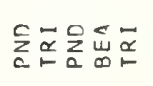 & 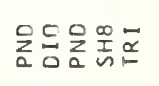 & 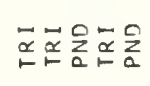 \\
\hline 。 & & $n$ & $n n$ & & $\pm n n$ & & $\backsim$ & $\sim$ & $n n$ \\
\hline 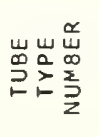 & 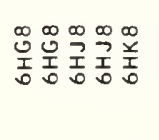 & 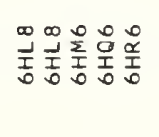 & 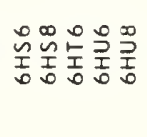 & 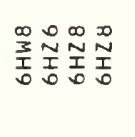 & 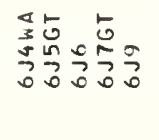 & 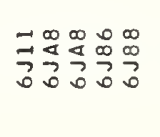 & 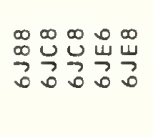 & 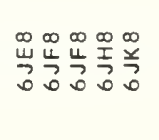 & 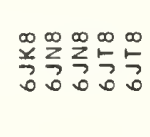 \\
\hline
\end{tabular}




\begin{tabular}{|c|c|c|c|c|c|c|c|c|c|}
\hline 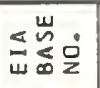 & 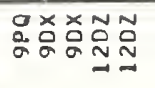 & 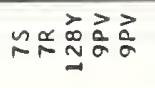 & 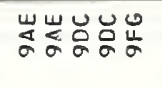 & 멱염영 & 믐몀 & $\approx$ & 忌导式 & 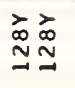 & 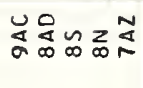 \\
\hline 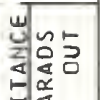 & 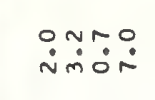 & $\begin{array}{l}0 \\
\dot{0} \\
\dot{I}\end{array}$ & $\ddot{\sim} \dot{\sim} \dot{\sim} \dot{\sim} \dot{0}$ & $\dot{0}$ & 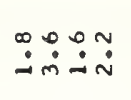 & $\ddot{n}$ & $\dot{\infty} \dot{\sim}$ & $\because$ & $\begin{array}{l}\sigma \circ 0 n \\
\dot{0} \dot{m} \sim\end{array}$ \\
\hline 牙峲 & $\because: \cong \dot{\Xi}$ & n̊: & نُ & $:$ & mo: & $\dddot{\Xi}$ & $\dot{m} \ddot{\sim}$ & $\stackrel{\infty}{-\infty}$ & 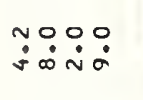 \\
\hline जी & 弟兑兰兰 & 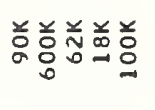 & 응요묘 & 兰 弟品 & 弟兑芯兑 & 总 & ․ㅡㅁㅇㅠ & 雚 & $\stackrel{D}{D}_{0}^{\sum}$ \\
\hline 䒺展 & $\stackrel{N}{\sim}$ & 움 & 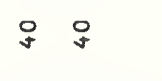 & $\hat{s}$ & $\stackrel{\circ}{\circ}$ & & $\stackrel{\circ}{r}$ & $\cong$ & $\stackrel{\circ}{\sim}$ \\
\hline 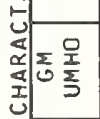 & 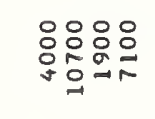 & 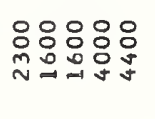 & 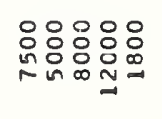 & 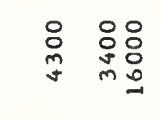 & 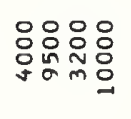 & $\underset{\sim}{\stackrel{2}{N}}$ & :웅 & 品: & 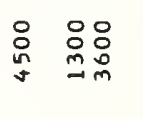 \\
\hline$=\frac{\pi}{2}$ & $\sigma N$ N & mors & $\pm 090 \mathrm{~m}$ & $-6-50$ & $+\mathbb{N}^{\sim} \simeq$ & $:$ & $\underset{\mathrm{m}}{\stackrel{\mathrm{m}}{ }}=$ & $\stackrel{N}{N}$ & $\stackrel{\sim}{N}+N D-$ \\
\hline i & 윳유ㅁㅠㅛㅇㅛ & 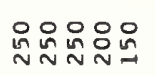 & 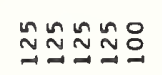 & 음 윽 & 咨品怘 N & 品 & $\stackrel{\mathscr{N}}{\simeq} \underset{\simeq}{\simeq}$ & 总品 & 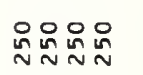 \\
\hline 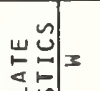 & 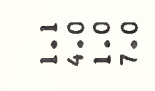 & 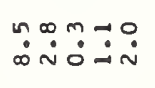 & $\ddot{\sim} \dot{\sim} \dot{\square}$ & $\stackrel{\circ}{\dot{m}} \stackrel{\dot{N}}{\mathbf{N}}$ & $\ddot{\dot{\prime}} \dot{m} \dot{\dot{L}} \dot{\sim} \dot{\sim}$ & $\stackrel{0}{\circ}$ & $\dot{\infty} \dot{\sim} \dot{m}$ & $\dot{m}$ & $\ddot{i} \dot{\dot{\sigma}}$ \\
\hline 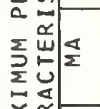 & n & $\stackrel{\circ}{\sim}$ & 유구 & $\approx$ & & & $\stackrel{\circ}{\circ}$ & & $\stackrel{n}{\simeq}$ \\
\hline 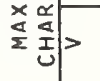 & 品品品品品 & 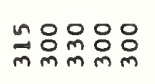 & 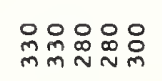 & 율 & 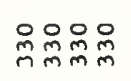 & : & 着售 & 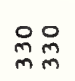 & 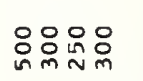 \\
\hline 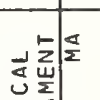 & 응융용요 & 品:윰융용 & 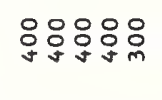 & 임임임요 & m: & : & 品员品 & 웅: & 잉윰윰 \\
\hline 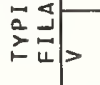 & 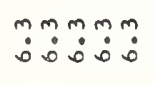 & mmmmm & mmmmm & mm:m & mmmm & $\dot{m}$ & $m \ddot{m}$ & $\ddot{m}: \ddot{m}$ & mm: \\
\hline$× \stackrel{\frac{u}{2}}{2}$ & IIIII & IIIII & IIIII & IIIII & IIII & I & $I I I$ & $I I$ & IIIII \\
\hline$\underset{\check{I}}{\stackrel{U}{\Psi}}$ & 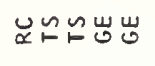 & 至主嵌 & 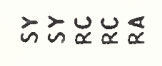 & 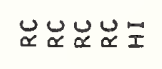 & らうらうゔ & $\dot{n}$ & ليّ لِّ لي & $\tilde{\sim} \approx$ & $\breve{\alpha} \curvearrowleft \mathscr{\propto} \cong \breve{\varpi}$ \\
\hline $\begin{array}{ll}山 \\
\stackrel{\infty}{\infty} & \frac{\alpha}{4} \\
2 & \text { I }\end{array}$ & 号怘岕岕怘 & 总怘 & 芯芯怘怘怘 & 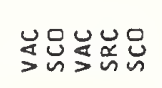 & 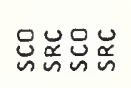 & $\underset{\check{u}}{q}$ & 岁导怘 & 岂怘 & 怘 导品号 \\
\hline 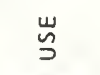 & 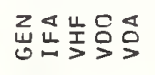 & 叫施出出 & 㟔爻号能堊 & 岂出殅饪堊 & 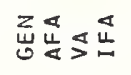 & $a$ & 只 & 总芯 & 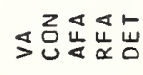 \\
\hline 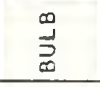 & 눔요 & そ゚ロロ゚ロ & ピトロ上요 & ゚レㄴํ요 & ゚゚요 & $\cong$ & ユロa & g。 & 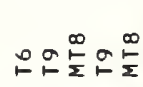 \\
\hline 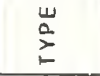 & 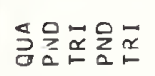 & 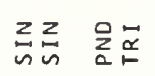 & 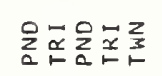 & 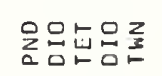 & 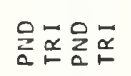 & $\underset{s}{s}$ & 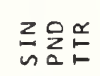 & & 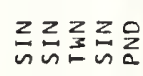 \\
\hline$\frac{o}{z}$ & 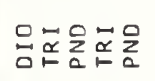 & 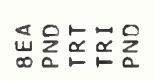 & 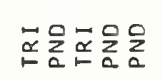 & 颔员虽㟔吕 & 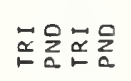 & 岕 & 믐름음 & 占恕 & 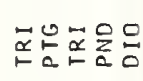 \\
\hline 岂 & $n n$ & $n n$ & $++n$ & $n$ & $n n$ & $\dot{n}$ & & $n n$ & $n \sim \stackrel{\infty}{\infty}$ \\
\hline 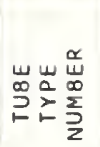 & 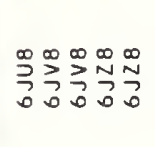 & 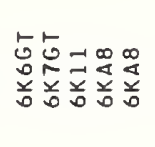 & 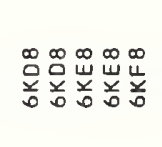 & 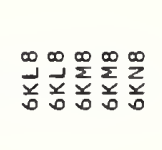 & 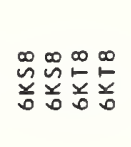 & $\begin{array}{l}\infty \\
0 \\
0 \\
\vdots \\
0 \\
0 \\
0 \\
0\end{array}$ & $\sum_{0}^{m} \frac{1}{2}=\frac{1}{0} \frac{1}{0}$ & 可 & 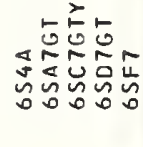 \\
\hline
\end{tabular}




\begin{tabular}{|c|c|c|c|c|c|c|c|c|c|}
\hline 岕岕岕 & 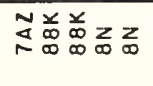 & 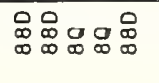 & 关山ू & 崖岩 & 必乞贡贡 & $\underset{\sigma}{\tilde{\sigma}}$ & 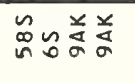 & $\approx$ & 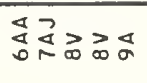 \\
\hline 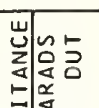 & 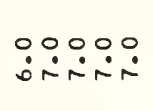 & $\because \dot{0}$ & $\stackrel{n}{\stackrel{0}{0}} \div$ & $\stackrel{\circ}{\dot{N}}$ & $\ddot{r}$ & $\ddot{0} \dot{0}$ & $\ddot{0}$ & $\stackrel{n}{r}$ & $\ddot{i} \dot{0} \dot{0}$ \\
\hline 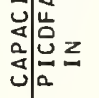 & 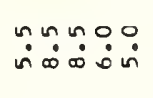 & $\stackrel{\sim}{\sim}$ & $\dot{\sim}$ & $\ddot{n}$ & $\stackrel{0}{\sigma}$ & $\dot{n}$ & $\dot{q} \dot{j}$ & $\stackrel{\circ}{\check{I}}$ & 约足: \\
\hline 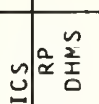 & 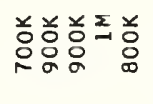 & 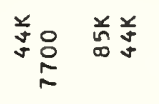 & 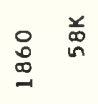 & $\begin{array}{l}\circ \stackrel{0}{0} \\
\text { O욤 } \\
\text { in }\end{array}$ & 弟 首 & $\stackrel{\sim}{\text { ⿷匚 }}$ & 응 & 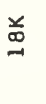 & 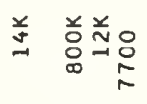 \\
\hline 䒺层 & & 윰응요 & $=8$ & $\stackrel{r}{\sigma}$ & $\stackrel{\circ}{r}$ & & o & & $=$ \\
\hline 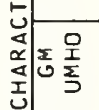 & 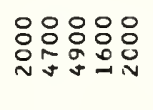 & :용 & $\stackrel{\circ}{:}$ & 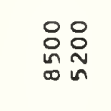 & 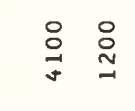 & : & 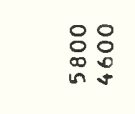 & $\frac{\circ}{\pi}$ & 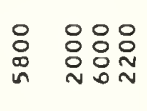 \\
\hline 氙 & $\simeq \simeq ニ m a$ & Na- $-\sim$ & $\stackrel{\infty}{\rightarrow} n-$ & 总四 & $\underset{\sim}{n}=0-$ & \$ิ & 운요 & $:$ & $\vec{y} \infty$ o우 \\
\hline 2. & 怘怘怘怘怘 & 䍚 & \& & 品品怘 & m怘 & m: & 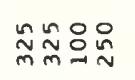 & 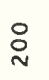 & 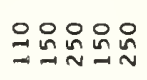 \\
\hline 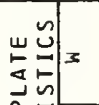 & $\ddot{n} \dot{m} \dot{m} \dot{0} \dot{\sim} \dot{\sim} \dot{m}$ & $\stackrel{\circ}{\dot{-}}$ & 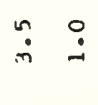 & $\ddot{i \dot{N} \dot{N}}$ & $\stackrel{\sim}{\sim} \stackrel{0}{\check{\sim}}$ & 웅 & $\ddot{i}$ & $\dot{n}$ & $\ddot{n} \quad \because \ddot{\infty} \dot{\sim}$ \\
\hline 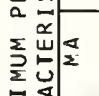 & & 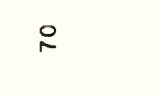 & 요 & & : & 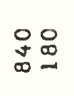 & 品只 & & $\stackrel{\infty}{*}: 0$ \\
\hline 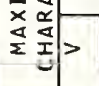 & :임윰요 & 융요 윰요 & $\stackrel{\circ}{\circ}$ & 䍚: & $\underset{m}{\stackrel{0}{0}}$ & 욤 & 兰兰怘怘 & $\stackrel{i}{\sim}$ & 䜣永: \\
\hline 过 & : & 임윰윰이 & 吕足怘 & 响品品 & 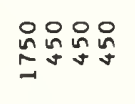 & 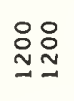 & 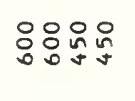 & $\stackrel{\circ}{\stackrel{0}{N}}$ & 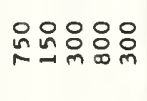 \\
\hline 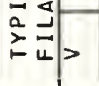 & 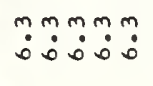 & 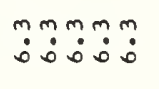 & m: & $\ddot{0}: \ddot{0}$ & mmm & $\stackrel{m}{m}:$ & mañ & $\tilde{\dot{0}}$ & m: \\
\hline $\begin{array}{l}\stackrel{u}{a} \\
\times \quad \sum^{a}\end{array}$ & IIIII & IIIII & III & III & エIII & $I I$ & IIII & $I$ & IIIII \\
\hline$\underset{\check{\Psi}}{\stackrel{U}{\Psi}}$ & $\ddot{\propto} \ddot{\propto} \tilde{\sim} \ddot{\propto}$ & 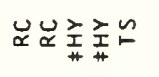 & え゙岕 & ه岕岕 & 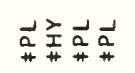 & 嵌充 & 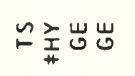 & i & $\vec{a}_{+} \vec{a}_{+} \vec{a}_{+} え$ \\
\hline 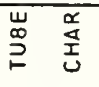 & 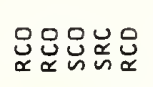 & 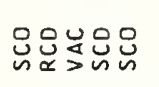 & 峉是呈 & 巡芯 & 号号品呈 & 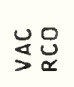 & 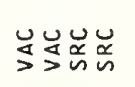 & 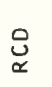 & 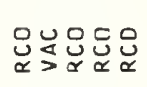 \\
\hline$\underset{⿱ 屮 凵}{\supset}$ & 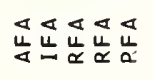 & 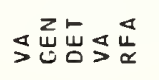 & 堃岂峞 & 全㟔点 & 吅㟧す & 吕台 & 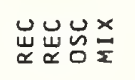 & $\stackrel{a}{a}$ & 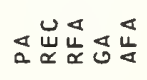 \\
\hline$\stackrel{\infty}{\infty}_{\infty}^{\infty}$ & 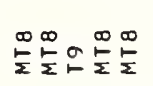 & gagag & ピ゚ & の゚ロ & レロロェ & $\sigma \sigma$ & ピロレ & $\cong$ & 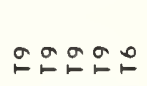 \\
\hline $\begin{array}{l}\omega \\
\vdots \\
\vdots \\
\end{array}$ & 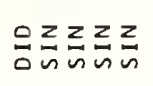 & 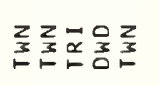 & $\underset{\sim}{z} \stackrel{\alpha}{\sim}$ & $\approx \underline{z} \underset{\alpha}{\alpha} \underline{\alpha}$ & 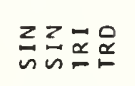 & $\underset{z}{z} \frac{z}{n}$ & $z_{s} z_{z} \sum_{0} \bar{\alpha}$ & $\frac{z}{n}$ & 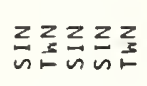 \\
\hline$\frac{a}{a}$ & $\sum_{a}^{0} \sum_{a} \sum_{a} \sum_{a}^{c} \sum_{a}$ & 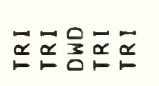 & $\vec{\alpha} \underset{\alpha}{\alpha} \bar{\alpha}$ & 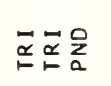 & 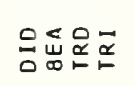 & 등 & 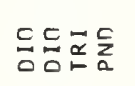 & $\underset{\infty}{\stackrel{⿱ 屮 凵}{山}}$ & 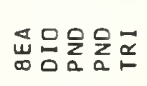 \\
\hline $\begin{array}{l}\text { uे } \\
\text { uे }\end{array}$ & ヘル芯芯 & $\dot{n} \dot{n} \quad n$ & nun & suns & susu & $\dot{n} n$ & ๓ฺ்nn & n & $\sin n$ \\
\hline 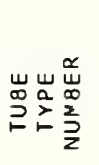 & 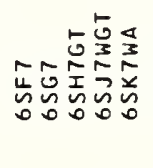 & 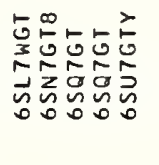 & 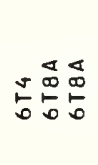 & 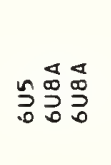 & 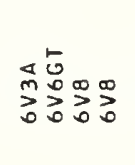 & 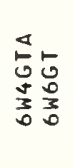 & 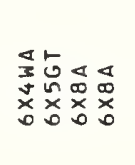 & $\begin{array}{l}\Delta \\
0 \\
0 \\
i\end{array}$ & 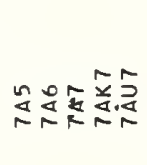 \\
\hline
\end{tabular}




\begin{tabular}{|c|c|c|c|c|c|c|c|c|c|}
\hline 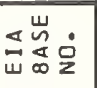 & 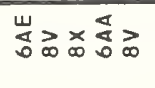 & 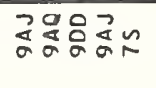 & 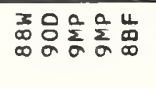 & 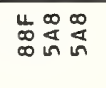 & 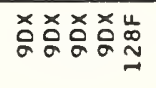 & 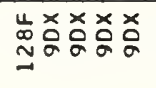 & 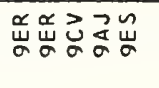 & 㟧岕岕㟧㟧 & 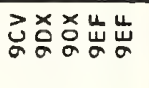 \\
\hline 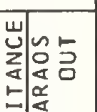 & $\because \because 0: \quad$ !n & $\dot{i}$ & $\because \stackrel{n}{\because}$ & $\dot{\sim}$ & 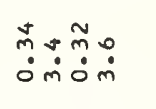 & 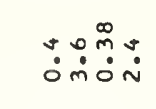 & å̃ñ. & $\ddot{0}$ & $\stackrel{\infty}{m}+0 \%$ \\
\hline ב & जि: & $\ddot{\infty}$ & 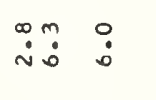 & $\dot{\sim}$ & ن் & n̊요 & $\ddot{m} \dot{0} \dot{0} \dot{n}$ & 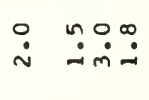 & ஸ்:0ْ \\
\hline 气̂y & 关总总芯瓶 & 总 & 兑 & 弟 & 䍗 & 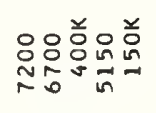 & 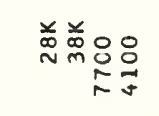 & 兰 㤩品品 & 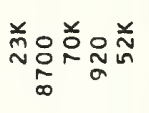 \\
\hline 点 & & $\stackrel{m}{m} \stackrel{\circ}{\sim}$ & 요 & 운 & $\stackrel{9}{9}$ & $\stackrel{\infty}{\sim}=$ & $\stackrel{\circ}{\sim} \stackrel{\infty}{\sim}$ & $\vec{\sim} \stackrel{2}{\sim}=$ & i $n^{\infty}$ \\
\hline \begin{tabular}{l|l}
0 \\
4 \\
\cline { 1 - 1 }
\end{tabular} & 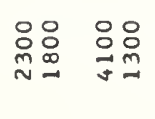 & 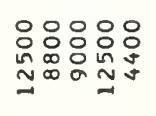 & 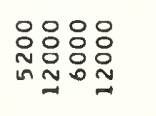 & : & 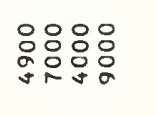 & 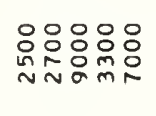 & 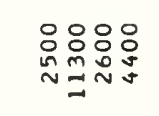 & 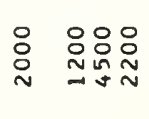 & 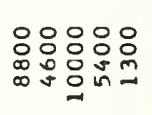 \\
\hline 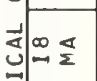 & $m_{m}^{\infty} v \sim$ & 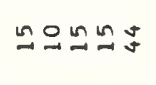 & 웜ㅇㅁ & No요 & $a n+m$ & 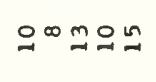 & a in $^{\circ}$ N & $\ln n-90$ & 品志品 \\
\hline is & 怘怘怘怘怘 & 음음유 & 융요욤요 & $\stackrel{O}{\sim} \underset{\sim}{\sim} \underset{m}{\sim}$ & 욤융유요 & 윳융윰요 & 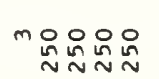 & 윳 & 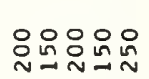 \\
\hline 氙: & 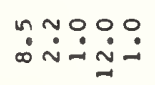 & 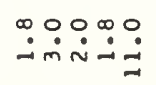 & 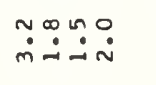 & 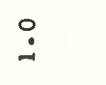 & 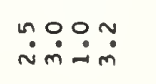 & 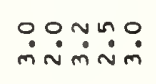 & 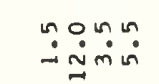 & 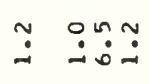 & 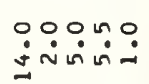 \\
\hline 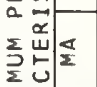 & $\Xi$ & $\stackrel{\sim}{\sim} \stackrel{\sim}{\sim} \underset{\varpi}{D}$ & $\approx \sim ⿻$ & 윰요 & n & 요 & ज & 용 & $\stackrel{\circ}{\Xi}$ \\
\hline 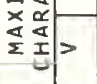 & 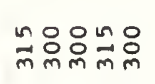 & 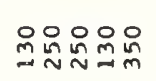 & 品曽恣怘 & 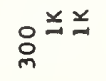 & 임임요 & 잉욤욤요 & 임욤요 & 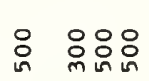 & 솔울요요 \\
\hline$\frac{\pi}{\Delta} \frac{\pi}{2}$ & 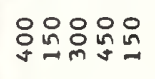 & 임임윰요 & :임임이 & 일융ㅇ & 员品品品品 & 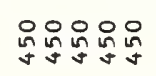 & 品品品品品 & 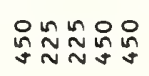 & 응융ㅇㅇㅇㅇㅇㅇ \\
\hline 等 & 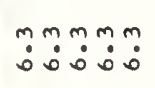 & 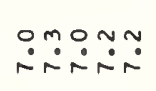 & 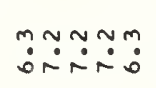 & $\ddot{m} \dot{m}$ & 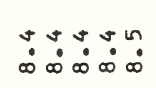 & 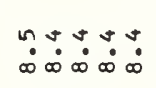 & 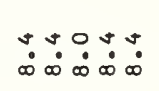 & 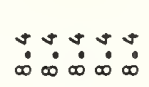 & $\dot{0} \dot{\infty} \dot{\infty} \dot{\infty} \dot{0} \dot{\sim}$ \\
\hline 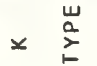 & IIIII & IIIII & IIIII & III & IIIII & IIIII & IIIII & IIIII & IIIII \\
\hline$\underset{\alpha}{\underset{\sim}{\Psi}}$ & 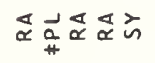 & 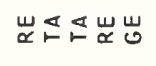 & 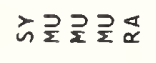 & $\frac{a}{a} \frac{1}{\sharp} \tilde{n}$ & 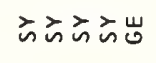 & 㟧吕出岕 & え゙うミ岕岕 & 嵌岕岕え方方 & \\
\hline 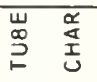 & 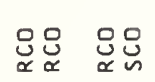 & 芯 & 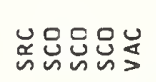 & 吠 & 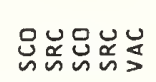 & 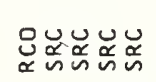 & 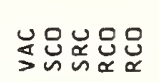 & 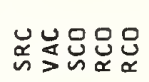 & 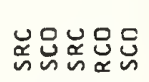 \\
\hline$\stackrel{u}{\check{\nu}}$ & 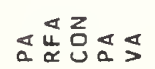 & 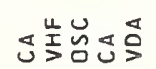 & 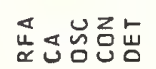 & $\$ \underset{\sim}{\underset{\sim}{u} \underset{\sim}{u}}$ & 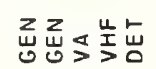 & 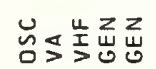 & 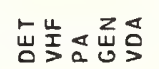 & 品岃\号品 & 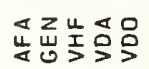 \\
\hline$\sum_{\infty}^{\infty}$ & 먐 & ロ゚ロ゚ロに & ロ゚ロロ゚ロ & 몽 & ேேロロロ & の゚レトュ & ゚ュレロ & ロ゚ロロレ & レ゚゚ロ゚ロ \\
\hline $\begin{array}{l}\underline{\omega} \\
\vdots \\
\vdots\end{array}$ & 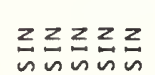 & 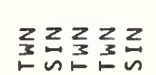 & 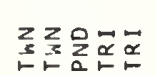 & 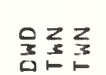 & 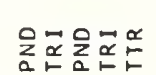 & 웅름뭄뭄 & 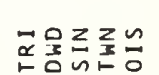 & 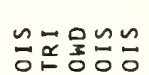 & 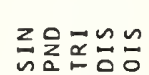 \\
\hline$\frac{0}{2}$ & 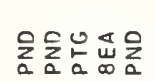 & 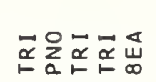 & 롬뭄문응웅 & 폼응둥 & 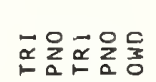 & 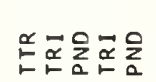 & 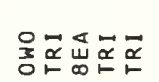 & 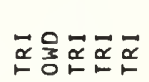 & 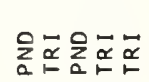 \\
\hline 亗 & $\backsim$ & & + & ヘn & nnnn & nnnn & n & & \\
\hline 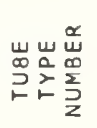 & 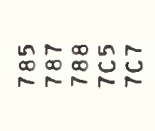 & 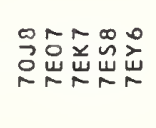 & 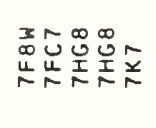 & マ゚̃N & 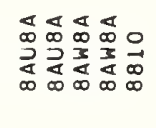 & 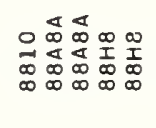 & 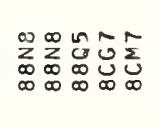 & 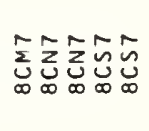 & 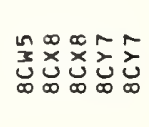 \\
\hline
\end{tabular}




\begin{tabular}{|c|c|c|c|c|c|c|c|c|c|}
\hline 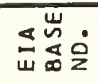 & 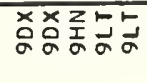 & 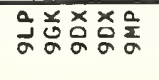 & 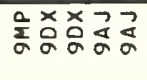 & 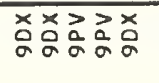 & 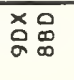 & 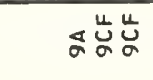 & 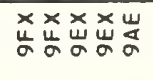 & 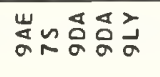 & 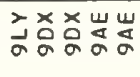 \\
\hline 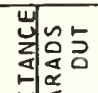 & 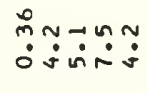 & ํํํ & ஜ் & $\stackrel{\circ}{\because \dot{m}} \stackrel{\infty}{-}$ & $\ddot{m}$ & 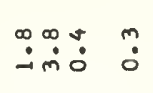 & $\ddot{\circ} \quad \stackrel{m}{\dot{N}}$ & $\begin{array}{l}\dot{\sim} \\
\dot{\sim}\end{array}$ & 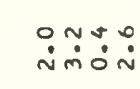 \\
\hline 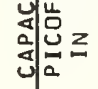 & 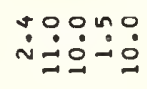 & $\dot{0} \dot{\sim}=$ & 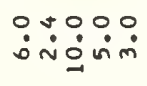 & $\ddot{\sim} \dot{m} \quad \stackrel{m}{m}$ & $\dot{0}$ & 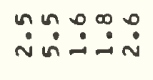 & $\dot{\sim} \dot{\sim} \quad \dot{m}$ & $\ddot{n} \dot{=}$ & 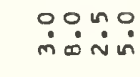 \\
\hline y. & 兰总兑 & 总兑并 & 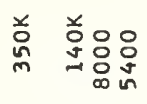 & 弟兑总酋弟 & 兑윰 & 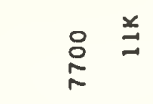 & 吕兑 品 & : & 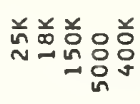 \\
\hline 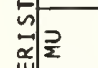 & 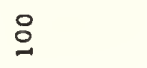 & $\stackrel{\sim}{\sim}:$ & 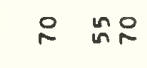 & 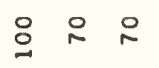 & ㅇ & $\stackrel{N}{ }=8$ & 㲾 & $\cong$ 只 & 운 \\
\hline \begin{tabular}{l|l} 
\\
\cline { 1 - 1 }
\end{tabular} & 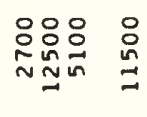 & 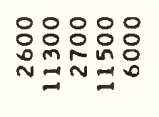 & 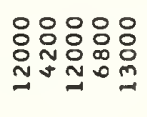 & 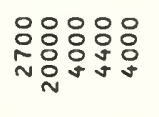 & 总足 & 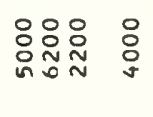 & 品品号品品 & 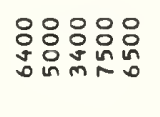 & 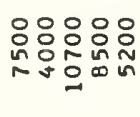 \\
\hline 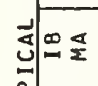 & $N \stackrel{N}{n} N \sim$ & $\sigma \underset{\sigma}{\infty} \stackrel{\sim}{\sim} \pm$ & ONNnO & $n=a+a$ & $i^{\circ}$ & ニㅇニㅇ & $\cong \simeq \partial_{\infty} \backsim \approx$ & $\simeq$ 용ㅇㅇㅁㅁ & $\vec{\sigma}+N \cong 0$ \\
\hline > & 品怘怘 : & 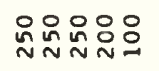 & 윰유숌요 & 유N윰윰요 & 品怘 & 음윰윰 & 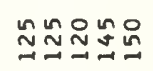 & 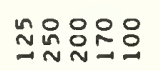 & 옥咨品品怘 \\
\hline 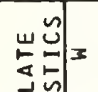 & $\because \because \dot{0}$ & 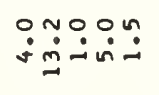 & 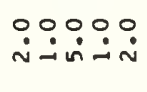 & 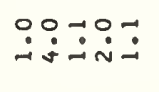 & $\dot{m} \dot{0}$ & $\ddot{\sim} \dot{\sim} \dot{\sim} \quad \dot{\sim}$ & $\ddot{\dot{\sim}} \dot{\sim} \dot{\sim} \dot{0} \dot{0} \dot{m}$ & 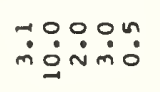 & $\because \because \ddot{\sim} \dot{\sim} \dot{\sim}$ \\
\hline 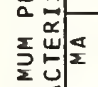 & $\stackrel{\circ}{\sim}$ & 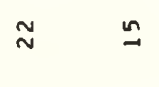 & 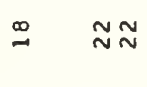 & & $\stackrel{2}{\sim}$ & さュ & in $:$ & $\stackrel{D}{\infty}$ & $\stackrel{n}{\sim}$ \\
\hline $\begin{array}{l}x \\
\frac{x}{2} \\
\frac{\alpha}{5}\end{array}$ & 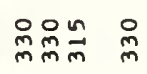 & 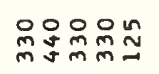 & 品品㤎品 & 㗇品品品品 & 品品 & 足症: & 啹品品品品 & 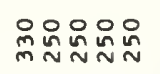 & 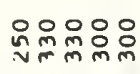 \\
\hline$\frac{1}{\alpha} \sum_{w}^{\frac{\pi}{2}}$ & :ㅇ::ㅇㅇ & 용: & 임ㅇㅁㅇㅇㅛ & 응용원욘 & 总品 & : & :임ㅇㅁㅇㅇㅛ & :잉요유: & 응용요 \\
\hline 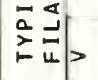 & 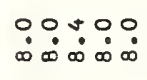 & 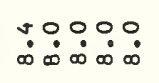 & 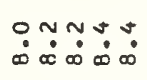 & $\ddot{\sim} \dot{\sim} \dot{\infty} \dot{\infty} \dot{\infty}$ & $\dot{\infty}:$ & 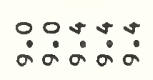 & 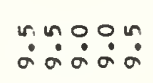 & 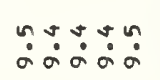 & 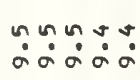 \\
\hline 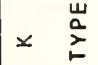 & IIIII & IIIII & IIIII & IIIII & $I I$ & IIIII & IIIII & IIIII & IIIII \\
\hline$\underset{\alpha}{\mathbb{u}}$ & 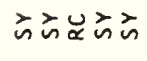 & 巡方え゙る & 灵吉求的公 & 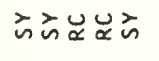 & 离公 & 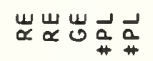 & 方方只品出 & 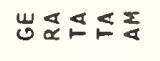 & そこュU山心 \\
\hline 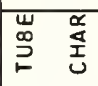 & 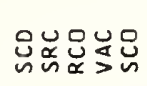 & 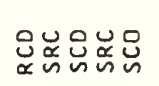 & 肙导芯怘怘 & 号总总怘品 & 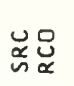 & 怘 号是㟔 & 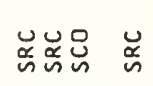 & 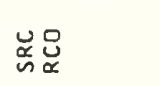 & 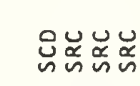 \\
\hline$\stackrel{u}{s}$ & 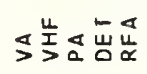 & 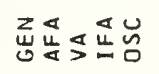 & 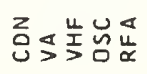 & 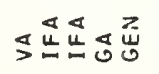 & 造出 & 忌忌出出出 & 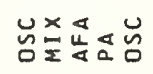 & 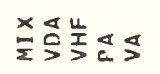 & 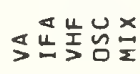 \\
\hline$\stackrel{D}{\infty}^{\infty}$ & ゚゚ロレトレ & トレレレト & ト゚レトト & ロ゚ロレト & 요 & ト゚゚レトゥ & ゚゚レ゚ロ & ゚゚ロレトレ & ト゚゚゚レ゚ \\
\hline $\begin{array}{l}\omega \\
a \\
2\end{array}$ & 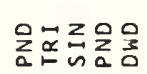 & 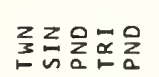 & 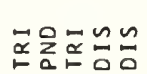 & 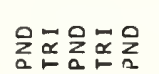 & 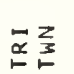 & 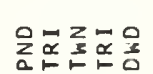 & 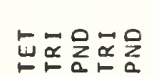 & 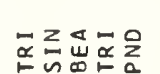 & 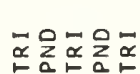 \\
\hline$\frac{0}{2}$ & 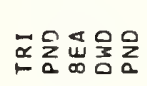 & 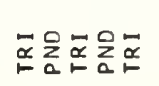 & 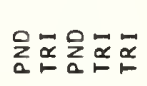 & 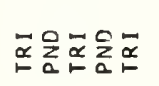 & $\sum_{a} \bar{\alpha}$ & 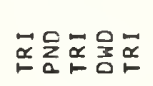 & 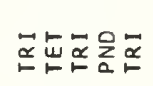 & 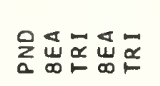 & 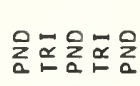 \\
\hline 岑 & $n n$ & $n n$ & & $\backsim$ & $n n$ & $n n$ & 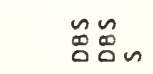 & $n \stackrel{n}{\mathscr{E}}$ & \\
\hline 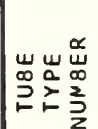 & 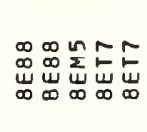 & $\begin{array}{l}\sim \\
0 \\
\\
\infty \\
\infty\end{array}$ & 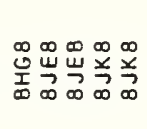 & 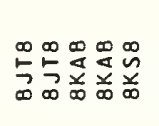 & 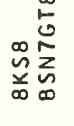 & 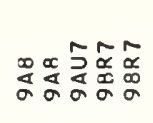 & 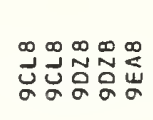 & 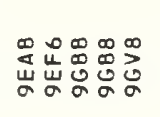 & 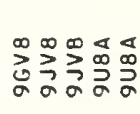 \\
\hline
\end{tabular}




\begin{tabular}{|c|c|c|c|c|c|c|c|c|c|}
\hline 崫号 & 弟希 & 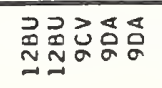 & 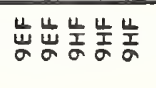 & 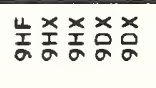 & 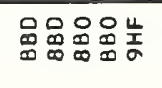 & 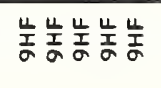 & 염영ㅇㅇㅇㅇㅇ & 영몀ㅇㅁㅇㅁㅇㅁㅇ & 중ㅁㅁ \\
\hline 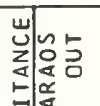 & $\because:$ & $\ddot{\sim} \dot{\sim} \dot{0} \dot{O}$ & 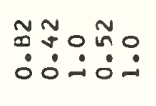 & $\stackrel{m}{\stackrel{n}{0}} \stackrel{\stackrel{0}{0}}{\dot{0}}$ & : & 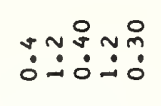 & ษ & 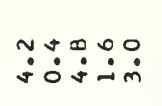 & $\ddot{m}:$ \\
\hline 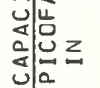 & $\dot{i} \dot{q}$ & 过茫 & ڤ̊ำ & $\stackrel{\sim}{\sim} \quad \stackrel{\sim}{\sim}$ & 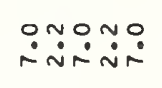 & ن & $\ddot{\circ} \dot{\sim} \dot{\sim} \dot{\sim} \dot{\sim}$ & 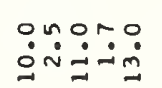 & ㅇ: \\
\hline$=\underline{=}$ & 总 & 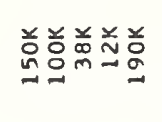 & 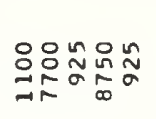 & 希 宕芯并 & 总品品总品 & 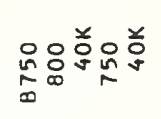 & 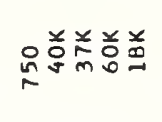 & 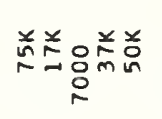 & 然 \\
\hline 司| & $\mathbb{s}^{2}$ & $n$ & ○ & : & $\circ \cong \sim \infty$ & 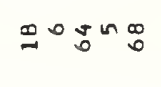 & nป잉 & $\stackrel{\circ}{\therefore}$ & $\stackrel{8}{q}$ \\
\hline \begin{tabular}{l|l}
5 \\
ân
\end{tabular} & 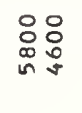 & 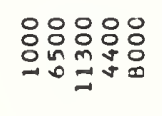 & 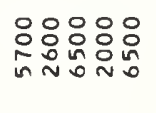 & 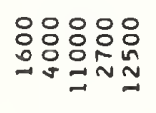 & 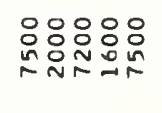 & 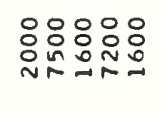 & 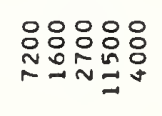 & 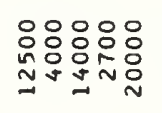 & 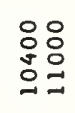 \\
\hline 式 & $\infty \infty$ & 地品 $\cong$ & gon & $-m \cong \sim \sim$ & $\underset{f}{n} \circ 0_{i n} \rightarrow n$ & og o $^{-1}$ - & $\mathscr{n}^{\circ} \sim N^{+}$ & $\stackrel{\sim}{\sim} \approx \sim=$ & $\approx N$ \\
\hline in & 品 & 只员品员占 & 品员品品品 & 윳윰윳유 & 㓢品品员品 & 虽品怘㶽怘 & 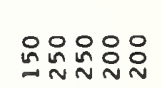 & 윰유윰유 & 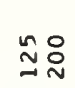 \\
\hline 氠兘 & $\stackrel{n}{-} \dot{0}$ & $\begin{array}{l}\because 00 \cong \\
\text {-ல் }\end{array}$ & 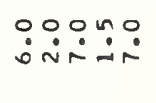 & : $: 9000$ & & & & & $\begin{array}{l}\circ 0 \\
\dot{\sim}\end{array}$ \\
\hline 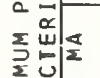 & & ng & 운드ㄴㅗㅡ & 웅ㅇㅁ & 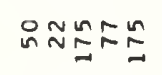 & 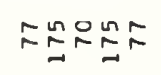 & 요 & & \\
\hline 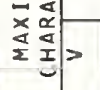 & 怘 & 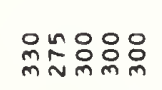 & 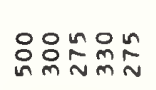 & 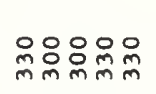 & 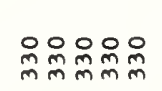 & 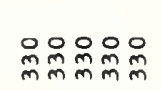 & 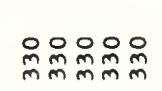 & 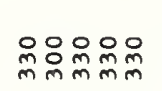 & 율요 \\
\hline 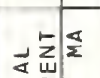 & 윰요 & 응용용요 & 용:-8: & 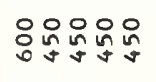 & 융융ㅇㅇㅇ & 응융용ㅇㅇ & 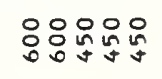 & 虽员品号品品 & $\begin{array}{l}0 \\
\text { 号品 } \\
\text { s. }\end{array}$ \\
\hline 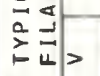 & $\ddot{n} \tilde{a}$ & 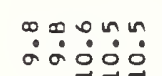 & 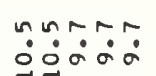 & テNNnn & 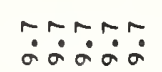 & 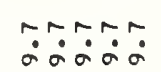 & 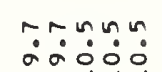 & : & $\because \because$ \\
\hline $\begin{array}{r}\frac{\omega}{2} \\
\times \quad \frac{a}{2}\end{array}$ & $I I$ & IIIII & IIIII & IIIII & IIIII & IIIII & IIIII & IIIII & $I I$ \\
\hline$\underset{\mathscr{~}}{\stackrel{S}{\alpha}}$ & えう & 岕岕方岕 & 売主施えら & 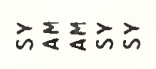 & 䏠炭㫕 & え主迹えう & 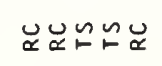 & 证重方公 & 山ु \\
\hline 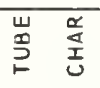 & $\begin{array}{l}\dot{\mathscr{\alpha}} \tilde{\sim} \\
\dot{\sim}\end{array}$ & 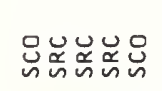 & 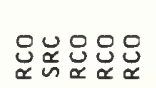 & 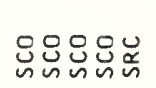 & 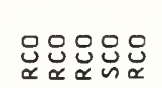 & 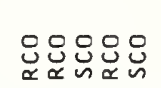 & 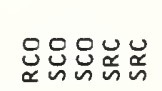 & 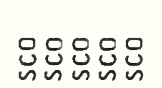 & 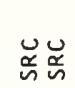 \\
\hline$\stackrel{u}{\check{\nu}}$ & $\underline{u} \frac{x}{2}$ & 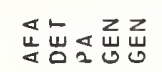 & 额号号号号 & 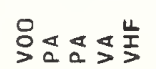 & 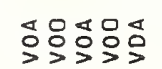 & 잉ㅇㅇㅇ용요 & 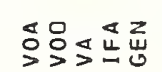 & 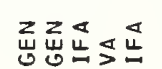 & 强堊 \\
\hline$\stackrel{\infty}{J}$ & 요 & テテ゚ロ゚ & ゚ロレトロ & ゚゚ュレ & 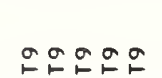 & 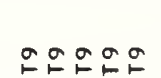 & のロロロロ & ஃ゚ㅁㅇㅛ & 두 \\
\hline$\underset{2}{u}$ & $\sum_{a} \underset{q}{\alpha}$ & 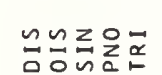 & $\because \backsim \backsim \backsim \backsim$ & 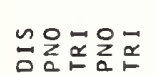 & ヘッレッレ & 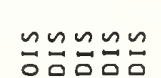 & 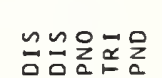 & 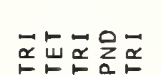 & 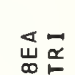 \\
\hline$\sum_{x}^{0}$ & 몸음 & 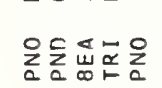 & 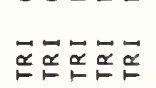 & 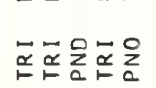 & 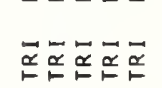 & $\vec{\propto}$ & 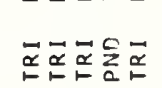 & 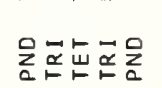 & 企崮 \\
\hline 㟧 & 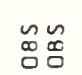 & $n n$ & 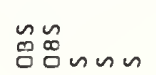 & 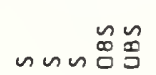 & $\backsim$ & ヘレn & $\backsim \backsim n$ & $n n$ & \\
\hline 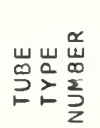 & 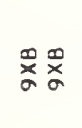 & 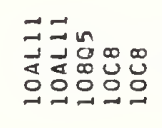 & 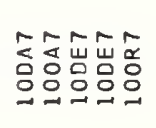 & 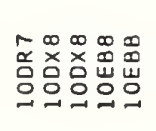 & 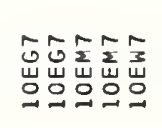 & 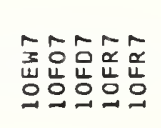 & 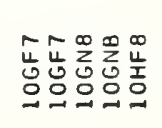 & 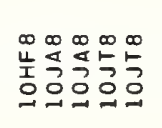 & 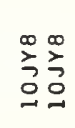 \\
\hline
\end{tabular}




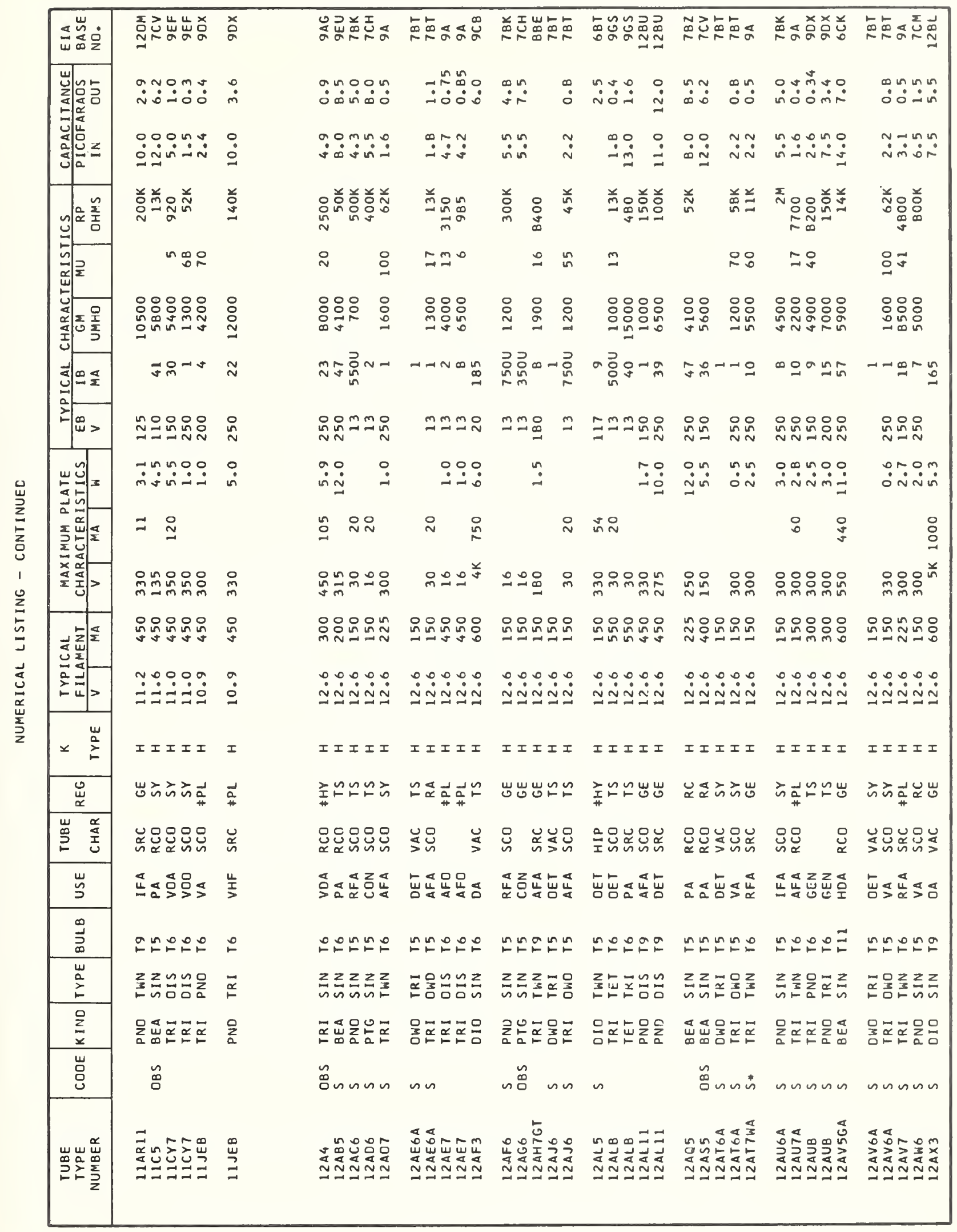




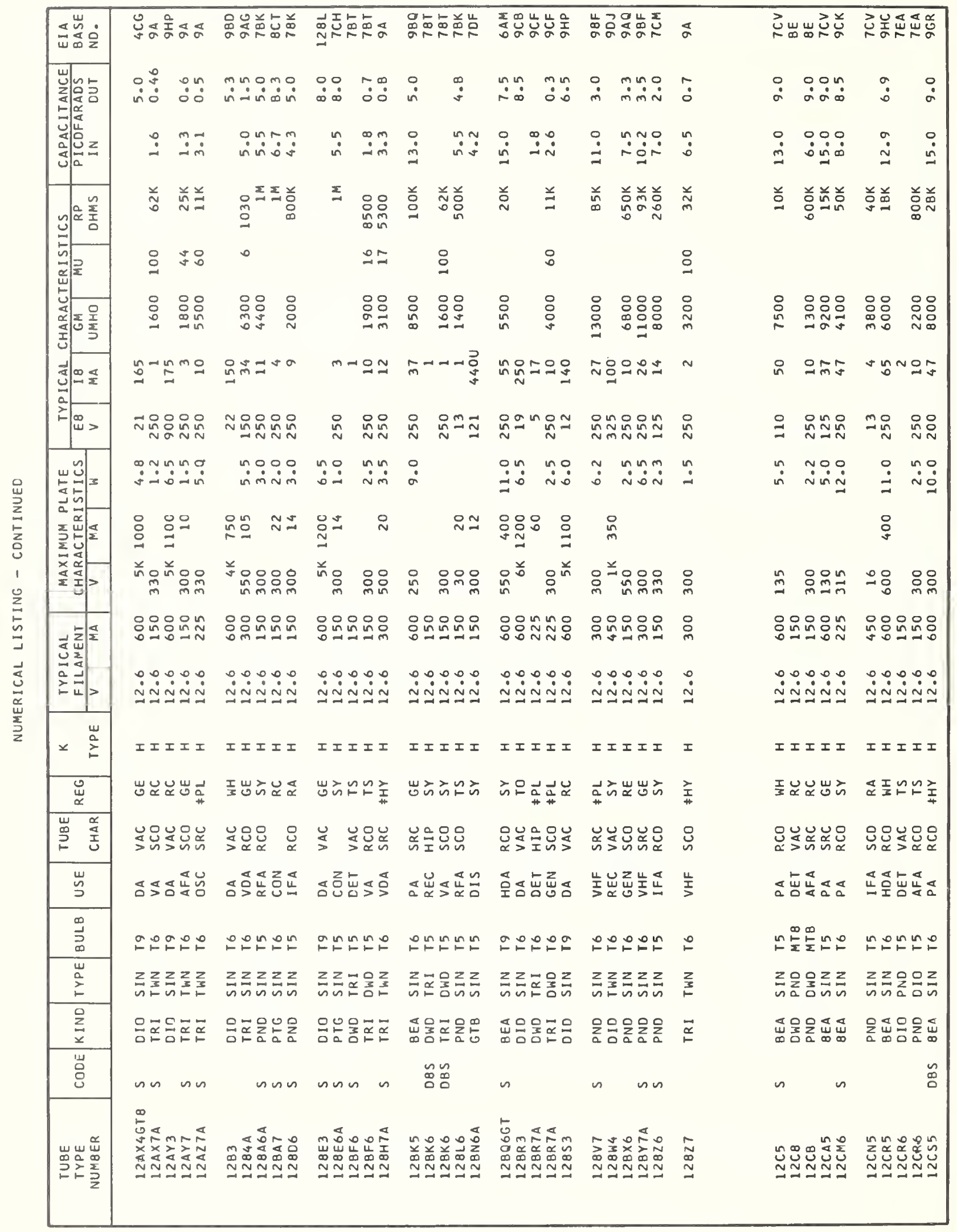




\begin{tabular}{|c|c|c|c|c|c|c|c|c|c|}
\hline 岂岂吕 & 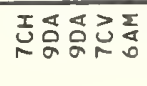 & 兽㒸 & 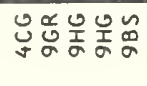 & 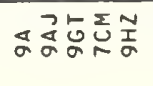 & 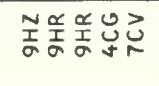 & 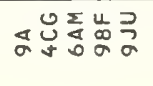 & 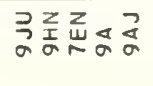 & 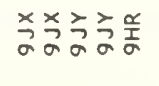 & 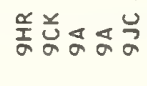 \\
\hline 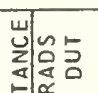 & 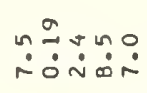 & $\stackrel{0}{\circ}$ & $\ddot{\sim} \dot{0} \dot{0} \sin$ & 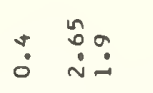 & 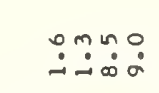 & $\begin{array}{l}0 \\
\dot{0} \\
\dot{0}\end{array}$ & $\because: \quad \stackrel{0}{0}:$ & $\dot{0} \stackrel{\infty}{m}$ & $\dot{0} 0 \stackrel{0}{\circ}$ \\
\hline $\begin{array}{l}0 \\
0 \\
0\end{array}$ & 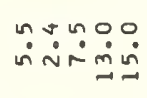 & $\stackrel{n}{\sim} \stackrel{n}{\infty}$ & 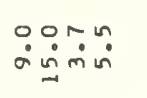 & $\stackrel{\circ}{\circ} \stackrel{0}{0}$ & 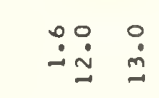 & $\stackrel{0}{\circ} \stackrel{0}{\circ}$ & $\ddot{\dot{m}} \dot{\sim} \dot{\sim} \dot{\sim} \dot{\sim}$ & $\stackrel{m}{=} \stackrel{m}{-}$ & $\begin{array}{l}0: \div \div: \\
0 \pm=-1\end{array}$ \\
\hline 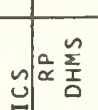 & 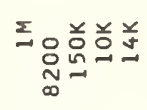 & 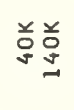 & 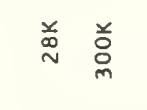 & 弟 吕兑 & 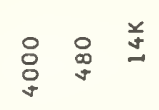 & 芯 苾总 & 이잃 & 응 & 怘 \\
\hline 氙| & 号 & & & 品 & & $\stackrel{\circ}{\circ}$ & $\therefore:$ & \pm & $=0$ \\
\hline 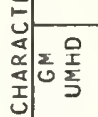 & 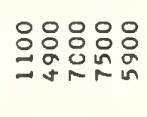 & $\begin{array}{l}\text { : } \\
\text { 윰 } \\
\text { m }\end{array}$ & $\begin{array}{l}\circ \\
:\end{array}$ & 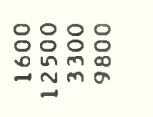 & 용 & 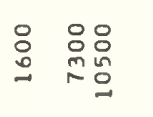 & 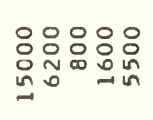 & 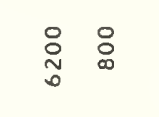 & 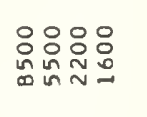 \\
\hline 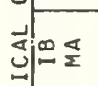 & 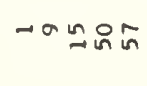 & $m N$ & $\underset{\infty}{n} \mathfrak{s}^{n}-8$ & $-\because N \simeq$ & omg in & 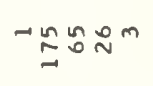 & o & 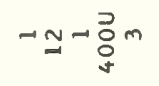 & an \\
\hline w > & 음윰윰유 & $m=$ & 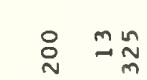 & 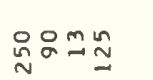 & $=$ m & 오N 윳유 & 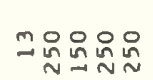 & $\stackrel{m}{=}$ & " 윳요요 \\
\hline 㟧泀| & 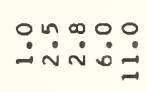 & & 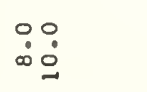 & $\stackrel{\infty}{\dot{\sim}} \quad \dot{m}$ & $\ddot{0} \quad \ddot{0} \quad \ddot{n}$ & 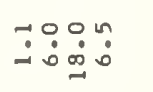 & $\ddot{\circ} \dot{\sim} \dot{\sim} \dot{\sim}$ & & \\
\hline 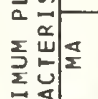 & 웅 & & 응유 윴 & $\stackrel{n}{\sim}-$ & $\stackrel{\circ}{\sim} \stackrel{\circ}{\stackrel{0}{\sim}}$ & 욤요 & & $i^{n}$ & $\stackrel{n}{N} N$ \\
\hline 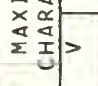 & 암윰욤요 & $\dot{m} m$ & 学品 & 品물울 & 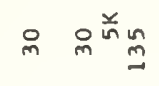 & 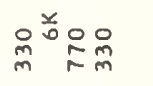 & 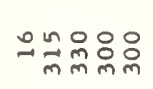 & $\therefore$ & 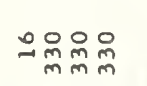 \\
\hline - $\frac{2}{4}$ & 음을윰용 & ํํㅁㅇㅠ & 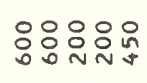 & 음욤욤요 & 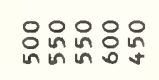 & 응용요 & 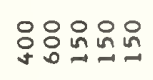 & 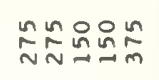 & 战㗊品品品 \\
\hline $\begin{array}{ll}2 & 2 \\
2 & \vdots \\
2 & 0\end{array} \mid>$ & 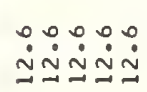 & $\begin{array}{l}0 \\
\dot{\sim}\end{array}$ & 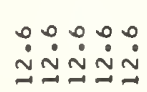 & 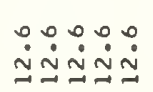 & 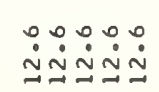 & 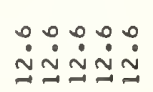 & 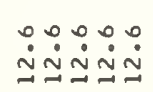 & 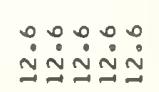 & 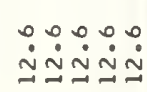 \\
\hline $\begin{array}{r}u \\
\times \quad \stackrel{u}{\vdots}\end{array}$ & IIIII & $I I$ & IIIII & IIIII & IIIII & IIIII & IIIII & IIIII & IIIII \\
\hline$\underset{\sim}{u}$ & 公岕㟧这方 & 离 & 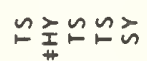 & 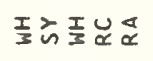 & ๕こニエ & 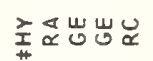 & 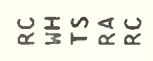 & 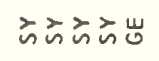 & 嵌公的公。 \\
\hline 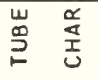 & 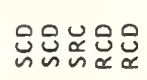 & 芯怘 & 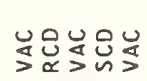 & 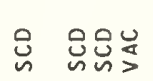 & 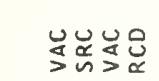 & Sư⿱ & 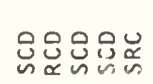 & 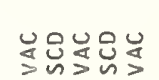 & 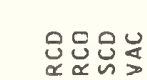 \\
\hline$\stackrel{u}{\leftrightharpoons}$ & 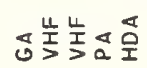 & 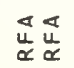 & 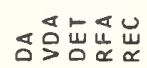 & 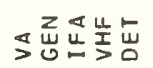 & 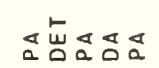 & 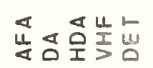 & 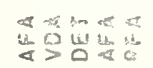 & 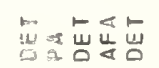 & 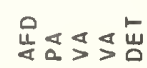 \\
\hline$\bigsqcup_{\infty}^{\infty}$ & ペ゚ロロミ & 乞n & ロロロュュ & ゚゚゚ロロ & ト゚ロロレ & ロュ゚゚ & ゚゚ロロュ゚ & ゚ロஃュュ & ゚レ요요 \\
\hline$\stackrel{u}{a}$ & 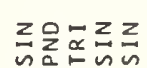 & zzz & 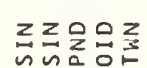 & 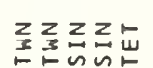 & 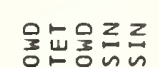 & 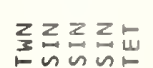 & 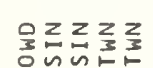 & 뜬옹몸옹는 & 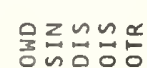 \\
\hline$\frac{0}{x}$ & 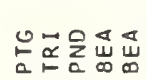 & 음음 & 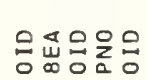 & 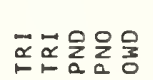 & 놈옹는웡ㅎㅀ & 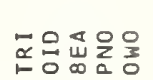 & 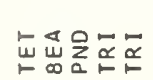 & 옳늠옴음옹 & 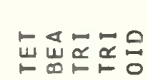 \\
\hline 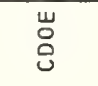 & ヘnヘnn & 品 & ڤ & $\begin{array}{lll}\sim & \sim & n \\
\infty & \infty & 0 \\
0 & 0 & 0\end{array}$ & $\stackrel{n}{\infty} \begin{array}{l}n \\
\text { Őnn }\end{array}$ & $\tilde{\Delta} \tilde{\Delta} n n n$ & $\backsim \quad \tilde{\Delta} n$ & & 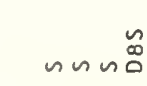 \\
\hline 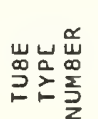 & 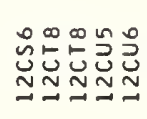 & 总总 & 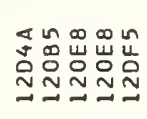 & 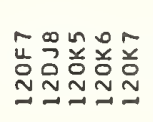 & 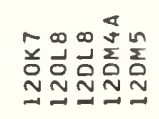 & 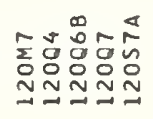 & 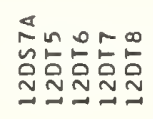 & 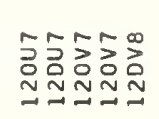 & 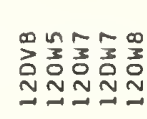 \\
\hline
\end{tabular}




\begin{tabular}{|c|c|c|c|c|c|c|c|c|c|}
\hline 崖崖呈 & 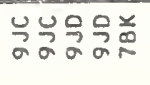 & $\begin{array}{l}\text { xx } \\
\text { wू }\end{array}$ & 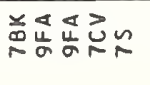 & 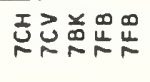 & 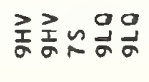 & 弟 & 壬志志导次 & 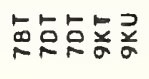 & 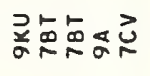 \\
\hline 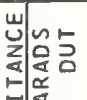 & 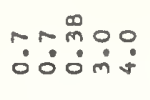 & & 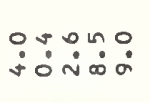 & ஸ்:日் & $\begin{array}{ll}\dot{0} & 0 \\
\dot{\infty} & \dot{0}\end{array}$ & $\ddot{n}$ & $\dot{0}$ & $\because ‡ \stackrel{\dot{\sim}}{\circ}$ & 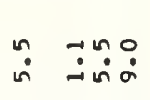 \\
\hline 送 & 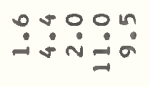 & & 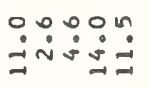 & تீ:0 & $\begin{array}{l}\dot{0} \\
\dot{5}\end{array}$ & $\stackrel{\infty}{\check{r}}$ & $\stackrel{\text { qn }}{\sim}$ & $\stackrel{\sim}{\dot{\sim}} \dot{\sim} \dot{\sim}$ & ڤִ \\
\hline$=0$ & 증ㅇㅁㅇㅁㅇ & & 肴。兑学 & 兑兰㒸 总 & 总 & 喕 & 差兑 & 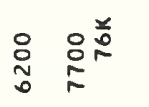 & 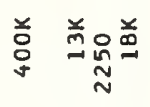 \\
\hline 勾展 & 응 & 임 & $\stackrel{n}{N}$ & nี & & & & 응으으 & $\pm N$ \\
\hline 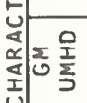 & 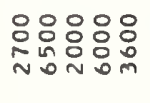 & 总足 & 沾品品: & 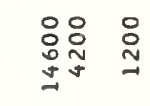 & 요요 & $\stackrel{8}{\circ}$ & 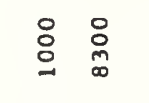 & 怘 品: & 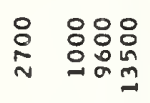 \\
\hline 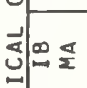 & $N \infty- \pm n$ & $\partial_{\infty}=$ & mN ⿱ㅡㅇำ & 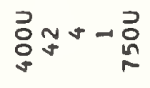 & $-\infty 0_{n}-\sigma$ & $\sim$ & -ー忌 & $-\quad-N-$ & $\sim: D$ \\
\hline 昰 > & 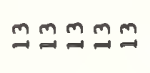 & $\stackrel{0}{\text { I }}$ & 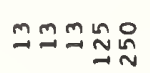 & 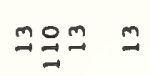 & 으: 윰음 & \pm & $m=$ & $m$ m & $=90$ \\
\hline 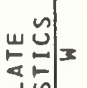 & $\ddot{n}: \ddot{n}$ & : & :0 & $\ddot{0}$ & $\ddot{\circ} \stackrel{0}{\circ}$ & & $\dot{0}$ & $\ddot{n}$ & $\dot{\sim} \dot{n}$ \\
\hline 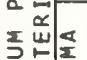 & & $\ln 8$ & $\stackrel{\square}{\square}$ & ㅇ & $9 \stackrel{n}{=}$ & 이 & 응 & -0 & - 유요 \\
\hline 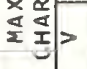 & 요 & 号员 & 누욤욤 & 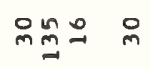 & 용유 & $\stackrel{p}{m}$ & 일윰요 & $\stackrel{\circ}{-}{ }_{m}^{\circ}$ & 욤임 \\
\hline $4 \bar{x}$ & 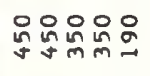 & 品号 & 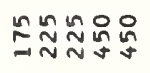 & 윰ㅇㅇㅁ욤요 & 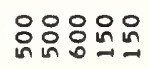 & $\stackrel{n}{\check{\Sigma}}$ & 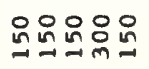 & 음욤욤욤요 & 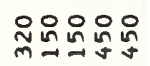 \\
\hline 事 & $\because: \because:$ & $\because \circ$ & $\because: \bullet:$ & $\because: \because:$ & $\because: 0$ & $\because$ & $:: \because:$ & $\because: \because:$ & 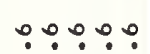 \\
\hline$\times \stackrel{\frac{\omega}{2}}{2}$ & IIIII & II & エエエエエ & Iエエエエ & エエエエエ & I & エエエエエ & IIIII & エエエエI \\
\hline 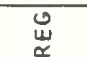 & 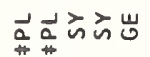 & 只品 & 岕えうららさ & 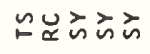 & 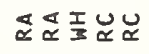 & $\cong$ & 乞ュュロむ & 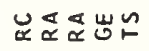 & 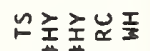 \\
\hline 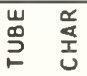 & 怘芯怘 & 芩 & 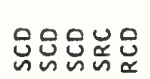 & 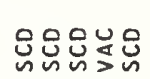 & 呆 & S & 通怘 & 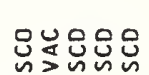 & 范莡 \\
\hline$\stackrel{u}{\breve{s}}$ & 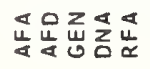 & 造范 & 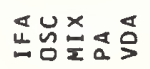 & 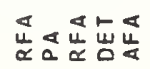 & 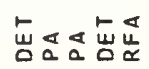 & $\frac{a}{a}$ & 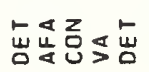 & 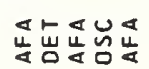 & 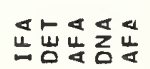 \\
\hline$\stackrel{D}{0}_{0}^{\infty}$ & ゚゚ロ & 온 & ペ゚ュே & 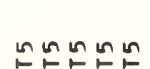 & レロテレ゚ & 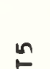 & ํำเำ & ヘレレロ゚゚ & ำคทำำ \\
\hline$\frac{w}{2}$ & 只只出元 & $\hat{\Sigma}_{\alpha}$ & zözz & $z \geq z \stackrel{\alpha}{\alpha}$ & 는응응 & $z$ & 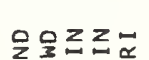 & 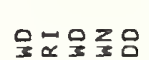 & 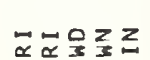 \\
\hline 울 & & & & & & 0 & & & \\
\hline$\underline{\bar{x}}$ & $=\underline{\underline{\prime}}$ & 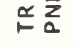 & $\bar{z}$ zán & 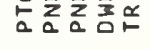 & 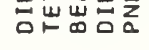 & $\bar{z}$ & 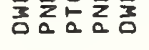 & 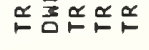 & 흠ㅎㅁㅁ \\
\hline 㟔 & $\begin{array}{l}\tilde{n} \\
\text { 品 } \\
0\end{array}$ & 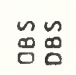 & 乞 & $n n$ & $n$ & & $\begin{array}{ll}n & \\
0 & n\end{array}$ & nnn & $\begin{array}{l}n \tilde{\infty} \\
\infty \\
\infty\end{array}$ \\
\hline 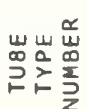 & 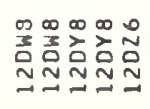 & 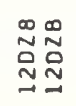 & 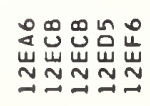 & 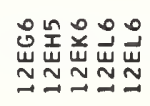 & 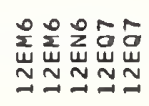 & $\stackrel{\stackrel{\sim}{\sim}}{\underset{\sim}{N}}$ & 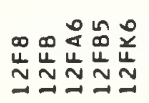 & 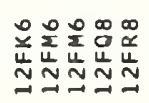 & 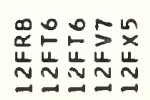 \\
\hline
\end{tabular}




\begin{tabular}{|c|c|c|c|c|c|c|c|c|c|}
\hline 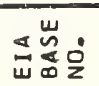 & 音音总希 & 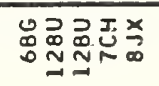 & 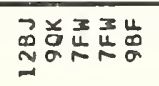 & 没总要 & 몽르 & g잉్며 & 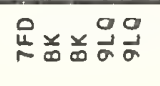 & $\approx$ & 己 \\
\hline 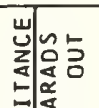 & 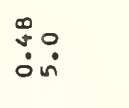 & $\because \because \stackrel{\square}{\check{I}}$ & $\dot{i}: \dot{0}: \dot{0}$ & $\because ?$ & $\dot{q}:$ & : & $\dot{m} \dot{0}: \dot{0}$ & & $\stackrel{\circ}{\circ}$ \\
\hline 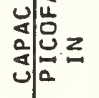 & ஸ̊: & $\begin{array}{l}\dot{\sim} \\
\stackrel{\sim}{0} \dot{0}\end{array}$ & 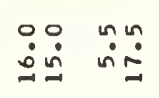 & $\begin{array}{l}00 \\
\dot{0}:\end{array}$ & $\dot{\sim}:$ & : & $\because: 0$ & & $\stackrel{\dot{m}}{=}$ \\
\hline ปી & 움 & 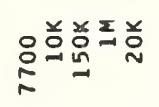 & 兑弟 立兑 & 总弟 & 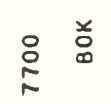 & 옹 웅 & 品 & 弟 & $\stackrel{m}{m}$ \\
\hline 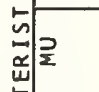 & $\stackrel{\circ}{-1}$ & $\stackrel{\circ}{\sim}$ & & & $\stackrel{\circ}{\sim}$ & 요 & & & \\
\hline \begin{tabular}{l|l} 
& \\
& 2
\end{tabular} & 号 名品 & 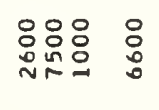 & 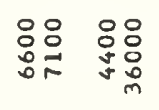 & 움윰 & : & 品总品 & 吕 & $\stackrel{\circ}{\circ}$ & $\stackrel{\circ}{\circ}$ \\
\hline 我电 & 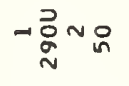 & $\sigma o-D_{0} n$ & 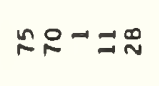 & 옷요 & $\sigma \infty \stackrel{\sim}{N}$ & an $\simeq$ & $d_{a} n \rightarrow \infty$ & 5 & s \\
\hline > & 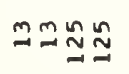 & 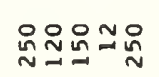 & 怘怘 惡怘 & 员怘怘 & 怘三怘 & $\stackrel{n}{\sim} \underset{\sim}{m}$ & m음요 & $\stackrel{\circ}{\text { : }}$ & $\stackrel{\circ}{=}$ \\
\hline 造占 & $\stackrel{0}{\circ}$ & $\ddot{\sim} \dot{n}: \stackrel{n}{=}$ & 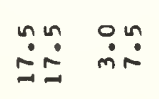 & \begin{tabular}{l}
$n \because 0$ \\
\hdashline$\cong 0$
\end{tabular} & $\ddot{i} \dot{0}$ & $\begin{array}{l}\dot{n} \\
\dot{\sim} \\
\end{array}$ & $\ddot{\infty}: \dot{0}: \dot{m}$ & $\stackrel{\circ}{0}$ & $\stackrel{n}{s}$ \\
\hline 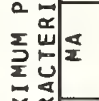 & & n & 요ㅇㅛㅛ & 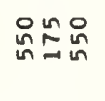 & 罗号 & $\stackrel{\circ}{N} \stackrel{n}{=}$ & & & $\cong$ \\
\hline 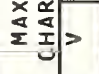 & 운요 & 品品䛔 & 옹유 & 운유 & 윰욤 & 苾 임 & 일욤유 & $\stackrel{\text { O }}{N}$ & $\stackrel{\circ}{n}$ \\
\hline 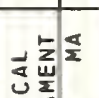 & 있임용 & 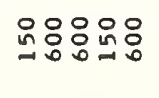 & 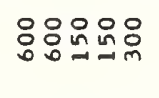 & 용용 & 윰욤욤 & 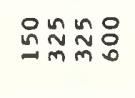 & 品品品品品 & : & : \\
\hline$\sum_{2}^{2}$ & 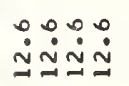 & 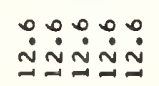 & 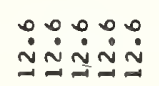 & $\begin{array}{l}\dot{0}: 0 \\
\dot{\sim} \stackrel{\sim}{\simeq}\end{array}$ & $\begin{array}{l}\dot{0}: 0 \\
\dot{\sim} \stackrel{\sim}{\beth}\end{array}$ & 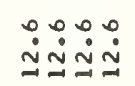 & 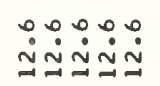 & $\stackrel{\dot{\sim}}{\check{\sim}}$ & $\stackrel{\dot{\sim}}{\simeq}$ \\
\hline$\times \sum_{2}^{0}$ & IIII & IIIII & IIIII & III & III & IIII & IIIII & $I$ & $I$ \\
\hline$\underset{\sim}{\stackrel{W}{\sim}}$ & ヘニさ主主 & え岕㟧岕匹 & 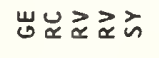 & $\bigcup_{\propto} \underset{\propto}{ }$ & え゙ّ & 嵌ええ゙と & 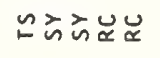 & 岕 & え \\
\hline 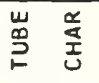 & 品怘 & 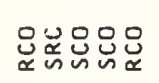 & 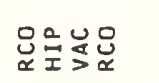 & 象怘怘 & $\stackrel{g}{\dddot{Q}}$ & 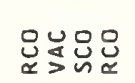 & 岕 & 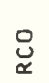 & $\underset{\varkappa}{0}$ \\
\hline 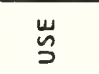 & 造导品饪 & 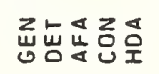 & 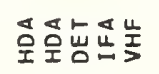 & 咹全品 & 总出区 & 忌出匹战 & 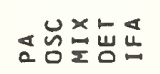 & $a$ & 今 \\
\hline$\sum_{0}^{\infty}$ & ㅇレ゚요 & ๓ロロッミ & エュュュュ゚ & $\underset{\Xi}{ } \cong \Xi$ & ペロ゚ & ロேロミ & ヒேロロロレ & $\stackrel{a}{1}$ & $\stackrel{2}{2}$ \\
\hline$\underset{⿱ 亠 䒑}{\varpi}$ & 늠쭌응뭄 & 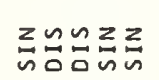 & 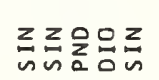 & 就录品 & 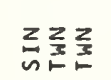 & 录出亩先 & 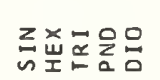 & $\frac{z}{n}$ & $\frac{z}{n}$ \\
\hline$\frac{a}{z}$ & 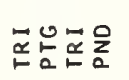 & 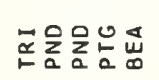 & 㟧岕品弡虽 & 岗山ే & 몸음음 & 古옴ㄴّㄴ & 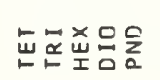 & $\underset{\varpi}{\varpi}$ & $\underset{\infty}{\mathbb{\infty}}$ \\
\hline 㟔 & & 足n & $n$ & $n n$ & $\approx$ & $n$ & & $n$ & \\
\hline 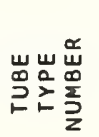 & 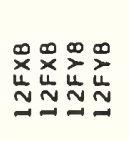 & 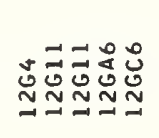 & 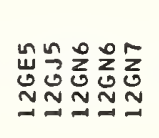 & 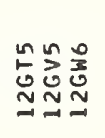 & 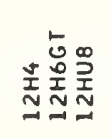 & 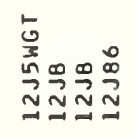 & 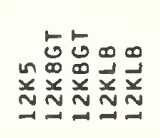 & 总 & $\stackrel{n}{\simeq}$ \\
\hline
\end{tabular}




\begin{tabular}{|c|c|c|c|c|c|c|c|c|c|}
\hline 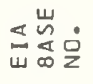 & 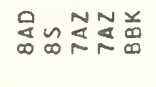 & 㤩乙施品品 & $\underset{\infty}{g}$ & 5 & $\approx$ & $\approx$ & $\stackrel{\infty}{\infty}_{n}^{\infty}$ & $\stackrel{s}{s}$ & 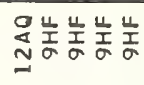 \\
\hline 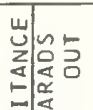 & $\because \because \quad \because \dot{r}$ & $\stackrel{\circ}{\dot{i} \dot{i} \sim} \dot{0}$ & $\dot{m}$ & $\dot{0}$ & $\stackrel{n}{i}$ & $\stackrel{\circ}{\circ}$ & & & 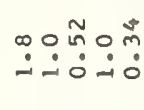 \\
\hline 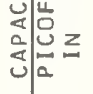 & $\because \because \quad \dot{\sim} \sim \dot{n}$ & $\ddot{\infty} \ddot{0} \dot{0} \dot{\sim}$ & $\stackrel{j}{j}$ & $\stackrel{0}{-}$ & $\stackrel{\circ}{\circ}$ & $\stackrel{0}{n}$ & & & 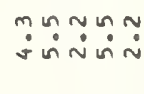 \\
\hline$y$. & 朔 弚ㅇㅇㅇ & 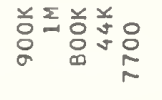 & 总 & $\stackrel{\text { I }}{=}$ & 兑 & $\stackrel{x}{\stackrel{x}{N}}$ & & & 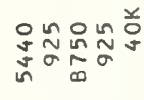 \\
\hline 点 & $\stackrel{0}{r}$ & $\stackrel{O}{N}$ & 음 & $\stackrel{i}{\sim}$ & & & & & $\mathscr{0} 0 \simeq 0$ \\
\hline 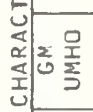 & 윰 品 & 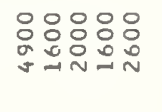 & $\stackrel{\circ}{\simeq}$ & : & $\frac{8}{9}$ & : & & & 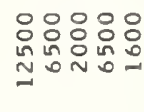 \\
\hline بـ & $+N \rightarrow \simeq$ & $=m \sigma N \sigma$ & -- & - & F & ษ & $?$ & nn & 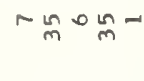 \\
\hline 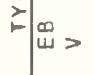 & 品怘 㤐怘 & 怘怘怘怘念 & $\stackrel{\circ}{\sim}$ & $=$ & $\stackrel{\circ}{\sim}$ & $\stackrel{\circ}{\sim}$ & $\stackrel{n}{N}$ & $\stackrel{n}{N}$ & 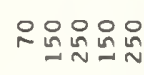 \\
\hline 过 & $\stackrel{\dot{m}}{-} \ddot{m}$ & 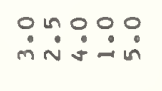 & $\tilde{0}$ & & $\dot{\check{I}}$ & $\dot{0}$ & & & 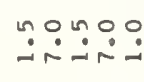 \\
\hline 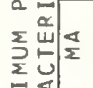 & $\Xi$ & $\stackrel{0}{r}$ & & $\cong$ & & $\stackrel{0}{\infty}$ & $\stackrel{\circ}{\sim}$ & 요 & $\stackrel{n}{\simeq} \stackrel{\text { I }}{\simeq}$ \\
\hline 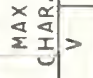 & 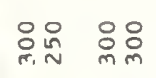 & 임윰욤요 & 일 & 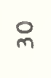 & $\frac{n}{n}$ & $\stackrel{\circ}{\circ}$ & 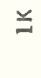 & 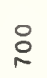 & 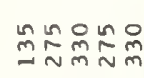 \\
\hline$-\frac{z_{u}}{2}$ & 品品品品品 & 品品品品品 & 吕品 & 品 & $\stackrel{n}{\sim}$ & : & 울 & : & 品品品品品 \\
\hline 년 & $\begin{array}{l}\dot{0} \dot{\sim} \dot{\sim} \\
\dot{\sim} \dot{\sim}\end{array}$ & 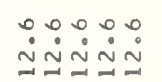 & 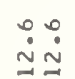 & $\dot{\sim}$ & $\stackrel{0}{\sim}$ & $\dot{\check{\sim}}$ & $\dot{\dot{\sim}}$ & $\dot{\sim}$ & $\ddot{\dot{m}} \dot{m} \dot{m} \dot{m} \dot{m} \dot{m} \dot{m}$ \\
\hline$\times \sum_{i}^{\frac{\omega}{2}}$ & IIIII & エエエエエ & II & $I$ & I & $I$ & $I$ & $I$ & エエエエエ \\
\hline$\underset{\sim}{\stackrel{\cup}{\Psi}}$ & 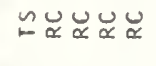 & 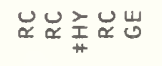 & 空至 & $\approx$ & $\cong$ & 岁 & $\cong$ & in & 幽ええええう \\
\hline 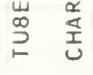 & 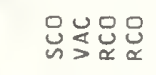 & 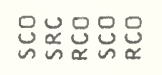 & 递 & 只 & $\stackrel{g}{\mathscr{c}}$ & $\underset{\varkappa}{\stackrel{Q}{\varkappa}}$ & $\stackrel{4}{\$}$ & 京 & 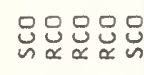 \\
\hline 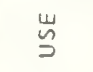 & 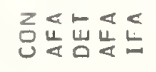 & 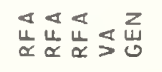 & 㟧s & 前 & $a$ & $a$ & $\underset{\alpha}{\breve{\alpha}}$ & $\underset{\alpha}{\breve{u}}$ & 造䓃号号号 \\
\hline$\stackrel{\infty}{\infty}^{\infty}$ & 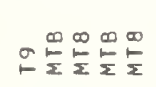 & 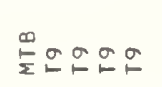 & $\sigma \sigma$ & $\stackrel{\circ}{\circ}$ & $\sigma$ & 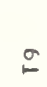 & $\approx$ & $\stackrel{N}{E}$ & 宝゚ロ゚゚ \\
\hline$\frac{\omega}{2}$ & 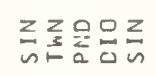 & 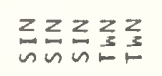 & 䓀号 & $\frac{z}{z}$ & $\frac{z}{s}$ & $\frac{z}{n}$ & $z$ & $\frac{z}{n}$ & そュュュュュ \\
\hline$\underset{z}{\underline{z}}$ & 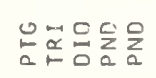 & $\sum_{a} \sum_{a} \sum_{a}^{c} \underset{\alpha}{a} \bar{\alpha}$ & 吕 $\bar{x}$ & $\underline{a}$ & $\underset{\infty}{\overleftrightarrow{\infty}}$ & 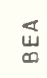 & $\frac{\mathrm{C}}{0}$ & 움 & 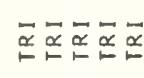 \\
\hline 岂 & $n n$ & $\backsim \backsim \backsim n$ & $n n$ & & $\backsim$ & $n$ & & $\tilde{0}$ & nnn \\
\hline 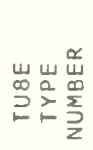 & 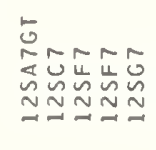 & 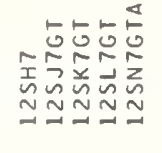 & 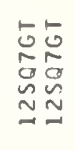 & 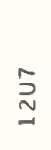 & ড & 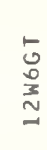 & $\stackrel{+}{\underset{x}{a}}$ & $\stackrel{\sim}{N}$ & 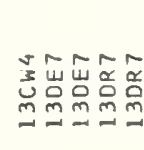 \\
\hline
\end{tabular}




\begin{tabular}{|c|c|c|c|c|c|c|c|c|c|}
\hline 造崖号 & 最品品㞬㞬 & 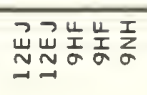 & Nㅜㅇ응요 & $\stackrel{\mathscr{\infty}}{\sim}$ & 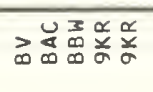 & 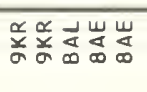 & 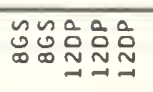 & 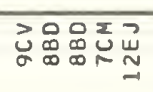 & 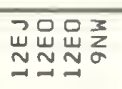 \\
\hline 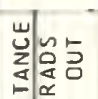 & 象 & : $\stackrel{\text { : }}{\stackrel{-}{-}}$ & 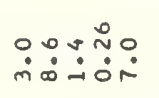 & & $\because: \stackrel{⿱}{\sim}$ & $\stackrel{\sim}{0}$ ơ & $\dot{0}$ & 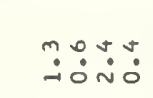 & 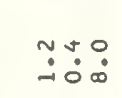 \\
\hline 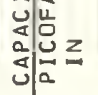 & $\ddot{\sim} \dot{\sim} \dot{\sim} \sim$ & $\stackrel{\sim}{\sim} \ddot{\sim} \dot{\sim}$ & 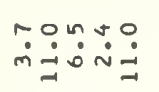 & $\stackrel{0}{j}$ & 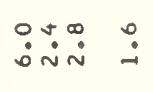 & $\stackrel{\infty}{\because} \stackrel{0}{\sim}$ & $\stackrel{\circ}{\sim} \doteq$ & $\ddot{0} \dot{\sim} \dot{\sim} \dot{\sim}$ & थि \\
\hline s. & 号弟号亭 & 总总品兑 & 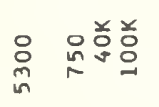 & & 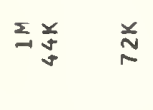 & $\underset{v}{J} \Sigma$ & 总总总兽 & 前。 & 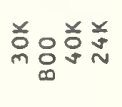 \\
\hline 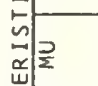 & 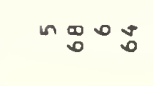 & ○ & $\stackrel{\infty}{\rightarrow}$ & & 욤 & 웅 & $\stackrel{\sim}{\sim}: \vec{v}$ & 00 & : \\
\hline 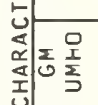 & 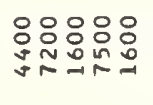 & 음윰윰어 & 욤요 & & :용 & 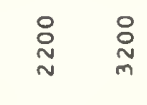 & 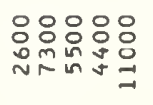 & 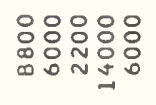 & 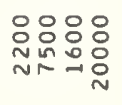 \\
\hline ل्र & $\simeq \mathrm{O}^{\circ} \rightarrow \mathrm{O}^{-}$ & 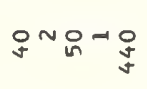 & 음요 & $\begin{array}{l}3 \\
0 \\
0 \\
\text { j }\end{array}$ & NNon? & ONuto & $\sigma^{4} \rightarrow \sigma_{N}$ & 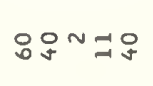 & $n \ln 20$ \\
\hline 尚 > & 돋욤욤요 & 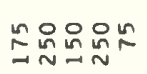 & 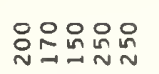 & $\stackrel{O}{\sim}$ & 욧요욤요 & 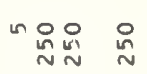 & 윰요 윰유 & 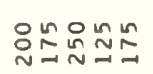 & 品品怘怘品 \\
\hline ๘ & Nợ & 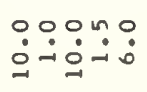 & 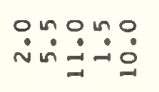 & & 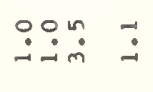 & $\because \stackrel{0}{-} \dot{\sim}$ & 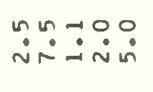 & : & 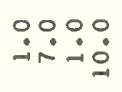 \\
\hline 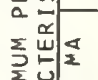 & 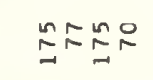 & in $\underset{N}{n} \frac{n}{N}$ & in $N$ & 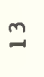 & & $\Xi$ & 운 & 용 in & in \\
\hline 这售势> & 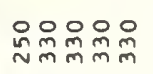 & 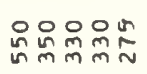 & 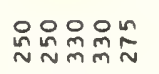 & 욜 & 윰욜 & 율율 & 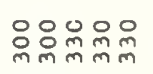 & 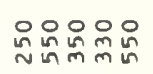 & 品瓷足品品 \\
\hline 戈运这 & 踶品品品 & 品员品品品 & 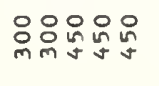 & 品 & 只品品品品 & 员品品品品 & 品品品品 & 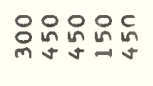 & 品总品品 \\
\hline 运手> & 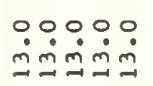 & 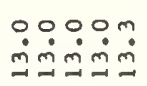 & 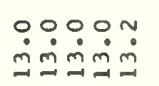 & $\ddot{\sim}$ & 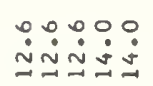 & 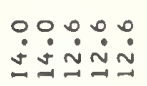 & 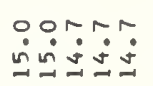 & 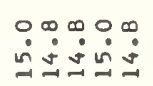 & 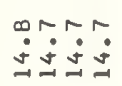 \\
\hline$\times \quad \stackrel{m}{a}$ & Iエエエエ & IIIII & エエエエエ & I & IIIII & IIIII & IIIII & IIIII & IIII \\
\hline$\underset{\sim}{\stackrel{U}{\sim}}$ & ミえううる & 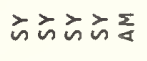 & $\varangle \leq u_{\propto}$ & 嵌 & ええこたえ岕 & 嵌岕えううう & え゙え゙せّ山心 & щّ & U્ \\
\hline 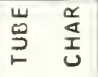 & 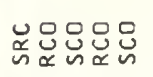 & 总怘品 & 导导芯 & & 总总芯导导 & 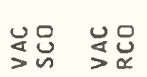 & 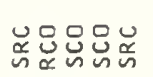 & 苂怘导怘 & 足怘品 \\
\hline$\underset{J}{\breve{y ~}}$ & 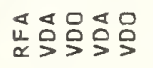 & 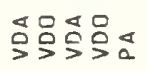 & 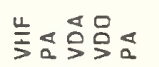 & $\approx$ & 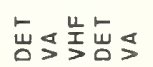 & 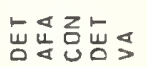 & 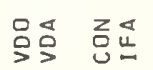 & 选号品范号 & 㞻号号号 \\
\hline$\sum_{\infty}^{\infty}$ & ㅁロㅁ & 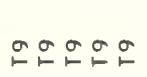 & ㄴேㅁำ & $\sigma$ & テロロ゚ロ & レレロேロ & 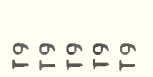 & 욤ำ & 욤ㅇ \\
\hline $\begin{array}{l}\vec{w} \\
\stackrel{a}{z} \\
\imath\end{array}$ & 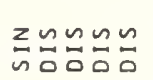 & 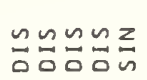 & 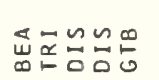 & $\sum_{0}$ & 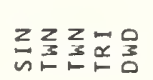 & 폼옹름움 & 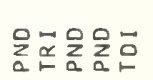 & 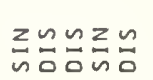 & 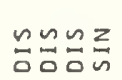 \\
\hline$\frac{0}{z}$ & 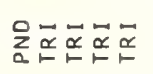 & 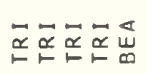 & 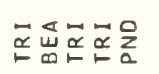 & 点 & 吴吕吕号号品 & 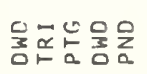 & 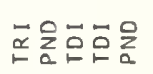 & 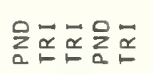 & 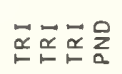 \\
\hline 岩 & & & & & $n \backsim n$ & $n n$ & $\tilde{\infty}$ & & \\
\hline 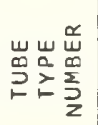 & 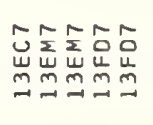 & 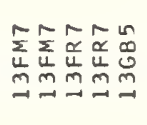 & 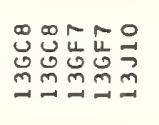 & $\stackrel{\circ}{\stackrel{2}{m}}$ & 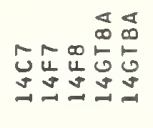 & 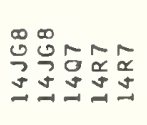 & 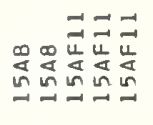 & 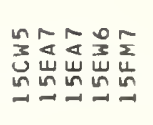 & 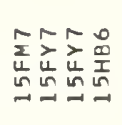 \\
\hline
\end{tabular}




\begin{tabular}{|c|c|c|c|c|c|c|c|c|c|}
\hline 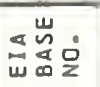 & 艺岂岂 & 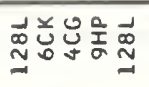 & 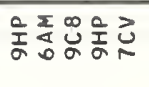 & 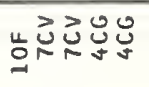 & 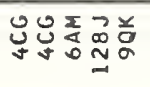 & 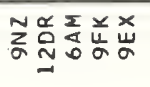 & 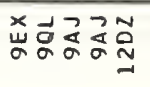 & 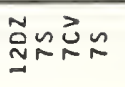 & 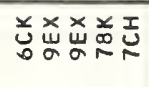 \\
\hline 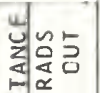 & $\begin{array}{l}00 \\
\dot{i}\end{array}$ & in & 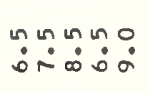 & 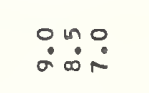 & ஸ் & 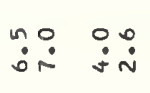 & $\dot{0}: \because \because \dot{0}$ & $\stackrel{0}{i} \dot{0}$ & $\begin{array}{lll}\circ & 0 \\
\end{array}$ \\
\hline 可总 & $\stackrel{0}{0}$ & 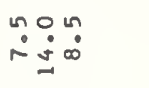 & $\stackrel{0}{\stackrel{n}{n}}$ & $\begin{array}{l}000 \\
\dot{n}=0\end{array}$ & $\begin{array}{l}000 \\
\ddot{\sim} \dot{0} \dot{0}\end{array}$ & $\because \quad \dot{0}$ & 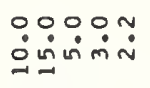 & $\stackrel{\circ}{=} \dot{m} \dot{n}$ & $\dot{\ddot{n}} \quad$ in \\
\hline ⿹气㐅ِ & $\stackrel{\substack{\infty \\
m}}{m}$ & 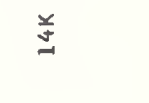 & 并 & 吕兑首 & 伵兑点 & 兯总总学 & 芯兑品品兑 & 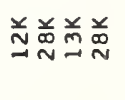 & 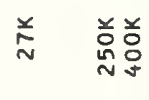 \\
\hline 战 & $\stackrel{\infty}{\sim}$ & & & & & $\begin{array}{l}\infty \\
0 \\
0\end{array}$ & EñN & & 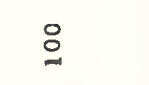 \\
\hline 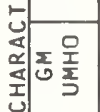 & $\begin{array}{l}\text { 웅 } \\
\text { 울 } \\
=\end{array}$ & : & 品 & 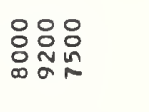 & 울:융 & 음 & 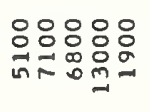 & 응: & 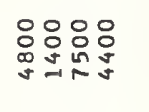 \\
\hline 或里 & $\stackrel{\infty}{+\infty}$ & 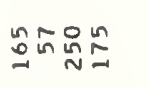 & 织员昌昌 & 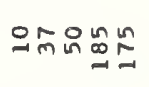 & 똥ำ & 웅욤ำ & pon & 군워 & $o_{0} \partial_{\infty}^{n} \underset{y}{n}=\sigma$ \\
\hline 覀> & 유N윳요 & 윴ñ & 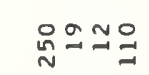 & 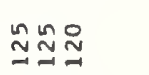 & 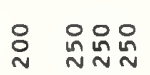 & 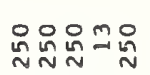 & 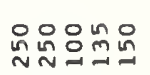 & 임윰유 & 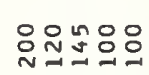 \\
\hline س & 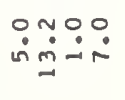 & 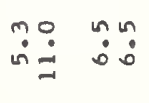 & 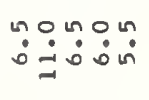 & in:O: & 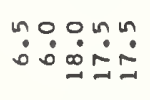 & 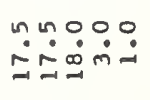 & & 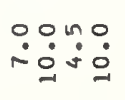 & 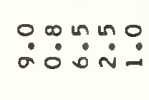 \\
\hline 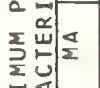 & $\stackrel{\circ}{\sim} \stackrel{n}{\sim}$ & 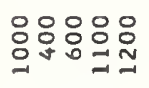 & 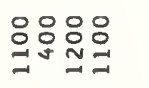 & ㅇ $\quad \stackrel{n}{\circ}$ & 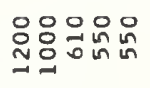 & 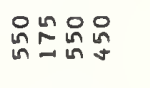 & $\stackrel{n}{\sim} \sim N$ 요 & 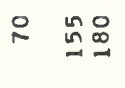 & $\frac{0}{m}$ in 0 \\
\hline > & 虽呆品品 & 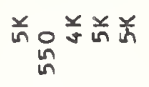 & 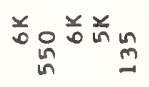 & 品品留 & 前웅유 & 웃유슈뮤 & 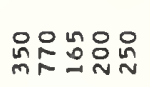 & 윳윰욤요 & 品品品品品 \\
\hline$\frac{1}{4} \bar{w} \frac{\pi}{2}$ & :윰윰 & 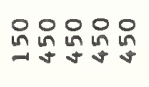 & 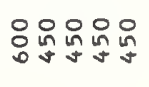 & 员员郘品品 & 品品品品是 & 品品㶽品品 & 品员品品品 & 员品品品 & 윰윰욤이 \\
\hline 2. & 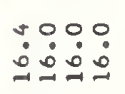 & 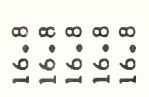 & 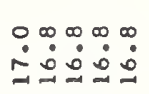 & 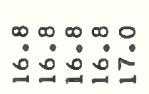 & 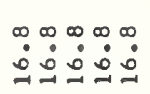 & 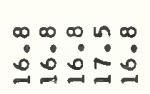 & م & فه & $\stackrel{0}{\bullet}: 000$ \\
\hline 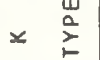 & IIII & IIIII & IIIII & IIIII & IIIII & IIIII & IIIII & IIII & IIIII \\
\hline$\underset{\ddot{\alpha}}{\stackrel{u}{\Psi}}$ & 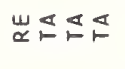 & Uు & 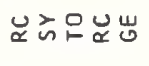 & 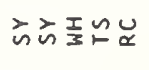 & I & 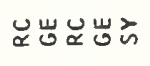 & 的芯方岕 & 岁旂五 & 岁品品方方 \\
\hline $\begin{array}{ll}山 \\
\infty\end{array}$ & 岁茄 & UY & 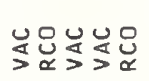 & 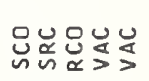 & 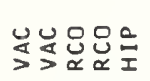 & 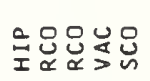 & 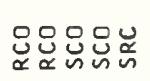 & 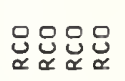 & 号怘 \\
\hline$\stackrel{u}{\check{\nu}}$ & 岧茂䛜 & 啥虽顿 & 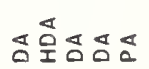 & 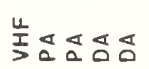 & 顿颚全全 & 这㩆咍 & 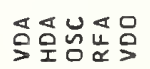 & 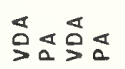 & 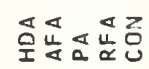 \\
\hline$D_{0}^{0}$ & 운요욤 & のゴの。 & ロロロロュ & คำณにロ & ๙ேミュニ & モさュュの & ロュュ゚ロ & ڤの』の & ロ゚ロにに \\
\hline 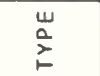 & 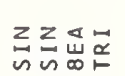 & 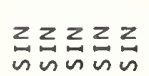 & 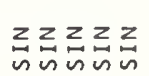 & 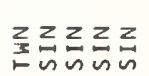 & 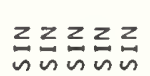 & zzżzo & 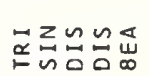 & 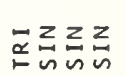 & 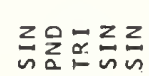 \\
\hline$\sum_{\substack{2 \\
\underline{x}}}$ & 음응문 & 음 & 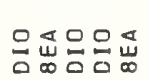 & 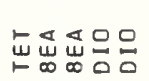 & 吕虽岕岕出 & 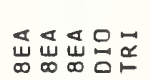 & 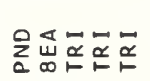 & 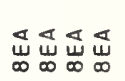 & 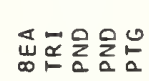 \\
\hline 岂 & & & & $\stackrel{\infty}{a} n n$ & & $\sim n$ & & $n n$ & $n$ \\
\hline 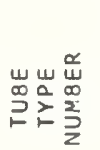 & $\begin{array}{l}n \\
0 \\
0 \\
0 \\
0 \\
0 \\
0\end{array}$ & 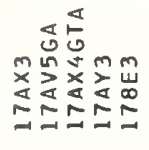 & 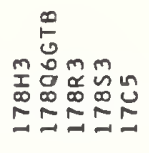 & 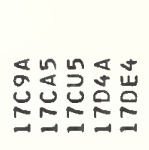 & 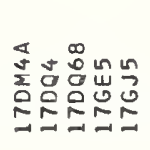 & 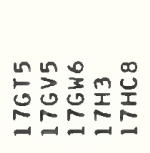 & 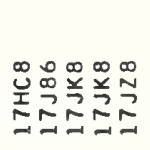 & 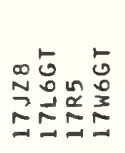 & 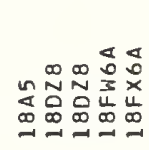 \\
\hline
\end{tabular}




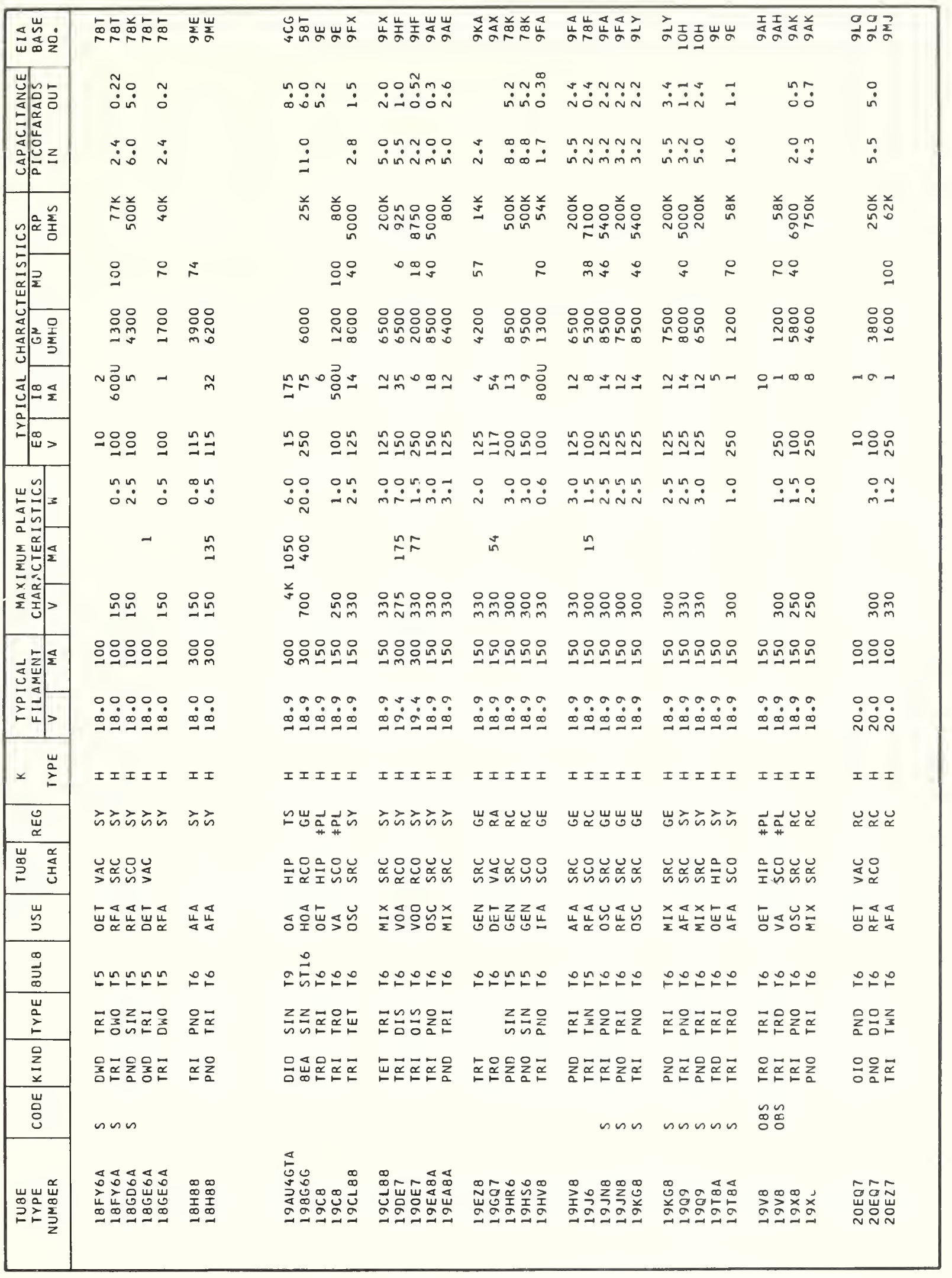




\begin{tabular}{|c|c|c|c|c|c|c|c|c|c|}
\hline 崫崖 & 酟总总 & 솜워 & 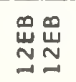 & 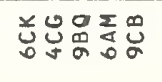 & 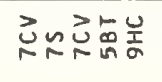 & 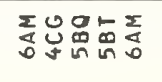 & 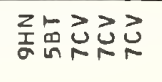 & 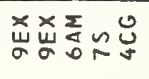 & $\approx q$ \\
\hline 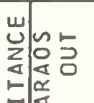 & $\begin{array}{l}n \circ \\
\infty \\
\infty\end{array}$ & $\stackrel{n}{:}$ & & 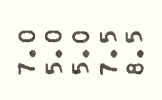 & $\overrightarrow{0} \quad \ddot{\sigma} \ddot{\infty} \dot{0}$ & 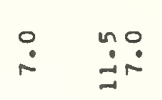 & $\begin{array}{l}\because 0 \\
\dot{\sigma} 00\end{array}$ & $\dot{0}$ & $\stackrel{0}{\circ}$ \\
\hline $\begin{array}{l}0 \\
0 \\
0\end{array}$ & $\begin{array}{l}00 \\
\dot{N} \sim\end{array}$ & & & $\begin{array}{l}0 \\
\dot{m}\end{array}$ & $\begin{array}{l}00 \sigma \\
\dot{\sim} \\
\dot{\sim}\end{array}$ & 요 & $\begin{array}{l}n: 000 \\
\dot{\sim} \\
\sim\end{array}$ & & $\stackrel{0}{\dot{n}}$ \\
\hline$v=\frac{n}{\alpha} \frac{n}{\Sigma}$ & 总。 & & 兑 & 品 응어 & 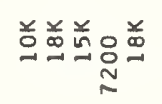 & 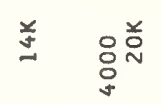 & 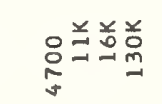 & 兰。 & 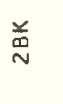 \\
\hline 䒺 & & & & & & & & $\stackrel{9}{9}$ & \\
\hline \begin{tabular}{l|l} 
\\
0
\end{tabular} & 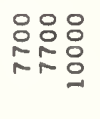 & & $\begin{array}{l}0 \\
0 \\
0\end{array}$ & $\begin{array}{l}\circ \\
\text { 요요 } \\
0 \\
\text { n } \\
\text { ñ }\end{array}$ & 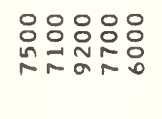 & $\begin{array}{ll}\circ & \circ \\
\text { in } & \circ \\
\text { in }\end{array}$ & 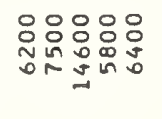 & 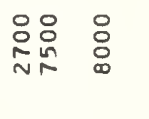 & : \\
\hline 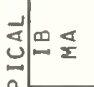 & โ요 & $\stackrel{n}{=}$ & $\stackrel{n}{\sim}$ & 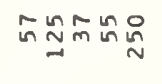 & 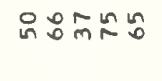 & ถ์ & 署워ำ & $m: \exists \stackrel{\Xi}{\simeq}$ & F⿻ \\
\hline w > & 들욤ำ & & $\stackrel{\circ}{N}$ & 品 Nี怘怘 & 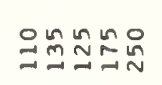 & 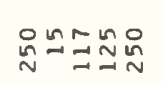 & 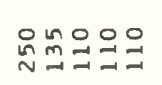 & $\stackrel{n}{N} \stackrel{n}{\sim}:$ & $\stackrel{\circ}{\circ=}$ \\
\hline 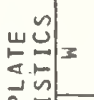 & $\begin{array}{l}000 \\
\dot{\sim} \underset{\sim}{\infty} \stackrel{\dot{s}}{N}\end{array}$ & $\stackrel{n}{0}:$ & 品吕 & 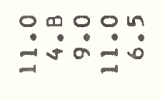 & 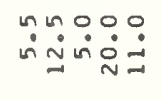 & 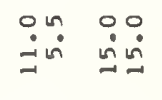 & 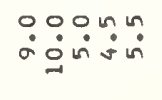 & 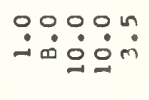 & $\stackrel{\circ}{\circ}$ \\
\hline 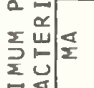 & 욜요 N & 을 & 胥足 & 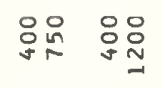 & 员号 & 암응영워 & 움윰 & $\stackrel{0}{\circ}$ & 总品 \\
\hline 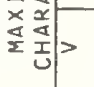 & 웃유 & 并并 & $\stackrel{x}{\frac{\pi}{\pi}}$ & 品学怘怘弟 & 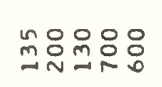 & 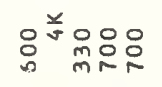 & 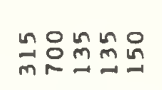 & 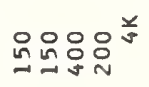 & 음웅 \\
\hline বي & 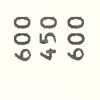 & 品品 & :웅 & : & 있임임 & 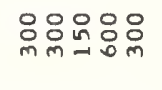 & 을욤요 & 임임임 & 잉요 \\
\hline 造牙> & $n 0 n$ & $\dot{\sim} \dot{\tilde{N}}$ & 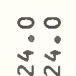 & :000웅 & ஜீட0:0 & :0000 & 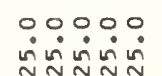 & :0000 & :웅 \\
\hline $\begin{array}{r}a \\
\times \\
\vdots\end{array}$ & III & $I I$ & II & エエエエエ & Iエエエエ & エエエエエ & IIエエエ & Iエエエエ & II \\
\hline$\underset{\sim}{\stackrel{u}{\Psi}}$ & 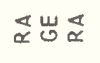 & $\ddot{u}$ & $\overleftrightarrow{\propto} \ddot{\propto}$ & 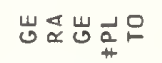 & ๔え岕岕甹 & えう岕えう & え岕议え゙せ & 主主出主出 & 嵌至 \\
\hline 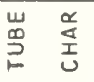 & 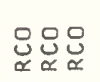 & 希 & $\underset{\square}{\longrightarrow}$ & 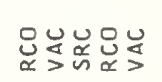 & 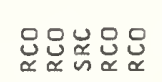 & 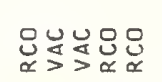 & 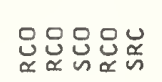 & 怘 & $\underset{\alpha}{\stackrel{S}{x}}$ \\
\hline 岁 & 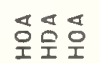 & 占 & ठّ̊a & 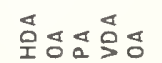 & 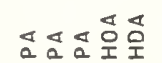 & 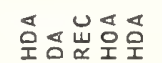 & 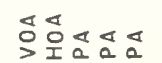 & 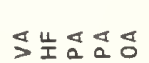 & 㟒 \\
\hline 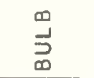 & 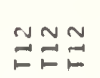 & g. & $\underset{7}{\simeq}$ & ジロレロ & ヒュュュュ゚ & きのッミュ & ๒ュュロロ & ゚ํに。 & F。 \\
\hline$\frac{\omega}{a}$ & 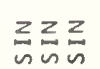 & $z_{n} \frac{2}{n}$ & 음응 & 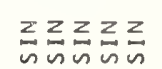 & 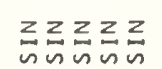 & 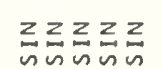 & 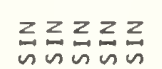 & 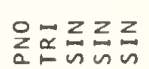 & $\begin{array}{l}z \geq z \\
n \\
n\end{array}$ \\
\hline$\stackrel{0}{2}$ & 岕出出 & 응응 & 음응 & 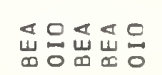 & 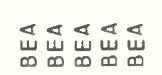 & 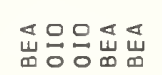 & 㟧出唋出出 & 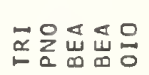 & 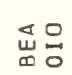 \\
\hline 岁 & 哭 & & & & 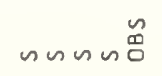 & $n \tilde{\tilde{\theta}}$ & $\tilde{\Delta}_{\tilde{\Delta}}$ & $n n$ & nn \\
\hline 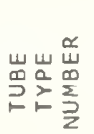 & 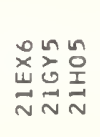 & 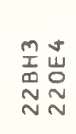 & 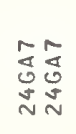 & 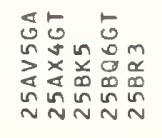 & 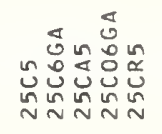 & 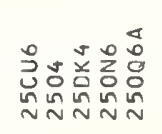 & 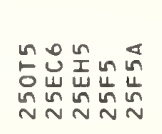 & 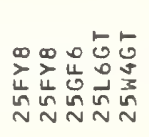 & 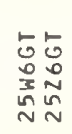 \\
\hline
\end{tabular}




\begin{tabular}{|c|c|c|c|c|c|c|c|c|c|}
\hline 崖岕岕 & 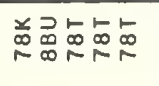 & 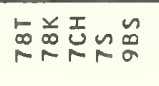 & $\frac{\frac{1}{2}}{\alpha}$ & 怘焉出 & 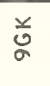 & 忒导怘 & 己ِّ & i & 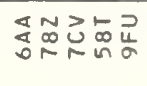 \\
\hline 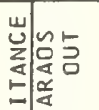 & 品 & ப웜 & & & $\dot{i}$ & OัN & $\dot{0}$ & $\ddot{0}$ & 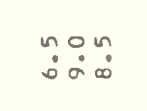 \\
\hline \begin{tabular}{l|l}
0 \\
0 \\
0
\end{tabular} & 00 & $\begin{array}{l}\infty 0 \infty \\
\dot{\sim} \dot{0}: \dot{ }\end{array}$ & & & $\stackrel{0}{0}$ & $\stackrel{0}{\dot{\infty}} \quad \dot{m}$ & $\stackrel{\dot{\sim}}{\stackrel{2}{ }}$ & $\dot{\dot{\Xi}}$ & $\because \because \ddot{\sim}$ \\
\hline 乌. & $\sum \quad \underset{0}{J}$ & 嗢 & & 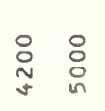 & 总 & 品 & $\stackrel{\check{N}}{\sim}$ & & 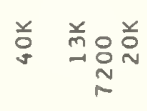 \\
\hline 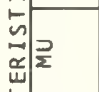 & 음 & $\stackrel{0}{-}$ & & & & $:$ & & & \\
\hline 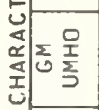 & $\begin{array}{l}\text { 요 } \\
\text { O유 } \\
\text { ㄴ }\end{array}$ & 요유 & & $\begin{array}{l}8 \\
\text { ¿ } \\
\text { m }\end{array}$ & $\stackrel{\circ}{\stackrel{一}{m}}$ & : & : : & $\begin{array}{l}\text { : } \\
\text { in }\end{array}$ & 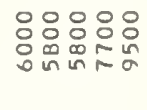 \\
\hline$\infty \frac{\pi}{2}$ & 유- & am:음 & ơ & 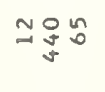 & 里 & $\stackrel{\text { N }}{\sim}$ & $\circ \stackrel{m}{\sim}$ & $\stackrel{n}{m}$ & すゴん゙゚ \\
\hline 齐 & $\stackrel{\circ}{N} \stackrel{\circ}{N}$ & 品怘怘怘 & $\cong$ & $\stackrel{\infty}{\sim} \stackrel{n}{\sim} \underset{\sim}{m}$ & $\stackrel{\circ}{\sim}$ & $\stackrel{\sim}{N} \stackrel{n}{\beth}$ & $\stackrel{\circ}{\approx}$ & $\stackrel{\circ}{\Xi}$ & 유르으모 \\
\hline 崖氙氙 & $\begin{array}{l}0 \dot{n} \\
\dot{m}\end{array}$ & $\ddot{\sim} \dot{0} \dot{\sim} \dot{\sim}$ & $\stackrel{\circ}{\circ}$ & :̊: & $\ddot{n}$ & $\dot{i} \quad \dot{i}$ & 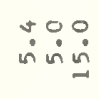 & $\dot{\circ}$ & 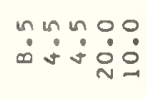 \\
\hline 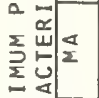 & & $\pm:$ & $\stackrel{n}{\sim}$ & $\stackrel{n}{\sim} \underset{\sim}{\infty}$ & & ${ }_{n=\infty}^{\infty}$ & 운 & & 욱 \\
\hline 这部 & 怘品 : & 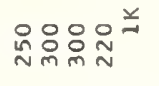 & $\stackrel{n}{\sim}$ & 品资足 & 卞 & 品 & 움융 & $\stackrel{\circ}{\stackrel{0}{n}}$ & 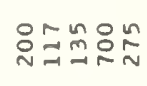 \\
\hline 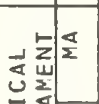 & 윰암웃 & 웃아융유 & : & : & $\stackrel{\circ}{2}$ & 울욤묘 & 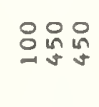 & 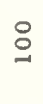 & 品品品品品 \\
\hline 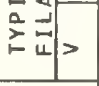 & 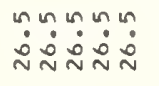 & 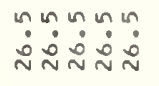 & $\dot{\dot{n}}$ & 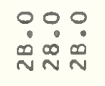 & $\stackrel{0}{\infty}$ & :O० & $\begin{array}{l}\text { OO० } \\
\dot{N} \tilde{\sim} \dot{\sim}\end{array}$ & $\begin{array}{l}\text { : } \\
\dot{m}\end{array}$ & 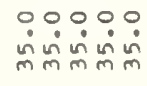 \\
\hline$\times \sum_{i}^{\frac{\omega}{a}}$ & エエエエエ & IIIII & $I$ & エエエ & $I$ & III & エエエ & $I$ & エエエエエ \\
\hline $\begin{array}{l}\stackrel{0}{\Psi} \\
\propto\end{array}$ & 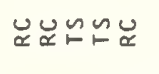 & 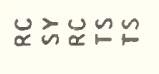 & $\sum$ & 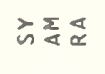 & $\overleftrightarrow{\alpha}$ & 山山 & $\dot{n} \propto ⿻ \mathbb{\alpha}$ & $\ddot{q}$ & 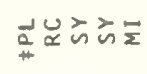 \\
\hline 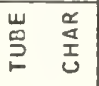 & 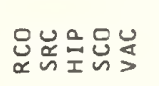 & 总怘 & $\ddot{n}$ & 号岕导 & $\underset{\mathscr{W}}{n}$ & 岸岁吕 & 炭岁品 & $\underset{\ddot{g}}{\sim}$ & 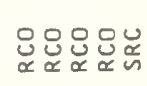 \\
\hline$\stackrel{m}{\leftrightharpoons}$ & 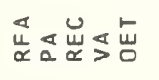 & 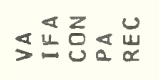 & 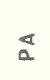 & 迁造呈 & $\frac{4}{4}$ & 嵌饪堊 & 造台台 & $a$ & 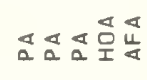 \\
\hline$\stackrel{\infty}{\mathcal{D}_{0}^{\prime}}$ & ヘロロロロ & ๓ュッゴ & $\approx$ & よ๐き & $\stackrel{2}{\leftarrow}$ & 먕 & ๓ミュ & $\stackrel{n}{\leftarrow}$ & のேッシ゚ \\
\hline $\begin{array}{l}u \\
a \\
2 \\
2\end{array}$ & 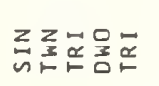 & 虽录录的录 & $\frac{z}{n}$ & 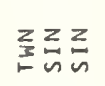 & $\frac{z}{n}$ & 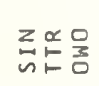 & 촌응응 & $\frac{z}{n}$ & 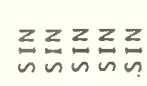 \\
\hline$\frac{0}{z}$ & 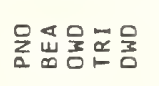 & 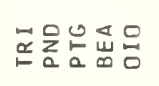 & $\underset{\infty}{\stackrel{凶}{\infty}}$ & 峞岕岕 & 哀 & 음움욤 & 选믐음 & $\underset{\infty}{\stackrel{4}{\infty}}$ & 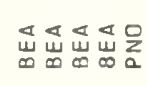 \\
\hline 㟔 & జ̊n & $n \stackrel{\infty}{\infty} \dot{\infty}+$ & & + & & & $n$ & $n$ & $n n$ \\
\hline 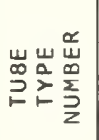 & 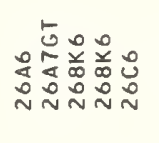 & 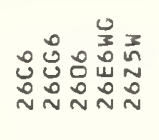 & 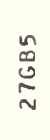 & 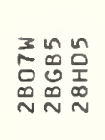 & $\begin{array}{l}0 \\
\text { ㅇ } \\
\text { N }\end{array}$ & 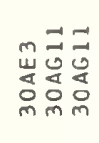 & 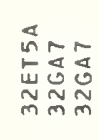 & 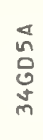 & 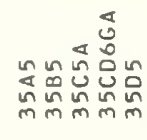 \\
\hline
\end{tabular}




\begin{tabular}{|c|c|c|c|c|c|c|c|c|c|}
\hline 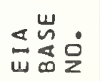 & 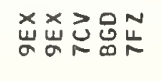 & 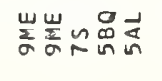 & $\because \frac{9}{0}$ & 若 & 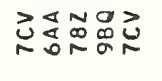 & 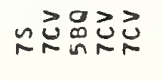 & 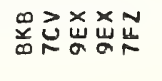 & 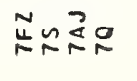 & $\underset{\underset{I}{Z} \underset{I}{Z}}{z}$ \\
\hline 矛聯占 & 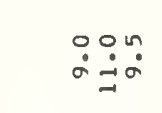 & & & & 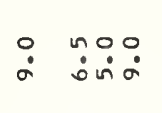 & $\begin{array}{l}0 \\
\dot{0} \\
\dot{\sigma}\end{array}$ & $\begin{array}{ll}0 & 0 \\
\sigma & 0\end{array}$ & $\dot{0}$ & $\because:$ \\
\hline 可造 & $\begin{array}{l}\because: 0 \\
\check{\sim} \stackrel{0}{=}\end{array}$ & & & & 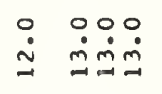 & $\stackrel{\circ}{\check{I}} \stackrel{\dot{\Xi}}{=}$ & 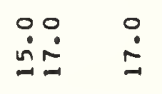 & $\stackrel{\circ}{\dot{ \pm}}$ & $\dot{n} \cong$ \\
\hline$s$ & 弟怘 & 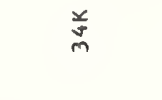 & & & 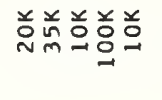 & 㒸总 壬弟 & 品弟关 & 吕 & 흥무 \\
\hline$\stackrel{a}{a}$ & 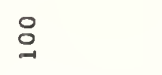 & 2 & & & & & \& & & 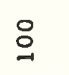 \\
\hline 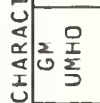 & 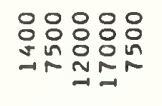 & 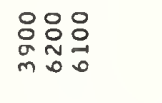 & & & 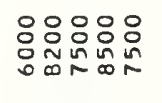 & 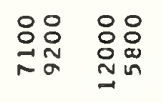 & 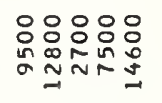 & 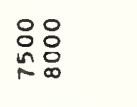 & 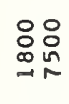 \\
\hline 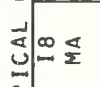 & $D_{\infty} \underset{y}{ } \tilde{m}$ & 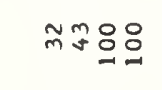 & 욤 & $\stackrel{n}{\sim}$ & 的织踏品 & 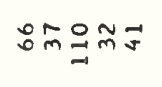 & $\stackrel{\infty}{\infty} \tilde{m}: \tilde{\sigma}$ & ถ゚ก์ล & 응 \\
\hline$\stackrel{\infty}{2}>$ & 옳 & 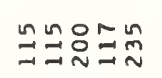 & $\stackrel{n}{\sim} \stackrel{n}{N}$ & $\stackrel{i}{\sim}$ & 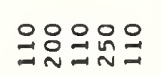 & 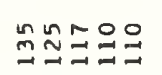 & 을요포 & 을ニ & $\stackrel{2}{I}$ \\
\hline س气 & 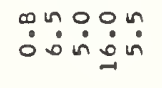 & $\ddot{0} \dot{0}: \dot{n}$ & & & 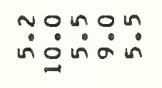 & 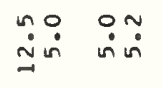 & $\begin{array}{l}n 000 \\
\dot{y} \\
\dot{y}\end{array}$ & $\ddot{n} \dot{0}$ & $\ddot{\circ}:$ \\
\hline 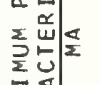 & no: & $\stackrel{n}{m}: 00$ & 융 & 品 & & $\stackrel{i}{i}$ & & 总品 & n \\
\hline 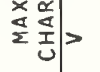 & 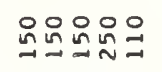 & 윰윰윰용 & 윰 & $\stackrel{n}{m}$ & 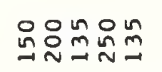 & 임임욤요 & 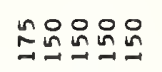 & 윰융ㅇㅇㅇㅛ & 品品 \\
\hline 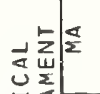 & 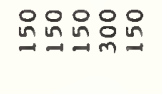 & 品品品品品 & 品品 & 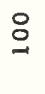 & 음욤욤욤 & 음욤욤요 & 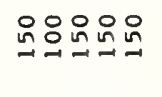 & 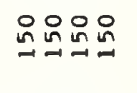 & 品只 \\
\hline 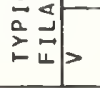 & O̊:00: & 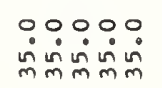 & 品 & $\stackrel{\circ}{\dot{m}}$ & 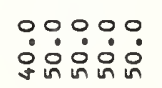 & 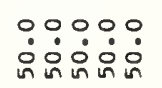 & 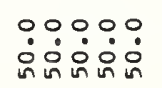 & 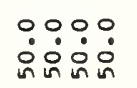 & $\begin{array}{l}0: 0 \\
\dot{\sim} \\
\dot{\sim}\end{array}$ \\
\hline$\times \frac{\vec{a}}{2}$ & IIIII & IIIII & $I I$ & I & IIエエエ & IIIII & IIIII & IIII & $I I$ \\
\hline$\underset{\sim}{\stackrel{\sim}{\Psi}}$ & 只品び & らうらららう & 方录 & $\ddot{\propto}$ & ええ゙ぴ゙ & 文志岕ええ & 我岕至主茾 & 岁岂え゙す & 岕 \\
\hline 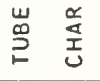 & 号 & Uي⿱口口) & 岸莛 & $\stackrel{y}{>}$ & 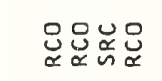 & 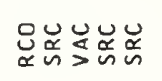 & 䓵 & 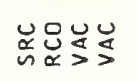 & 总号 \\
\hline 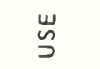 & 造造造全品 & 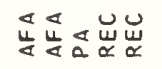 & $\underset{\sim}{u} \underset{\sim}{u}$ & $\underset{\sim}{\breve{w}}$ & 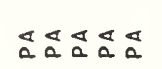 & 造岕岕品 & 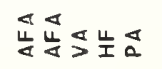 & a $a \underset{a}{u} \underset{\alpha}{u}$ & $\$ a$ \\
\hline$\stackrel{\infty}{0}_{\infty}^{\infty}$ & レ゚ロミュ & レレのにロ & 天吕 & $\bumpeq$ & レロのレロロ & 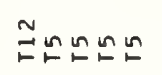 & ロேレ゚ロ & レロのの & 口 \\
\hline$\sum_{\substack{a \\
\check{2}}}$ & 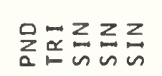 & 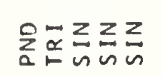 & $\frac{z}{n} \frac{z}{n}$ & $\frac{z}{n}$ & 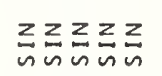 & 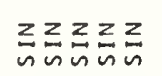 & 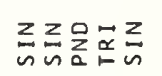 & 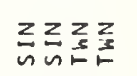 & 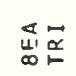 \\
\hline$\underset{\underline{x}}{\underline{2}}$ & 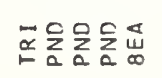 & 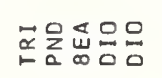 & 음음 & 뭉 & 虽岕岕岕岕 & 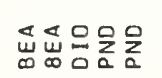 & 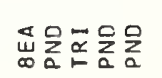 & 峞出ㅁㅁㅁ음 & 㑒岕 \\
\hline 过 & & $\sim$ & & $n$ & & & & & \\
\hline 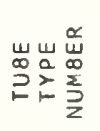 & 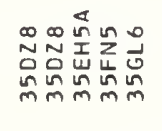 & 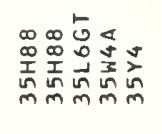 & 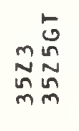 & 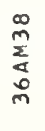 & 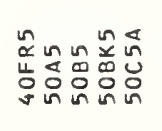 & 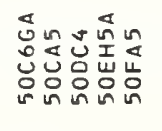 & 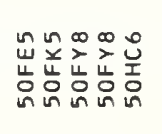 & 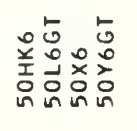 & 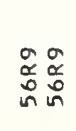 \\
\hline
\end{tabular}




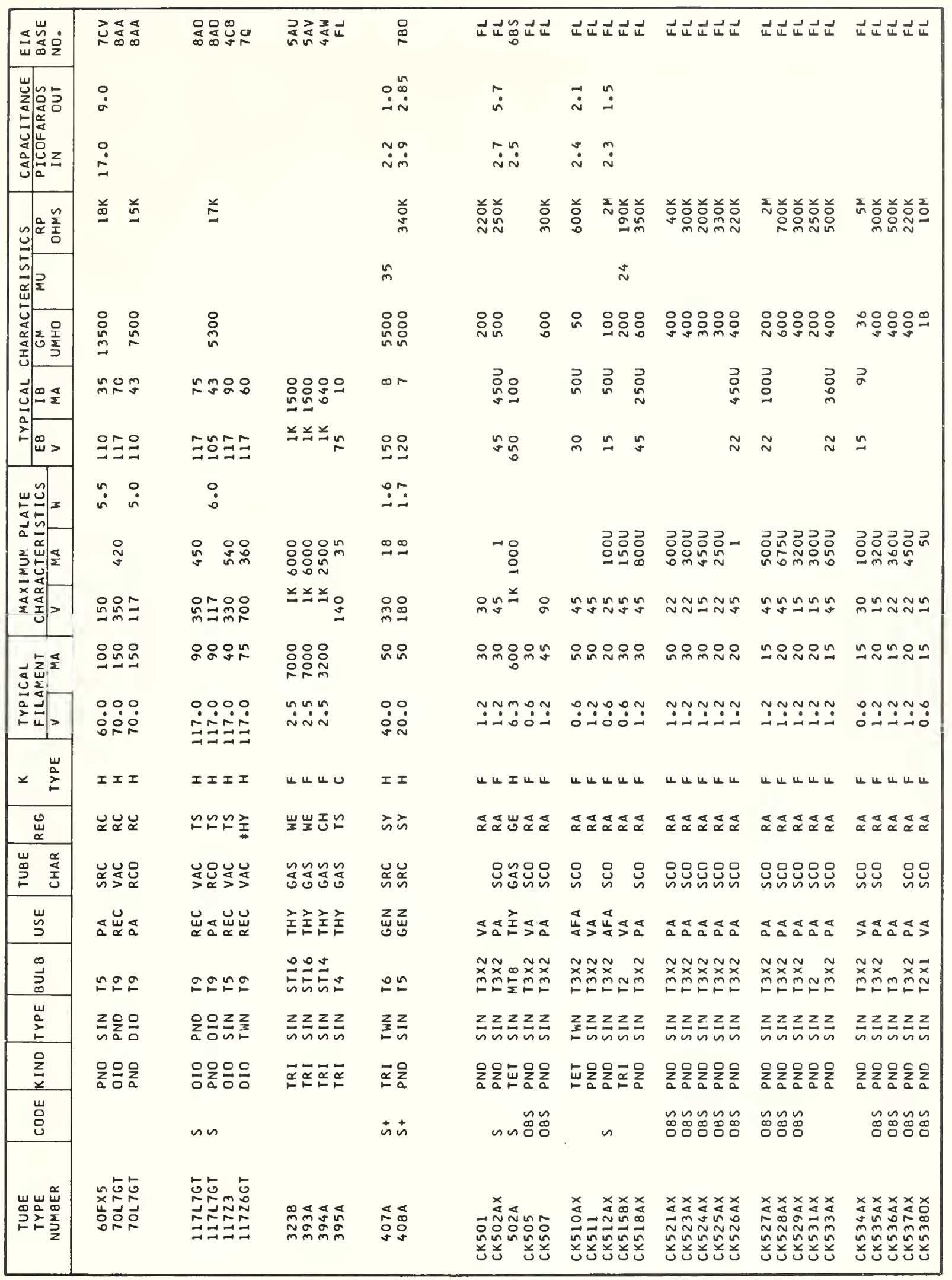




\begin{tabular}{|c|c|c|c|c|c|c|c|c|c|}
\hline 造崖号 & $\vec{u} \vec{u} \vec{u} \vec{u} \vec{u}$ & $\vec{u} \vec{u} \vec{u} \vec{u} \vec{u}$ & $\vec{u} \vec{u} \vec{u} \vec{u} \vec{u}$ & & $\sum_{0}^{5}$ & 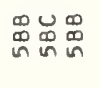 & 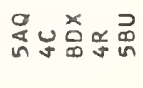 & $\vec{u} \vec{u} \vec{u} \vec{u}$ & $\vec{u} \vec{u}$ \\
\hline 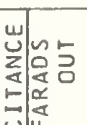 & & & & & $\stackrel{0}{\circ}$ & $\dot{m} \dot{m}$ & & & $\stackrel{m}{-}$ \\
\hline 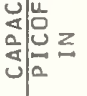 & & & & & $\stackrel{\circ}{:}$ & $\dot{m} \dot{m}$ & & & 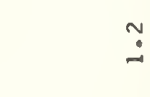 \\
\hline كِ & 兑㤩总 三 & 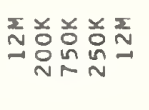 & 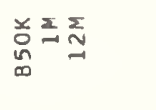 & & & 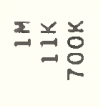 & & & \\
\hline 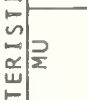 & & & & & & $\stackrel{n}{\sim}$ & & & \\
\hline \begin{tabular}{l|l}
0 \\
\cline { 1 - 1 }
\end{tabular} & 암욤요 & 品: & 유 용유 & & 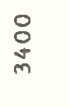 & 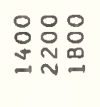 & & & \\
\hline 至 & & 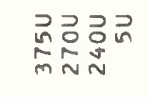 & $\stackrel{\vec{N}}{=}$ & $\begin{array}{l}\text { Oे } \\
\text { O } \\
\text { n }\end{array}$ & 웃 & NOR & m & 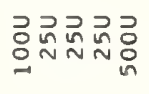 & ำ N N \\
\hline$m>$ & & N윰N & $\approx$ & in & 品品 & 유ㅇㅠㅛ & N & 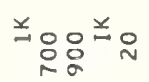 & 兰兰 $n \cong$ \\
\hline 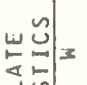 & & & & & $\stackrel{\circ}{\stackrel{0}{\simeq}}$ & $\because \because:$ & & & \\
\hline 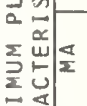 & 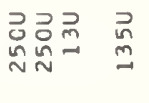 & जे & 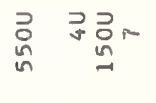 & s & 울 & & 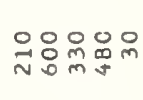 & 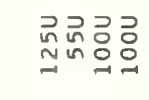 & 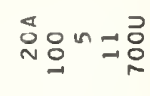 \\
\hline > & NONN표 & $\cong n$ & $\stackrel{n}{*} \approx 000$ & $\stackrel{.}{\sim}$ & 울 & $\begin{array}{l}\text { 品品品 } \\
\text { NN }\end{array}$ & 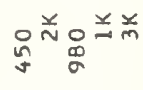 & 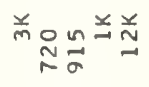 & 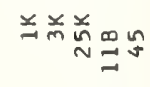 \\
\hline 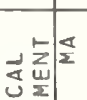 & $\simeq \backsim \backsim \simeq 0$ & $\infty$ 응ㅇㅇㅇㅇ & 윰ำ & : & :: & 品品品 & 욤요 & 요 & 品 \\
\hline $\begin{array}{ll}2 & 4 \\
2 & 4\end{array}$ & 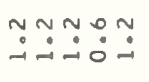 & ن & $\because: \because \cong:$ & $\cong$ & $\dot{0}$ & $\ddot{0}: \dot{m}$ & $\dddot{m}$ & $\stackrel{n}{\check{I}}$ & 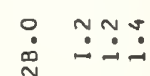 \\
\hline$x \stackrel{u}{a}$ & レルиルи & レルนルน & ичиน & $u$ & $I I$ & III & แи & מטنט & エงиии \\
\hline$\underset{\alpha}{\stackrel{u}{\alpha}}$ & 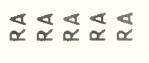 & 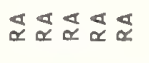 & 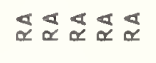 & 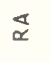 & ư & $\underset{\propto}{u} \underset{\propto}{u}$ & 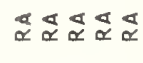 & 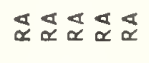 & 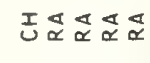 \\
\hline 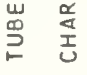 & 号 总号 & 号导导导导 & 号导导怘怘 & $\stackrel{y}{>}$ & 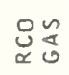 & 곯요 & 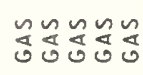 & 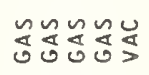 & 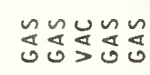 \\
\hline$\stackrel{u}{s}$ & 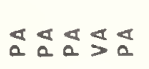 & 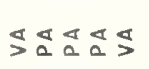 & 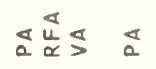 & $\underset{\alpha}{\breve{u}}$ & 造充 & 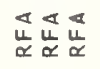 & 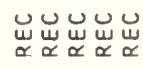 & 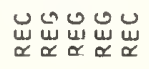 & 主出出品呈主 \\
\hline$\sum_{\infty}^{\infty}$ & $\begin{array}{l}\vec{X} \vec{X} \vec{X} \vec{X} \\
\underset{N}{N} \underset{N}{N} \underset{\sim}{N}\end{array}$ & 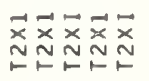 & 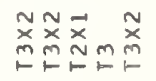 & $m$ & 是告 & 웡웡 & 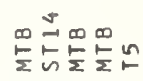 & MEMEM & ヒロッュル \\
\hline$\underset{⿱ 亠 䒑}{2}$ & 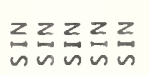 & 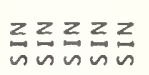 & 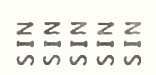 & $\frac{z}{n}$ & $\begin{array}{l}z z \\
n \sim n\end{array}$ & 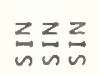 & 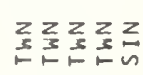 & 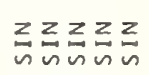 & 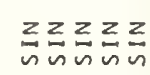 \\
\hline$\stackrel{0}{\underline{x}}$ & 呈员员员虽 & 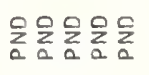 & 吴吴吴吕虽 & $\stackrel{0}{0}$ & 吴宫 & 궁훔음 & 음음음음음 & 응응음음음 & 余吅品 $\vec{\alpha}$ \\
\hline 岑 & 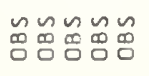 & $\begin{array}{lll}n & n \\
0 & \infty & 0 \\
0 & 0 \\
0\end{array}$ & 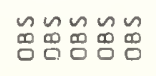 & $\tilde{\infty}$ & $\tilde{\infty}$ & ص̃ & 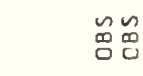 & 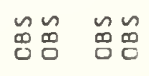 & $\widetilde{c} \tilde{a} \tilde{\Delta}$ \\
\hline 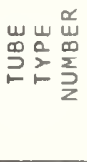 & 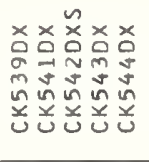 & 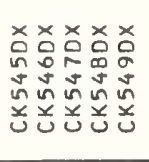 & 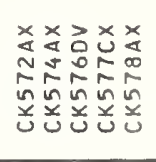 & $\begin{array}{l}\frac{a}{2} \\
\text { s. } \\
\vdots \\
u\end{array}$ & 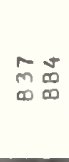 & 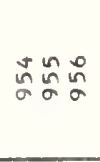 & 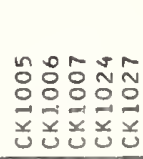 & 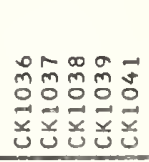 & 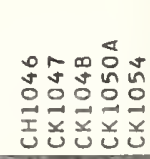 \\
\hline
\end{tabular}




\begin{tabular}{|c|c|c|c|c|c|c|c|c|c|}
\hline 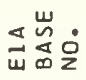 & $\vec{u} \vec{u} \vec{u}$ & 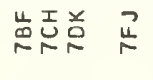 & a s & $\tilde{0}$ & J & 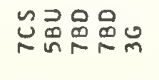 & 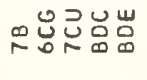 & 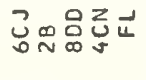 & 品邑出岂忌 \\
\hline 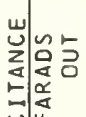 & & $\because \because ّ$ & $\stackrel{\dot{0}}{\stackrel{ \pm}{ }}$ & & $\dddot{\infty}$ & 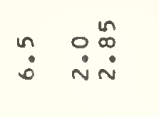 & 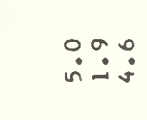 & $\ddot{\circ}:$ & $\stackrel{n}{\infty} \stackrel{n}{\sim} \stackrel{0}{-}$ \\
\hline 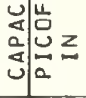 & & vinn & $\stackrel{\circ}{\dot{r}}$ & & $\stackrel{\circ}{=}$ & $\stackrel{\sim}{\infty} \ddot{m}:$ & 웅 & $\stackrel{0}{-}$ & $\ddot{j} \dot{m} \stackrel{\dot{N}}{N}$ \\
\hline 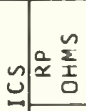 & $\stackrel{\circ}{\circ}$ & 品 & 2 & & & 兑兑 & 弟品 兰兑 & & 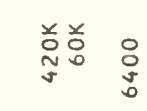 \\
\hline 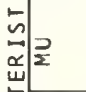 & & $\approx$ in & & & & & $\approx \pm$ & & $\stackrel{n}{m}$ \\
\hline 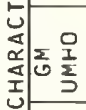 & & 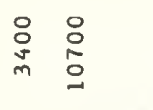 & $\stackrel{\circ}{\cong}$ & & : & : 음 & 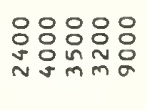 & & 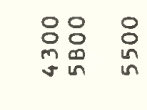 \\
\hline 势 & $\stackrel{D^{n} N}{\sim}$ & n๐® & $\stackrel{p}{\beth}^{N}$ & in욤 & $\stackrel{\circ}{\circ}$ & 东 & $\stackrel{\sim}{\sim} \mathscr{\infty}^{n} \vec{N}$ & 经总ニュa & $\sim N 2 O^{\infty}$ \\
\hline 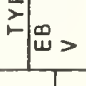 & 용요 & 음윰융요 & $\stackrel{n}{\sim} \stackrel{0}{\sim}$ & :용 & $\stackrel{\circ}{\sim}$ & 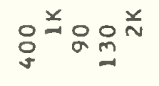 & 있용요 & 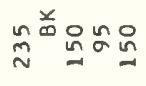 & 经品员二识 \\
\hline 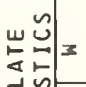 & & 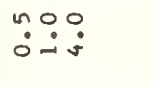 & & & $\stackrel{\dot{n}}{\sim}$ & 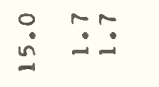 & 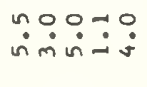 & & $\stackrel{\circ}{\dot{i}} \stackrel{\circ}{\dot{m}}$ \\
\hline 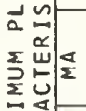 & $\partial_{m} \infty \sim N$ & - 윰ำ & : & 옹 & $\stackrel{\circ}{\sim}$ & 요용 & 앙 웅 & 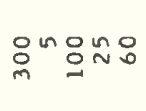 & ง ㅇN요 \\
\hline 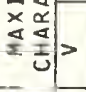 & 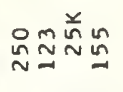 & 노욤욤요 & 总 & $\underline{u}$ & 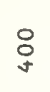 & 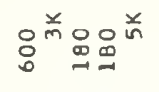 & 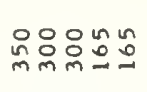 & 음윰욤워 & 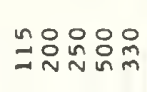 \\
\hline 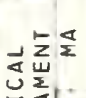 & : & 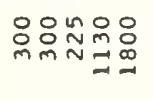 & : & 융요 & in & 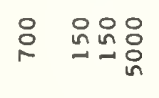 & 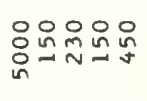 & 品䍚品 品 & 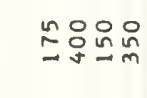 \\
\hline 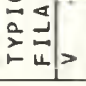 & $\dddot{\sim}$ & 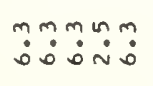 & $\ddot{\sim}:$ & $\stackrel{m}{m}:$ & $\ddot{0}$ & $\dot{0} \dot{0} \dot{0} \dot{0} \dot{n}$ & 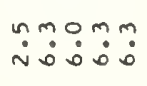 & 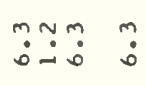 & $\ddot{0}: \ddot{0}: \dot{0}$ \\
\hline$\times \quad \frac{w}{2}$ & טיטי & IエエUI & $4 I$ & $I I$ & I & uUIIu & IIIII & $I \backsim I U I$ & UIIII \\
\hline$\underset{\sim}{\mathbb{\Psi}}$ & 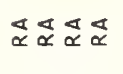 & えええええうさ & $\ddot{\varkappa}$ & II & $\ddot{\propto}$ & 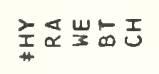 & 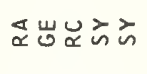 & ええらうえらう & 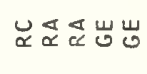 \\
\hline 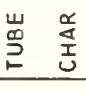 & 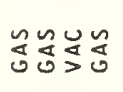 & 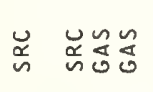 & 这怘 & 踏 & $\underset{\propto}{\mathscr{Y}}$ & 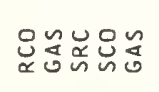 & 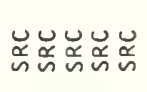 & 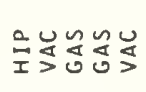 & 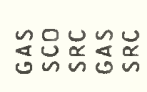 \\
\hline$\stackrel{w}{s}$ & 㐓怘岕出 & 范艺洁出主 & $\underset{\propto}{\stackrel{u}{>}}$ & 主主 & $a$ & 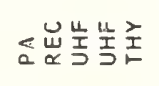 & 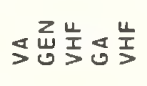 & 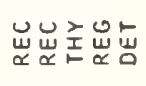 & 岀崖峷主忌 \\
\hline$\stackrel{\infty}{\infty}_{\infty}^{\infty}$ & คNㅗ & ヘュルロロ゚ & 央里 & 은 & $\cong$ & コュッロロ゚ & 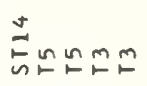 & MேロロF & ピュ゚ュ゚ \\
\hline$\frac{w}{a}$ & 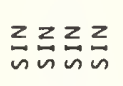 & 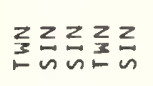 & $z_{n} z$ & 沗交 & $\frac{z}{n}$ & 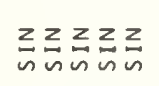 & 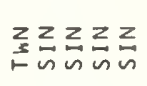 & 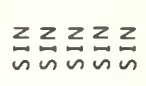 & 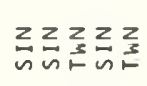 \\
\hline$\underset{z}{2}$ & 음뜸음음 & 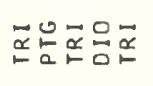 & 음음 & 宫出 & 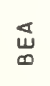 & 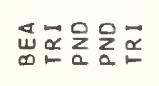 & 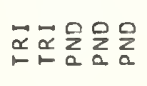 & 음움움웅 & 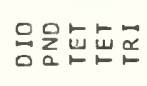 \\
\hline 㟔 & 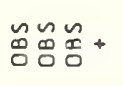 & nn $\stackrel{\sim}{0 . *}$ & $\stackrel{\sim}{a} \pm$ & $\tilde{\Delta}+$ & & 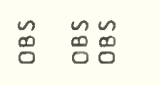 & 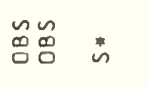 & 专 & $n$ \\
\hline 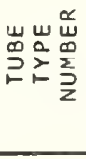 & 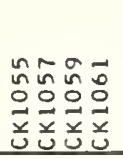 & 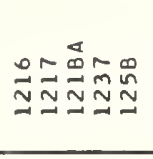 & 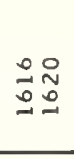 & 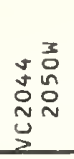 & $\begin{array}{l}2 \\
\text { o } \\
0 \\
0\end{array}$ & 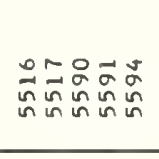 & $\begin{array}{l}\infty \\
0 \\
0\end{array}$ & 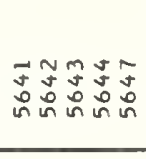 & 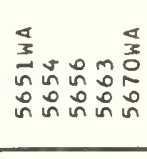 \\
\hline
\end{tabular}




\begin{tabular}{|c|c|c|c|c|c|c|c|c|c|}
\hline 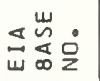 & $\vec{u} \vec{u}$ पे & 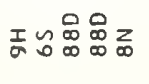 & $\underset{i}{\infty}$ & 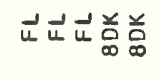 & 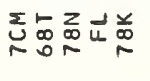 & 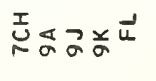 & $\vec{\psi} \vec{u} \vec{u}$ & 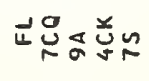 & 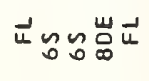 \\
\hline 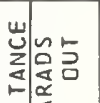 & $\ddot{m} \dot{m} \dot{m} \dot{m} \dot{s}$ & 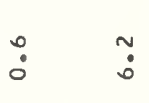 & & 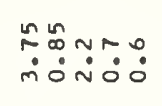 & $\dot{m} \dot{m} \dot{\sim} \dot{m}$ & ن̊: & & :̊n & $\dot{\sim} \quad \dot{\square}$ \\
\hline ي & $\dot{\sim} \ddot{\dot{i}} \ddot{\sim} \dot{0}$ & : & & $\begin{array}{l}n \\
\dot{n}\end{array}$ & $\dot{m} \dot{\sim} \dot{\sim} \dot{\sim}$ & $\ddot{n}$ & & $\stackrel{\circ}{\circ}$ & $\dot{q}$ \\
\hline 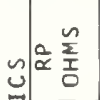 & 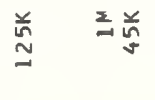 & 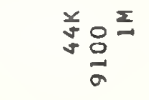 & & 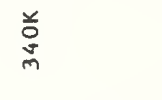 & & 㒸兑 & & 兽号 & $\begin{array}{l}\text { D } \\
\text { D } \\
\text { N }\end{array}$ \\
\hline 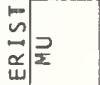 & $\stackrel{1}{=0}$ & $\stackrel{\circ}{\circ}$ & & $\stackrel{N}{\sim} R$ & & 움요 & & $\simeq$ & \\
\hline 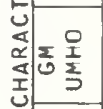 & 웅임임이 & 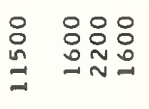 & & 品品总品 & 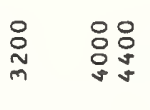 & 욹윰윰 & : & 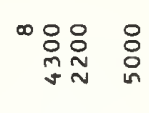 & 号 \\
\hline 药 & $m s N \tilde{N}$ & m욤ㅇ & $\stackrel{\infty}{\sim}$ & $\cos m N$ & $\ln 080$ & 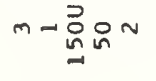 & ๓ & 㐫원 & n 요요 $0^{\infty} \stackrel{?}{\circ}$ \\
\hline$\underbrace{\infty}_{\infty}>$ & 恶嵒 & 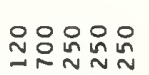 & & 임엄욤요 & 옴요요요 & 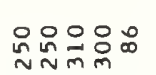 & 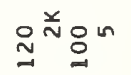 & 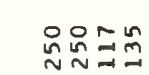 & 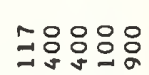 \\
\hline 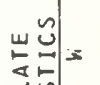 & $\stackrel{n}{i}$ & 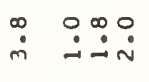 & & $\because \because \ddot{m} \dot{0}$ & $\stackrel{\because}{-} \quad \dot{\sim} \dot{m}$ & $\begin{array}{l}0 \infty 00 \\
\dot{0} 0 \dot{0}\end{array}$ & $\stackrel{-}{-}$ & $\dot{\dot{m}} \stackrel{\sim}{\sim}$ & $\dot{-}$ \\
\hline 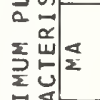 & $0=\frac{2}{2}$ & 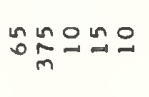 & $\stackrel{n}{\simeq}$ & $\stackrel{2}{\sim}: \stackrel{\sim}{\sim} \tilde{N}^{m}$ & 용욤 & 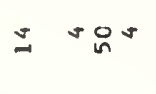 & 옳ำ & 무요 & N \\
\hline 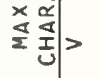 & 品啰些品品 & 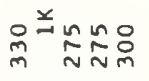 & 号 & 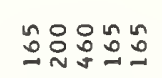 & 施 & 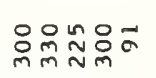 & 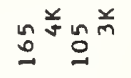 & 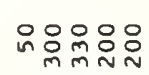 & 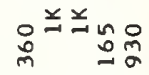 \\
\hline 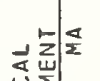 & 욤엄욤요 & 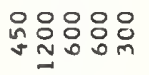 & $\stackrel{\circ}{\sim}$ & 并咨品品品 & ^ & 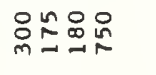 & $\stackrel{\circ}{\stackrel{2}{2}}$ & 虽㔯 & 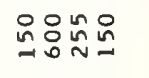 \\
\hline 造车了> & 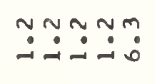 & 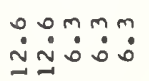 & $\dot{m}$ & $\ddot{\circ} \ddot{\circ} \ddot{\circ} \dot{0}$ & 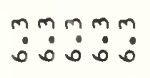 & $\begin{array}{l}m \\
\dot{0} \\
\dot{\sim}\end{array}$ & $\stackrel{m}{\because} \stackrel{\sim}{-}$ & 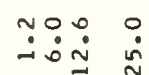 & mon:m \\
\hline$\times \frac{\omega}{2}$ & $u \cup u \cup I$ & IIIII & I & IIIII & Iエエエエ & IIIIU & IиUи & $u U I U I$ & IIIIU \\
\hline$\underset{\sim}{~}$ & 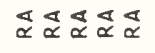 & 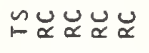 & سّ & 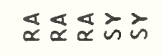 & 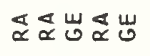 & 岁岕岕 & 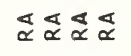 & 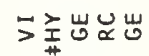 & 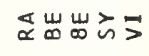 \\
\hline 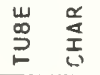 & 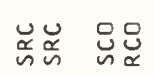 & 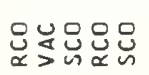 & 约 & 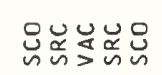 & 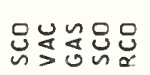 & 号怘怘芯 & 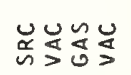 & 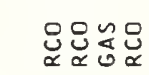 & 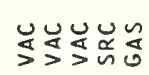 \\
\hline 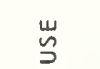 & 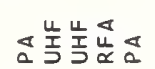 & 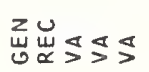 & 主 & 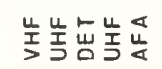 & 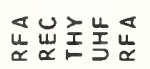 & 导\\
岌㟧 & 殅出出出 & 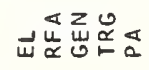 & 㞻出出殅出 \\
\hline$\stackrel{S}{\infty}_{\infty}^{\infty}$ & 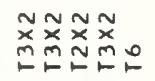 & レニ゙ロ昂 & $\curvearrowleft$ & EேェME & 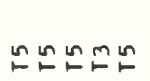 & ピ゚゚ロヒ & 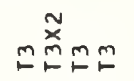 & ๓ュレロロ & 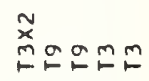 \\
\hline$\underset{2}{u}$ & 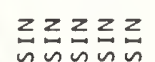 & 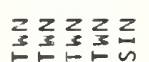 & $\frac{z}{n}$ & 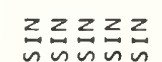 & 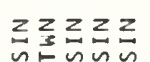 & 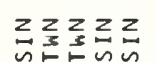 & 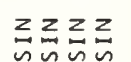 & 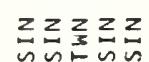 & $z_{3} z_{1} z_{1} z$ \\
\hline$\frac{0}{2}$ & 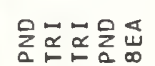 & 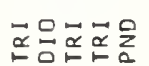 & 点 & 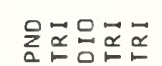 & 呈品岕品只 & 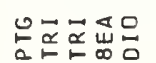 & 吴虽品品品 & 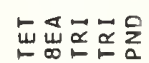 & 응응믕응 \\
\hline 岂 & $n$ & 芯芯志志志 & $n$ & $\dot{n}+* *$ & 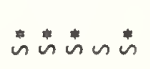 & 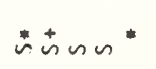 & $\pm \quad$ & $\stackrel{\infty}{\infty}+\dot{\infty} n$ & ヘッら \\
\hline 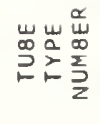 & 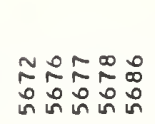 & 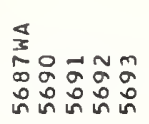 & 足 & 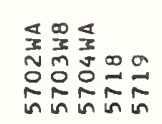 & 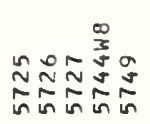 & 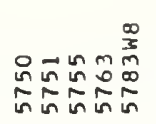 & 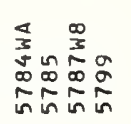 & 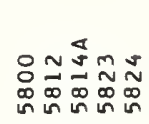 & 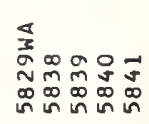 \\
\hline
\end{tabular}




\begin{tabular}{|c|c|c|c|c|c|c|c|c|c|}
\hline 崖崖 & 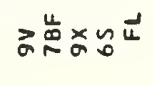 & แ & $\vec{\psi} \overrightarrow{4} \vec{u} \vec{\Phi}$ & 㟧 & 㟧品兑㟧峞 & 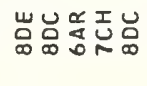 & 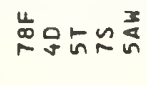 & 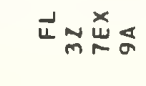 & 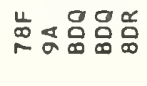 \\
\hline 岕结号 & 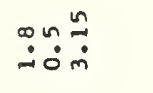 & $\stackrel{\sim}{\sim} \dot{\sim} \dot{\sim}$ & $\dot{v}$ & $\stackrel{9}{-}$ & 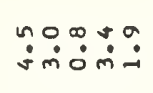 & 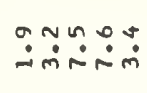 & $\ddot{0}$ & $\stackrel{n}{0}$ & $\because \ddot{0}: \ddot{n}$ \\
\hline 造 & 品 & $\ddot{\sigma} \dot{\sim} \dot{\sim}$ & $\stackrel{\sim}{\sim}$ & $\stackrel{9}{0}$ & 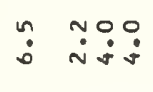 & 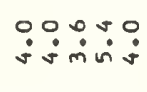 & $\vec{m}$ & $\stackrel{0}{\circ}$ & 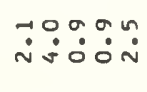 \\
\hline$\tilde{u}$ & 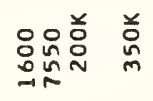 & 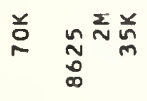 & $\Sigma_{\infty}^{\Sigma}$ & $\begin{array}{l}\text { ․ } \\
\text { D }\end{array}$ & $\begin{array}{l}\text { 总兑 } \\
\text { 足 }\end{array}$ & 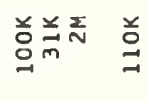 & 品 & 鮎 & 유유 \\
\hline 点 & $\mathcal{M} \stackrel{\infty}{N}$ & in & - & & 용 & & $\stackrel{n}{N}^{v}$ & $N$ & 政ニ品 \\
\hline 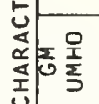 & 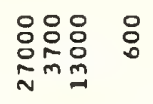 & 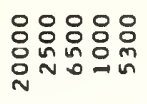 & 윰어 & 号 & 总 & 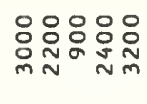 & 吕品 & $\underset{\substack{\circ \\
\sim}}{\stackrel{\circ}{\sim}}$ & 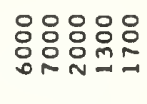 \\
\hline 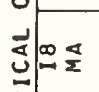 & $\tilde{N}^{n} \pm D^{0} D_{\infty}^{0}$ & $\infty+\infty \sim n$ & 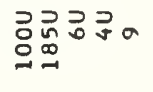 & $r$ & 品再ND & mmNon & $\infty: \underset{\sim}{\mathbb{N}}: \stackrel{m}{m}$ & N & 。m \\
\hline is & 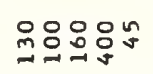 & 品品怘怘品 & 원 $\underset{\sim}{\sim}$ & 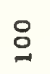 & 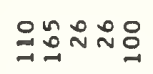 & 눙욤요 & 歌品品品品 & 응옴음움 & 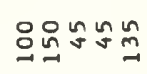 \\
\hline 岕: & $\because \because \ddot{\sim}$ & $\stackrel{\sim}{\because} \stackrel{\sim}{\sim} \dot{\sim}$ & & $\div$ & 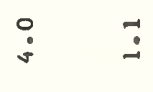 & $\because \because$ & 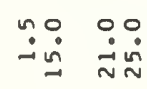 & $\stackrel{\circ}{i}$ & $\because: \quad$ \\
\hline 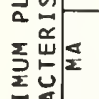 & 舫억ㅇㅇㅛ & $\sim \stackrel{\sim}{\sim}$ & 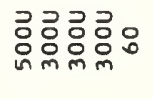 & 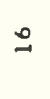 & 옴웜요 & 엄요 & 용 & 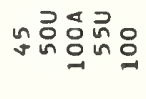 & 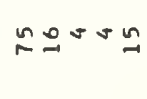 \\
\hline 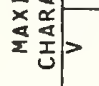 & 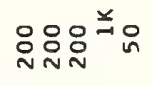 & 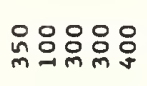 & 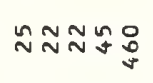 & $\stackrel{n}{0}$ & 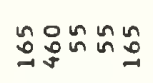 & 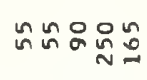 & 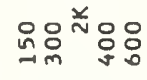 & 욤욜 & 品品品品品 \\
\hline 运管至 & 임윰임임 & 品品嵒品吕 & 웃ㅇㅇㅁㅇㅛ & $\cong$ & 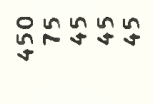 & 约品品号品 & 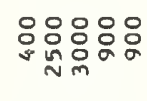 & $\stackrel{\circ}{\stackrel{n}{=}}$ & 莡 N \\
\hline 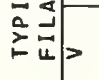 & mm & ח: & 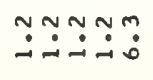 & $\ddot{0}$ & 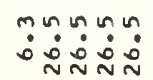 & 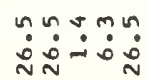 & m: & $\stackrel{n}{9}$ & 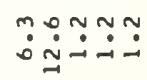 \\
\hline$\times \stackrel{\substack{u \\
2}}{2}$ & IIIIU & IUIII & レルレレエ & $I$ & エエエエエ & IエUエエ & エルルエエ & IUU U & IエレU ᄂ \\
\hline$\underset{\sim}{\mathbb{~}}$ & 虫 & $\sum_{*} \underset{\propto}{\sim} \underset{\propto}{u} \tilde{L}$ & 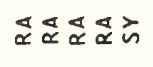 & i & らうえらうご & えうむ嵌え & 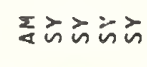 & 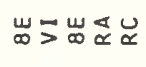 & 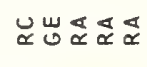 \\
\hline 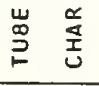 & 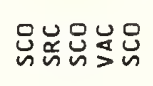 & 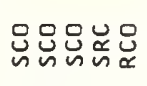 & 芯 总怘芒 & $\underset{\sim}{\sim}$ & 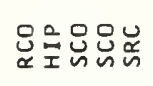 & 号怘怘芯芯 & 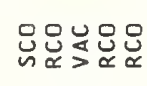 & 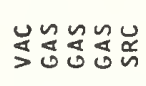 & 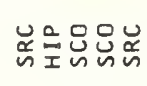 \\
\hline 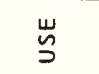 & 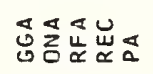 & 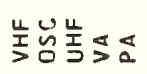 & 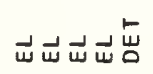 & $\frac{4}{5}$ & 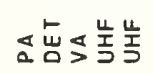 & 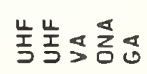 & 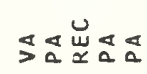 & 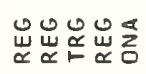 & 艺艺堊㞬堊 \\
\hline 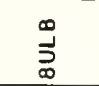 & レロュロ辛 & 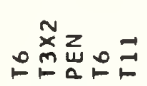 & 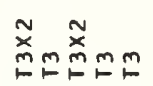 & $m$ & MMMmm & ツேロロロே & $\stackrel{N}{N} \underset{F}{ } \mathfrak{N}$ & ロேトロロュ & ヘロッmm \\
\hline $\begin{array}{l}m \\
\vdots \\
\vdots\end{array}$ & 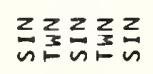 & 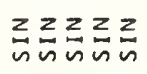 & 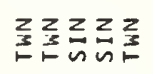 & $\frac{z}{n}$ & 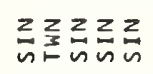 & 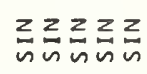 & 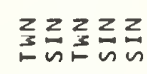 & 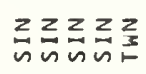 & 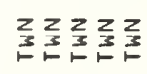 \\
\hline$\sum_{\underline{z}}^{0}$ & 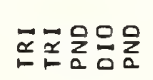 & 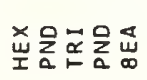 & 뜬은응음 & $\sum_{a}^{o}$ & 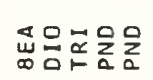 & 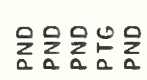 & 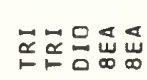 & 믐뭄뭄 & 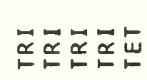 \\
\hline 㟔 & ทังทñ & $\approx$ & nேn & $\dot{n}$ & Bnn nn & $n$ "nnn & ص̃ñ & is & 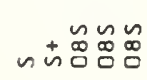 \\
\hline 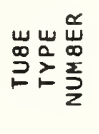 & 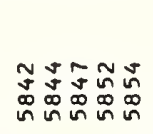 & 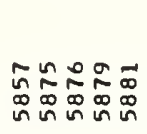 & 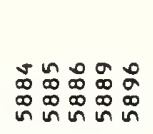 & 吕 & 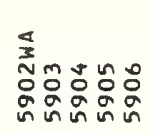 & 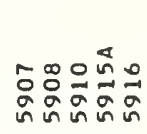 & 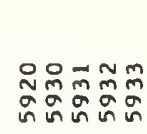 & 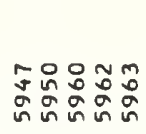 & 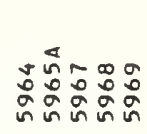 \\
\hline
\end{tabular}




\begin{tabular}{|c|c|c|c|c|c|c|c|c|c|}
\hline 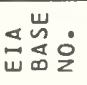 & 号山山㤩总 & 乞 & 壬出恕 & 㟔品山㟧乞 & 山山山山山出品品 & 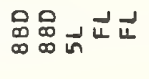 & 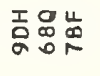 & 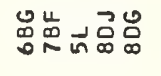 & 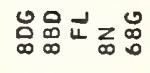 \\
\hline 矛高客 & 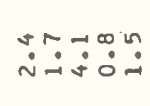 & & $\stackrel{0}{\dot{r}} \stackrel{n}{r}$ & 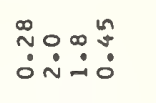 & $\because 0 \hat{\sim}$ & $\stackrel{\sim}{\sim} \dot{\sim}$ & $\ddot{n} \dot{0}$ & $\stackrel{m}{\sim} \stackrel{\stackrel{\infty}{0}}{\stackrel{0}{0}}$ & 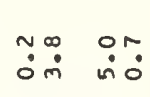 \\
\hline 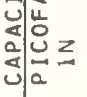 & 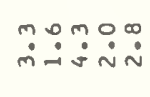 & & 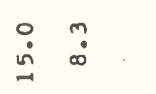 & $\dot{\sim} \dot{\sim} \dot{\sim} \dot{\sim} \dot{\sim}$ & 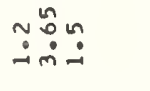 & $\because: 0$ & $\ddot{\infty} \doteq \dot{\sim}$ & 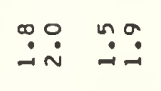 & $\because \dot{m} \quad \because \because$ \\
\hline كِ & こ & 总 号 & 总疋 & $\begin{array}{l}\stackrel{\circ}{0} \\
\text { 怘 } \\
\text { 怘 }\end{array}$ & 怠芯 & 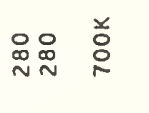 & $\underset{\sim}{\stackrel{D}{\sim}}$ & : & 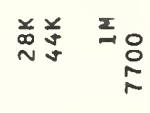 \\
\hline 氛 & $\stackrel{n}{\sim}=$ & $n$ & & $\stackrel{n}{m} \infty \underset{m}{\infty}$ & $\cong \pm$ & $N \sim$ & $\stackrel{\infty}{m}$ & $\beth \stackrel{\infty}{m}$ & 욤요 \\
\hline $\begin{array}{lll}0 & \\
0 & =\end{array}$ & 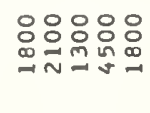 & \begin{tabular}{ll}
$\circ$ & $\circ$ \\
$\circ$ & $\circ$ \\
$\circ$ & \multirow{2}{*}{}
\end{tabular} & 吕 & 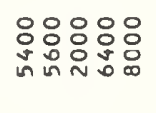 & 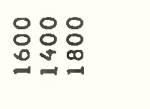 & 응 :윰 & 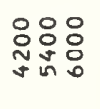 & 总: & 윳요 윰 \\
\hline$=\frac{\pi}{2}$ & $m+\sim O a$ & 군용ㅇㅁ & 윰요 옹 & $0 \sigma=a \frac{2}{5}$ & $\checkmark ง m \underset{\sim}{\infty}$ & 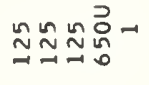 & sña & $0^{\infty} \stackrel{\cong}{\simeq}$ & $\sim \sim \mathcal{B}$ 응ㅇ \\
\hline > & 讨 & 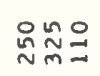 & 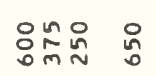 & 음엉ㅇㅇㅁㅇㅠ & 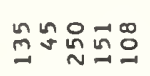 & 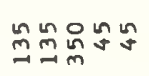 & 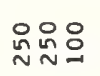 & 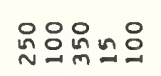 & 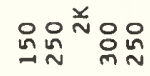 \\
\hline 氙实 & mis & 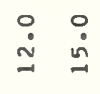 & $\stackrel{\circ}{\stackrel{0}{\leftrightarrows}}$ & 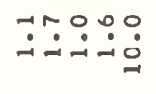 & $\stackrel{+}{0} \stackrel{0}{0}$ & 울 & $\dot{\sim} \underset{\sim}{\sim} \dot{\sim}$ & $\dot{m} \dot{0}$ & $\dot{m} \dot{m}$ \\
\hline 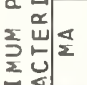 & 组 $\approx$ 品 & 怘肙 & 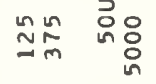 & $\approx \stackrel{\infty}{\sim} \pm \sim$ & $\Rightarrow$ 워용ㅁㅇ & 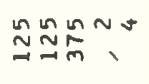 & $0 \stackrel{0}{\stackrel{n}{N}}$ & $\stackrel{\sim}{\sim} \underset{\sim}{N} \stackrel{N}{N}$ & $m \stackrel{\circ}{0}$ \\
\hline 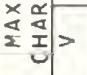 & ปัง & $\stackrel{D}{e}^{\stackrel{n}{N}}$ & 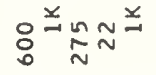 & 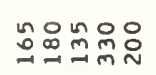 & 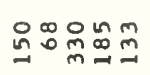 & 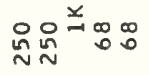 & 응요 & 일욜 & n \\
\hline 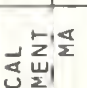 & 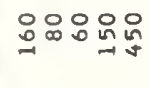 & 잉요 & 品: & 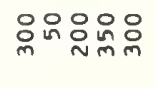 & 옳옴 & 윳윰유 & 음윰요 & 虽品品品品 & 品品 品先 \\
\hline 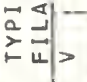 & 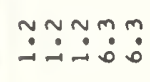 & $\ddot{\dot{0}} \dot{m} \dot{0}$ & $\ddot{~}$ & monm & 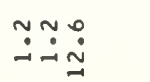 & 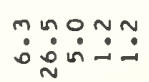 & mm? & 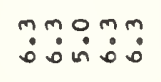 & $\ddot{\dot{0}}$ \\
\hline$\times \quad \sum_{2}^{m}$ & แルルII & III & エルエルエ & エエルエエ & U L I U U & エエエルル & III & エエエエエ & IIUエI \\
\hline$\underset{x}{\stackrel{W}{W}}$ & ๕氐えうう & 岗岗岕 & 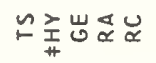 & え゙せさう岕 & 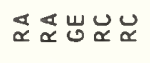 & & 岗乞U్ & 嵌这岗えう & えうミ゙ラ \\
\hline 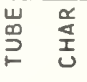 & 递怘岕岕岙 & 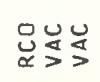 & 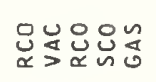 & 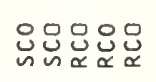 & 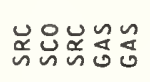 & 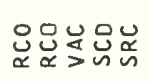 & 엃웜 & 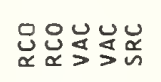 & 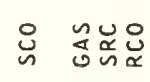 \\
\hline 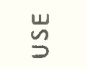 & 㞬堊范忌佋 & ه广 & 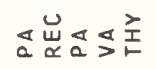 & 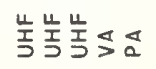 & 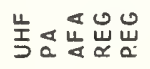 & 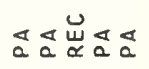 & a & 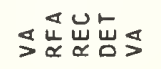 & 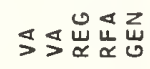 \\
\hline$\stackrel{\infty}{د}$ & 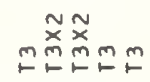 & ๕ேニ & 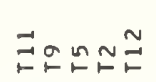 & 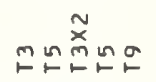 & 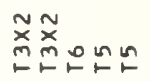 & 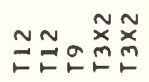 & ゚コュ & ロேロロேே & 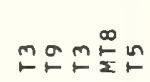 \\
\hline$\sum_{2}^{\frac{w}{2}}$ & 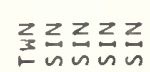 & 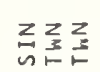 & 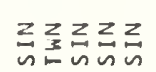 & 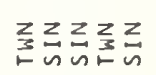 & 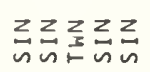 & 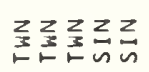 & 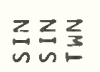 & 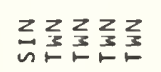 & 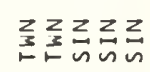 \\
\hline$\frac{\varrho}{2}$ & 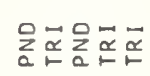 & 㟧음문 & 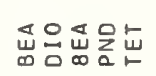 & 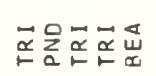 & 폼름뭄음듬 & 몬든응응 & 㟔岕䓃 & 喜吕ㅇㅇㅁㅁㅁㅁㅁㅁ & $\vec{\alpha} \overrightarrow{\underline{\alpha}}$ \\
\hline 岂 & $n^{+}$ & Eñn & $\begin{array}{l}n \\
0_{0} \\
0\end{array}$ & 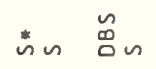 & $\backsim \dot{\sim} \dot{s} \dot{s}$ & $\dot{\sim} \backsim \dot{\sim} \stackrel{\infty}{\infty}_{0}^{\infty}$ & $\dot{n} \dot{n} n$ & 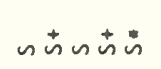 & 芯品 $\dot{\sim} \sim$ \\
\hline 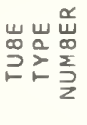 & 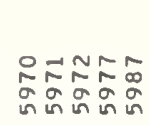 & 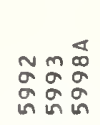 & 응융뭉ㅁㅇ & 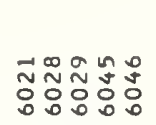 & 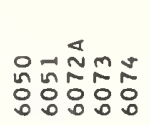 & 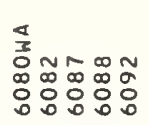 & \begin{tabular}{l}
\multirow{2}{*}{$\begin{array}{l}\infty \\
\sigma\end{array}$} \\
00 \\
0
\end{tabular} & 뭉음으 & 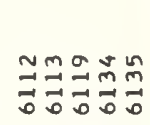 \\
\hline
\end{tabular}




\begin{tabular}{|c|c|c|c|c|c|c|c|c|c|}
\hline 造崫员 & 弟囬宮祭山 & ü & 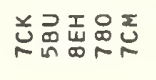 & 品求 & ద్వ & 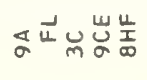 & 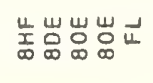 & 啰 & 可氮总 \\
\hline 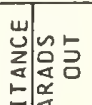 & $\dot{0}$ & $\stackrel{n}{n} \underset{\sim}{n} \stackrel{\infty}{\infty} \stackrel{\infty}{\sim} \underset{\sim}{\sim}$ & $\because \stackrel{n}{\sim} \dot{\sim} \dot{\sim} \dot{m}$ & $\dot{0}: \dot{0}$ & $\stackrel{n}{a} \quad \therefore$ & 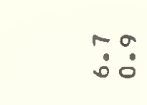 & 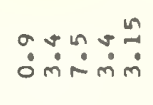 & $\because \quad \dot{j}$ & 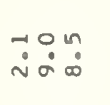 \\
\hline 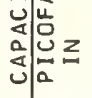 & 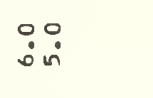 & $\ddot{\square} \ddot{\sim} \dot{\sim} \dot{\sim}$ & $\ddot{n} \quad \because \dot{0}$ & $\stackrel{\square}{\square}$ & $\stackrel{\sim}{i} \quad \dot{j}$ & $\dot{\sim} \quad \ddot{\sim} \dot{\sim}$ & $\dot{\sim}+\dot{0}: \dot{0}$ & $\dot{\sim} \quad \stackrel{\sim}{\sim} \dot{\sim}$ & 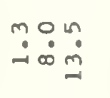 \\
\hline$y$ & 풍 & 홍 & ․ㅡㅁ & 姜。兑并 & 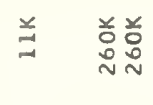 & 웅 & 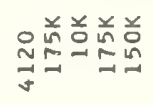 & $\sqrt[x]{N}$ & 总 : \\
\hline 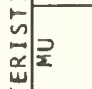 & & $\stackrel{\infty}{=}$ & & 욤 & $:$ & $\vec{m}$ & $\stackrel{ }{r}$ & 品: & $\simeq$ \\
\hline 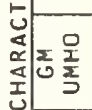 & : & 웅음음 & 욤 & 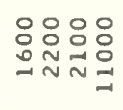 & $\begin{array}{l}\circ \\
\text { 品 品 } \\
\text { n }\end{array}$ & 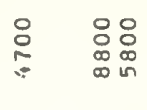 & 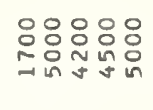 & 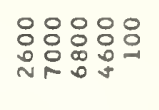 & 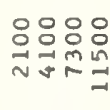 \\
\hline 矛这 & $=00 \stackrel{\sim}{\sim} \underset{\sim}{\vec{D}}$ & 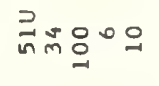 & $\bigcirc_{-1}^{m \infty n}$ & No & 음요 & $\sim N-\vec{n}^{\infty}$ & 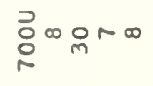 & vomr & ○ \\
\hline > & 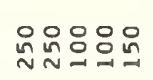 & 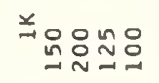 & 品 弟品怘 & 品品 & 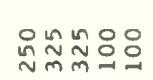 & 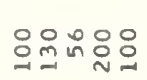 & 음음음 & 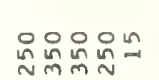 & 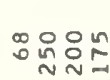 \\
\hline 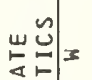 & $\ddot{m} \dot{m}$ & 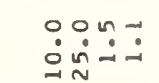 & $\stackrel{0}{\stackrel{n}{\sim}} \quad \dot{\sim}:$ & 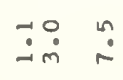 & $\ddot{n} \quad \because \dot{-}$ & $\because \quad \dot{0}$ & $\because \because \because \because \stackrel{\infty}{\circ}$ & 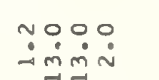 & $\dot{m} \dot{m}: \dot{0}$ \\
\hline 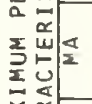 & mog & 응 & 임요 운 & $N^{\sigma}$ in & 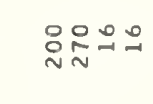 & $\Xi \sim \infty O N$ & mำ & 요 总 & r m \\
\hline $\begin{array}{l}x \\
\frac{x}{2} \\
2\end{array}$ & 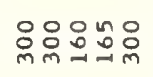 & 兰吅品品品 & 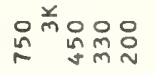 & 도ㄱㅠㅛㅁㅇㅛ & 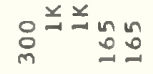 & 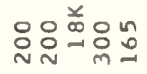 & 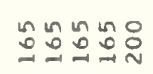 & 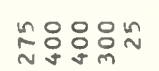 & 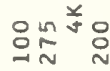 \\
\hline - 1 空 & 임 & 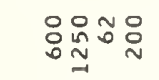 & 울 윰욤 & 옴욤요 & 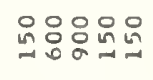 & 욤 & 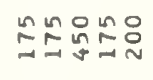 & 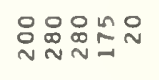 & 웡요욤욤 \\
\hline 足过 & $\ddot{m} \ddot{0}$ & $\ddot{0} \dot{0} \dot{0} \dot{\sim} \dot{0}$ & $\stackrel{\dot{0}}{\sim} \ddot{0} \dot{0}$ & $\ddot{m} \ddot{\sim} \sim \dot{0}$ & 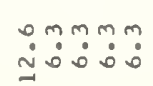 & 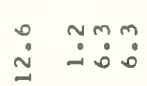 & m & $\ddot{0} \dot{0} \dot{0} \dot{0}:$ & ב:m: \\
\hline $\begin{array}{r}\frac{w}{a} \\
\times \quad 2\end{array}$ & IIUU & UエエルI & IUIII & IIUI & エエエエエ & エUルエI & IIIII & エエエエル & UIII \\
\hline$\underset{\sim ّ}{\tilde{\alpha}}$ & 岕岕岕岸 & 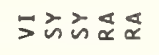 & 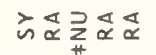 & 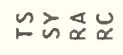 & 岁岕岕方方 & 嵌出嵌至品 & 只只品品壬 & 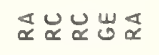 & 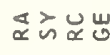 \\
\hline 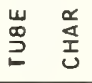 & 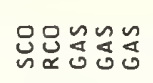 & 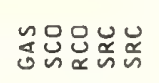 & 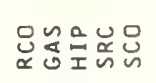 & 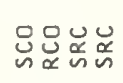 & 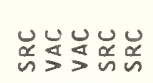 & 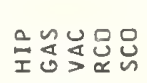 & 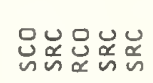 & 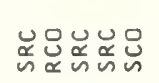 & 总怘足怘 \\
\hline$\stackrel{u}{\breve{s}}$ & 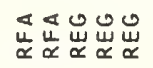 & 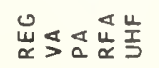 & 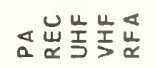 & 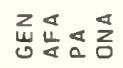 & 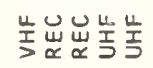 & 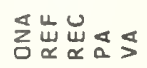 & 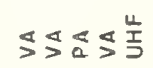 & 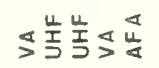 & Uू̆ \\
\hline D્ڤ & 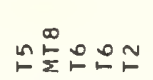 & 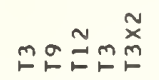 & 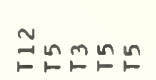 & ロロッュ & ロロュロロ & ゚ロロロ & คேロロロ & 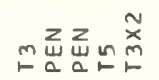 & 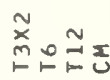 \\
\hline 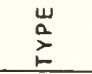 & 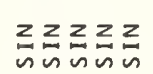 & 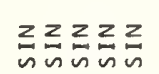 & 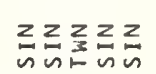 & 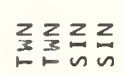 & 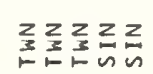 & 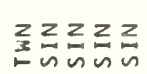 & 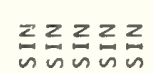 & 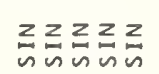 & 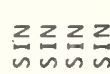 \\
\hline$\sum_{2}^{0}$ & 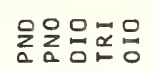 & 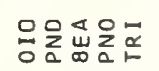 & 出桴웅응음 & 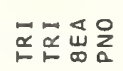 & 똔응응웅응 & 运品吕出㟧 & 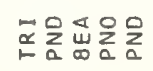 & 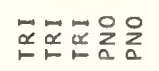 & 뭄ㅆㅀ 出出 \\
\hline 㟔 & 菜范路 & $n \tilde{D}^{+}$ & $n \tilde{\tilde{\sigma}}_{\tilde{\sigma}} n n$ & $\dot{n} \dot{n} n$ & 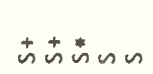 & $\stackrel{\sim}{\sim} \tilde{\mathscr{O}}++$ & $++ \pm+\dot{n}$ & $\dot{n} n$ & ڤ્口 \\
\hline 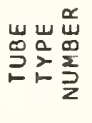 & 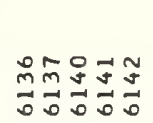 & 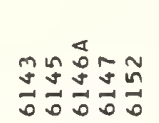 & 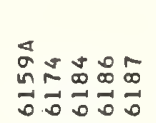 & 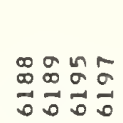 & 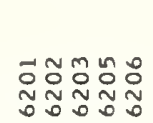 & 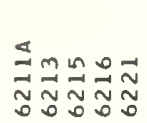 & 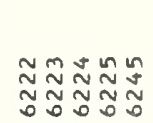 & 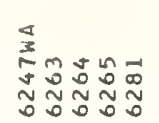 & 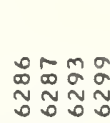 \\
\hline
\end{tabular}




\begin{tabular}{|c|c|c|c|c|c|c|c|c|c|}
\hline 㟧虽 & 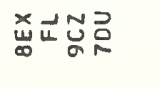 & 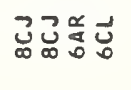 & 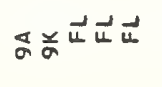 & 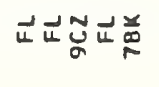 & 흐 & $\vec{u}$ & 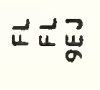 & 氙山品品山 & 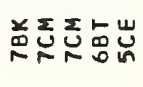 \\
\hline 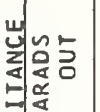 & $\ddot{0}$ & 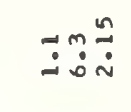 & Fin & $\dot{0}: \dot{\sim}$ & $\ddot{m}$ & $\stackrel{\sim}{\sim} \dot{0}:$ & $\ddot{m} \dot{m}$ & $\stackrel{8}{0}$ & 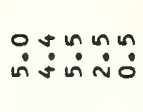 \\
\hline 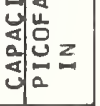 & $\because \ddot{m}$ & $\dot{\sim} \dot{m} \dot{\sim}$ & $\ddot{j}$ & $\dot{m}:$ & $:$ & $\stackrel{n}{\stackrel{n}{2}}$ & $\stackrel{\infty}{\dot{j}} \stackrel{n}{j}$ & 宜 & $\ddot{n} \dot{n} \tilde{N}$ \\
\hline$y=\frac{n}{\Sigma}$ & : & 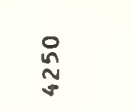 & 용 & 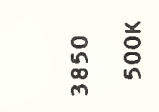 & & 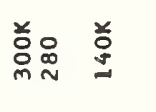 & 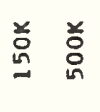 & 㟢喕 & $\Xi \Xi \Sigma \quad$ \\
\hline 년룰 & $\stackrel{\infty}{\sim}$ & $\tilde{m}=$ & $\mathcal{q}$ & $\stackrel{i}{\sim}$ & & $N$ & & & $:$ \\
\hline $\begin{array}{ll}0 \\
0\end{array}$ & $\begin{array}{l}0 \\
0 \\
0 \\
0\end{array}$ & 응ㅇㅇㅇㅇㅇㅁ & 응ㅇㅇㅇㅇㅛ & 옹 & $\stackrel{\text { O }}{\text { : }}$ & :용유 용요 & $\stackrel{\circ}{\circ}$ & 용 & 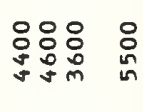 \\
\hline 현 & N ${ }_{\text {Oํㅠ }}=$ & mont & 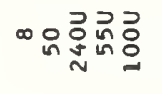 & 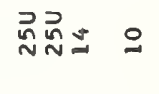 & $\checkmark$ & 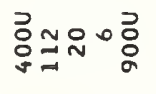 & $\infty \simeq \infty$ & $-m \underset{\sim}{\infty} \underset{\infty}{\infty}$ & $=r a 00$ \\
\hline 党 & 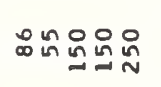 & 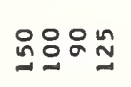 & 品: & 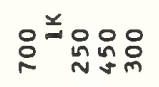 & $\stackrel{\circ}{\beth}$ & 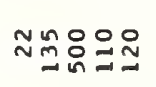 & 옴욤오 & 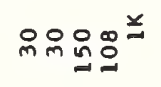 & 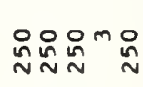 \\
\hline 둰 & $\ddot{m} \tilde{m}$ & 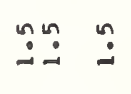 & $\dot{0} \dot{\sim}$ & $\stackrel{\leftrightarrow}{\dot{m}}$ & $\dot{\sim}$ & $\dot{0} \div \dot{0}$ & $\because \dot{0}$ & $\ddot{0}$ & $\dot{m} \dot{m} \dot{m} \dot{m}$ \\
\hline 可 & $\checkmark \infty$ 임욤 & 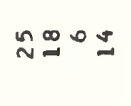 & 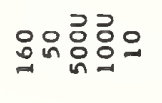 & 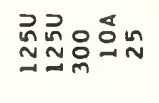 & $\stackrel{\infty}{\sim}$ & 옹ำำ & $\stackrel{\sim}{N}$ 요 & n 윰욤 & : \\
\hline 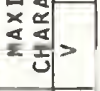 & 욜 $\stackrel{n}{\sim}$ & 品品品品 & : & 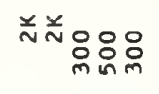 & $\stackrel{\infty}{\infty}$ & 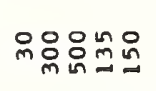 & 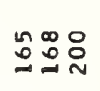 & 品品误足 & 总㗇品战品 \\
\hline 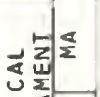 & $\stackrel{9}{8}$ & 总品品品 & $\underset{\sim}{\mathfrak{n}} \underset{m}{\mathfrak{n}} \stackrel{0}{0}$ & 윰 & $\stackrel{\circ}{N}$ & 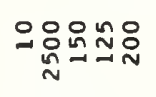 & $\stackrel{\circ}{\stackrel{0}{N}}$ & 용 & 品品品品品 \\
\hline $\begin{array}{lll} & 0 \\
0 & -1\end{array}$ & $\stackrel{m}{\check{0}}$ & 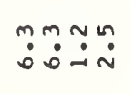 & 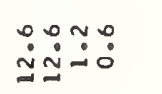 & $\stackrel{\dot{0}}{\stackrel{0}{0}}$ & $\dot{m}$ & 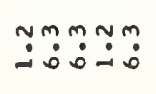 & $\ddot{m}: \stackrel{m}{0}$ & $\dddot{\check{-}}$ & $\ddot{0}: \ddot{0}: \dot{m}: \dot{0}$ \\
\hline 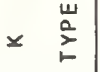 & IUIU & IIUи & IIинU & U UI & $I$ & $\| I I U I$ & IUI & ט ט ט Lا & IIIII \\
\hline$\underset{\sim}{\stackrel{u}{\Psi}}$ & えすう㟒夛 & 岕岕匹ð凹 & 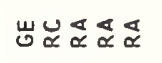 & 凹む凹 & 山 & 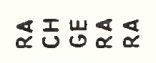 & 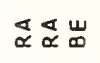 & 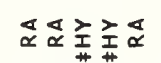 & سુ \\
\hline 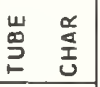 & 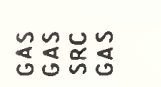 & 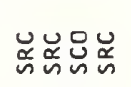 & 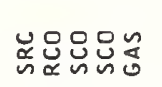 & 造造造怘怘 & 怘 & 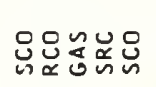 & 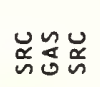 & 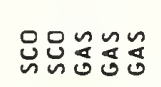 & 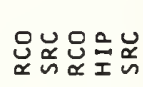 \\
\hline$\stackrel{山}{s}$ & 嵌 & 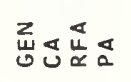 & 台堊顿顿㟒 & 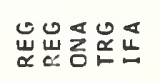 & $\underset{a}{a}$ & 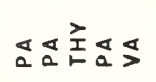 & 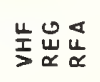 & 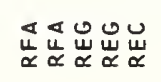 & 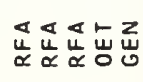 \\
\hline$\sum_{\infty}^{\infty}$ & ๓ேェ゚ロロ & 요ロㅛ & 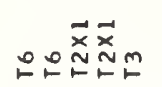 & ேே゚ロே & $\stackrel{\circ}{\llcorner}$ & 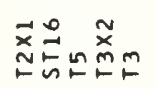 & ๓ேே & 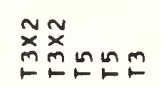 & 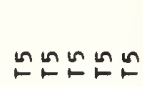 \\
\hline$\stackrel{m}{\vdots}$ & 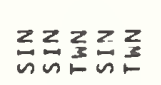 & 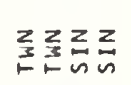 & 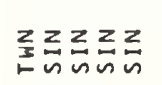 & 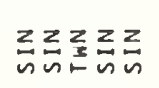 & $\frac{z}{n}$ & 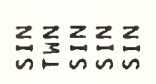 & 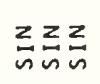 & 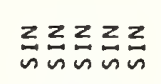 & 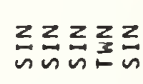 \\
\hline$\sum_{\underline{z}}^{0}$ & 웅웅뭄뭄 & 몬몬윰웜 & 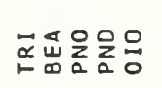 & 응음문ㅁํㄴ음 & $\varliminf_{0}$ & 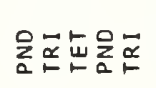 & 층음웅 & 응릉응음음 & 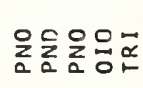 \\
\hline 岁 & 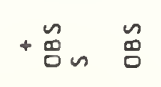 & $\dot{n}+\infty$ & $+n n n n$. & 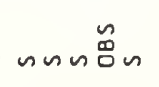 & $\tilde{0}$ & n̊ & $\dot{n}+\stackrel{\infty}{0}$ & $\dot{n} \dot{n}$ & susunos \\
\hline 至 & 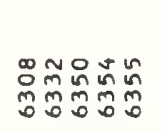 & 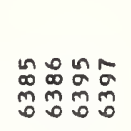 & 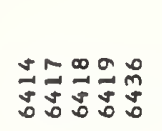 & 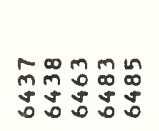 & $\begin{array}{l}0 \\
0 \\
0 \\
0 \\
0\end{array}$ & 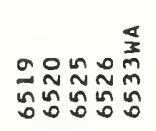 & 号芯芯 & 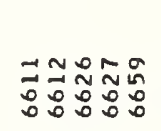 & $\begin{array}{l}: \overrightarrow{0}: 1 \\
: 00 \\
: 00: 0\end{array}$ \\
\hline
\end{tabular}




\begin{tabular}{|c|c|c|c|c|c|c|c|c|c|}
\hline 岕岕员 & 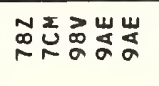 & 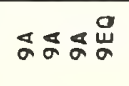 & 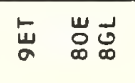 & 弟屾山吕 & 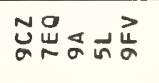 & 山山山゙ & zo⿱ & エ よらら莒 & $\vec{u} \underset{\infty}{u} \breve{\infty}_{\infty}$ \\
\hline 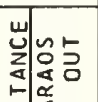 & 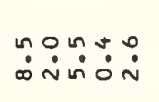 & $\ddot{\circ}$ & $\because \dot{m}$ & $\ddot{0} \dot{0}$ & $\because \ddot{\circ}: \dot{0}:$ & $\ddot{n} \quad \ddot{n} \dot{\sim}$ & $\ddot{\circ}$ & นُ & 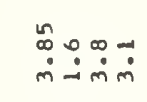 \\
\hline $\begin{array}{l}0 \\
0\end{array}$ & 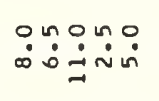 & $\stackrel{\sim}{\sim} \ddot{\sim}: \dot{\sim}$ & $\ddot{\sim} \dot{0}$ & $\ddot{i} \dot{0}$ & 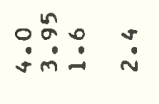 & $\dot{n} \quad \dot{m}$ & 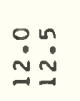 & $\ddot{0} \ddot{m} \quad \ddot{m}$ & $\ddot{n} \dot{\sim} \dot{\sim} \dot{\sim} \dot{\sim}$ \\
\hline$s=\frac{n}{\alpha}$ & 兰兑兑品兑 & 兰。 兰응 & $\Sigma \Sigma_{0}^{2}$ & 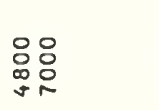 & 总弟 弟 & $\begin{array}{l}0 \\
\text { o } \\
\text { जै } \\
\text { m }\end{array}$ & & ঃ & $\begin{array}{l}\text { 함 } \\
\text { 并 }\end{array}$ \\
\hline 氛 & o & $:=8$ & & N5 & $\stackrel{i}{\sim} \stackrel{n}{n}$ & & & $\stackrel{\infty}{\sim} \stackrel{m}{\sim}$ & \\
\hline 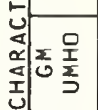 & 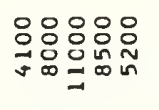 & 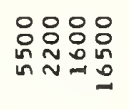 & 육 & 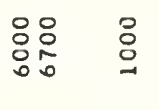 & $\begin{array}{l}\circ: \\
\circ \\
i \\
i\end{array}$ & 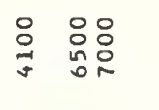 & 品 & 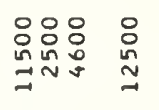 & 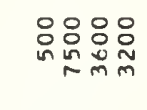 \\
\hline 矛車 & 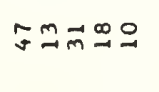 & 우구 & 으융 & 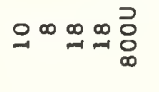 & $\pm \sim \stackrel{\sim}{I}$ & 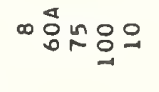 & $\stackrel{m}{\sim}$ & 웅욤요 & 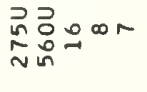 \\
\hline 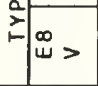 & 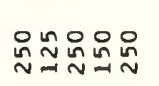 & 은요욤요 & $\stackrel{N}{N}=\stackrel{x}{\stackrel{N}{N}}$ & 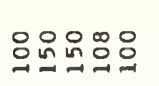 & 怘 N & 옥:윰유 & 운 & 윰욤욤 & min \\
\hline 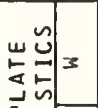 & 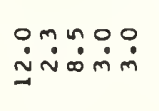 & $\ddot{\sim} \dot{\sim} \dot{\sim} \dot{\sim} \dot{\sim}$ & บำ & $\ddot{\sim} \dot{\sim} \quad \ddot{0}$ & 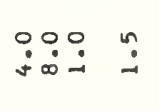 & $\begin{array}{l}\because \quad \dot{\sim} \\
\sim\end{array}$ & 움 & vinn : & $\ddot{m}: \dot{0}$ \\
\hline 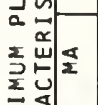 & & $\approx$ & 율요음 & 임윰 & 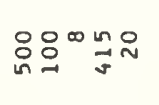 & 옴욤요 & $g_{0}$ & No일ㄹ & 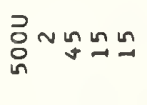 \\
\hline 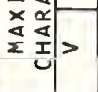 & 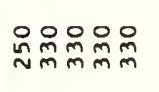 & 윰윰율을 & 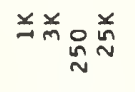 & 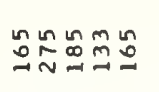 & 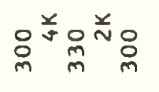 & 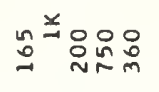 & 용요 & 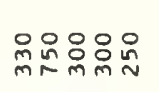 & 弟品怘怘怘 \\
\hline 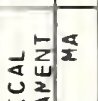 & 虽品品品品品 & 음욤욤요 & 욤요 & $\stackrel{0}{\sim} \stackrel{n}{N}$ & 욤욤욤요 & : & 品 & 운융윰유요 & 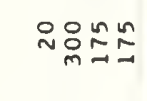 \\
\hline 竞击|> & 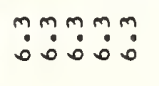 & 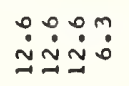 & 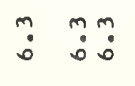 & $\ddot{m} \stackrel{m}{\ddot{0}} \quad \dot{0}$ & 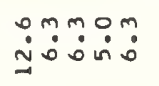 & 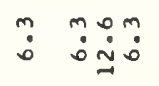 & $\stackrel{m}{\dot{0}} \stackrel{0}{\sim}$ & : & ฯ \\
\hline $\begin{array}{r}\frac{w}{a} \\
\times \quad \frac{2}{z}\end{array}$ & IIIII & IIII & IUII & I I U & IIIII & IUエエエ & $I I$ & IIIII & UルIII \\
\hline$\underset{\alpha}{\stackrel{\Psi}{\alpha}}$ & سّ سِّ سِّ سِّ & 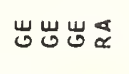 & 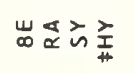 & え岕空主匹 & 虫 & 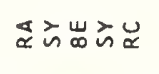 & えu & 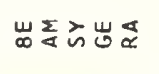 & 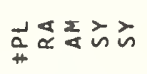 \\
\hline 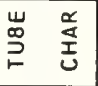 & 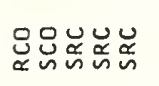 & 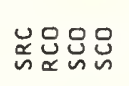 & 造导怘怘 & 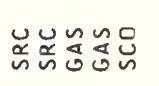 & 造怘 岩芦 & 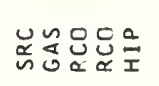 & 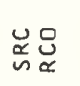 & 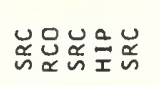 & 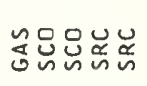 \\
\hline 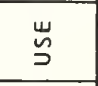 & 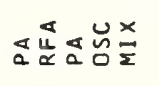 & 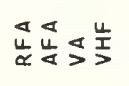 & 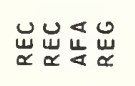 & 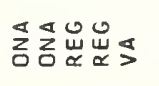 & 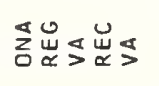 & 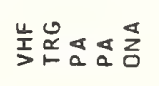 & s⿷ & 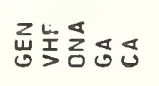 & 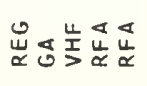 \\
\hline$\stackrel{D}{\infty}_{\infty}^{\infty}$ & ペロ゚ロレ & ゚レ゚ & ேㅗำ & คำ上ロ & ロロロ゚ & 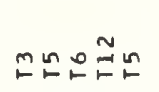 & ag & ゚ジ゚ロ゚ & ロேロ゚ロロ \\
\hline $\begin{array}{l}m \\
\stackrel{u}{2} \\
\Sigma \\
\end{array}$ & 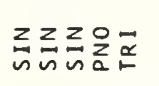 & 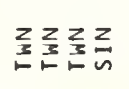 & 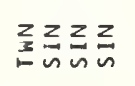 & 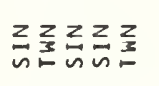 & 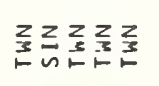 & 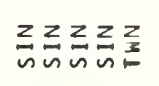 & $\frac{z}{n} \frac{2}{n}$ & 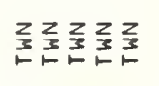 & 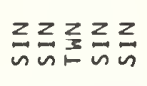 \\
\hline $\begin{array}{l}0 \\
\underline{z} \\
\end{array}$ & 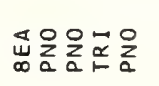 & 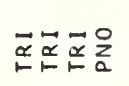 & 음음동 & 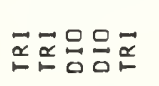 & 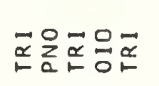 & 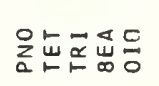 & $\sum_{a}^{0} \underset{\infty}{w}$ & 吕㟔吕吕品 & 응년믐음 \\
\hline $\begin{array}{l}\text { Uू } \\
\text { ठ }\end{array}$ & nususus & nunst & $\underset{\infty}{\infty}++$ & 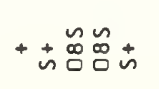 & 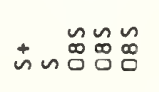 & $+\stackrel{\infty}{\infty}+n$ & $n n$ & $\sim \stackrel{\infty}{\infty} \dot{\infty}$ & $\stackrel{\substack{\infty \\
0}}{\infty} \dot{\sim}$ \\
\hline 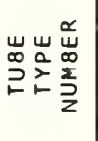 & 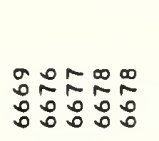 & 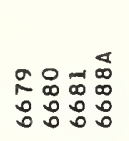 & 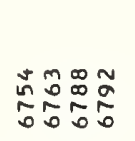 & 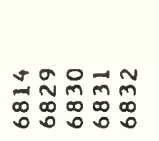 & 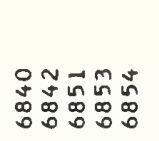 & 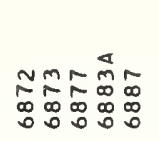 & 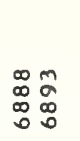 & 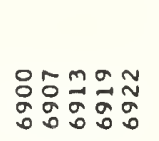 & 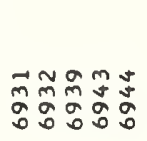 \\
\hline
\end{tabular}




\begin{tabular}{|c|c|c|c|c|c|c|c|c|c|}
\hline 崖崖员 & 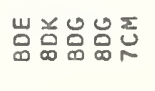 & 倹员岕山山 & な空志ェ导 & 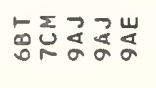 & 岕吕吕岕 & 号 & 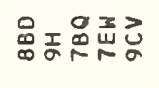 & 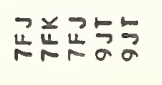 & 虫岀 $\vec{\omega}$ \\
\hline 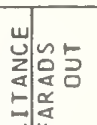 & ñ & $\begin{array}{l}n \dot{\infty} \\
\dot{\sim} \dot{\sim} \dot{\infty}\end{array}$ & 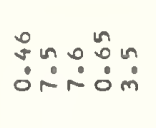 & 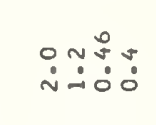 & 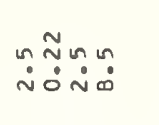 & 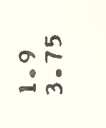 & $\stackrel{\dot{\sim}}{\sim} \dot{\sim} \dot{\sim}$ & mo: & $\ddot{n}$ \\
\hline 矛造 & 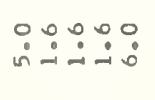 & \begin{tabular}{l}
$n: 0$ \\
\hdashline 00
\end{tabular} & \begin{tabular}{l}
0 \\
\hdashline$\dot{0}$ \\
-
\end{tabular} & ڤ̊: & 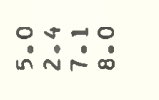 & $\stackrel{n}{\sim}$ & $\ddot{0}: \dot{0}: \dot{0}$ & mó & $\ddot{n}$ \\
\hline y) & 오 & 吕 & 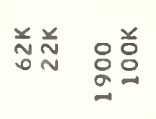 & 总品。 & 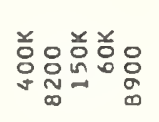 & 蓆 & 品 芯 & 总 & \\
\hline 䒺 & $\stackrel{0}{2} \underset{n}{n}$ & 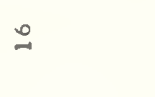 & 익 & 용요 & 品 & $\stackrel{i}{\sim}$ & $n$ N & $=$ & \\
\hline 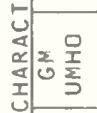 & 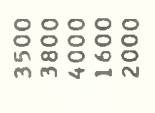 & 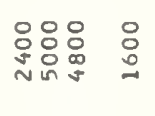 & $\begin{array}{l}: \\
:\end{array}$ & 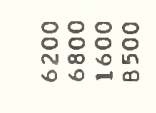 & 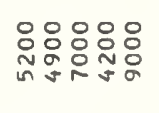 & 용 & 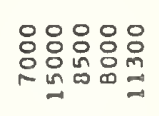 & 웅 & $\stackrel{\circ}{\circ}$ \\
\hline 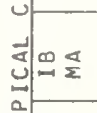 & $\stackrel{\sim}{\sim} \sigma \vec{g}_{\infty}$ & 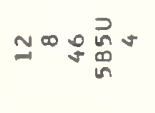 & $-N 0 \%$ & $\sigma 00-\infty$ & 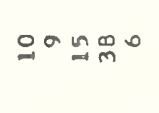 & $\infty \infty$ & $\stackrel{N}{\sim} \sim 20 \%$ & $\begin{array}{l}\circ: 0 \sigma \simeq \\
: 000\end{array}$ & 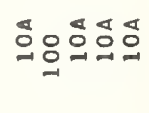 \\
\hline 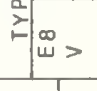 & 응욤욤요 & 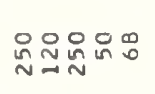 & 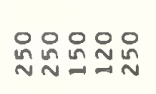 & き品怘品品 & 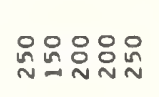 & 웅요뭉 & 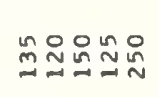 & $\stackrel{\sim}{*} \underset{\sim}{\sim} \underset{N}{N}$ & 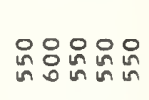 \\
\hline 돈 & 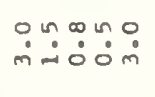 & $\begin{array}{ll}\infty & \infty \\
\dot{\sim} \dot{\sim} & \dot{0}\end{array}$ & 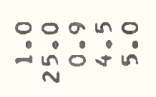 & №n & $\begin{array}{l}\infty \backsim 000 \\
\dot{\sim} \dot{\sim} \dot{m} \sigma\end{array}$ & $\because \div$ & 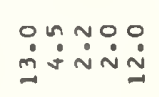 & ث̊ & $\stackrel{0}{\stackrel{n}{N}}$ \\
\hline 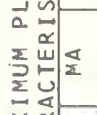 & 늠요 & 유 윰 & 宇乎 & : & $\stackrel{0}{-}$ & N욤유 & 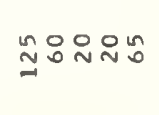 & 이윰ㅇ & 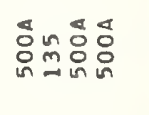 \\
\hline 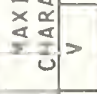 & 品品怘怘虽品 & 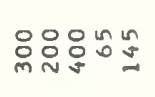 & 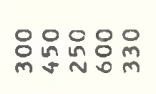 & 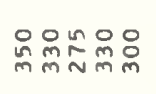 & 品品品卢品 & 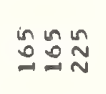 & 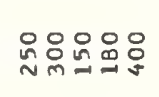 & 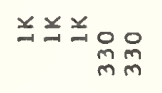 & 兰怘并兰 \\
\hline 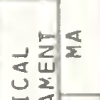 & 品路品品品 & 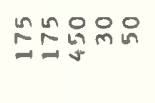 & 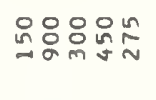 & 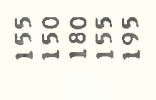 & 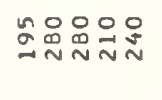 & 윰유 & 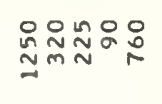 & 品品品品 & $\stackrel{\circ}{N}$ \\
\hline 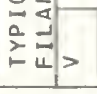 & mmmmm & $\begin{array}{l}\dot{\sim} \dot{0} \dot{0}: \dot{\sim} \\
\dot{\sim}\end{array}$ & : & 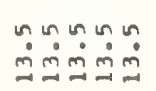 & 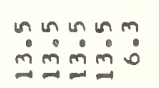 & $\ddot{m}: \dot{m}$ & :ீ:m & 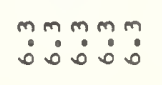 & $\dot{m}$ \\
\hline 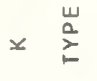 & IIIII & エエエルи & IIIII & IIIII & IエエエI & แIU & Iエエエエ & エエエエエ & ט ט \\
\hline$\underset{\tilde{\alpha}}{\stackrel{u}{u}}$ & 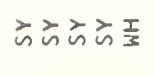 & 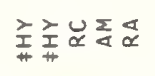 & & & بِّ & 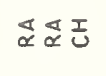 & 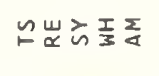 & 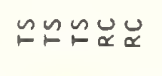 & 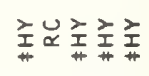 \\
\hline 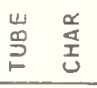 & 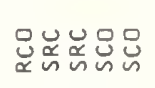 & 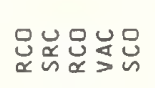 & 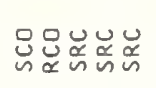 & 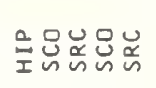 & 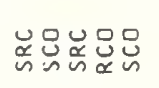 & $\underset{\alpha}{\tilde{u}} \tilde{u}$ & 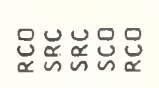 & 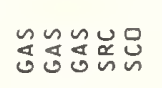 & 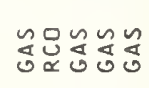 \\
\hline 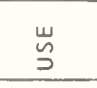 & 巡忌忌忌出品 & 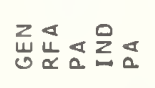 & 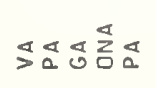 & 占造造忌导 & 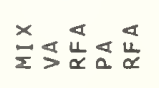 & 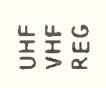 & 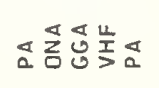 & 喜主主饪す & 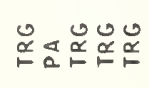 \\
\hline 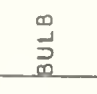 & mmmman & ํㅗำ & レジロ゚゚ & ピロ゚゚ロ゚゚ & 운욣 & Mm̃ & シュロロロ & ゚レレ & ๓ュュュnッ \\
\hline 晟 & 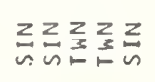 & 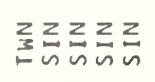 & 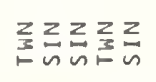 & 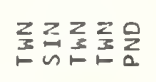 & 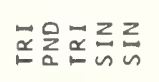 & $\begin{array}{l}z z z \\
\text { śn }\end{array}$ & 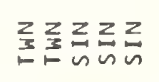 & 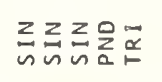 & 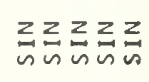 \\
\hline$\frac{0}{z}$ & 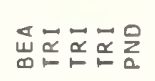 & 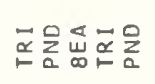 & 吕岕导怘吕吕 & 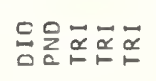 & 员忌员出㟧 & 몬음ㅇㅁㅁ & 余吕亮怘吕 & 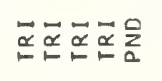 & せ出岕岕出 \\
\hline 㟔 & $+\stackrel{+}{s} \dot{\omega}+\omega$ & 跑㗊心 & $\backsim$ nsn & sunuñ & 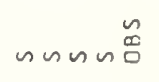 & $\dot{\omega} \dot{n}$ & 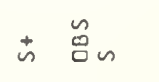 & 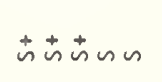 & 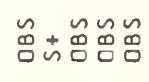 \\
\hline 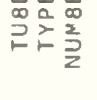 & 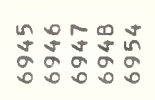 & 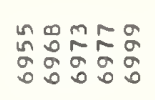 & 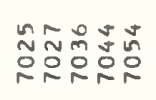 & 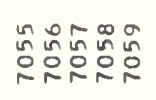 & 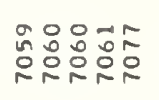 & 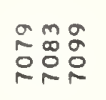 & 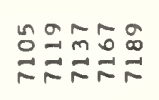 & 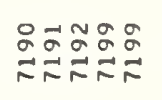 & 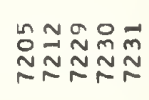 \\
\hline
\end{tabular}




\begin{tabular}{|c|c|c|c|c|c|c|c|c|c|}
\hline 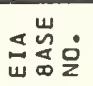 & 山品吕崖怘 & 玹品山 & 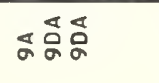 & 亗 & ๔る 总孞 & 岀岀怘恕 & 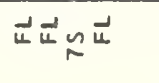 & 号忌 & $\vec{\psi} \vec{u} \vec{u} \vec{u}$ \\
\hline 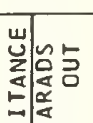 & $\stackrel{m}{\sim} \dot{m}$ & : & m̊ñ & $\dot{m}$ & 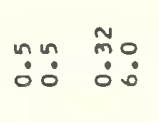 & 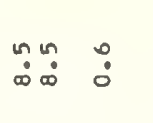 & $\dddot{n} \ddot{i}$ & $\stackrel{j}{j}$ & $\dot{m}$ \\
\hline $\begin{array}{ll}0 \\
0 \\
0\end{array}$ & $\dddot{n} \quad \dot{0}$ & 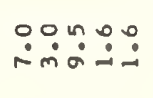 & 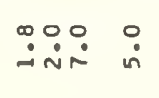 & $\stackrel{0}{\ddot{n}}$ & 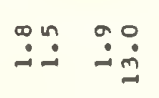 & ñ: & $: 0$ & $\dot{\theta}^{\infty} \dot{m}$ & $\stackrel{\infty}{-}$ \\
\hline$s=\frac{n}{2}$ & $\stackrel{\substack{n \\
N}}{\frac{0}{0}}$ & 호윰융 & 品兑 品 & & 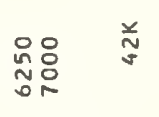 & : & 兑兑 & & : \\
\hline 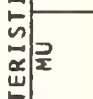 & in $^{n}$ & min & $=\tilde{N} \quad \stackrel{\infty}{0}$ & $\sim$ & 요은 & $\stackrel{\infty}{\sim}$ & & 요 & a \\
\hline 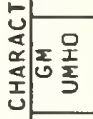 & :용요 & 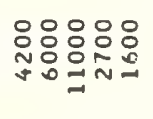 & 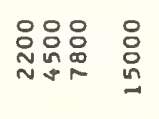 & 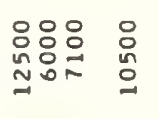 & $\begin{array}{l}80 \\
\text { m } \\
\text { m }\end{array}$ & 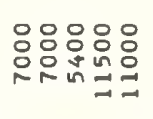 & 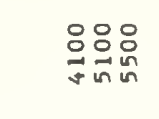 & 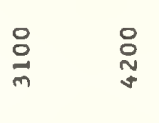 & $\stackrel{\circ}{\stackrel{\circ}{N}}$ \\
\hline 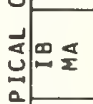 & 옹요 & $0 \sigma \pm v-$ & $\simeq \cong \simeq \sim \curvearrowleft$ & $\stackrel{n}{\sim} \underset{\sim}{\sim}$ & エニN & 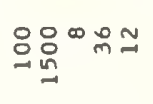 & rr. & $r r$ & 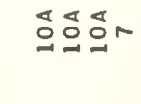 \\
\hline$w_{\infty}$ & 요ㄹㅛㅛ & 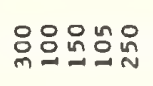 & 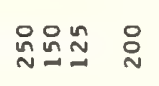 & 品怘 & 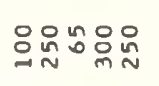 & 总品怘品 & 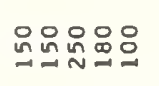 & ¿뭉 & 总品品品 \\
\hline 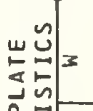 & 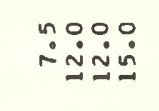 & $\because \because \underset{*}{*}:$ & $\ddot{m} \dot{\sim} \dot{n} \dot{m}$ & 沜: & $\ddot{\sim} \dot{\infty}: \dot{0}:$ & 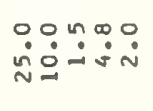 & $\stackrel{0}{\circ}$ & & $\stackrel{0}{-}$ \\
\hline 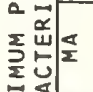 & ঐ̊ & $\stackrel{\infty}{\sim} \simeq D^{\infty}$ & $\stackrel{N}{\sim} \stackrel{\sim}{N}$ & 을욤웜워 & NNㅇ & mo $n=$ & $\simeq \infty \stackrel{\infty}{=}$ & : : & m号 \\
\hline 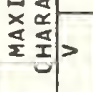 & 兰品弚兰。 & 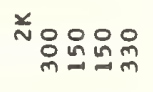 & 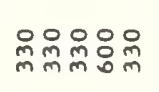 & 跡品䛔品 & 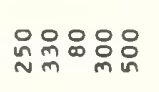 & 号啹确 & 品品品品 & 융요 & ঃ \\
\hline 过起范 & 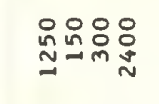 & 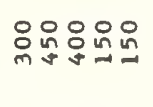 & 品으수류 & 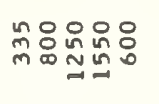 & 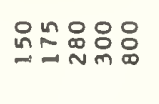 & 品怘品品怘 & 윱윰유 & 윰윰욤요 & $\stackrel{n}{\simeq}$ \\
\hline 造通> & mmm & 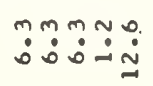 & 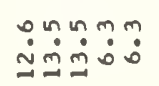 & $m: \ddot{m}: \ddot{0}:$ & : & nmmom & $\ddot{m}: m$ & m:Mmm & $\ddot{m}$ \\
\hline 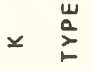 & Uエエエエ & IIIII & IIIII & IIIII & IIUII & IIIII & U UII & IIUIU & Iט ט \\
\hline$\underset{\propto}{\mathbb{\Psi}}$ & 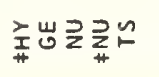 & 惢え゙ぇひ岕 & 岕ええ゙せ山。 & 茲岗岗岗岗 & 社空レ元岕 & & ヘニエ & 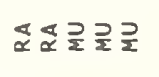 & 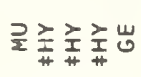 \\
\hline 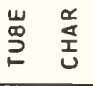 & ๔્ડ & 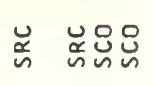 & 号品号号号 & 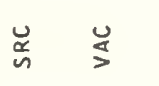 & 号怘芯 & 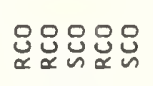 & 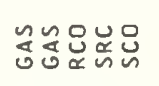 & 怘 & 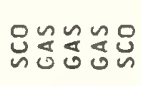 \\
\hline$\stackrel{\breve{s}}{\breve{s}}$ & 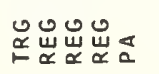 & 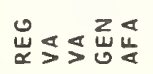 & 品岩幽出堊 & 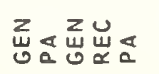 & 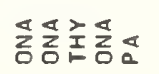 & 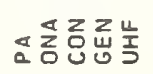 & 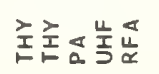 & 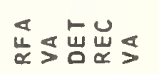 & 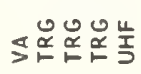 \\
\hline$\sum_{\infty}^{\infty}$ & ๓゚ロロミ & 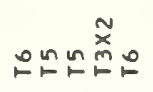 & ㅇレミㅀ & 인디 & ேロロ & モュュレさ & ேㅁㅁㅁ & ேேッேே & ロேロロロさ \\
\hline 盛 & 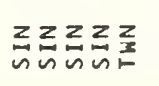 & 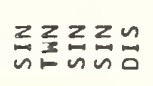 & 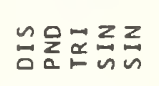 & 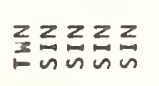 & 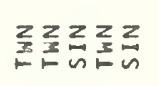 & 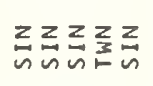 & 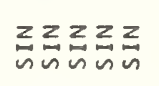 & 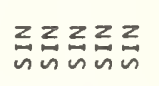 & 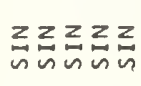 \\
\hline$\sum_{\underline{z}}^{0}$ & 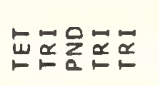 & 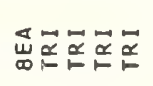 & 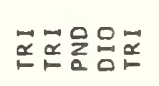 & 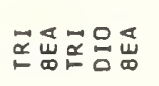 & 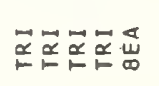 & 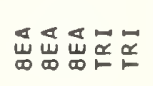 & 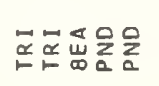 & 爷是음음모 & 剈出出出 \\
\hline 㟔 & थू $\sim n n$ & 嘧品 n & 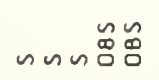 & $\dot{n}^{+}+++\dot{n}$ & 免嘿 & $n \dot{4} n$ & $n n$ & $n$ & 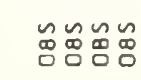 \\
\hline 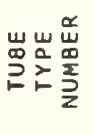 & 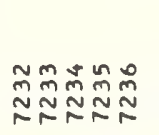 & 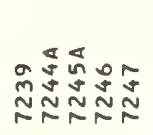 & 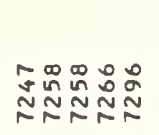 & 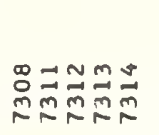 & 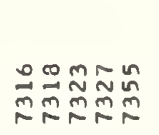 & 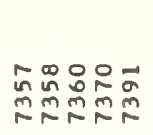 & 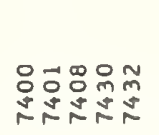 & 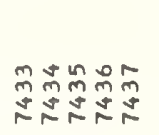 & 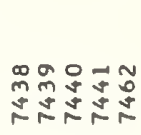 \\
\hline
\end{tabular}




\begin{tabular}{|c|c|c|c|c|c|c|c|c|c|}
\hline 崖崖 & 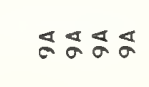 & 兼品吉 & 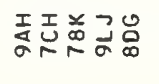 & 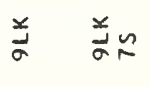 & 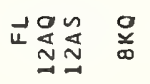 & $\vec{u} \vec{u} \vec{u} \vec{u} \vec{u}$ & $\vec{u} \vec{u}$ & $\stackrel{w}{a}$ & 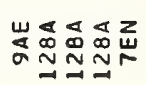 \\
\hline 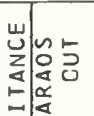 & $\because \stackrel{n}{\circ} \stackrel{n}{\circ} \stackrel{n}{\circ}$ & 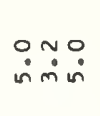 & 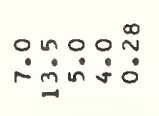 & 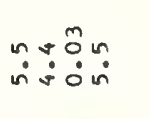 & 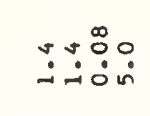 & & $\hat{o} \sigma$ & $\dot{m}$ & $\stackrel{\infty}{\dot{\sim}}$ \\
\hline $\begin{array}{ll}0 & 0 \\
0 \\
0\end{array}$ & $\because \stackrel{n}{\sim} \stackrel{\dot{\sim}}{-}$ & 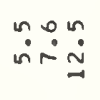 & min & ำง & 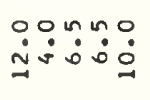 & & $\ddot{\sim} \sim$ & $\stackrel{\sim}{i}$ & $\dot{0}$ \\
\hline 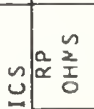 & 용 & $\Sigma$ & 石 & 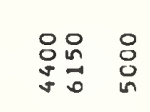 & 总 & & $\stackrel{x}{\vdots}$ & 兑 & 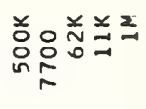 \\
\hline 总 & ニニล음 & & & 용 & $\stackrel{g}{m} \stackrel{n}{\cong}$ & & $\stackrel{\infty}{\infty}$ & $\stackrel{\infty}{=} \stackrel{\infty}{=}$ & $=\therefore 0$ \\
\hline 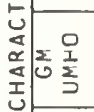 & 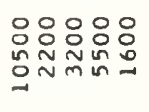 & 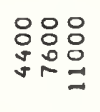 & 응ㅇㅇㅇㅇㅛ & 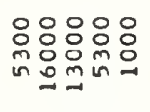 & 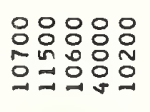 & & : & 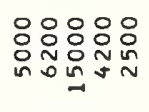 & 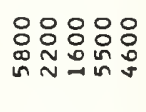 \\
\hline 幽 & $\infty 0 \propto 0-$ & =웡와 & 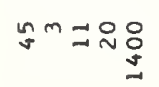 & 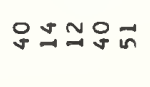 & 음요 $\stackrel{2}{\sim}$ & & 总 & $\simeq 0 \cong$ & 으음ㅇ \\
\hline$\vec{\infty}>$ & 品品品品怘 & 욧요요 & 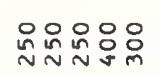 & 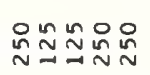 & 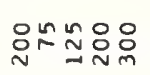 & 总员 & 윰욤요 & 品足品品 & 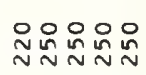 \\
\hline 造䓃. & 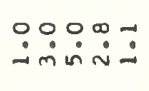 & $\dot{m} \ddot{m} \dot{\check{n}}$ & $\begin{array}{l}\ddot{m}-\dot{m} \dot{\sim} \dot{\sim} \\
\dot{\sim}\end{array}$ & 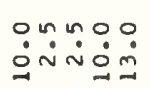 & $\begin{array}{l}\because 0 N \text { in o } \\
\dot{j} \dot{\sim} \text { ing }\end{array}$ & & $\ddot{0}:$ & 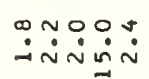 & $\ddot{m} \dot{m} \ddot{\dot{i}} \dot{\sim} \dot{N}$ \\
\hline 2 & $\stackrel{n}{N} \underset{N}{N}$ & n & $\stackrel{\circ}{\sim}$ & 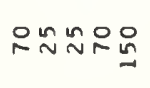 & 뮷유윰 & 웅응ㅇㅁㅇㅠ. & 造夰 & 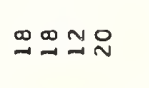 & $\stackrel{\circ}{\sim}$ \\
\hline 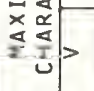 & 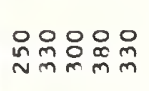 & 윰윰요 & 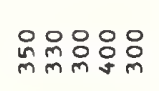 & 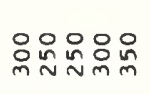 & 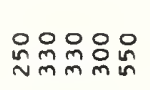 & 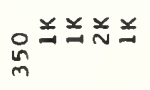 & 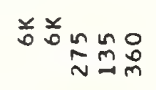 & $\stackrel{n}{n} \underset{\sim}{n}{ }^{n}:$ & 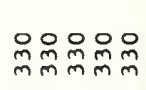 \\
\hline 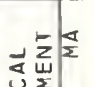 & 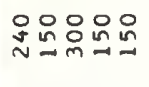 & 임윰 & 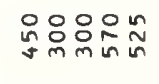 & 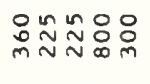 & 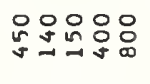 & & $\stackrel{O}{\stackrel{9}{N} \stackrel{n}{N}}$ & 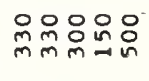 & 总品品品品 \\
\hline 这年, & تُّ & $\ddot{0}: m$ & 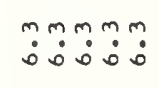 & 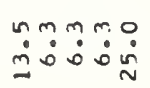 & mmmm & & 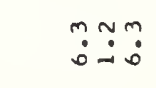 & mm & 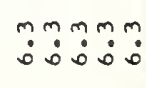 \\
\hline $\begin{array}{r}\stackrel{u}{a} \\
\times \quad 2 \\
2\end{array}$ & IIIII & III & IIIII & $I I I I I$ & IIIII & טنט ט & U U и & IIIII & IIIII \\
\hline$\underset{\sim}{\stackrel{\leftrightarrow}{\sim}}$ & 岕ららららら & ららら & ららうら主え & $\underbrace{}_{\propto} \underset{\alpha}{u} \underset{\alpha}{u}$ & 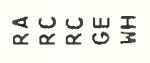 & 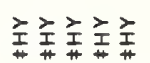 & 空主嵌芯兄 & 泫嵌〉方 & 方至主至京 \\
\hline 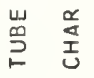 & 总怘品 品 & 品 & 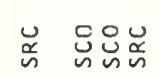 & 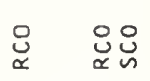 & 号怘 茲 & 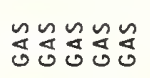 & 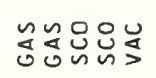 & 岕号 & $\underset{\alpha}{g_{\alpha}} \underset{\sim}{\underline{\alpha}} \underset{\sim}{u}$ \\
\hline 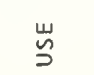 & 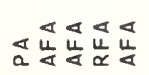 & 造崖崖 & 㗱出出芯 & 造岂峷崖台 & 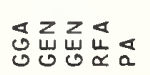 & 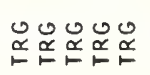 & 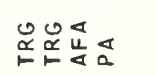 & 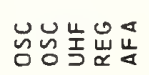 & 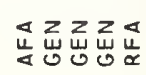 \\
\hline$\stackrel{\rho}{\infty}_{\substack{\infty\\
}}^{\infty}$ & こ゚レロ上 & $\curvearrowleft \curvearrowleft$ & 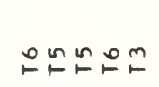 & 늠렴욤 & 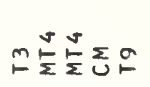 & MMM吕 & 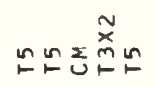 & ゚ㅠํํㄴㅇㅛ & ゚トニュル \\
\hline$\underset{\Sigma}{u}$ & 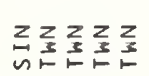 & 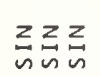 & 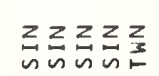 & 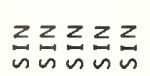 & 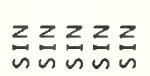 & 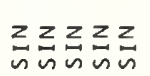 & 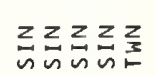 & 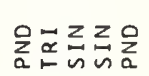 & $\ddot{\alpha}$ \\
\hline$\sum_{2}^{\circ}$ & 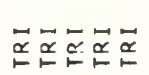 & 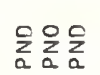 & 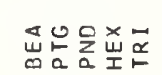 & 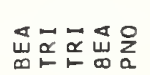 & 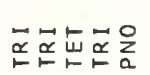 & 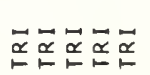 & 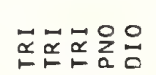 & 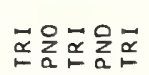 & 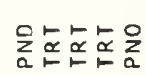 \\
\hline 㟧 & $\dot{n}+\dot{\omega} \dot{s}$ & $\dot{\omega}^{+}+$ & $++\dot{\sim} \dot{s}$ & $\dot{n}^{++} n$ & $++n$ & $+\dot{s} \dot{\sim}+\dot{n}$ & $\dot{n} \dot{n} n+$ & $++n$ in & \pm \\
\hline 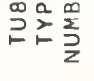 & 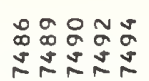 & 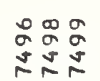 & 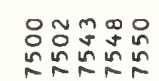 & 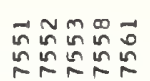 & 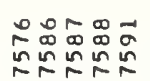 & 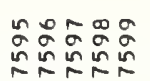 & 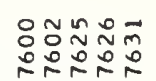 & 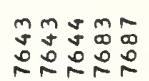 & 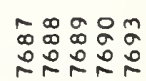 \\
\hline
\end{tabular}




\begin{tabular}{|c|c|c|c|c|c|c|c|c|c|}
\hline 岕岕员 & 竎杀 & 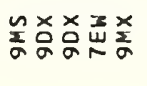 & 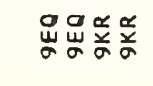 & 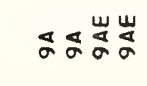 & 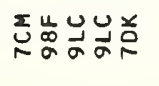 & 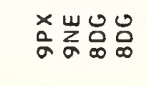 & 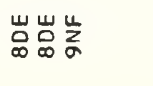 & & ج \\
\hline 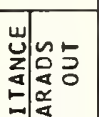 & $\stackrel{0}{\circ}$ & $\ddot{m} \dot{\sim} \dot{\sim}: \dot{m}:$ & $\stackrel{\sim}{\tilde{O}} \dot{\sim} \dot{\sim} \dot{\sim} \stackrel{ \pm}{\sim}$ & 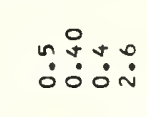 & 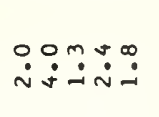 & 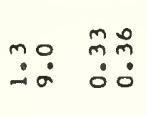 & $\stackrel{n}{0}$ & $\stackrel{\circ}{0}$ & $\stackrel{\infty}{\infty} \stackrel{\infty}{-}$ \\
\hline 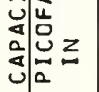 & $\stackrel{0}{\dot{I}}$ & 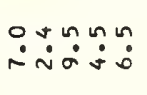 & 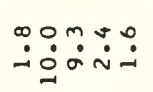 & 芒 & 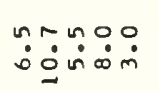 & 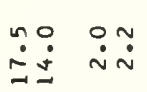 & 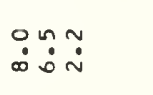 & $\ddot{n}$ & $\dot{n} \ddot{\dot{n}}$ \\
\hline$s \mid \frac{n}{\alpha}$ & E。 & 弟总兑总。 & 弟弟 & 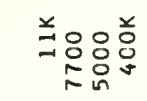 & 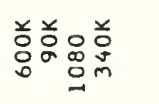 & 윰유 & 흐욤 & & $\stackrel{\Sigma}{N}$ \\
\hline 矛 & & $\stackrel{\sim}{\sim}$ & $\approx$ & $\begin{array}{l}0=0 \\
0=0\end{array}$ & n ${ }_{\infty}^{\circ}$ & nㅗㅇ & $\stackrel{n}{\sim}$ & & $\infty m$ \\
\hline \begin{tabular}{l|l} 
\\
0
\end{tabular} & 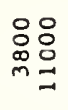 & $\begin{array}{l}: \\
: \\
0\end{array}$ & 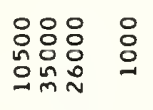 & 운유 & 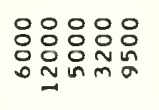 & 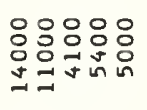 & 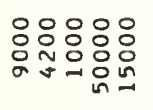 & $\begin{array}{l}\circ \\
8 \\
\text { 웅 }\end{array}$ & 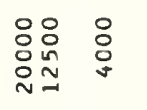 \\
\hline$=\frac{\pi}{2}$ & $\sigma \stackrel{\infty}{\circ}$ & $\stackrel{\infty}{\sim} \sim \underset{\sim}{*}$ & 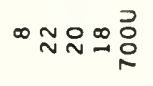 & 오오오 & $\infty \stackrel{\sim}{\sim} \sim \sim \sim$ & 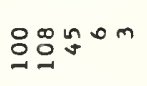 & 윰 노 & $\stackrel{n}{m}$ & 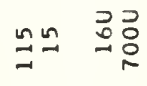 \\
\hline$\infty$ & 욤요 & 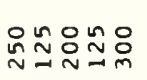 & 윰요 & 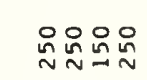 & 윳요욤욤요 & 임욧요 & 요믕ㅇㅁㅇㅁㅇ & $\stackrel{n}{m}$ & 음 = in \\
\hline 出氙 & mo: & O̊: & 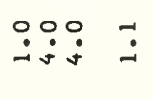 & 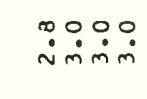 & 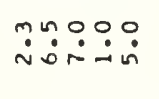 & 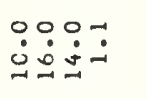 & 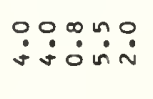 & $\dot{0}$ & $\ddot{m} \dot{m}$ \\
\hline 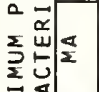 & $\simeq$ & $\stackrel{\sim}{*} \quad \stackrel{0}{*}$ & $\stackrel{2}{\sim}$ 品 & $\stackrel{\circ}{\sim}$ & $\stackrel{n}{\simeq} \stackrel{0}{=}$ & $\stackrel{D}{\sim} \sim N N$ & og & in & 品品 - \\
\hline 永齐趁> & 울욤 & 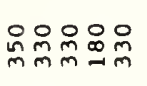 & 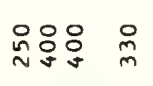 & 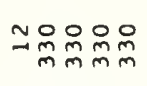 & 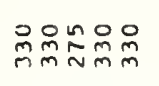 & 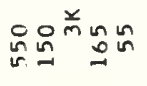 & 话品品品 & $\stackrel{\circ}{\sim}$ & 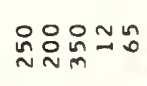 \\
\hline ব) & 윰요 & 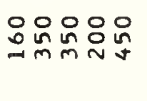 & 움욨ñ & 川品品路号 & 임윰요 & 윰윰융요 & 읔음ㅇㅁㅇㅇㅛ & $\stackrel{9}{q}$ & 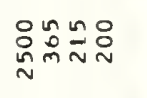 \\
\hline 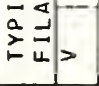 & $\dot{m}:$ & 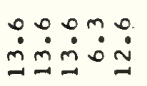 & mMmo̊ & 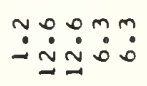 & 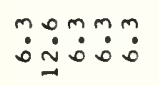 & 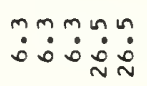 & : & $\ddot{b}$ & $\ddot{0} \dot{0} \dot{0} \dot{0} \dot{n}$ \\
\hline$\times \quad \begin{array}{l}a \\
\Sigma \\
\Sigma\end{array}$ & II & IIIII & エエエエエ & UIIII & Iエエエエ & IIIII & IIIII & I & IIIIU \\
\hline$\underset{\sim}{\underset{\sim}{u}}$ & $\sum 幺$ & 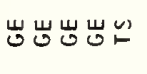 & 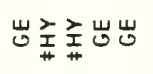 & 㟧主文文京 & 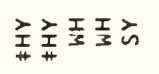 & 主え゙岕うう & 方方岕岕 & $\frac{5}{4}$ & こえ゙ぇミ \\
\hline $\begin{array}{ll} \\
\infty \\
\infty\end{array}$ & & 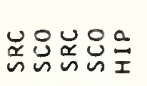 & 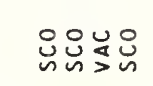 & 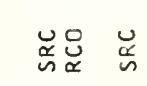 & 炭号品 关 & 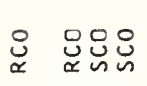 & 怘品 & 怘 & 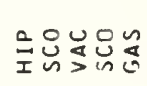 \\
\hline$\stackrel{u}{2}$ & $a$ & 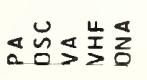 & 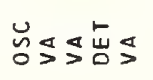 & 击造识文 & 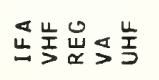 & ه承出出 & 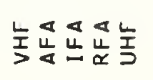 & $\frac{u}{I}$ & ¿\㟧山㟧 \\
\hline 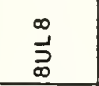 & $\approx g$ & レ゚゚に゚ & こ゚レ゚゚ & セレ゚ト゚ & ピロレロ & 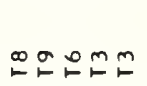 & 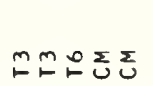 & $\therefore$ & 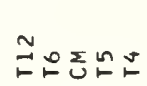 \\
\hline $\begin{array}{l}\omega \\
\vdots \\
2 \\
\Sigma\end{array}$ & $z \frac{z}{n}$ & 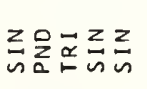 & 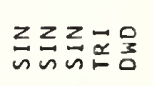 & 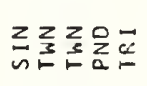 & 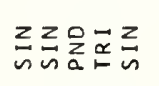 & 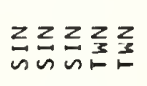 & 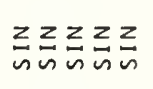 & $\frac{z}{n}$ & 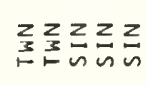 \\
\hline$\frac{0}{2}$ & 员岕 & 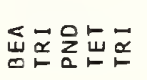 & 总员员号号舍 & 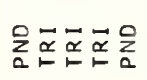 & 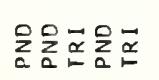 & 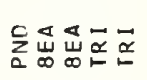 & 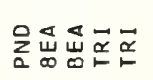 & $\sum_{2}$ & 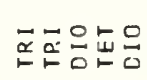 \\
\hline 岂 & $\dot{n} n$ & $n$ & nnnn & $\dot{\Delta} \dot{\dagger} \dot{\omega}$ & シがレッ & $+n++\dot{n}$ & $+\dot{\sim}+\backsim n$ & + & $\sim$ \\
\hline 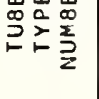 & 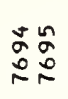 & 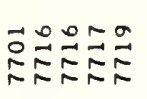 & 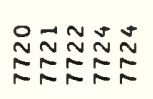 & 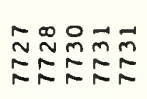 & N⿳⺈⿵冂丶m & 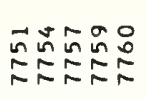 & 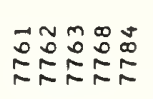 & $\begin{array}{l}\infty \\
\stackrel{\infty}{\sim}\end{array}$ & 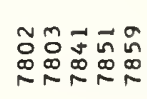 \\
\hline
\end{tabular}




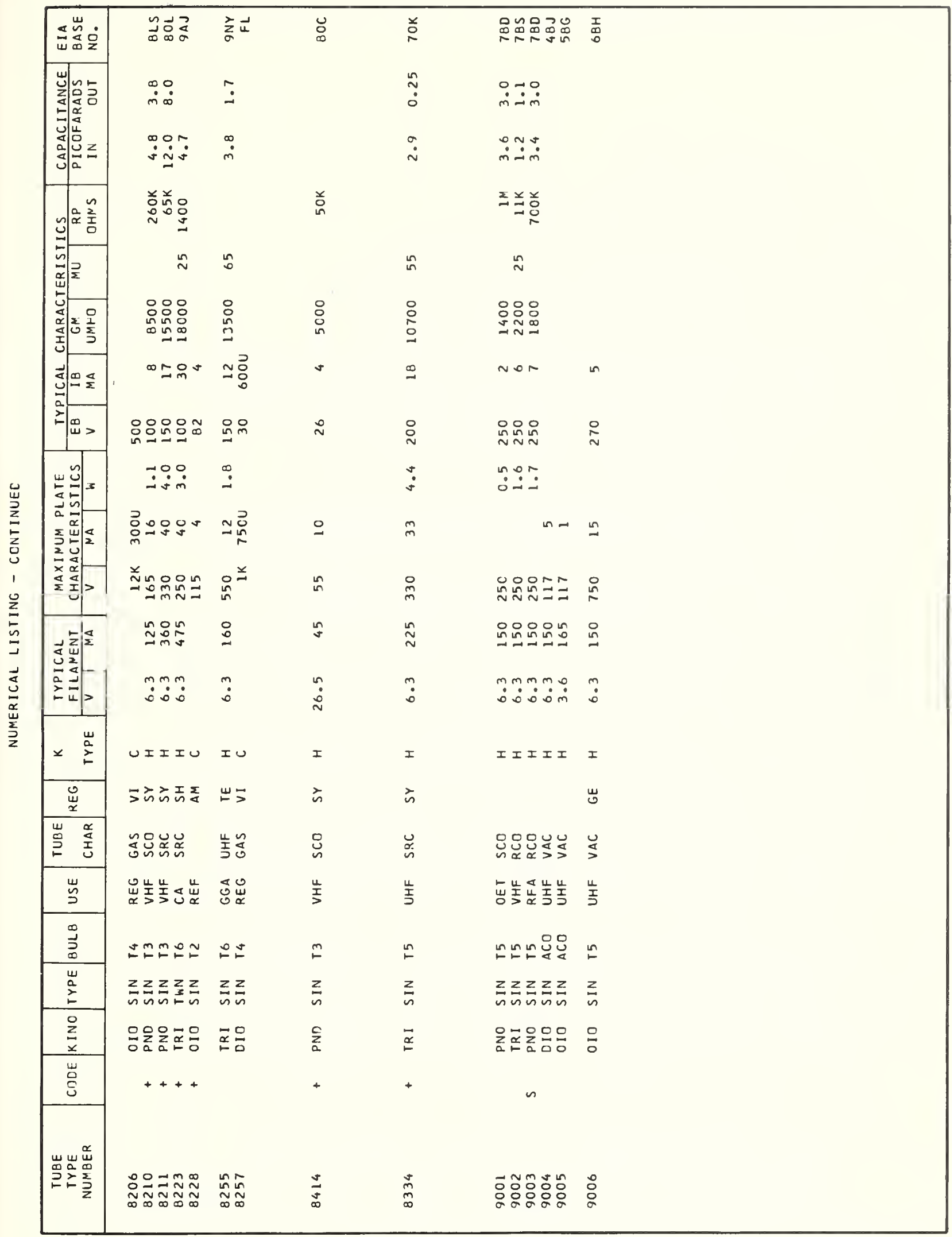




\section{Characteristic Listing of Data on Receiving Tubes}




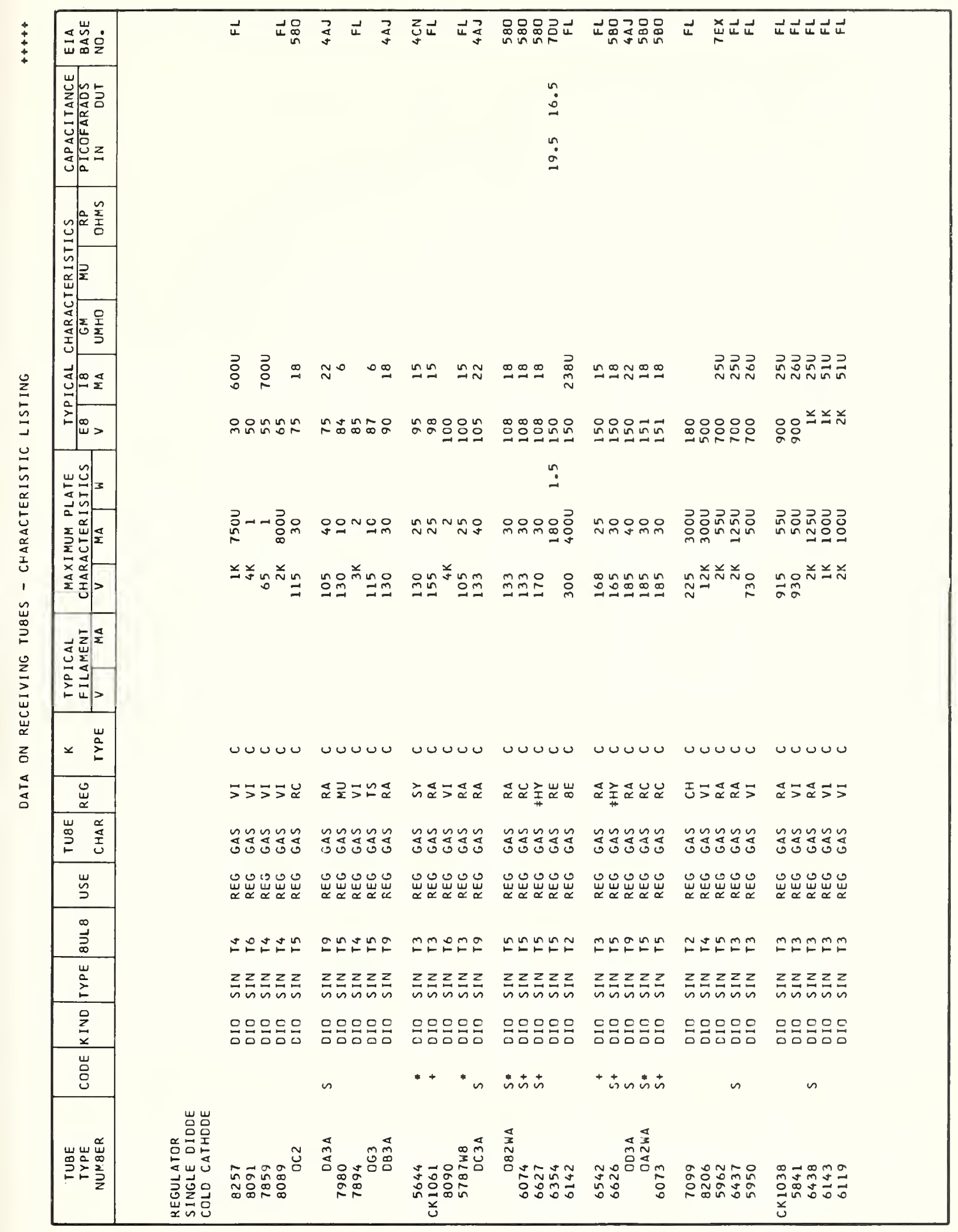




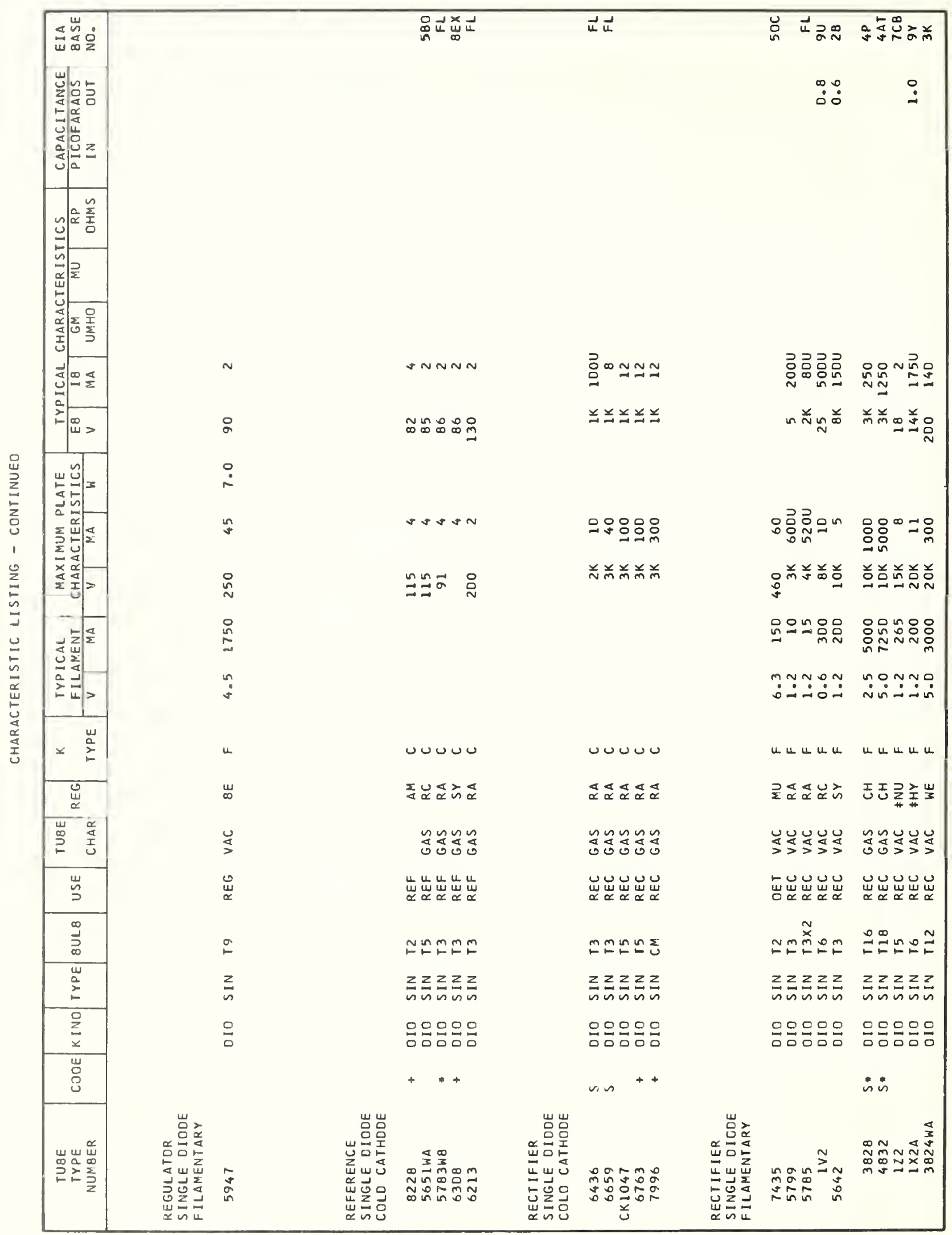




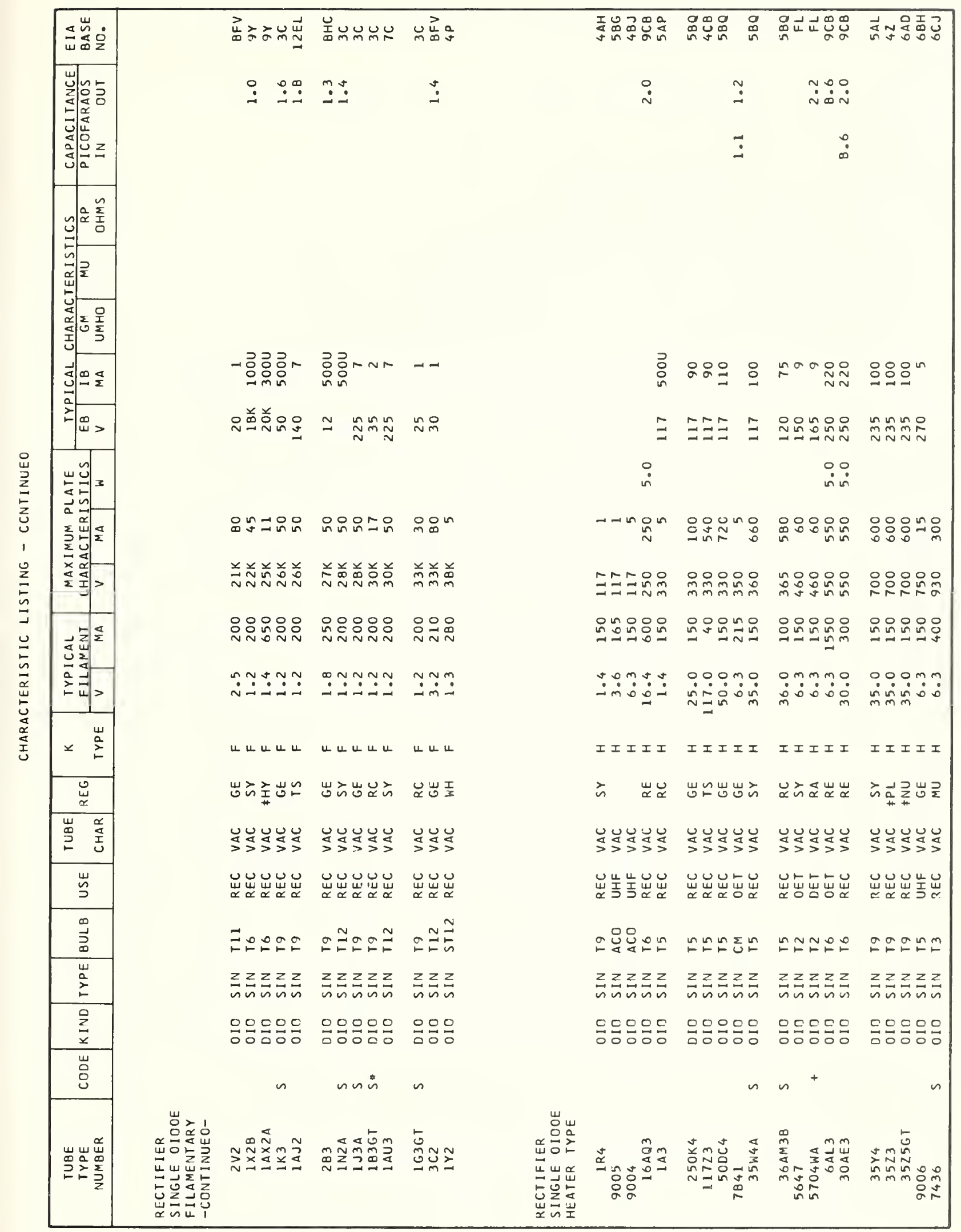




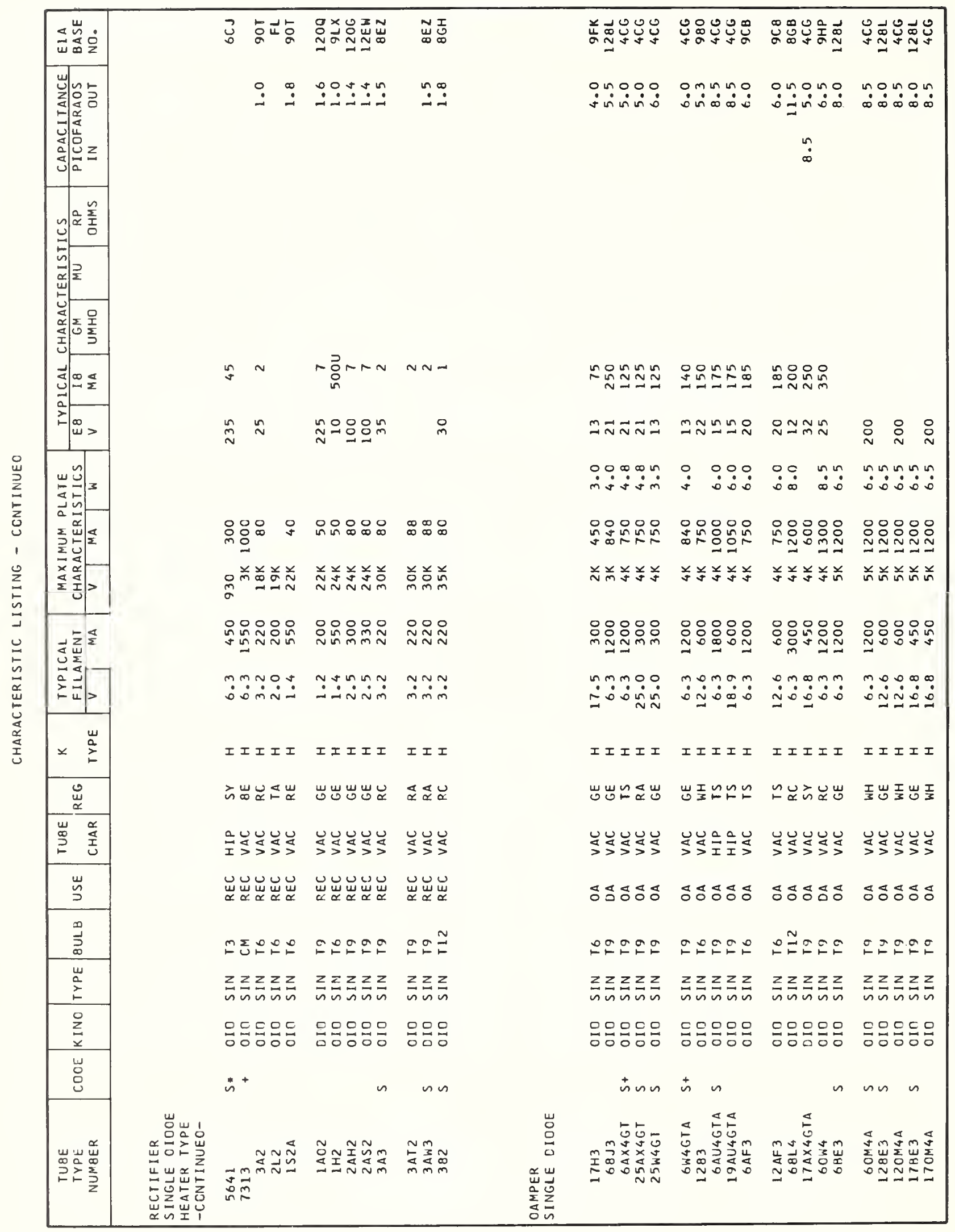




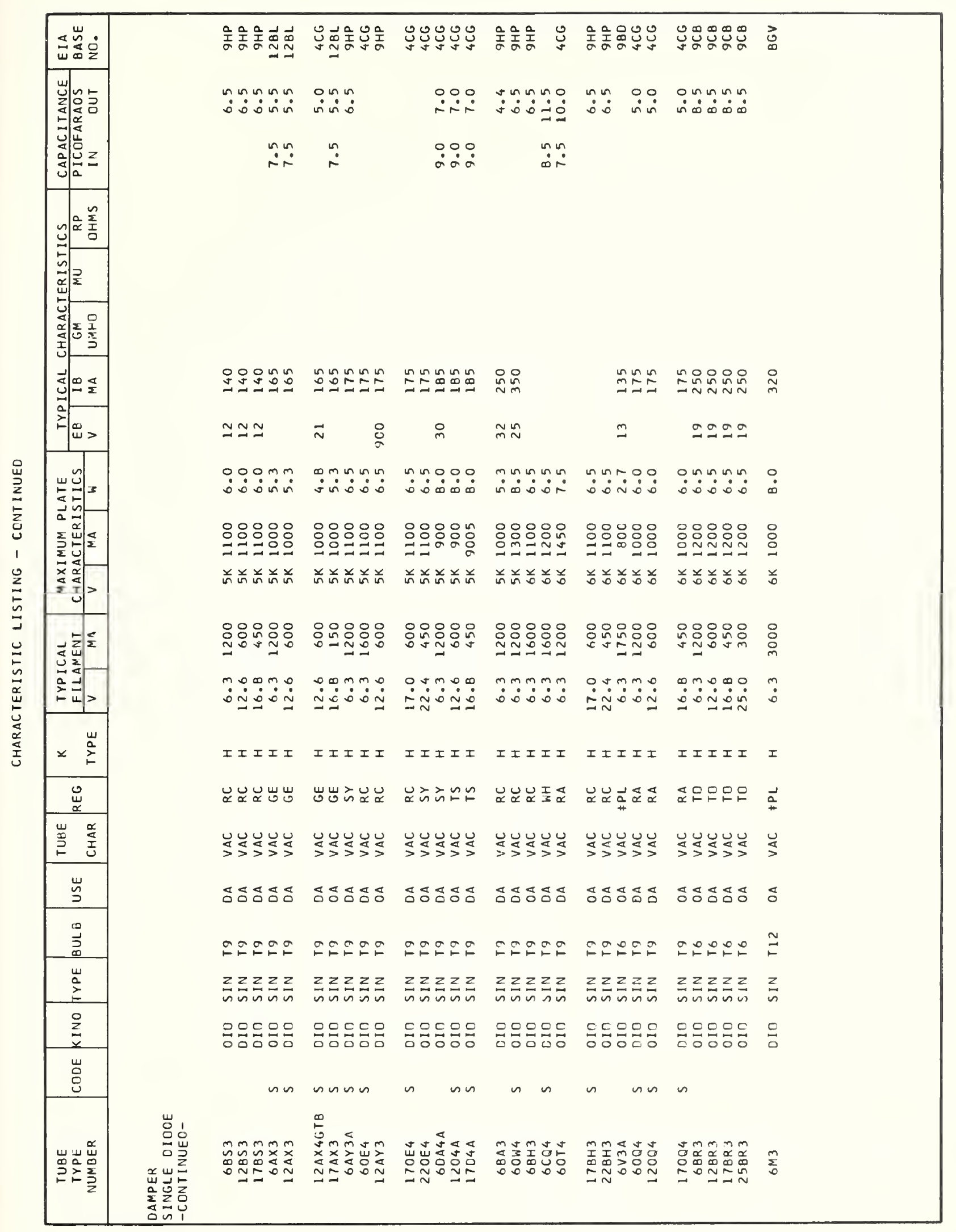




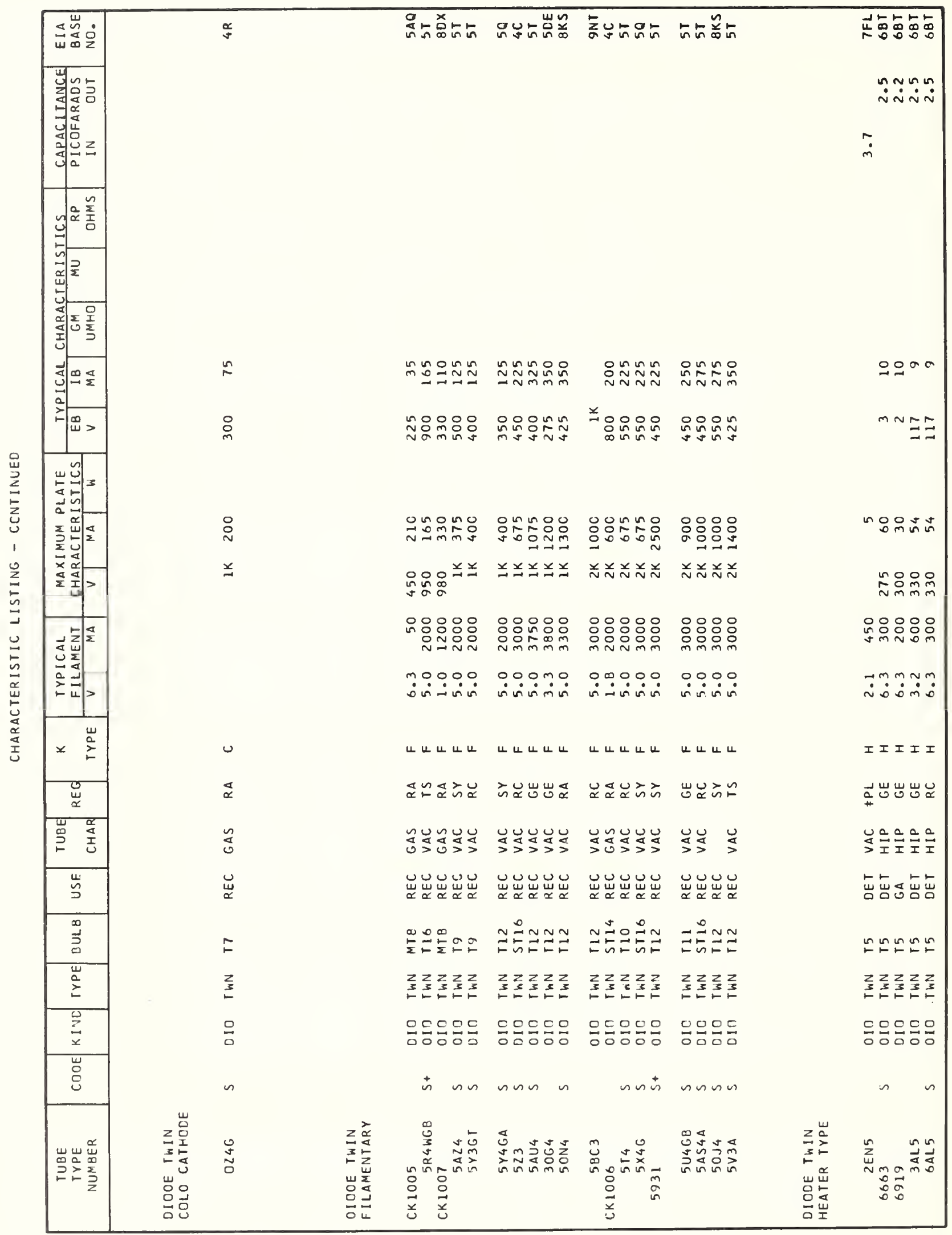




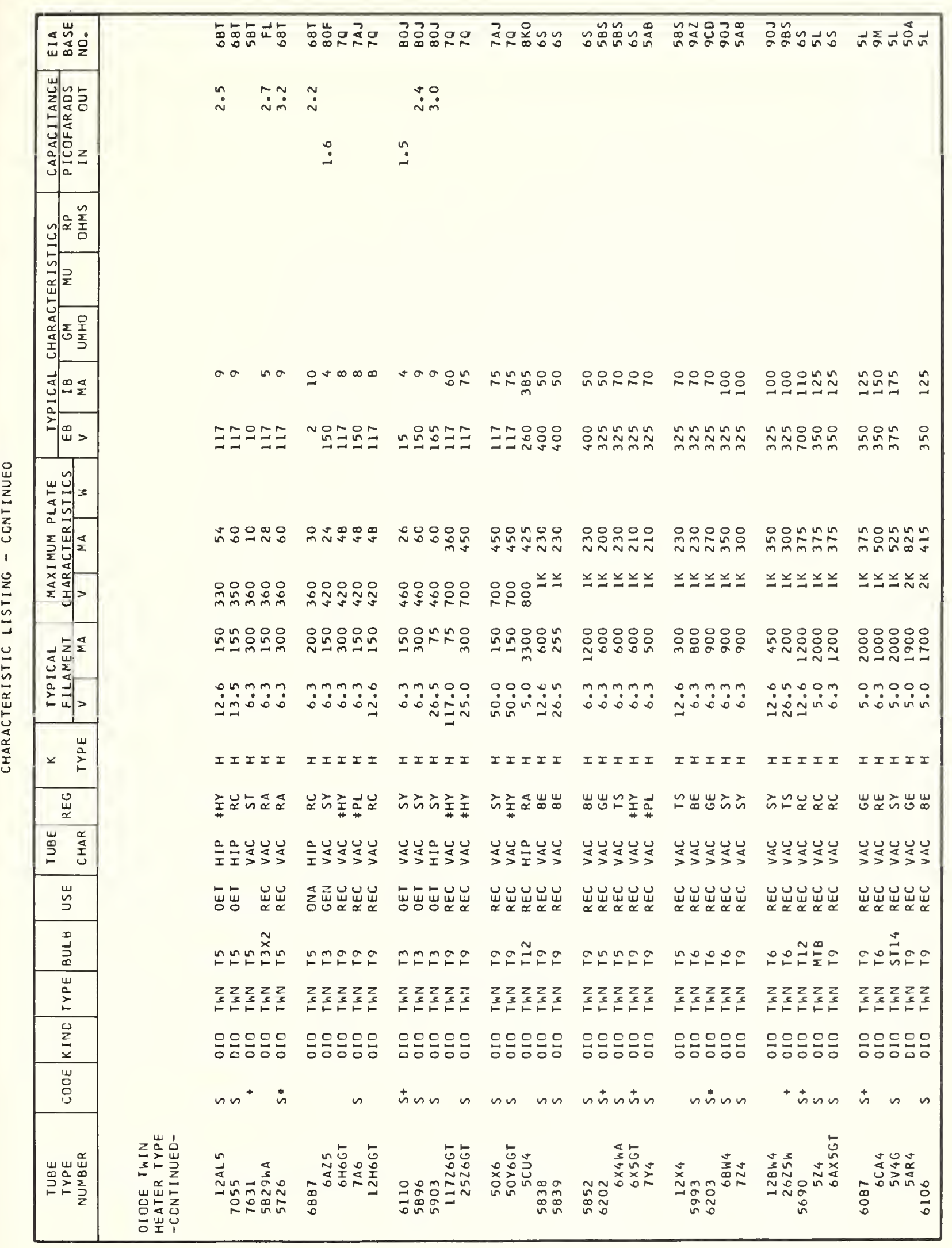




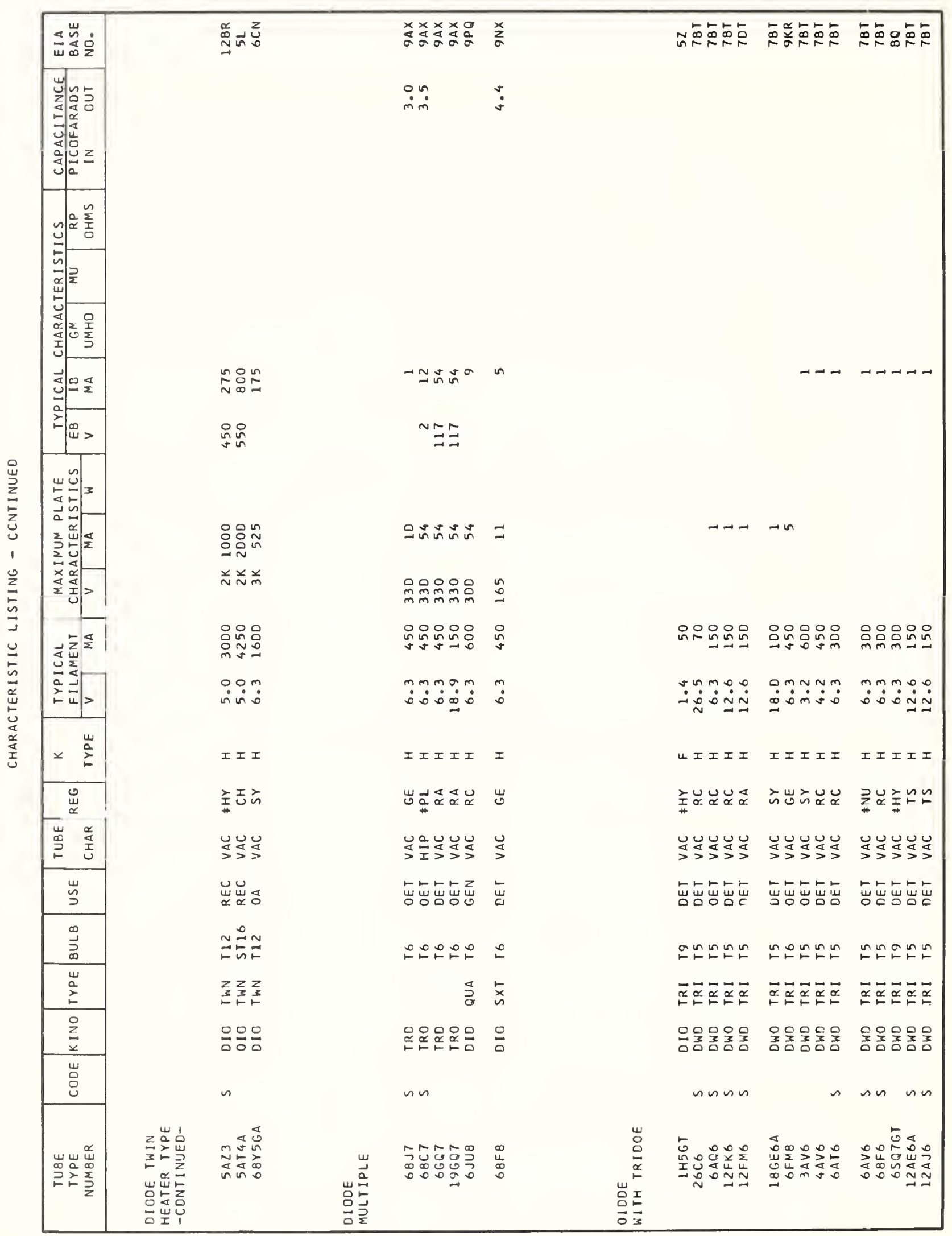




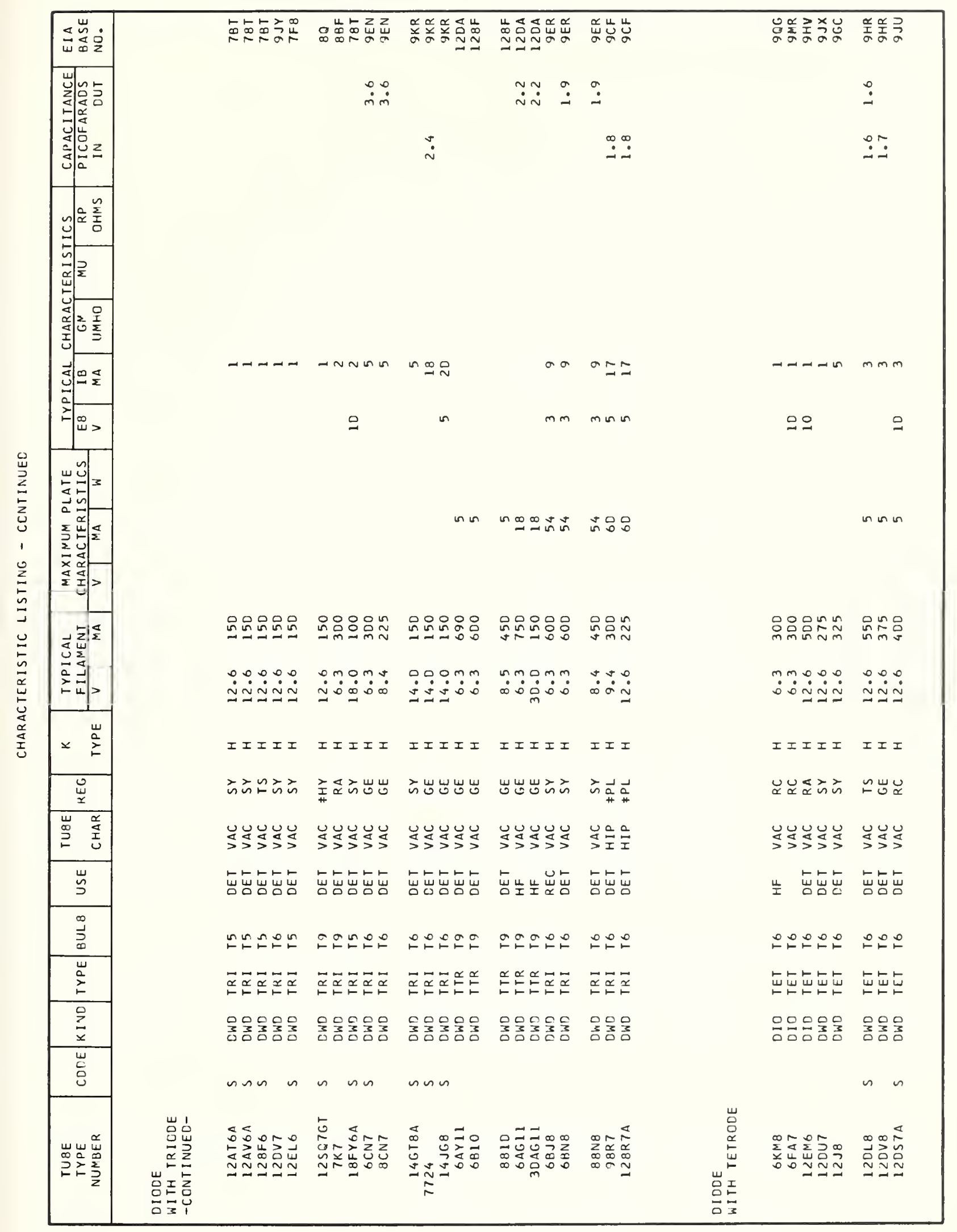




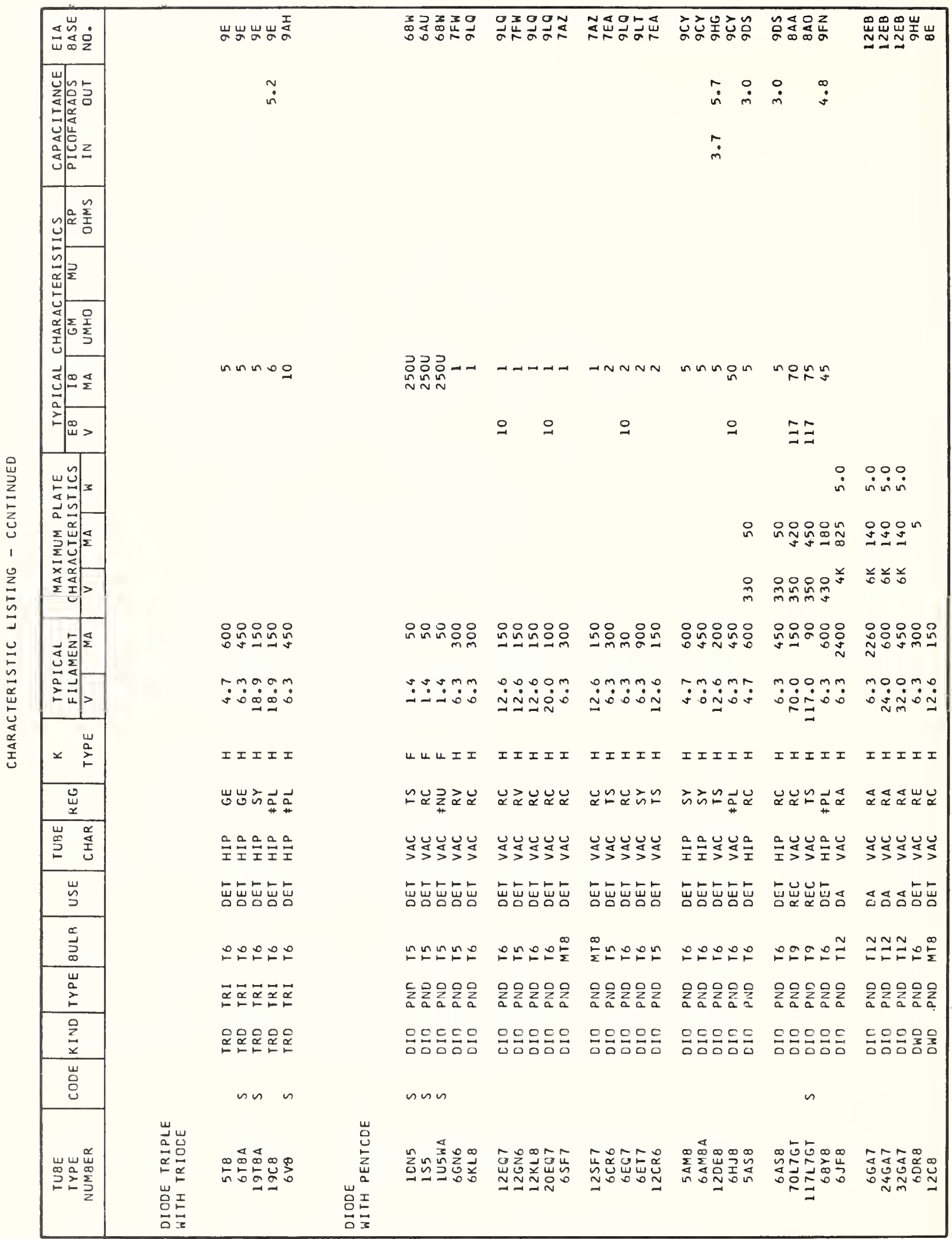




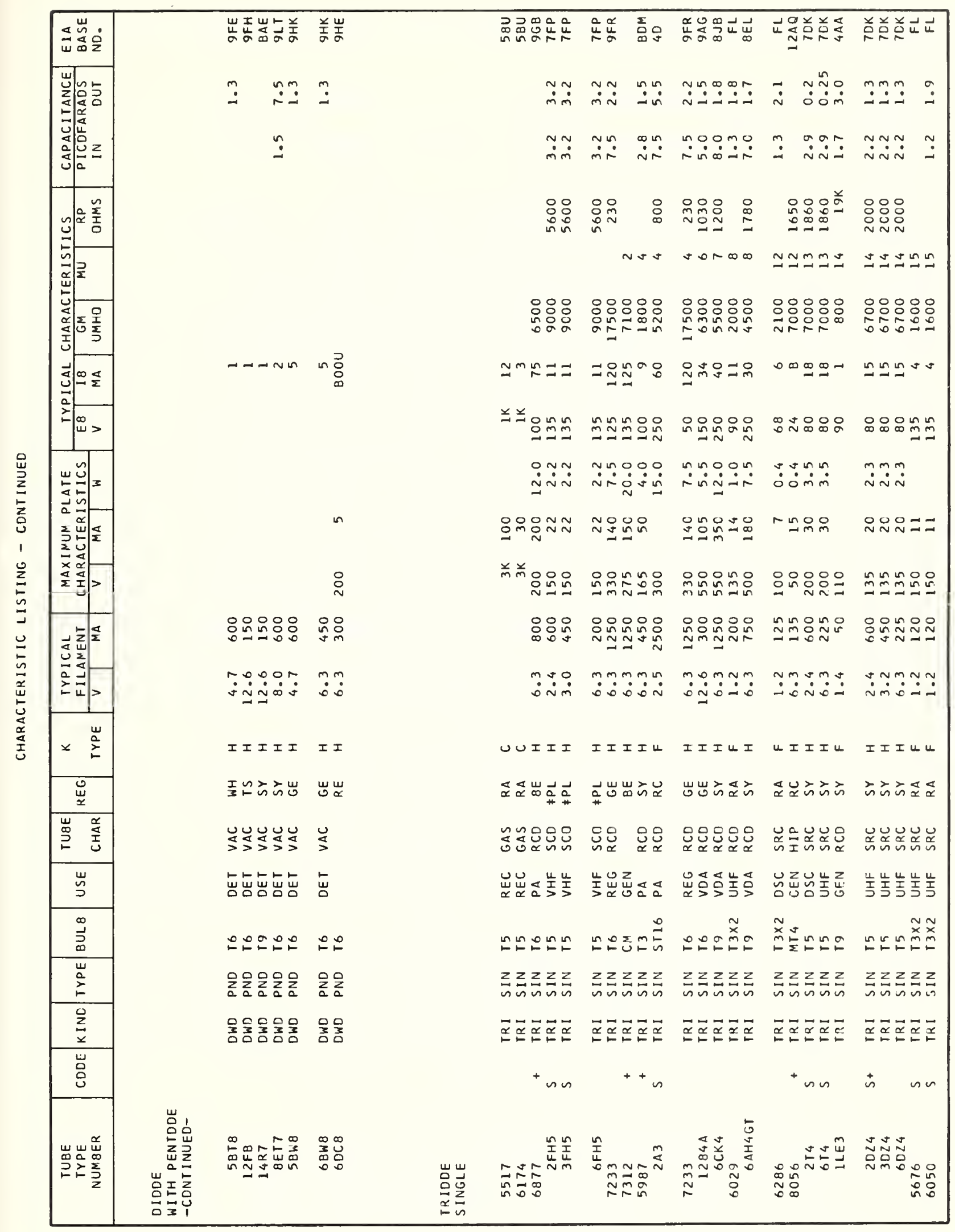




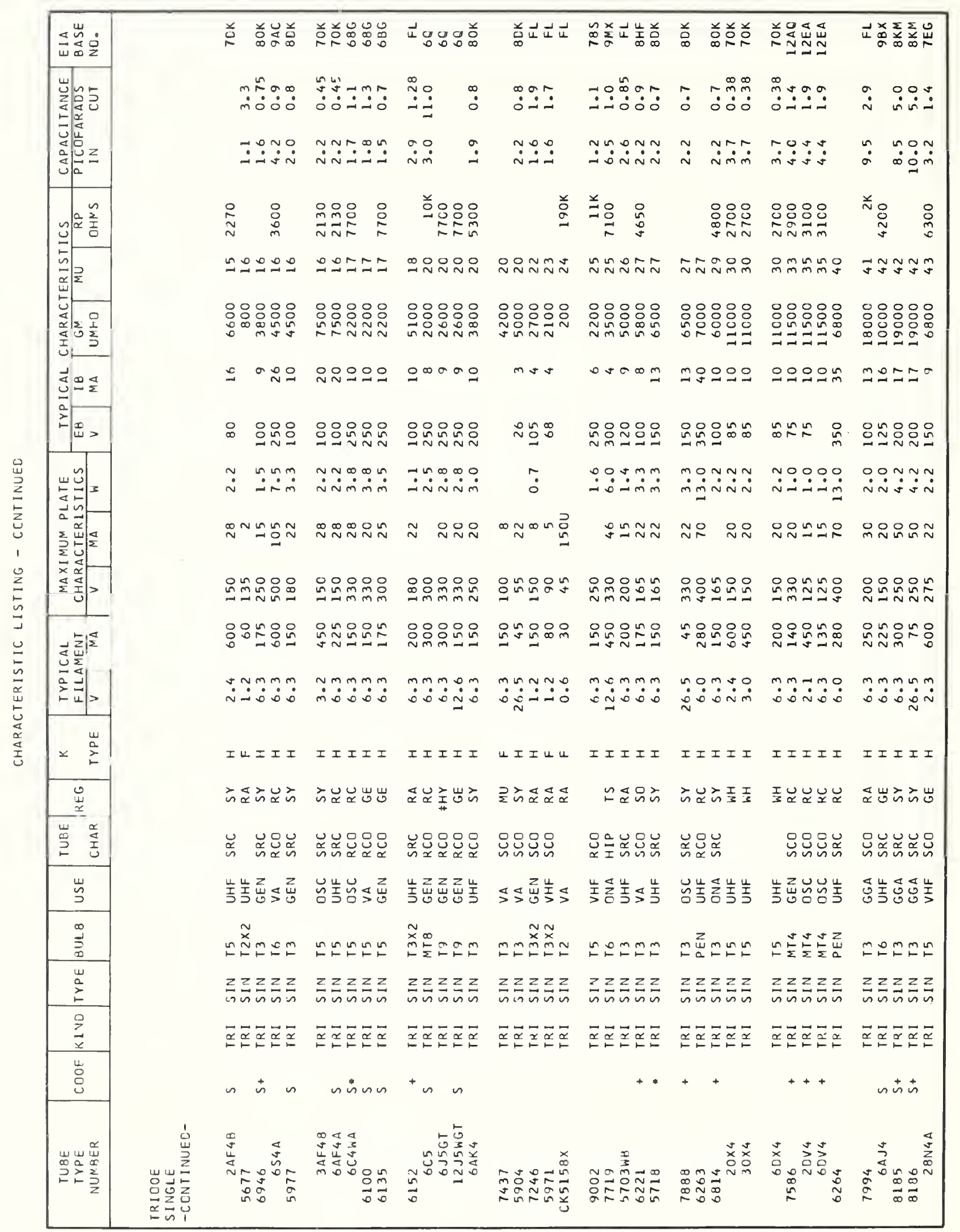




\begin{tabular}{|c|c|c|c|c|c|c|}
\hline 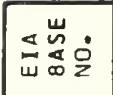 & 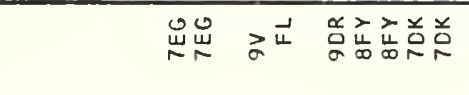 & 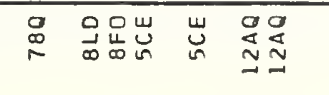 & 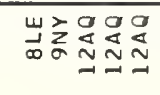 & 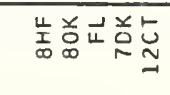 & 亮哭选总总 & 总总 \\
\hline 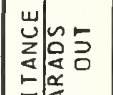 & ن. & 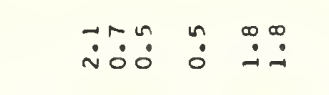 & 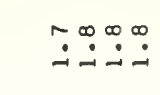 & 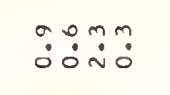 & 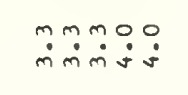 & 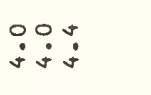 \\
\hline 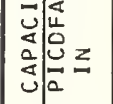 & 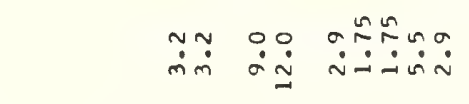 & 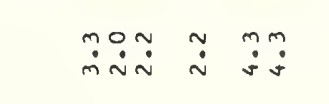 & 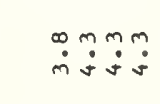 & 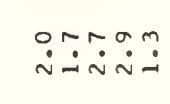 & 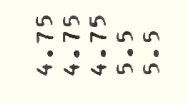 & 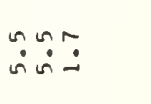 \\
\hline 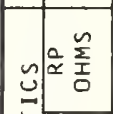 & 踞 & 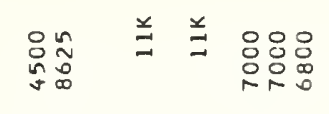 & 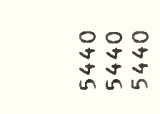 & $\stackrel{̊}{\Im} \quad:$ & 总品 & 总品品 \\
\hline 䒺屋 & 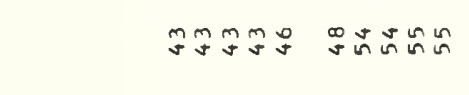 & 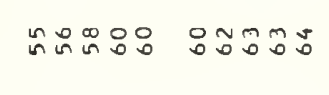 & 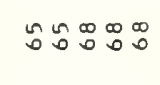 & 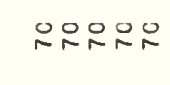 & 아삼맘 & RRRNN \\
\hline & 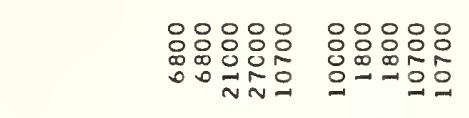 & 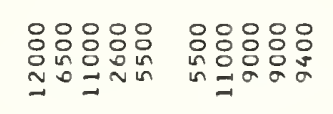 & 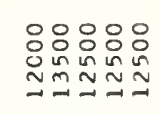 & & 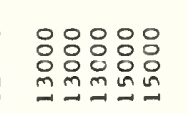 & 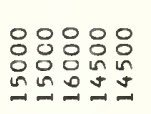 \\
\hline$\frac{4}{\infty}=\frac{\pi}{2}$ & 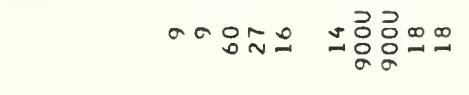 & $\cong \Phi \infty 0 \varrho \simeq r r$ & & 혼 & $\Xi \Xi \Xi \simeq \simeq$ & $\simeq \simeq \simeq \simeq \simeq$ \\
\hline 政> & 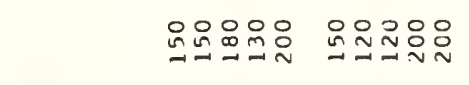 & 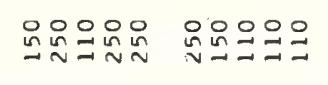 & 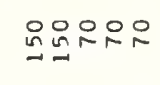 & 음윳윰요 & 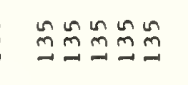 & 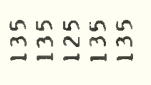 \\
\hline 通氙: & 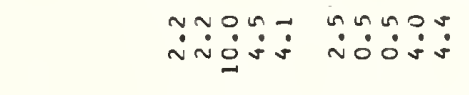 & 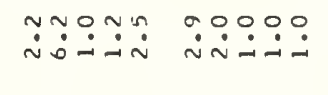 & 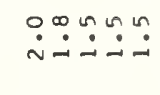 & 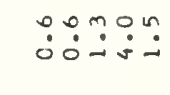 & 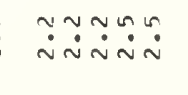 & 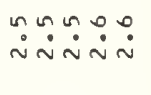 \\
\hline 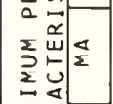 & 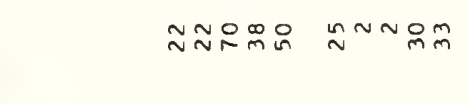 & 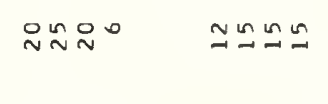 & $\stackrel{N}{2}$ & $m m \circ 0$ & 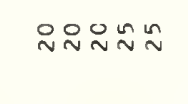 & ผュก๊ก \\
\hline 宏部> & 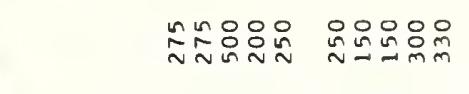 & 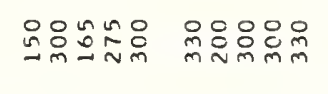 & 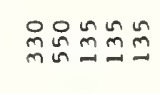 & 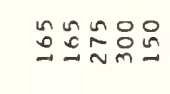 & :유윰유 & 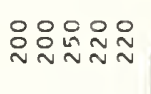 \\
\hline 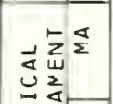 & 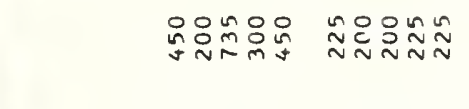 & 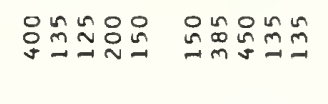 & 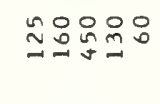 & 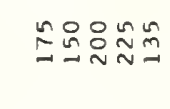 & 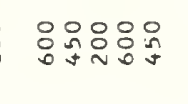 & 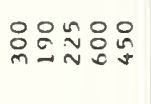 \\
\hline 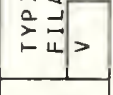 & 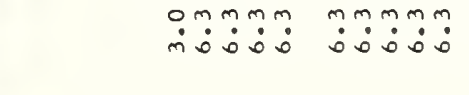 & 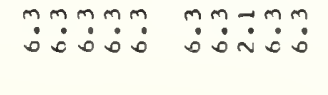 & 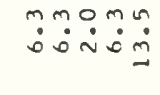 & & 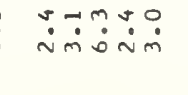 & 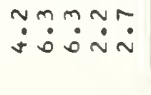 \\
\hline$\simeq \stackrel{\vec{\omega}}{\check{\Sigma}}$ & 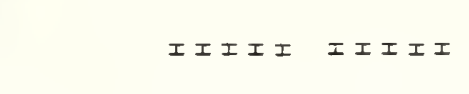 & エエエエエ エエエエエ & & & & IIIII \\
\hline$\stackrel{\vec{*}}{\vec{*}}$ & 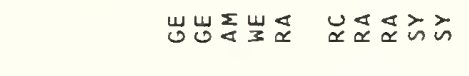 & 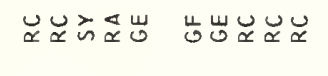 & 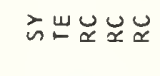 & 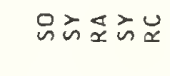 & 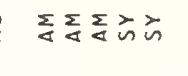 & 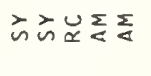 \\
\hline $\begin{array}{l}\text { 岕 } \\
\stackrel{2}{2} \\
\end{array}$ & 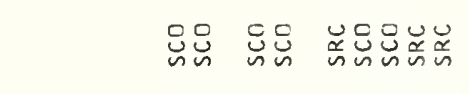 & 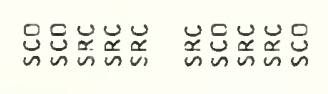 & 总㟱总总导 & & 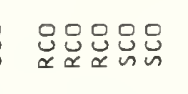 & 品品 \\
\hline 岁 & 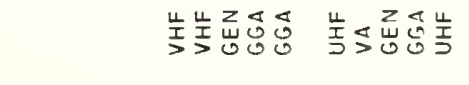 & 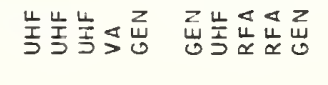 & 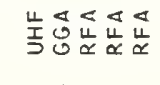 & & 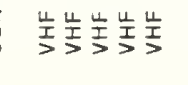 & 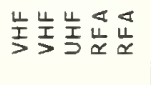 \\
\hline 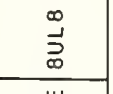 & 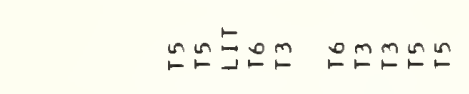 & 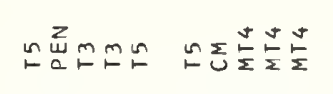 & 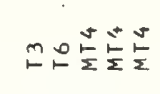 & & ヘロロロロュ & 气ロ蛋んロ \\
\hline 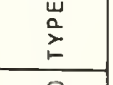 & 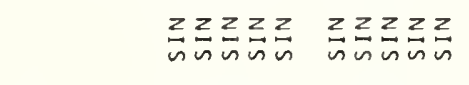 & 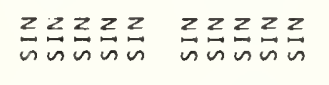 & 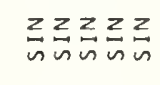 & $\sin z \sin _{2} \sin _{n}$ & 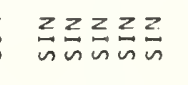 & 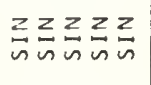 \\
\hline$\frac{O}{\underline{z}}$ & 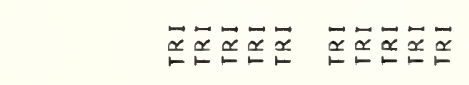 & 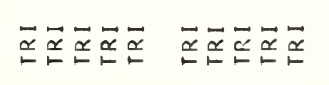 & 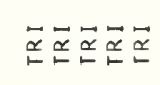 & $\bar{\alpha} \underline{\underline{\alpha}} \underline{\underline{\alpha}} \underline{\underline{\alpha}} \underline{\underline{\alpha}} \underline{\underline{\alpha}}$ & $\underline{\underline{\alpha}} \overline{\underline{\alpha}} \overline{\underline{\alpha}} \underline{\underline{\alpha}} \overline{\underline{\alpha}} \overline{\underline{\alpha}}$ & $\overrightarrow{\underline{\underline{x}}} \underline{\underline{\underline{x}}} \underline{\underline{\underline{\alpha}}} \overrightarrow{\underline{\alpha}} \overline{\underline{x}}$ \\
\hline 峉 & $n \quad \dot{n}^{+}+$ & 古婄的部 & & & & + \\
\hline 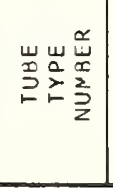 & 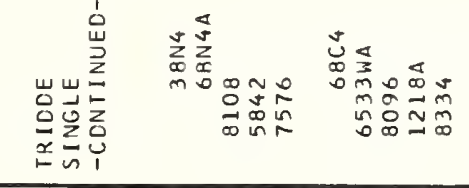 & 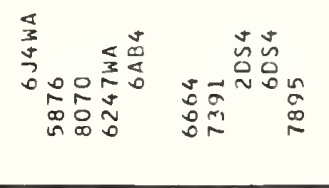 & 勿 & 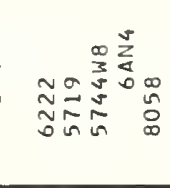 & 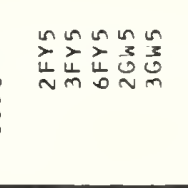 & 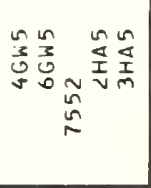 \\
\hline
\end{tabular}




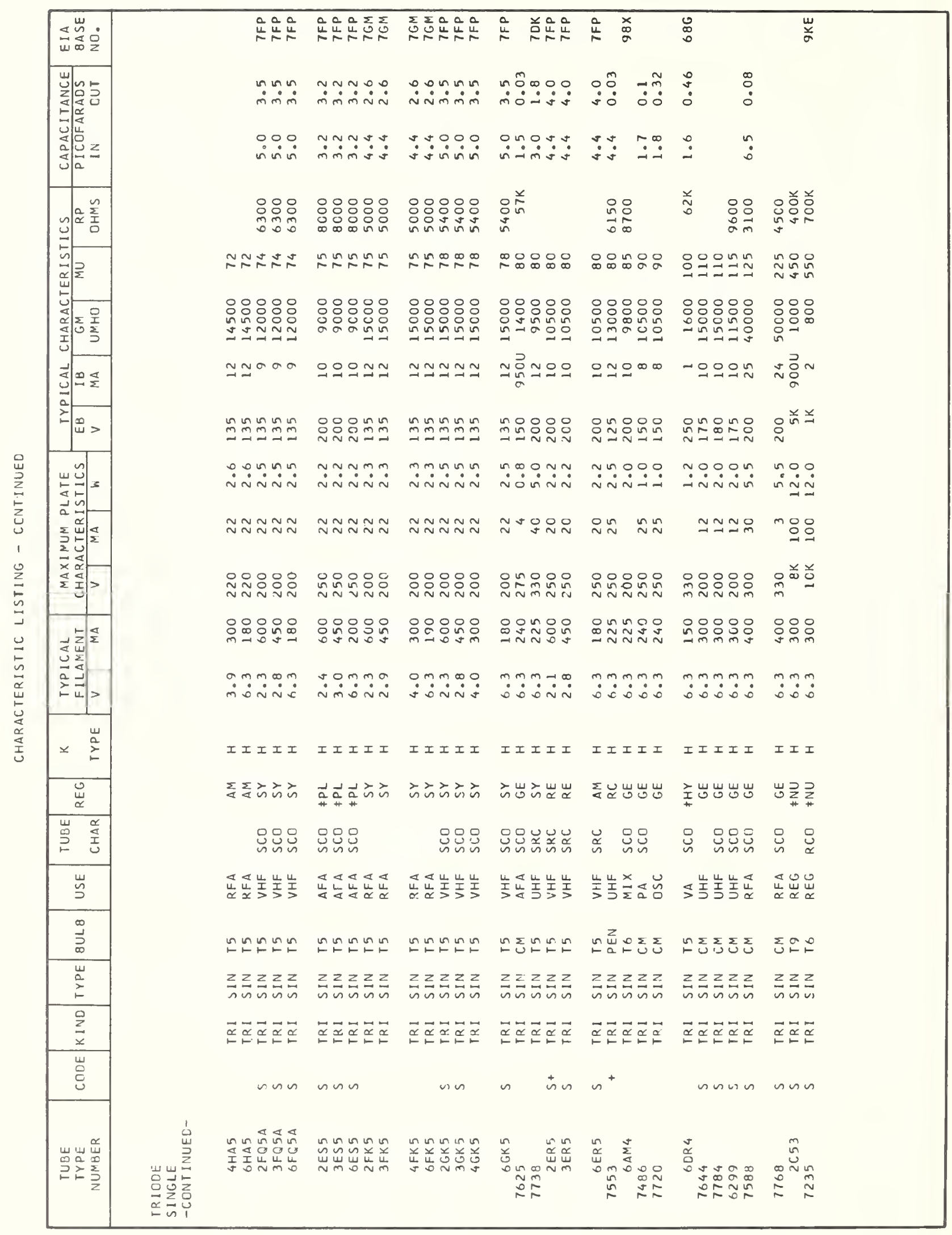




\begin{tabular}{|c|c|c|c|c|c|c|c|c|c|}
\hline 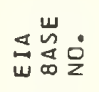 & & 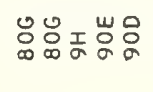 & 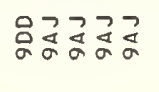 & 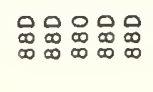 & 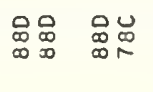 & 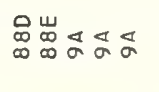 & 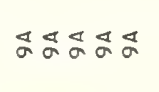 & 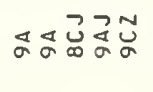 & ふエエホさ岕 \\
\hline 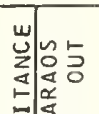 & & $\stackrel{\sim}{N} \stackrel{\infty}{\sim} 0$ n & s? & ヘ N N N & $\ddot{m} \dot{\sim} \ddot{-} \dot{-}$ & $\because: \Delta:$ & 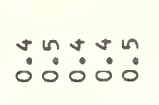 & 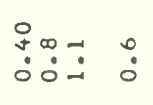 & $\stackrel{0}{\circ} \quad \stackrel{\leftrightarrow}{\circ}: \stackrel{\infty}{\circ}:$ \\
\hline 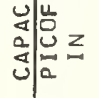 & & $\ddot{\square}: \dot{0}$ & $\ddot{0}$ & 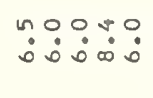 & $\dot{a}: \stackrel{0}{0} \dot{0}$ & $\because \quad \stackrel{\square}{*}:$ & $\stackrel{0}{\circ} \stackrel{0}{-} \stackrel{0}{-}:$ & $\because \dot{m} \dot{\sim} \dot{\sim}$ & 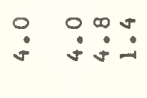 \\
\hline s. & & $\stackrel{\circ}{\sim}$ & 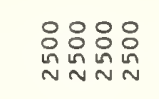 & 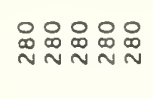 & 品 兽品 & 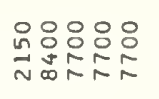 & 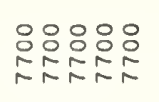 & 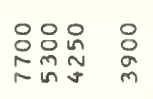 & $\begin{array}{l}\circ 0 \\
\text { 品 }\end{array}$ \\
\hline 点 & & & & $N N N N N$ & $\ln n \infty 0 \Omega$ & ニ゚ュニニ & ニニニニニ & $\bumpeq ニ ュ \infty$ & $\stackrel{\infty}{\sim} \stackrel{\infty}{\sim} \underset{\sim}{\sim} \stackrel{\sim}{\sim}$ \\
\hline 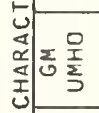 & & : & 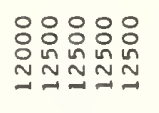 & 응ㅇㅇㅇㅇㅇㅇㅇㅠ & 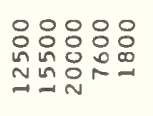 & 응융유 & 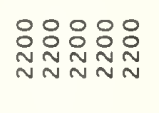 & 旾足: & 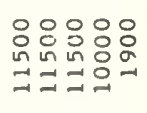 \\
\hline$-\infty=\frac{\pi}{2}$ & & 욤요 & 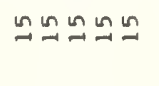 & $\stackrel{\cap}{\cong} \cong \stackrel{\sim}{\simeq \beth} \cong$ & 웛 & 잉ㅇㅇㅇㅇ & 으오오오으 & 응 $=$ & 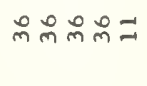 \\
\hline 常 > & & 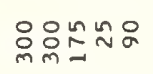 & 옹ㅇㅇㅇㅇ & 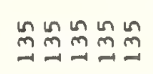 & 옥응으용요 & 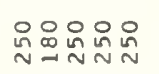 & 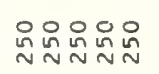 & 윴욤요 & 오엄엄요 \\
\hline 世 & & O̊ & : & $\because 0000$ & 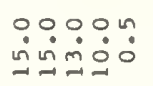 & 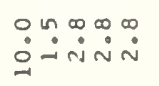 & $\begin{array}{l}\infty \\
\dot{\sim} \dot{m} \dot{m} \dot{m} \dot{m}\end{array}$ & 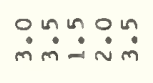 & $\begin{array}{l}\infty \sim \infty \\
\dot{m} \dot{j}: \dot{\sim}\end{array}$ \\
\hline 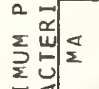 & & $\stackrel{N}{N}$ & $N N N N N$ & 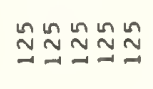 & 黾: & 용ㅇㅇ & ONN & 워묘 & n \\
\hline 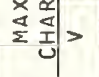 & & 임윰일요 & 일욤욤욤 & 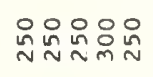 & 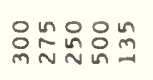 & 옳임윰요 & 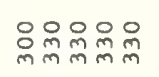 & 윩욤윰요 & 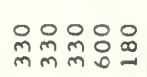 \\
\hline 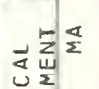 & & 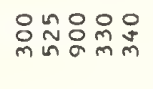 & 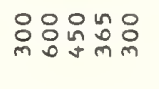 & 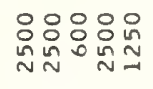 & 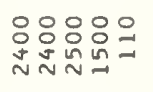 & 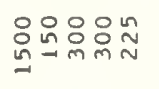 & 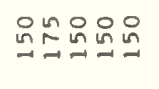 & 음윰욤욤 & 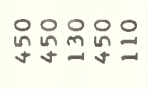 \\
\hline 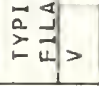 & & 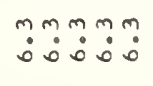 & 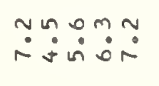 & $\ddot{0} \dot{0} \dot{0} \dot{\infty} \dot{0} \dot{\sim}$ & $\ddot{0} \dot{m} \ddot{0} \dot{0} \dot{0} \dot{\sim}$ & 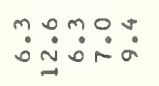 & 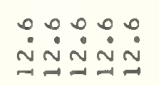 & 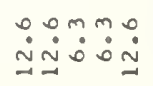 & 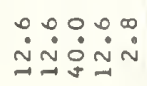 \\
\hline 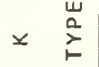 & & IIIII & IIIII & IIIII & エエエエル & Iエエエエ & IIIII & IIIII & $I I I I U$ \\
\hline$\underset{\check{x}}{\stackrel{\leftrightarrow}{x}}$ & & 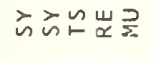 & 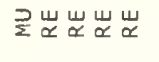 & 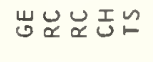 & 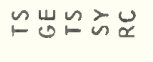 & え岕岕岕 & 古㟧方嵌ら & 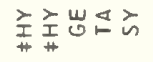 & こ岗にええう \\
\hline 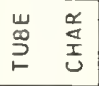 & & 岑品 怘 & 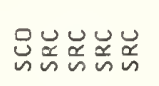 & 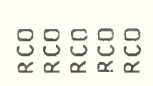 & 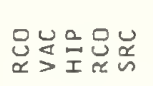 & 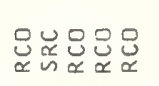 & 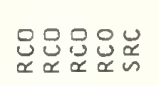 & 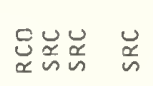 & 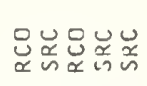 \\
\hline 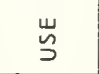 & & 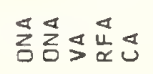 & Uذّ & 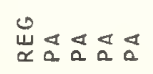 & ه & 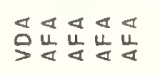 & 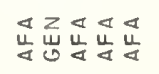 & 造吉䏦出 & 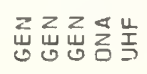 \\
\hline$\sum_{\infty}^{\infty}$ & & ๓ேロレ゚ロ & ト゚ト゚ロ゚゚ & モュュュ゚ & モュュュュ & ロコロレロ & ஃ゚ロレロレ & ゚゚ロレ゚゚ & ゚ேレロに \\
\hline 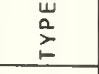 & & $\begin{array}{l}z_{3} z_{3} z \\
3 \leq 3 \\
1\end{array}$ & 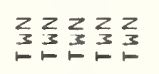 & $\begin{array}{l}z_{3} z_{3} z_{3} \\
1 \\
1\end{array}$ & $\begin{array}{l}z_{3} z_{3} z_{3} \\
1 \leq 151\end{array}$ & $\begin{array}{l}z_{3} z_{3} z_{3} \\
1 \leq 1 \\
1\end{array}$ & $\begin{array}{l}z_{3} z_{3} z_{3} \\
1 \\
1\end{array}$ & $\begin{array}{l}z_{3} z_{3} z_{3} \\
1 \\
1\end{array}$ & 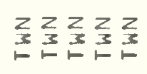 \\
\hline 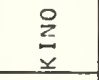 & & 吕品吕喜吕 & 吕吕吕吕吕 & 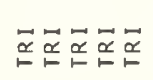 & 吕吕吕吕吕 & 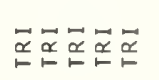 & 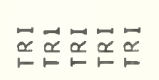 & 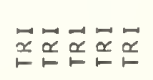 & 吕吕吕吕品 \\
\hline 号 & & 市 & & 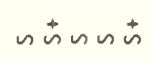 & $n n \sim s$ & $\backsim$ & 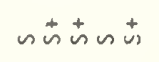 & $\dot{n} n^{+} n$ & 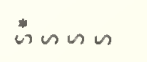 \\
\hline 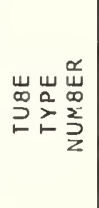 & 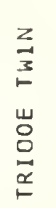 & 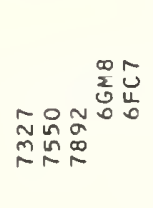 & 岀点出出出出怘 & 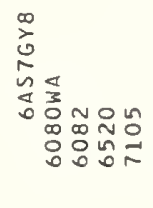 & 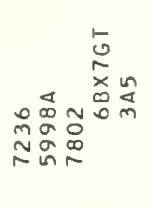 & 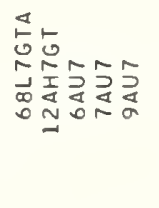 & 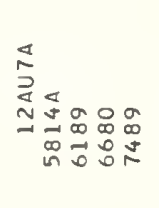 & 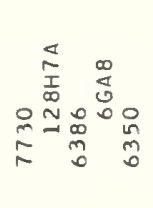 & 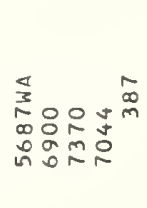 \\
\hline
\end{tabular}




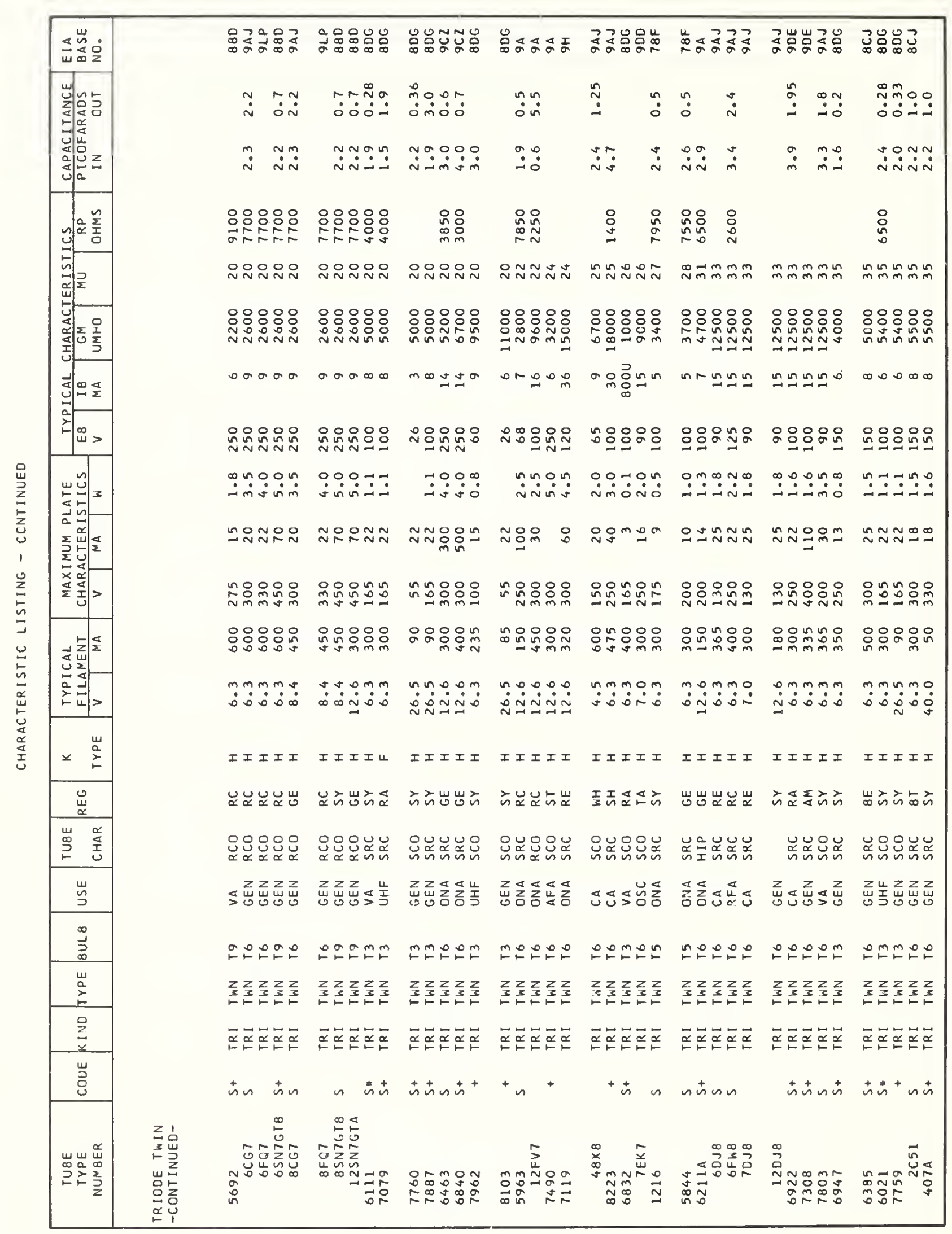




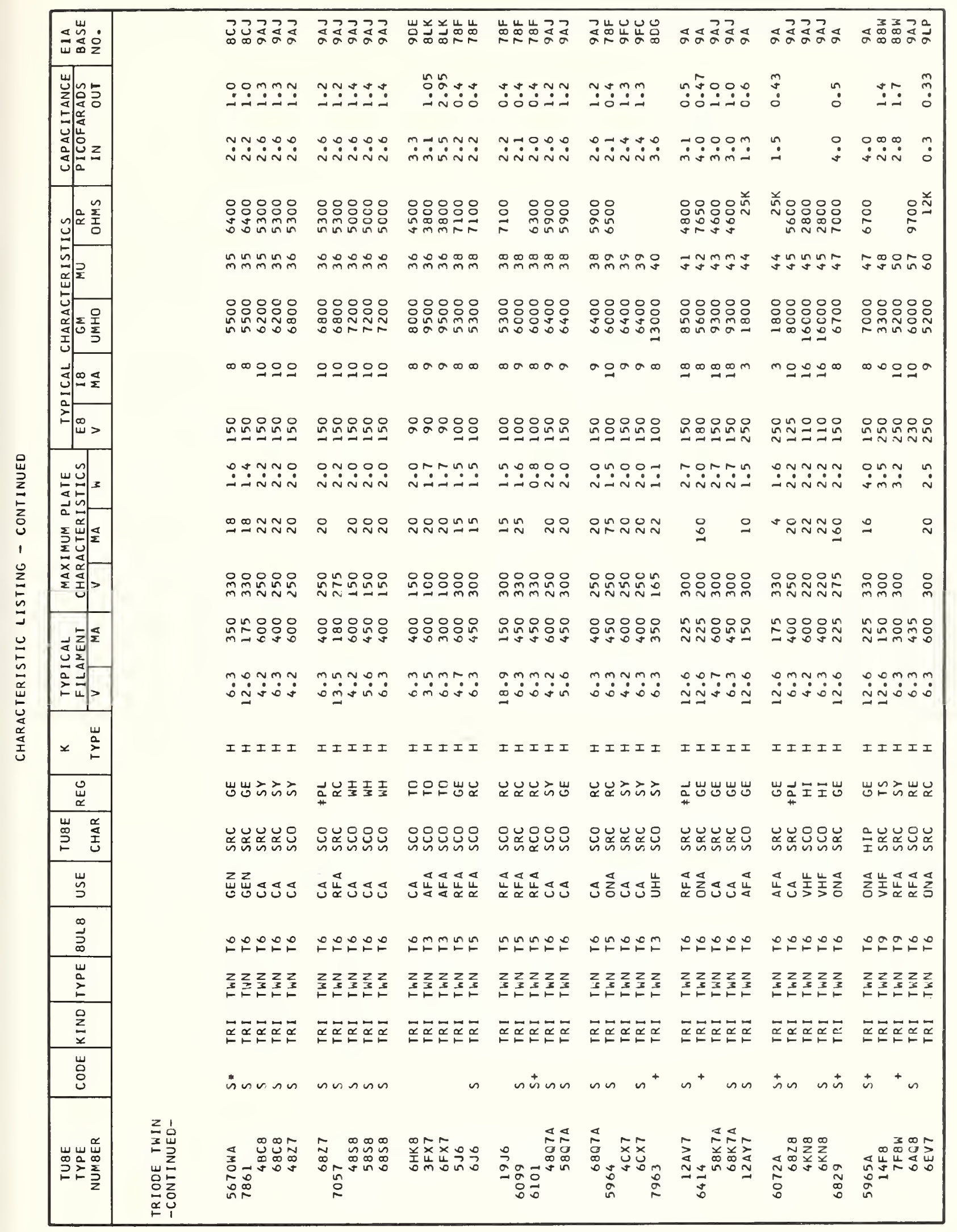









\begin{tabular}{|c|c|c|c|c|c|c|c|c|c|}
\hline$\leq \underset{w}{\omega} \dot{\infty}$ & & 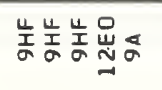 & 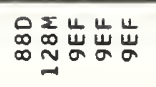 & 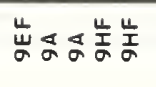 & 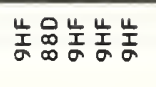 & 岕岕出出怘 & $\stackrel{N}{\infty}_{\infty}^{\Sigma} \sum_{\infty}^{\Sigma} \sum_{\infty}^{\Sigma} \sum_{\infty}^{\Sigma} \sum_{\infty}^{\Sigma}$ & 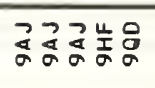 & 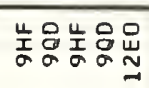 \\
\hline 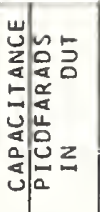 & & 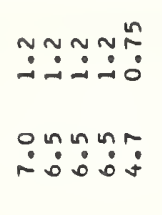 & 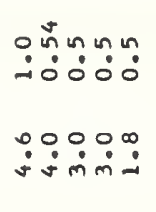 & 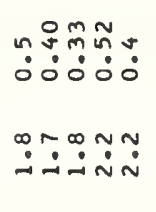 & 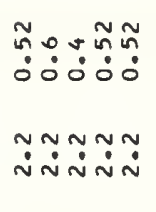 & 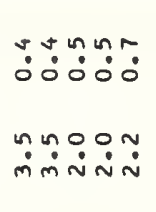 & 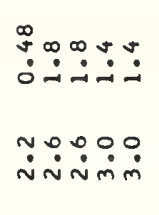 & 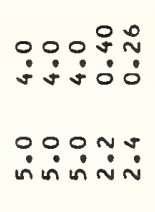 & 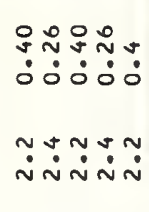 \\
\hline 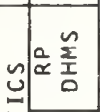 & & : & 兑品品 & 兑足只品 & 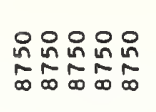 & 吕웜웡유 & 융ㅇㅁㅇㅛ & :용ㅎㅁㅇㅝ & 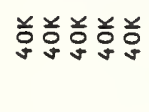 \\
\hline 矛 & & $0000 \mathrm{~m}$ & 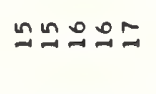 & ニニュロ品 & $\stackrel{\infty}{\sim} \stackrel{\infty}{\sim} \underset{\sim}{\sim} \stackrel{\infty}{\sim}$ & $\stackrel{\infty}{\sim} \vec{\sim} \vec{\sim} \tilde{N}$ & Ñలํํำ & 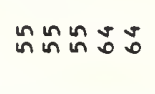 & T. \\
\hline 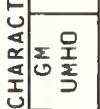 & & 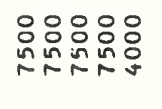 & 品足品莡 & 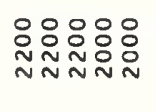 & :윰유윰유 & 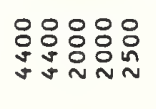 & 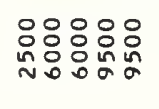 & 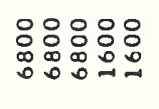 & ㅇ:ㅇㅇㅇㅁ \\
\hline$=\frac{\alpha}{2}$ & & n웡의 & $\exists テ \sigma \sigma O$ & $\cong 0 \simeq 0$ & 00000 & 유윰n & $\infty \sim \sim \sigma \sigma$ & $\operatorname{nnn} n-1$ & カールーナ \\
\hline $\begin{array}{ll}\infty & \\
& \end{array}$ & & 员员品品手 & 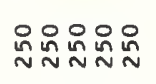 & 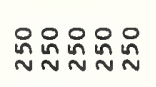 & 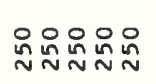 & 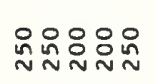 & 윰융용ㅇㅁ & 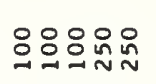 & 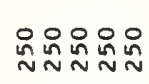 \\
\hline 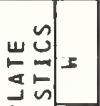 & & :O:0: & ب̃ & 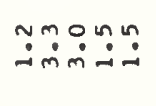 & 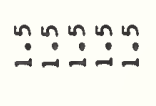 & 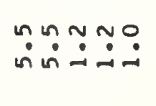 & $\stackrel{0}{-}$ & :゚̊ロ & 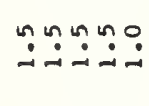 \\
\hline 存离 & & 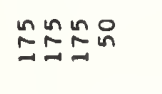 & 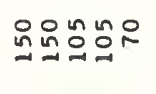 & NN & NNลNล & 유융 & 유ㅇㅠㅠㅇㅠ & NNNON & 유슛ำ \\
\hline 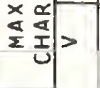 & & 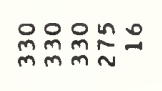 & 品品总品品 & 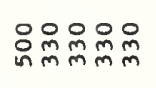 & 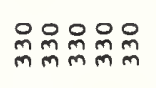 & 品品品品品 & 品品品品品 & 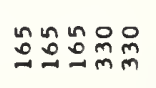 & 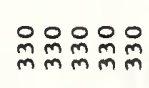 \\
\hline 运氙 & & 跸品品品 & 양ㅇㅁㅇㅇㅇ용요 & 号品品品: & 음용요 & 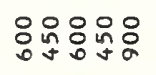 & 응유욤요 & 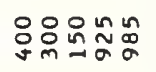 & 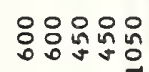 \\
\hline 象部> & & 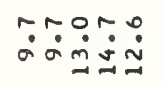 & $\ddot{0} \dot{0} \ddot{0} \dot{0} \dot{0} \dot{0}$ & 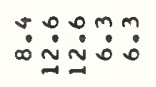 & 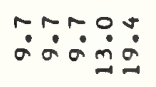 & $\ddot{\dot{0}} \dot{0} \dot{0} \dot{0} \dot{\infty} \dot{0}$ & $\ddot{m} \ddot{m} \dot{m} \dot{m} \dot{m}$ & ن & 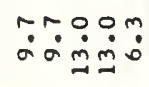 \\
\hline$\times \stackrel{u}{\stackrel{u}{a}}$ & & IIIII & IIIII & IIIII & IIIII & IIIII & IIIII & IIIII & IIIII \\
\hline$\underset{x}{\vec{\Psi}}$ & & 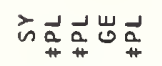 & 惢岕えええ & らうら岕えうら & 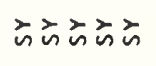 & 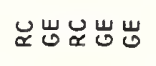 & 岁吕吕吕吕 & 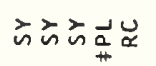 & 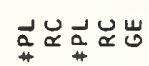 \\
\hline 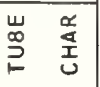 & & 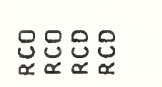 & 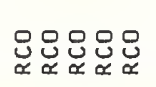 & 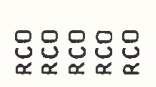 & 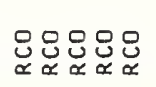 & 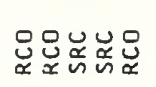 & 总怘怘芯 & 怘导导导怘 & 号号号品怘 \\
\hline$\stackrel{\breve{s}}{\leftrightharpoons}$ & & 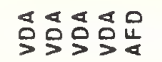 & 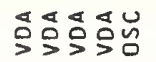 & 品跎品品 & 品品品品品 & 号号品品品 & 品厤出品 & 氙出品号品 & $\begin{array}{l}\text { 옹品品品 } \\
\text { 品 }\end{array}$ \\
\hline 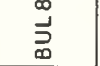 & & そロにロレ & ロの゚トロ & ト゚レ゚ロ & ゚ロロロェ & レレレロロ & ロேツロே & レロレにロ & ロேロロロ \\
\hline$\stackrel{\omega}{a}$ & & 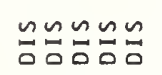 & ニニニニッ & $\begin{array}{l}\approx \backsim \backsim \backsim \backsim \\
\square \square\end{array}$ & 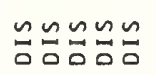 & 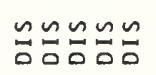 & 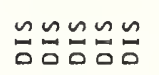 & 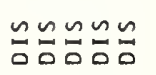 & 气四气 \\
\hline$\frac{0}{z}$ & & 乔びロ゚ロロロ & 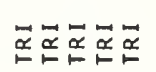 & 吕吕吕吕吕 & 吕品乔品品 & 吕号吕吕吕 & 吕吕吕吕吕口 & 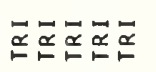 & 品吕品吕品 \\
\hline 응 & & $n n$ & & nேnnn & $\backsim n n$ & & & $n$ & $\backsim$ \\
\hline 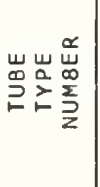 & 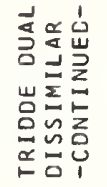 & 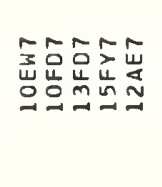 & 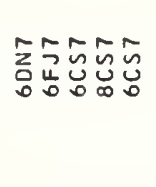 & 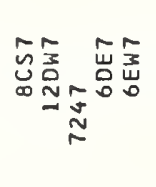 & 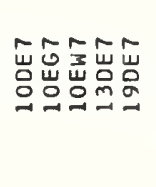 & 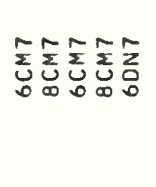 & 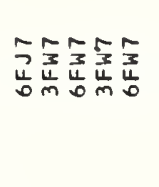 & 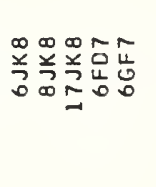 & 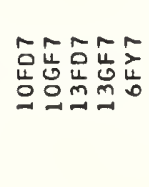 \\
\hline
\end{tabular}




\begin{tabular}{|c|c|c|c|c|c|c|c|c|c|}
\hline 岂岩虽 & & 品品总离品 & 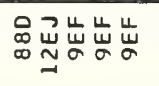 & 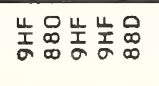 & 岌㞬萦品容岕 & 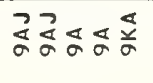 & 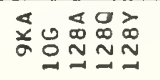 & 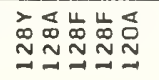 & 态孞 \\
\hline 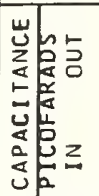 & & 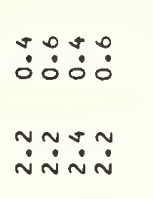 & 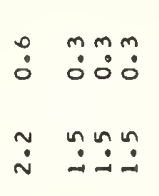 & 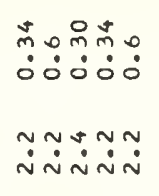 & 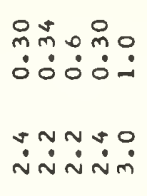 & 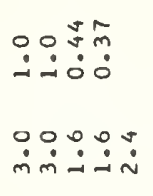 & $\begin{array}{c}\stackrel{m}{-} \\
\dot{\sim} \dot{\sim} \stackrel{0}{\dot{\sim}}\end{array}$ & 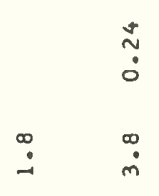 & $\begin{array}{l}\stackrel{N}{N} N \infty \\
\dot{0} 0: \\
\infty 00 \\
\dot{m} \dot{0} \dot{m}\end{array}$ \\
\hline 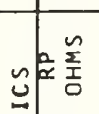 & & 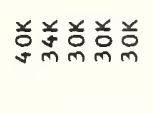 & 弟㒸兰芯芯芯 & 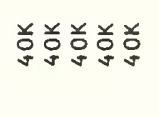 & 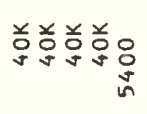 & 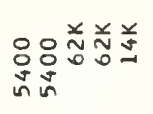 & 壬兰兰总希 & 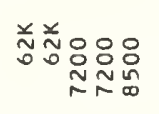 & 总前弟 \\
\hline 战 & & 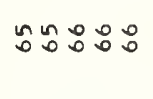 & : : & 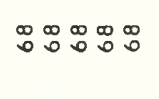 & 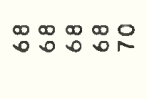 & 웅으음 & 䀡品吕吕 & 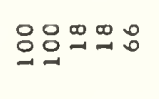 & 믕우 \\
\hline 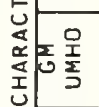 & & :융유유 & 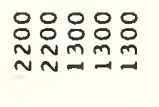 & 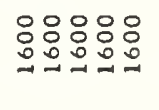 & 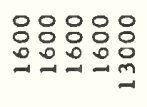 & 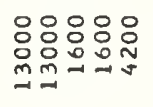 & 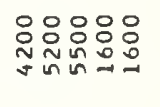 & 용요 & $\begin{array}{l}\text { 응응 } \\
\text { 용유 }\end{array}$ \\
\hline 造 & & TNNNN & $\sim \sim \sim \longrightarrow \longrightarrow$ & 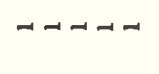 & $-1--0$ & 욕 & a & $-1-0 \infty$ & $\infty \rightarrow-$ \\
\hline in & & 虽怘怘怘怘 & 員怘怘怘怘 & 品怘怘怘怘 & 員怘怘怘怘 & 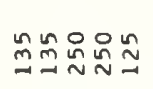 & 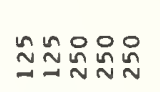 & 怘怘怘怘怘 & $\stackrel{n}{\cong} \stackrel{\sim}{N} \cong$ \\
\hline 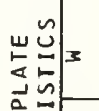 & & : & ○: & 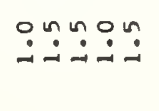 & 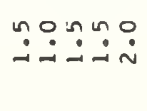 & $\ddot{\sim} \dot{\sim} \sim \stackrel{\sim}{\sim} \dot{\sim}$ & $\begin{array}{l}0 \\
\dot{\sim} \dot{\sim} \dot{\sim}\end{array}$ & $\because \dot{m} \dot{m} \dot{\sim}$ & $\ddot{\sim} \dot{\sim}$ \\
\hline 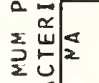 & & $\stackrel{\sim}{\sim}$ & & NARO & KRNลN & $\approx \tilde{N}$ & $\stackrel{i}{N}$ & $\stackrel{\sim}{\sim}$ & \\
\hline 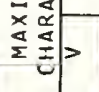 & & 品品品品品品 & 品品品品品品 & 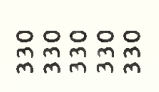 & 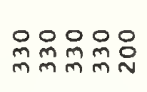 & 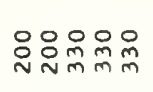 & 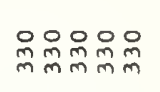 & 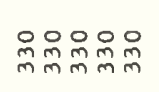 & 있율요 \\
\hline 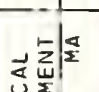 & & 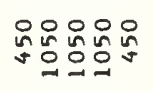 & 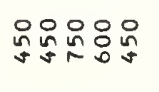 & 영유: & 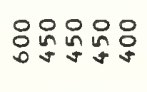 & 硑员品品品 & 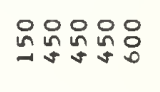 & 埙品品品 & 움웅 \\
\hline $\begin{array}{lll}2 & 2 \\
2 & 5 \\
2 & 4\end{array} \mid>$ & & 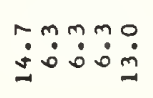 & 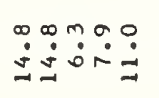 & $\ddot{\circ} \dot{0} \dot{0} \dot{\circ} \dot{\circ}$ & 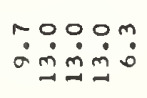 & $\dot{0} \dot{0} \dot{\sim} \dot{\sim} \dot{\sim} \dot{0}$ & $\ddot{\infty} \dot{0} \dot{0} \dot{0} \dot{0}$ & 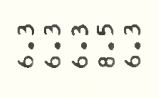 & : \\
\hline$× \sum_{\substack{a \\
\Sigma}}^{\frac{\omega}{2}}$ & & IIIII & IIIII & IIIII & IIIII & IIIII & IIIII & IIIII & $I I I$ \\
\hline$\underset{\varpi}{\breve{Z}}$ & & 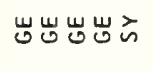 & 嵌岕岕岕 & えうえうゔと & えうえううらう & えううえ岕 & 岂公主岕岕 & 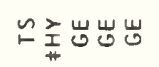 & لّ \\
\hline 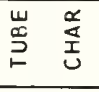 & & 号怘怘怘 & 怘 总怘怘 & 号导导总怘 & 号号怘怘怘 & 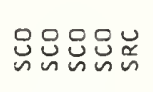 & 电怘品 & 导 & 号怘导 \\
\hline 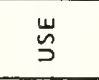 & & 응용요 & 㔛品号号 & 员品品号号 & 品品品品出 & 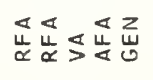 & 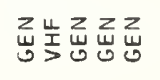 & 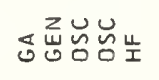 & 饪晨 \\
\hline$\stackrel{\infty}{\infty}$ & & そ゚テすの & の゚ロ゚ロ & ト゚ロ゚ロ & 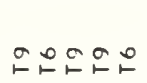 & ト゚ロ゚ュ゚ & ロロ & ロレロロロ & ஜே天 \\
\hline 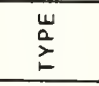 & & 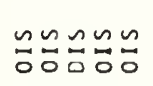 & 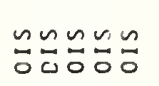 & 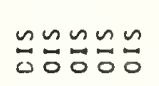 & 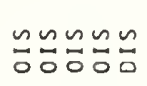 & 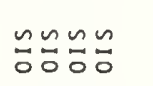 & & 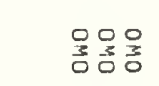 & 욱움음 \\
\hline$\stackrel{0}{\underline{z}}$ & & 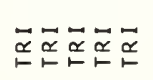 & 品吕品品吕 & 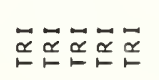 & 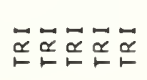 & 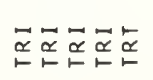 & 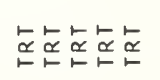 & 吕串吕吕串 & 吕嵒品 \\
\hline 음 & & $n n$ & & $\backsim \sim \backsim$ & $\sim$ & $n n$ & $\backsim$ & $\backsim$ & \\
\hline 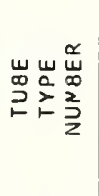 & 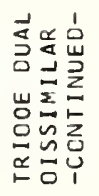 & 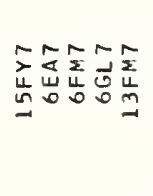 & 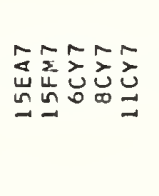 & 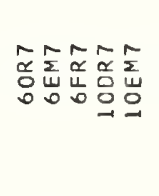 & 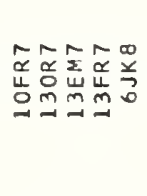 & 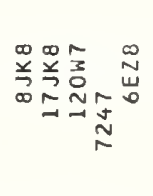 & 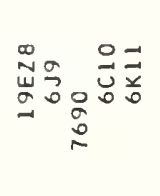 & 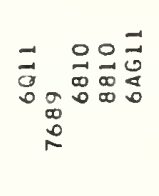 & 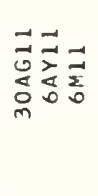 \\
\hline
\end{tabular}




\begin{tabular}{|c|c|c|c|c|c|c|c|c|c|}
\hline 崖崖呈 & & 旅占京占 & 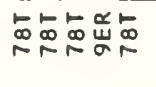 & 品岂岂岕。 & 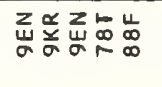 & 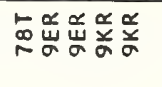 & 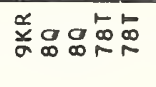 & 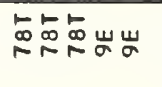 & 甹岁山 \\
\hline 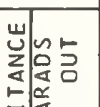 & & 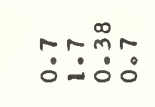 & 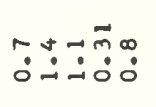 & ஜோஷ் & 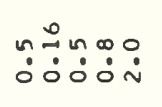 & N & 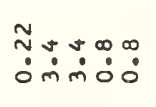 & ¿ & $\because$ \\
\hline \begin{tabular}{l|l}
0 \\
0
\end{tabular} & & $\stackrel{\infty}{\sim} \dot{\sim} \stackrel{\infty}{\sim} \dot{\sim}$ & 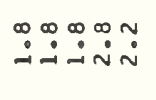 & ஸ̆ & 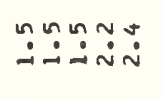 & $\dot{\sim} \ddot{\sim} \dot{m} \dot{\sim} \dot{\sim}$ & $\begin{array}{l}\infty \sim \sim \\
\dot{-} \dot{\sim} \dot{\sim}\end{array}$ & ஸั山 & $\stackrel{\circ}{-}$ \\
\hline$=\stackrel{n}{x}$ & & 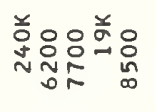 & 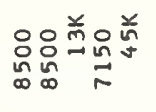 & 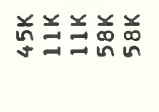 & 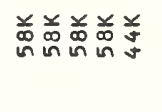 & 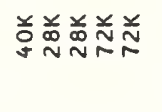 & 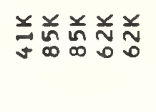 & 壬弚总总兽 & 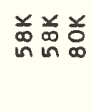 \\
\hline 䒺 & & กคำ & ニュュำ & 등ㅇㅇㅇㅇㅁㅇㅠ & 웃유운무 & 윰NN & 응ㅇㅇㅇㅇㅇㅇㅇㅇ & 응응응웅 & 유유 \\
\hline 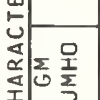 & & : & ::윰요 & 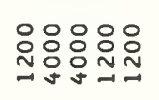 & 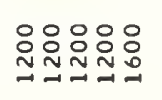 & 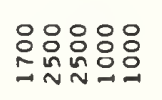 & 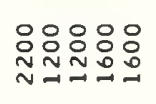 & 음욤요 & 음요 \\
\hline 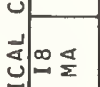 & & 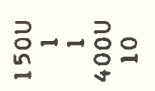 & 웜- - & 옷음ㅇ- & $\neg-\neg \rightarrow N$ & - N 흥응 & 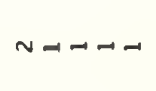 & - & -ー흠 \\
\hline ĩ & & 오ッㅗㅛ & 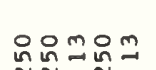 & 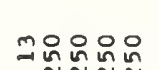 & 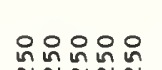 & 응욥욥용요 & 은은으으음 & 은응응요은 & 응요응 \\
\hline 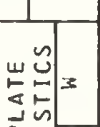 & & $\stackrel{n}{n}$ & $\tilde{\sim} \dot{\sim}:$ & $\begin{array}{l}N \sim N N \\
\tilde{n} \tilde{N} \\
\dot{\sim}\end{array}$ & 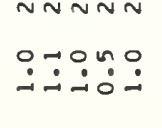 & 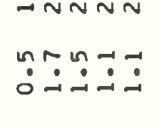 & 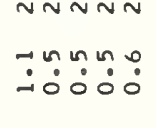 & 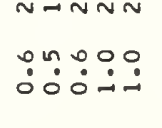 & $\stackrel{\circ}{\circ}$ \\
\hline 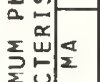 & & 융ำ & NNㅇ & $\stackrel{\circ}{N}$ & & & & & \\
\hline 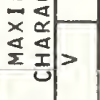 & & 음요 욤 & 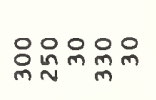 & 이임임욤 & 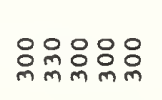 & 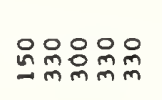 & 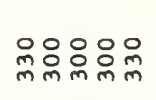 & 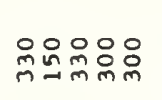 & ㅇ户ㅁ욤요 \\
\hline$\left.\frac{1}{\alpha}\right)^{\frac{\pi}{2}}$ & & 음욤욤욤요 & 윰움욤욤 & 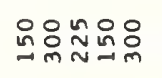 & 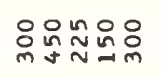 & 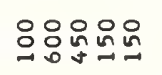 & 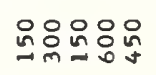 & 임음윰용 & 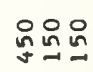 \\
\hline$\sum_{i \leq 1}^{0}=$ & & 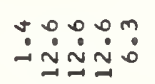 & 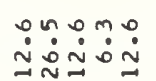 & $\dot{\sim} \dot{\sim} \dot{\sim} \ddot{\sim} \dot{0}$ & $\ddot{\circ} \ddot{0} \dot{m} \ddot{\sim} \dot{0}$ & OM: & 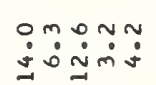 & mo: & $\dot{m} \dot{a}$ \\
\hline$\times \sum_{\Sigma}^{\frac{u}{\vdots}}$ & & แIIエエ & エエエエエ & IIIII & IIIII & Iエエエエ & Iエエエエ & Iエエエエ & III \\
\hline$\underset{\sim}{\underset{\sim}{\Psi}}$ & & 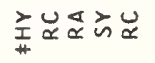 & 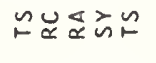 & 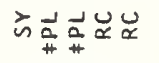 & 岁岕岕えむ & ええええ岕出 & 崩主主的。 & 㳎ええら岕出 & 声え吉 \\
\hline 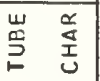 & & 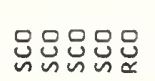 & 足 & 恿灾总总总 & 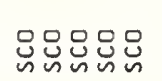 & 号怘怘怘 & 恿总总怘怘 & 怘芯怘怘怘 & 号号怘 \\
\hline$\stackrel{u}{\sim}$ & & 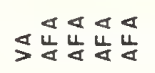 & 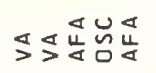 & 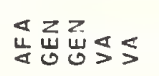 & 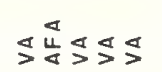 & 㟧堊堊凹 & 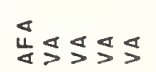 & 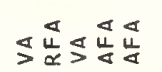 & $\$ \frac{4}{4}$ \\
\hline$\stackrel{D}{\infty}^{0}$ & & ロேロロロ & ロேッロロロ & ロロ゚ロロッ & คํำの & 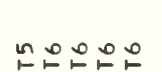 & ゚ロテレュ & ๓ュュュロ゚゚ & ゚ㅗㅇㅛ \\
\hline$\frac{\omega}{\frac{\omega}{\nu}}$ & & 을오으을오 & 오오오로오 & 오오오오오 & 오오오오오 & 오오로오오 & 오오을오오 & 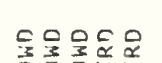 & $\underset{\propto}{\alpha} \underset{\propto}{ }$ \\
\hline - & & & & & & & & & \\
\hline$\underline{x}$ & & 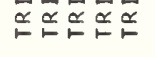 & 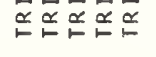 & 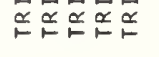 & 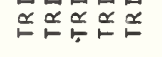 & 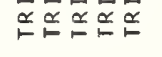 & 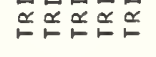 & 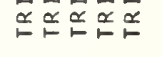 & $\propto$ \\
\hline 号 & & $n n \backsim$ & nun us & nn & $\backsim$ & $n n$ & $\backsim n$ & $\sin n \in$ & $n n$ \\
\hline 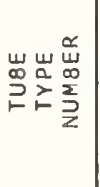 & 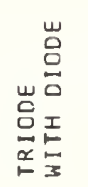 & 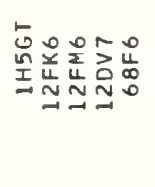 & 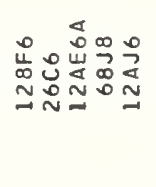 & 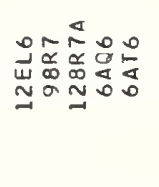 & 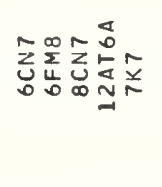 & 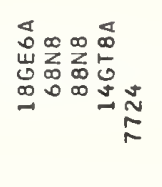 & 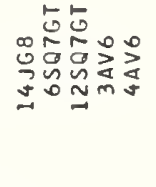 & 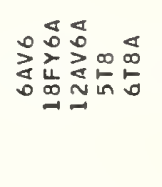 & 类点罗 \\
\hline
\end{tabular}




\begin{tabular}{|c|c|c|c|c|c|c|c|c|c|}
\hline 岂崫吊 & & 岕岕岂岕す & 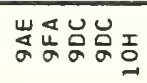 & 岁岕岕岂岕 & 岁岕岕岕岂 & 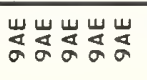 & 岁岁崩岕岕岕 & 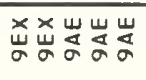 & 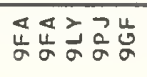 \\
\hline 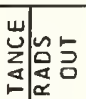 & & 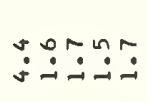 & $\ddot{\sim} \dot{\sim} \dot{\sim} \dot{\sim} \dot{\sim}$ & $\stackrel{n}{\rightarrow} \ddot{\circ} \stackrel{0}{\circ} \stackrel{0}{\circ}$ & $\stackrel{0}{:} \stackrel{m}{\because} \stackrel{m}{\circ} \stackrel{0}{\circ}$ & : : : : : & 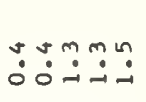 & $\ddot{0}$ & 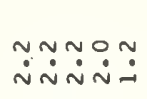 \\
\hline 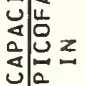 & & 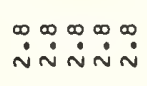 & $\ddot{\sim} \dot{\sim} \dot{\sim} \dot{\sim} \dot{\sim} \dot{\sim} \dot{m}$ & $\dot{\sim} \quad \dot{m} \dot{m} \dot{\sim} \dot{\sim}$ & $\dot{\sim} \dot{\sim} \dot{m} \dot{m}$ & $\dot{\sim} \dot{\sim} \dot{m} \dot{m} \dot{\sim} \tilde{\sim}$ & $\dot{\sim} \dot{\sim} \dot{\sim} \dot{m} \dot{0} \dot{\sim} \dot{\sim}$ & $\dot{m} \dot{m} \dot{0}$ & 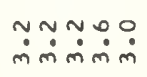 \\
\hline 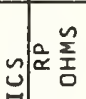 & & 용 & 品品品品 & 品: & $\begin{array}{l}8 \\
8 \\
0\end{array}$ & 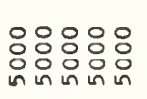 & 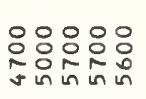 & 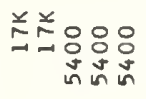 & 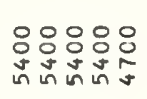 \\
\hline 氙 & & 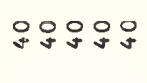 & 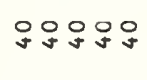 & 영웡ㅇㅇㅇㅇ & 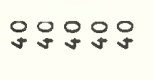 & 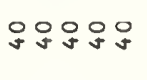 & 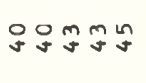 & 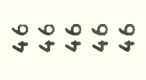 & 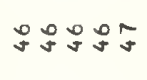 \\
\hline 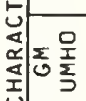 & & 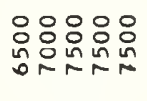 & 욧요 & 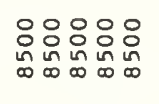 & 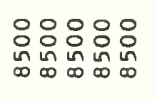 & 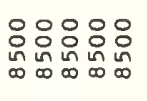 & 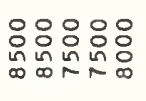 & 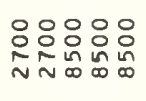 & 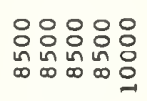 \\
\hline 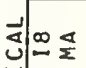 & & $\simeq ロ さ さ さ$ & 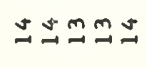 & 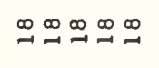 & 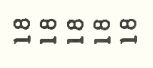 & $\stackrel{\infty}{\sim} \underset{\sim}{\sim} \stackrel{\infty}{\sim} \stackrel{\infty}{\sim}$ & $\stackrel{\infty}{\sim} \underset{\sim}{\sim} \underset{\sim}{\sim} \simeq$ & $m m \Xi \pm J$ & $さ さ さ さ ん$ \\
\hline خ & & 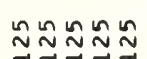 & $\stackrel{\sim}{\sim} \underset{\sim}{\sim} \underset{\sim}{ } \underset{\sim}{\sim} \sim$ & 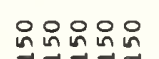 & 㶽品㶽品品 & 㶽识㶽㶽品 & 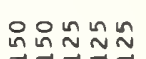 & $\stackrel{\sim}{\sim} \cong \cong \cong$ & 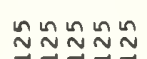 \\
\hline تص & & 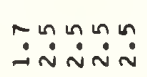 & $\stackrel{n}{i} \dot{\sim} \quad \dot{\sim}$ & $\begin{array}{l}\sim \sim 00: \dot{\sim} \\
\dot{\sim} \dot{\sim} \dot{\sim}\end{array}$ & 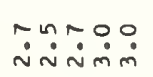 & نं $\dot{\sim} \dot{m} \dot{0} \dot{0}$ & 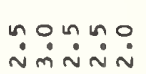 & 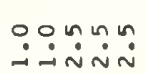 & $\ddot{\sim} \dot{\sim} \dot{\sim} \dot{\sim} \dot{\sim} \tilde{\sim}$ \\
\hline 2 & & & 융유 & & & & $\stackrel{2}{2}$ & & 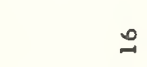 \\
\hline 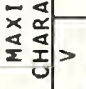 & & 拣品品品品 & 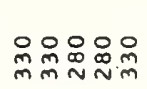 & 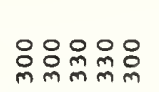 & 임임일요 & 을있일ㅇ & 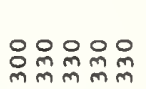 & 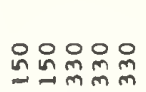 & 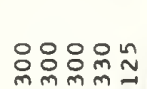 \\
\hline$-\frac{1}{2} \frac{\pi}{2}$ & & 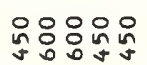 & 웅용용요 & 용융융용 & 总员路员品 & 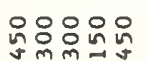 & 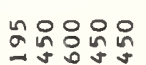 & 운욤요 & 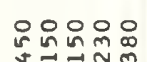 \\
\hline 造焉> & & 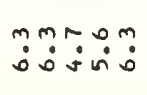 & 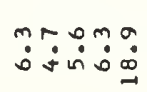 & 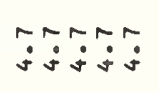 & $\ddot{0} \ddot{0}: \ddot{0}: \dot{0}$ & $\dot{0} \dot{0} \dot{\sigma} \dot{\infty} \dot{\infty} \dot{0}$ & $\ddot{m} \dot{0} \dot{0} \dot{0}$ & 웅ํํ & $m a \sigma n m$ \\
\hline$\simeq \quad \stackrel{u}{a}$ & & IIIII & エエエエエ & エエエエエ & IIIII & IIIII & Iエエエエ & エエエエI & エエエエエ \\
\hline$\underset{\sim}{\breve{u}}$ & & 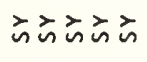 & 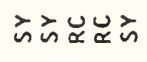 & え゙ぇ岕ひ出 & 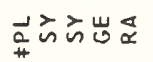 & 岕岕岕え出 & ひ京岁岁 & 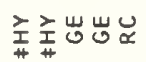 & 岕岕岕岕え \\
\hline 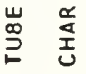 & & 怘 & 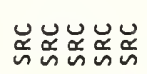 & 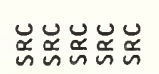 & 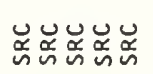 & 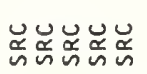 & 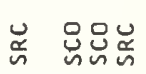 & 怘 & 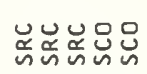 \\
\hline$\stackrel{u}{ٌ}$ & & 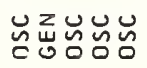 & 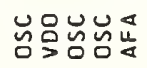 & 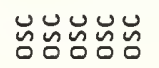 & 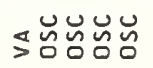 & 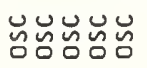 & 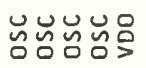 & 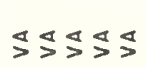 & 品品出出出 \\
\hline$\stackrel{\infty}{\infty}_{\infty}^{\infty}$ & & 욘 & レ゚レロレ゚ & ゚゚゚゚ロ & レ゚ロレ゚ & 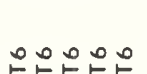 & ゚゚゚゚゚ロ゚ & ゚レ゚ロ & ゚゚゚レレ \\
\hline$\frac{\omega}{2}$ & & 을울울을 & 足足足是是 & 足足是品是 & 을을울을을 & 之ㅜㄹ물을 & 을일울을을 & 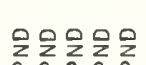 & 울을를 \\
\hline$\sum_{2}^{0}$ & & 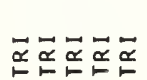 & 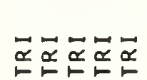 & 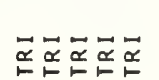 & 品采品吕吕 & 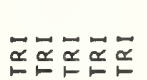 & 吕吕怘吕吕 & 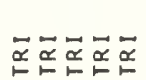 & 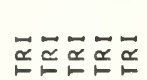 \\
\hline 岕 & & $n$ & $n^{++} n$ & 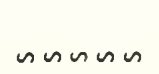 & nேnேn & $\backsim \sim n$ & $n \dot{n}$ & $n n$ & $n \backsim n$ \\
\hline 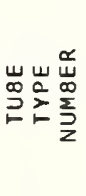 & 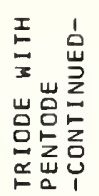 & 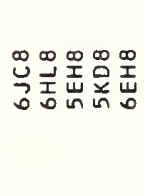 & 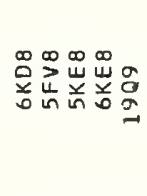 & 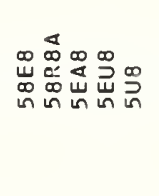 & 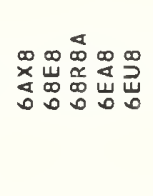 & 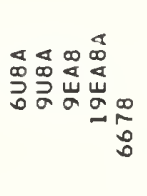 & 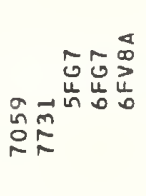 & 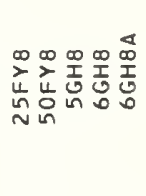 & 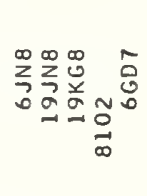 \\
\hline
\end{tabular}




\begin{tabular}{|c|c|c|c|c|c|c|c|c|c|}
\hline 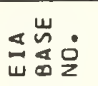 & & 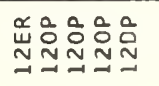 & 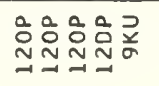 & & $\check{\infty}$ & & 山山山 & & 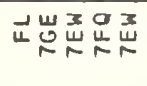 \\
\hline 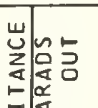 & & $\stackrel{\infty}{\dot{-}} \dot{m} \dot{m}$ & $\stackrel{\sim}{\sim} \dot{N}$ & & $\stackrel{v}{m}$ & & $\ddot{m} \ddot{m} \dot{0} \dot{\sim}$ & & 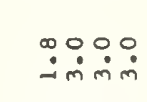 \\
\hline 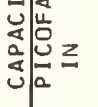 & & $\dot{\sim} \dot{\sim} \dot{v}$ & $\ddot{m} \dot{m} \quad \dot{N}$ & & $\tilde{0}$ & & $\ddot{m} \dot{m} \dot{m} \dot{N}$ & & $\dot{n} \dot{*}: \dot{q}$ \\
\hline 气. & & 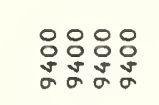 & 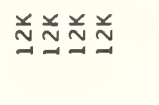 & & & & & & 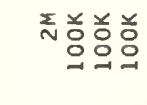 \\
\hline 点 & & $\stackrel{\infty}{\vec{v}} \vec{v} \vec{v} \vec{v}$ & 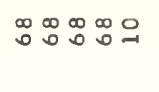 & & & & 엉ํำ & & \\
\hline 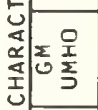 & & 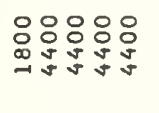 & 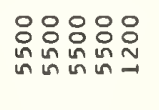 & & & & 옹옹요 & & 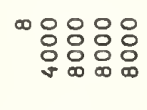 \\
\hline 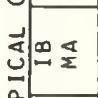 & & $\ln \theta 000$ & rrrr- & & * & & $\rightarrow-\neg$ ป & & 곡로엉ㅇㅇㅇㅇ \\
\hline 光 & & 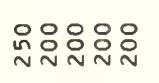 & 옷유: & & $\stackrel{\circ}{\circ}$ & & N $\sim \sim \sim ⿻ 上$ & & $=\stackrel{n}{\cong} \cong$ \\
\hline 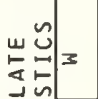 & & ¿̊: & 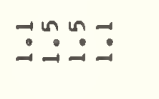 & & $\stackrel{\infty}{\dot{0}}$ & & \begin{tabular}{l}
$\infty \infty$. \\
\hdashline 0
\end{tabular} & & $\dot{i} \dot{\sim} \dot{\sim}$ \\
\hline 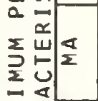 & & $\stackrel{\circ}{\sim}$ & & & & & nN & & 응 윳유 \\
\hline 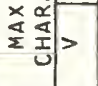 & & 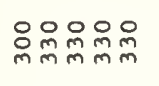 & 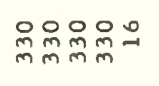 & & $\stackrel{n}{\simeq}$ & & 约莳赵员怘 & & 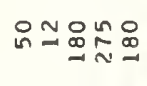 \\
\hline 运茊这 & & 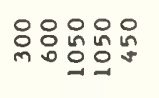 & 응용요욤요 & & 온 & & 앰용용요 & & 웅웡용요 \\
\hline 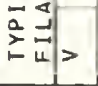 & & 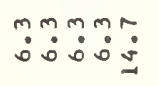 & 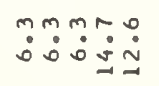 & & 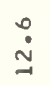 & & 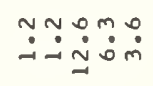 & & 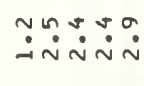 \\
\hline$\times \underset{2}{a}$ & & IIIII & IIIII & & $I$ & & せuIII & & uIIII \\
\hline$\underset{\sim}{\stackrel{\cup}{\Psi}}$ & & $\curvearrowleft$ & 山ّ & & $i$ & & 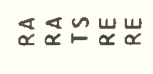 & & ラェ \\
\hline 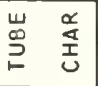 & & 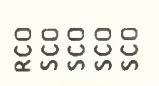 & 品怘导怘怘 & & & & 号 & & 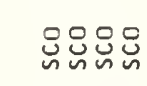 \\
\hline$\stackrel{w}{s}$ & & 品总吋改 & 药出宸 & & $\ddot{n}$ & & 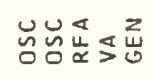 & & 山凯蒫㞬堊 \\
\hline$\stackrel{\infty}{\infty}_{\infty}^{\infty}$ & & ののののの & ロの゚ロ゚ & & $\stackrel{q}{\sim}$ & & 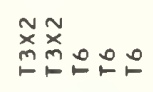 & & 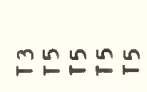 \\
\hline $\begin{array}{l}u \\
a \\
\vdots \\
\end{array}$ & & 온웅음웅음 & 응웅응웅염 & & $\underset{⿱ 亠 乂}{\stackrel{x}{I}}$ & & 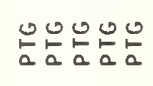 & & $\frac{z}{n} \frac{z}{n} \frac{z}{3} \frac{z}{n}$ \\
\hline$\underset{\underline{z}}{\underline{\underline{z}}}$ & & 몸ㅁㅁㅁㅇㅁㅇㅁㅁ & 홈ㅁㅁㅁㅁㅁㅁ & & $\vec{a}$ & & 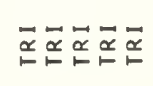 & & 岃出出出 \\
\hline 岂 & & & & & & & $n n$ & & nun \\
\hline 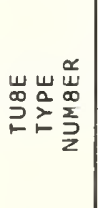 & 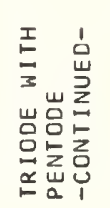 & 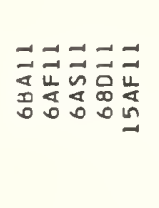 & 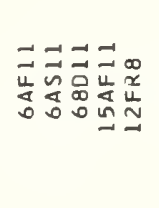 & 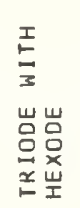 & 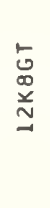 & 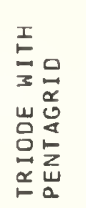 & 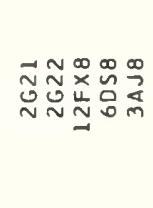 & $\begin{array}{l}\text { 岁出 } \\
\text { ỡ } \\
\text { 点苾 }\end{array}$ & 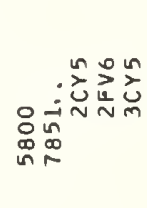 \\
\hline
\end{tabular}




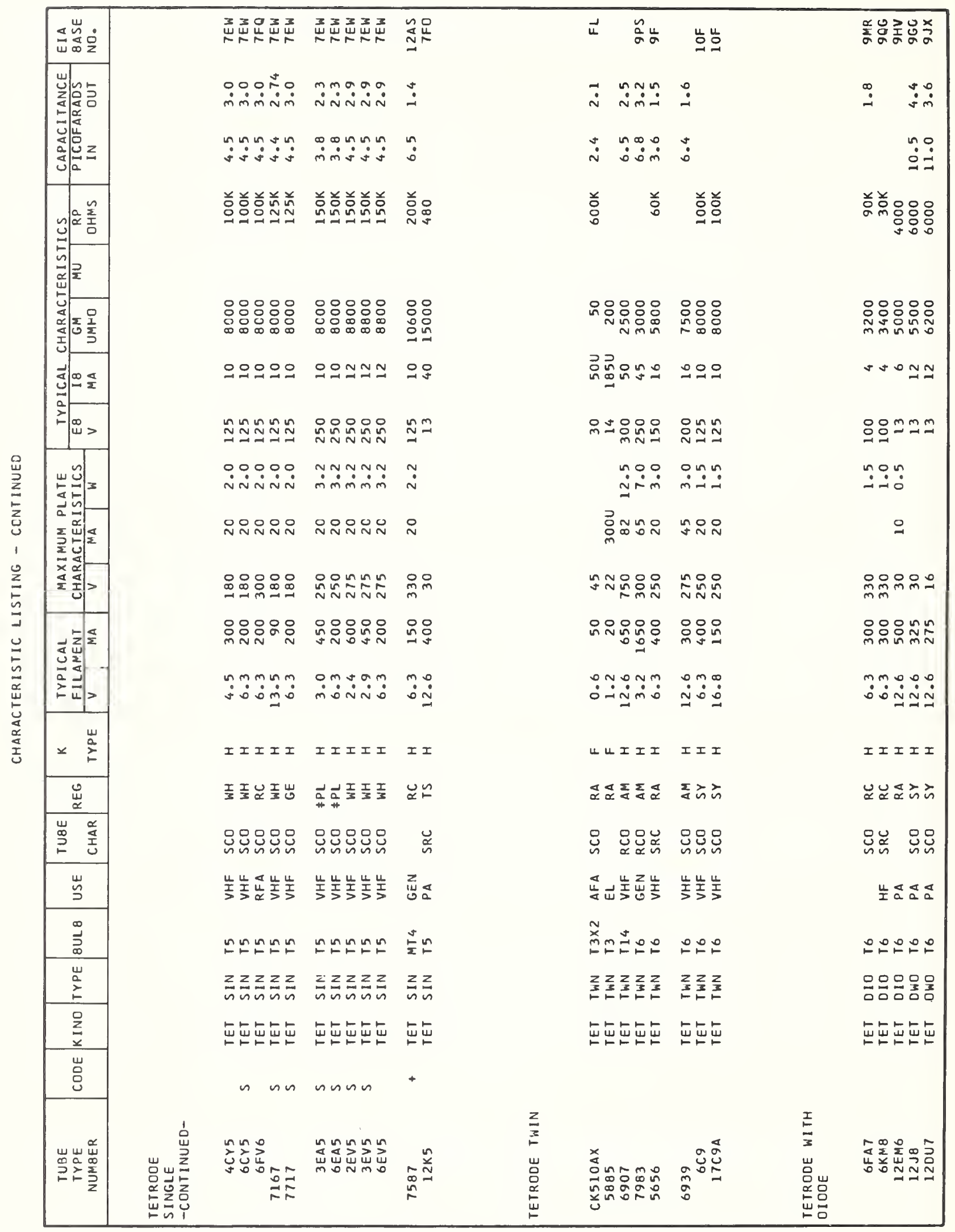




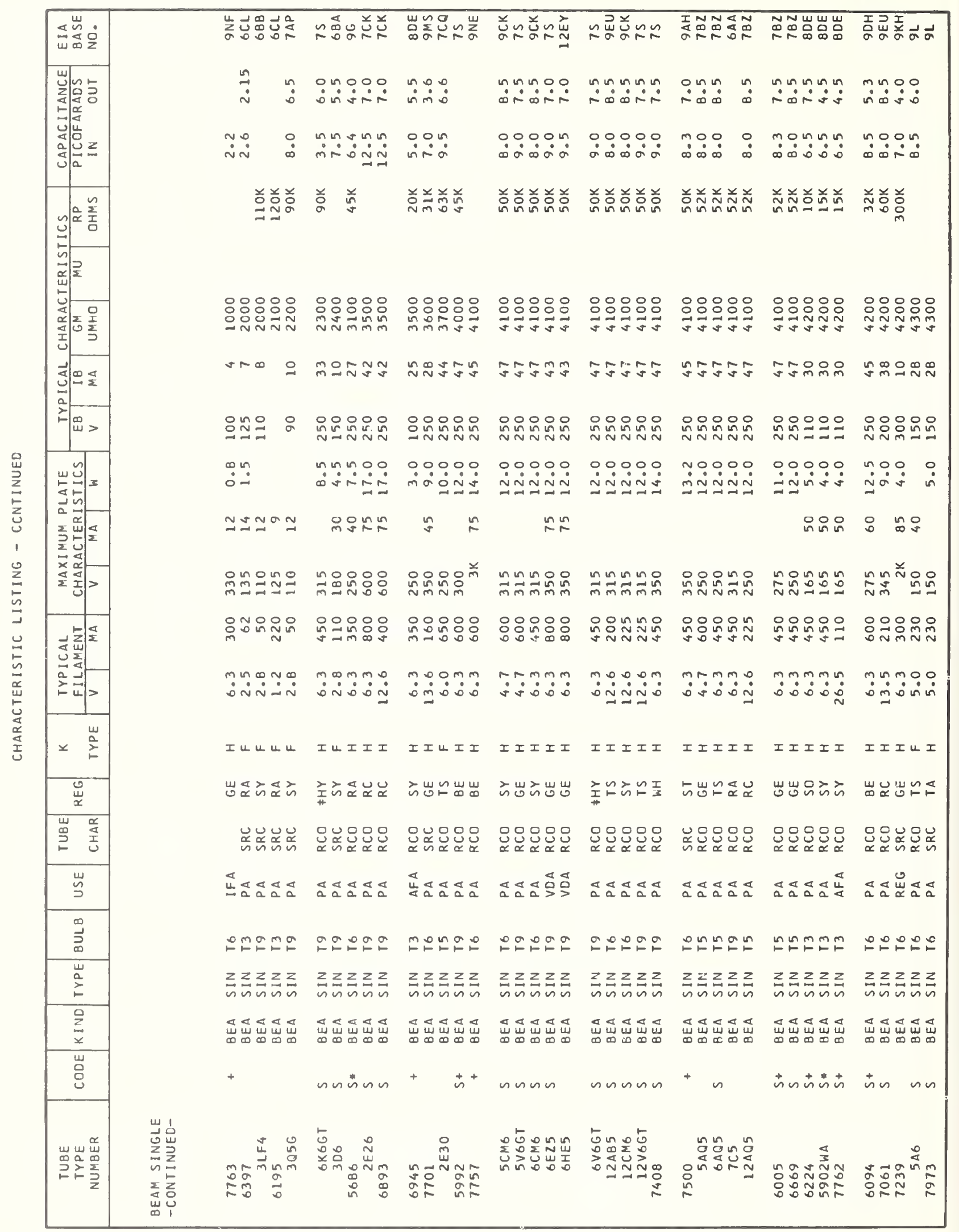




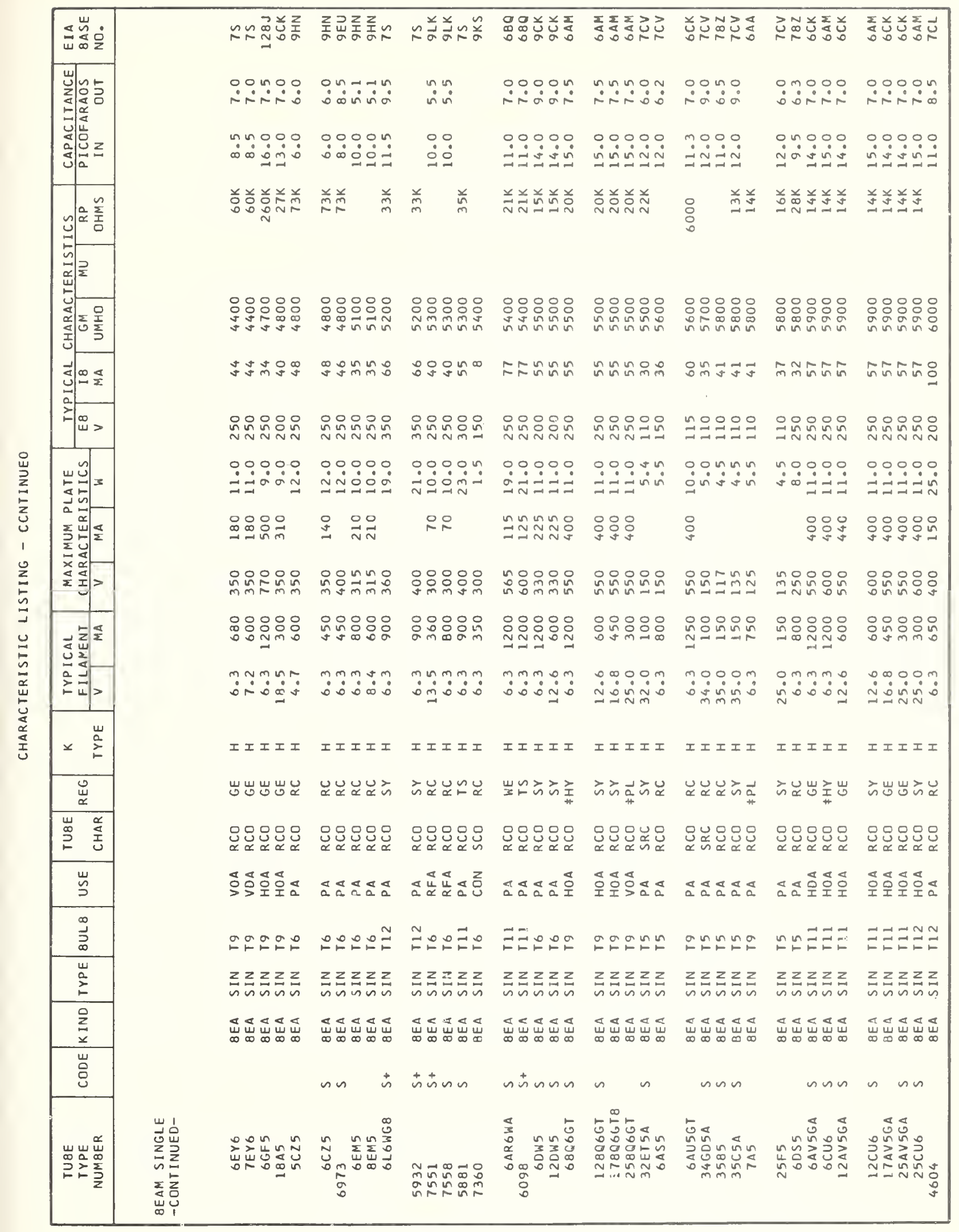




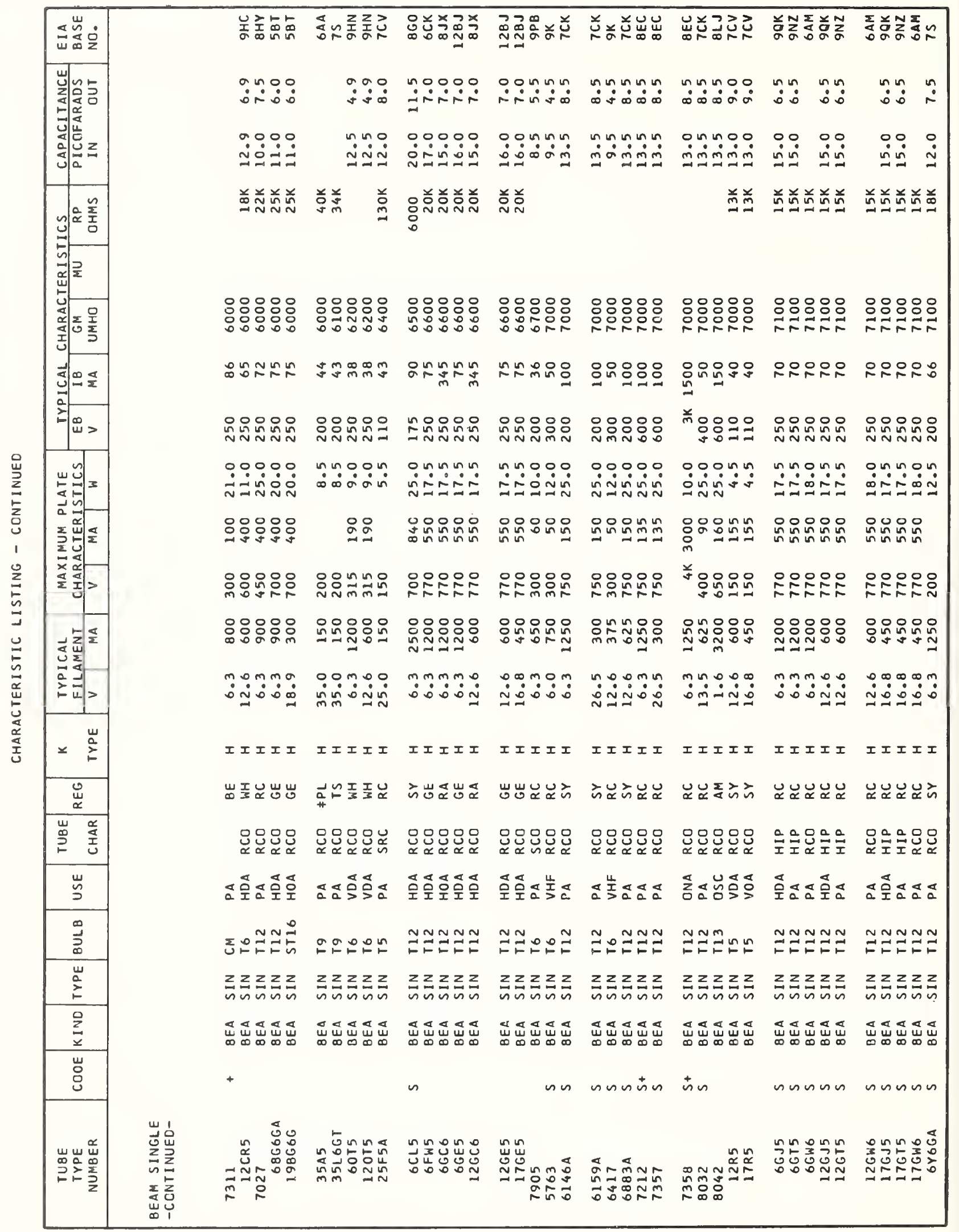




\begin{tabular}{|c|c|c|c|c|c|c|c|c|c|}
\hline 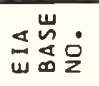 & & ヘヘュするす & 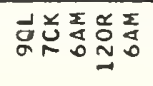 & 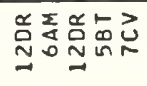 & 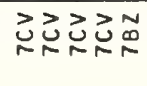 & 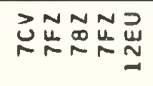 & 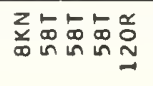 & 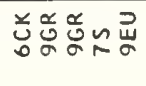 & 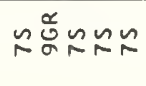 \\
\hline 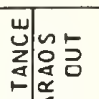 & & $\because: 0$ & 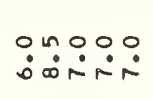 & $\ddot{\sim} \ddot{\sim} \dot{0} \dot{0}$ & 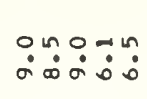 & 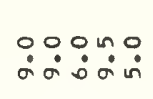 & 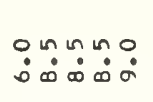 & 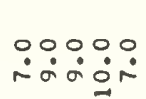 & $\begin{array}{lll}0 & 0 \\
\sigma & 0 & 0\end{array}$ \\
\hline 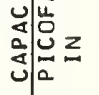 & & $\dot{n}$ & 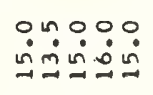 & 品品品品 & 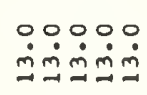 & 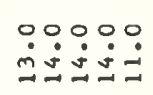 & $\begin{array}{l}0000 \\
\dot{M} \dot{N} \dot{N} \dot{N}\end{array}$ & 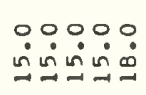 & 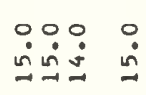 \\
\hline u. & & 单吕首兑兑 & 兑 曾酋酋 & 芯芯曾。兑 & 吕兰弟弟兰 & 吕弟兰兰 & 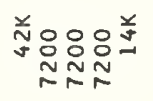 & 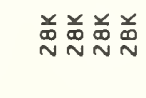 & 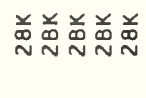 \\
\hline 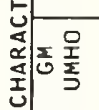 & & 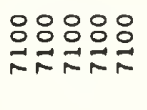 & 음윰윰유 & 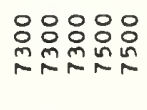 & 品品总总品 & 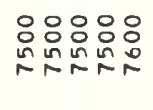 & 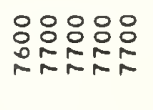 & 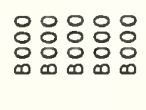 & : : \\
\hline 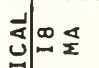 & & 몽용요 & 웅ํํำน & 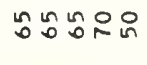 & 유용요요용 & 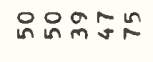 & ง & 实寺吉 & ษง์ัง \\
\hline 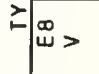 & & 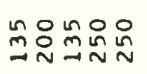 & 虽员怘怘怘 & 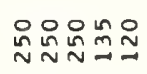 & 옳어읔으 & 으크응 & 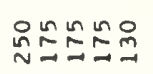 & 응윰유유 & 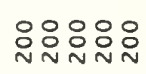 \\
\hline 崖至 & & 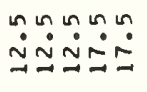 & 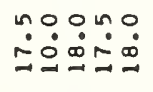 & 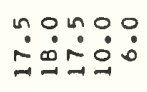 & 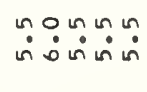 & 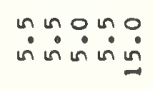 & : & 連: & :웅ㅇㅇㅇ \\
\hline 宝氙区 & & $\stackrel{n}{\stackrel{n}{=}}$ & 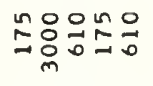 & 约오ำำ & & $\stackrel{0}{\cong} \stackrel{0}{-1}$ & 응윰욧 & $\stackrel{0}{\simeq}$ & 品怘望 \\
\hline $\begin{array}{l}x \\
x \\
x \\
x\end{array}$ & & 유N윰유 & 웡유유 & 웃ㅇㅇㅇㅇㅛ & 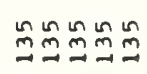 & 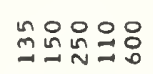 & 음욤유 & :용윰유 & 임임윰이 \\
\hline 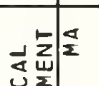 & & : & 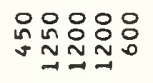 & 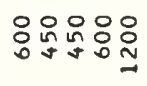 & 영용용요 & 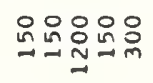 & 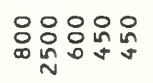 & : & 음: \\
\hline 24- & & & $\infty m M M D$ & & & $00 \mathrm{mon}$ & mmoOO & & \\
\hline - & & $\stackrel{\sim}{\sim}$ 造 $\cong$ & $0000 \cong$ & $\simeq 20 \approx$ & 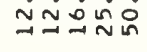 & 品品吕向 & $00 \stackrel{\sim}{m} \vec{\sim}$ & $\stackrel{2000}{\circ}$ & $0 \simeq \simeq \simeq$ \\
\hline$\times \quad 2$ & & Iエエエエ & IIIII & IIIII & IIIII & IIIII & IIIII & Iエエエエ & IIIII \\
\hline$\underset{\propto}{u}$ & & 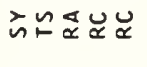 & & 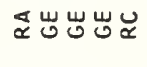 & 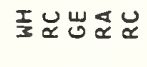 & 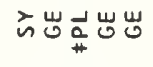 & 岕岕出方嵌 & 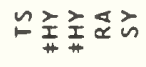 & 空主考出嵌 \\
\hline 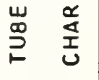 & & 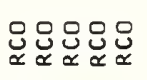 & 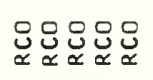 & 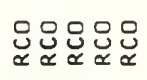 & 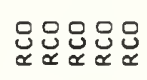 & 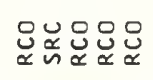 & 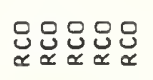 & 엃웛 & 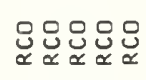 \\
\hline 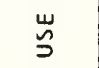 & & 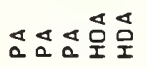 & 오옹오오옴 & 오오모옹ㅇㅇ & 造造造造 & 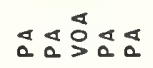 & 똥오오옹오 & 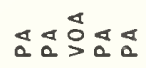 & 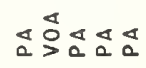 \\
\hline$\sum_{\substack{3 \\
\infty}}^{\infty}$ & & ショミミミ & そミミミミ & モュュュュ & 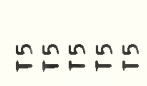 & 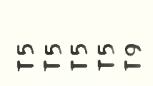 & ロ゚ミミミ & こ゚ロ゚の & ஜ゚ロにの \\
\hline $\begin{array}{l}\omega \\
\vdots \\
\vdots \\
\llcorner\end{array}$ & & 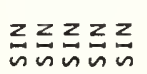 & 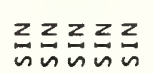 & 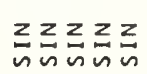 & 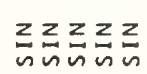 & 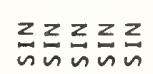 & 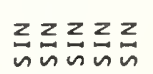 & 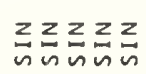 & 就就的 \\
\hline$\stackrel{0}{\underline{z}}$ & & 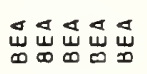 & 岕岕 & 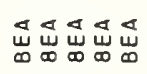 & 岗出出出岗出 & 㟧出出 & 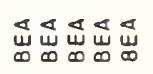 & 峞岕岕出出 & 峞出出出岕 \\
\hline 엄 & & $n \dot{s}$ & $n$ & $n$ & $n n$ nn & $n$ & $n n$ & $n \backsim n$ & $\backsim$ nnn \\
\hline 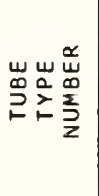 & 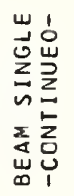 & 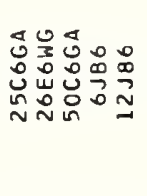 & 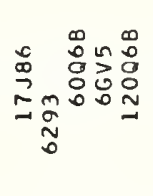 & 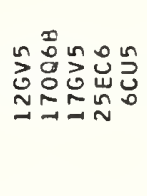 & 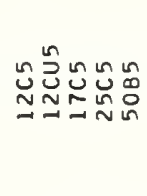 & 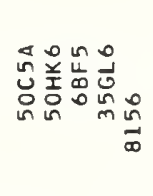 & 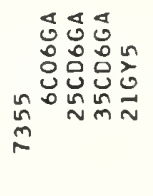 & 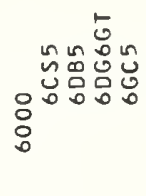 & 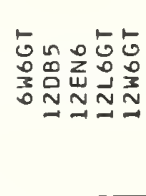 \\
\hline
\end{tabular}




\begin{tabular}{|c|c|c|c|c|c|c|c|c|c|}
\hline 岀崖呈 & & ヘニニニュ & 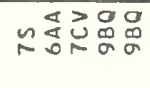 & 品吕怘岕岕 & 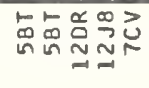 & 总就总音 & 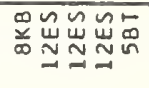 & 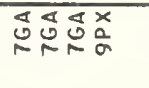 & 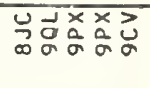 \\
\hline 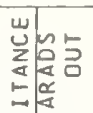 & & $\begin{array}{l}0 \\
\dot{0}\end{array}$ & 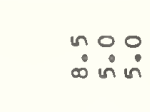 & 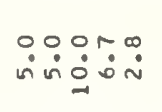 & 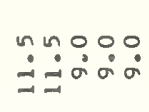 & 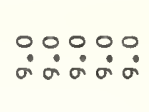 & $\dot{0}$ & $\dot{\sim} \dot{\sim} \dot{\sim} \dot{\dot{\sigma}}$ & 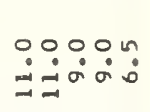 \\
\hline 题 & & $\stackrel{0}{\dot{n}}$ & 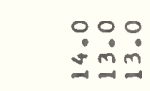 & 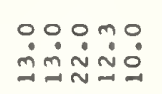 & 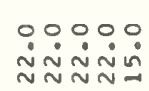 & 웁ㅁํ் & $\begin{array}{ll}0 & 0 \\
& \quad\end{array}$ & 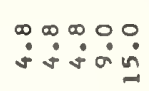 & $\begin{array}{l}\circ 000 \\
\dot{\sim} \dot{\sim} \\
\dot{U}\end{array}$ \\
\hline 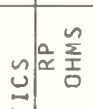 & & $\stackrel{\text { a }}{\sim} \underset{\sim}{\sim} \underset{\sim}{\sim} \underset{\sim}{\sim} \stackrel{0}{\sim} \underset{\sim}{\sim}$ & 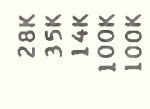 & 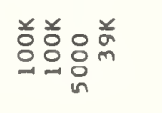 & 家品 & 弟弟首总。 & 응요 & 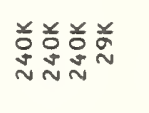 & 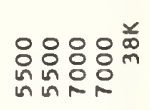 \\
\hline \begin{tabular}{l|l}
0 \\
4
\end{tabular} & & $\begin{array}{l}\text { 융ㅇㅇ } \\
: 00 \\
\infty\end{array}$ & 용ㅇㅇㅇㅇㅛ & 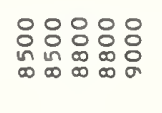 & :유윰유. & 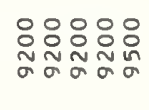 & 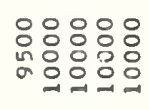 & 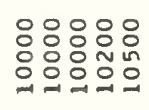 & 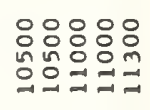 \\
\hline 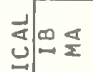 & & 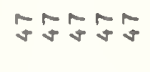 & 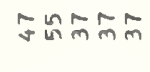 & 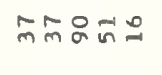 & 우욤ํำ & 的战的品 & 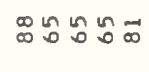 & 으웅요욤 & 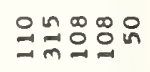 \\
\hline 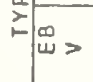 & & 운유: & 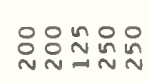 & 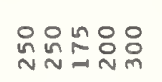 & 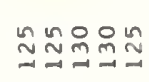 & 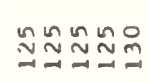 & 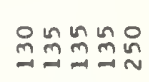 & ํㅗㄴㅗำ & 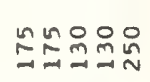 \\
\hline 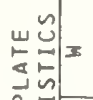 & & : & :ํㅜㅇㅇㅜ & ஊீ:00: & 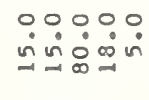 & 品㩆 & 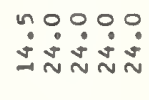 & 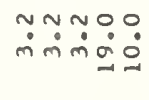 & 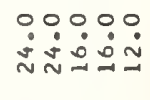 \\
\hline 王氙| & & $\stackrel{\circ}{\circ}$ & & 웃워 & 옹윰요 & & : & 유윰요 & $﹎{0}^{\circ} \stackrel{n}{m}$ \\
\hline 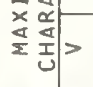 & & : & 总克品怘怘 & 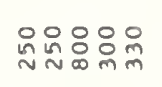 & 옴유늄ㅁ & 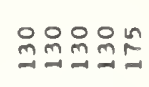 & 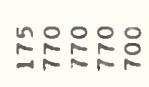 & 윰윰요 & 吠染品品品 \\
\hline 在这娄 & & 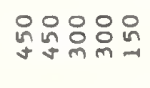 & 品品品怘: & 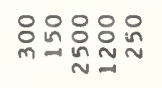 & 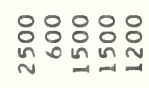 & 咨品品怘 & 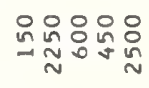 & 品咨啰品 & 总品品递: \\
\hline 这这> & & 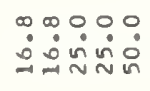 & 品怘: & 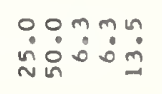 & : & 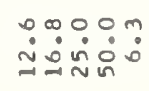 & 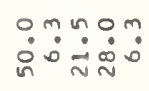 & 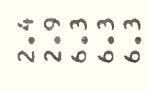 & 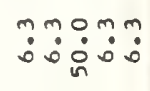 \\
\hline$\times \quad \frac{\omega}{z}$ & & エエエエエ & エエエエエ & Iエエエエ & IIエII & Iエエエエ & IIIII & IIIII & エエエエエ \\
\hline$\underset{\sim}{\stackrel{u}{\alpha}}$ & & 公孚主嵌㟧 & 岕えええ岕岕 & 嵌甹里主岁 & 元え岕嵌嵌 & 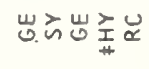 & 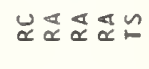 & 岕出岕公岕 & 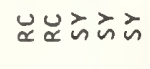 \\
\hline 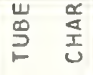 & & 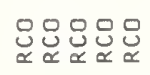 & 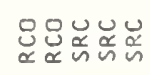 & 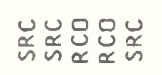 & 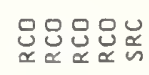 & 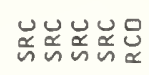 & 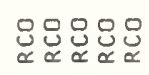 & 号总总 & 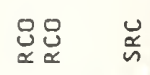 \\
\hline 岁 & & 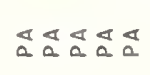 & 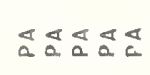 & 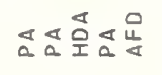 & 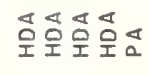 & 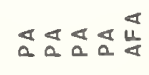 & 选造唓呈。 & 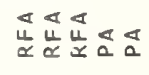 & 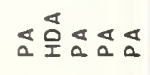 \\
\hline$\stackrel{D}{\infty}^{\infty}$ & & ロ゚ミ゚ロ & ゚゚ロ゚゚゚ & ゚゚ュュ゚゚ & モュュュュ & ヒロッロ & のミュュュ & 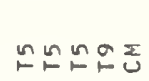 & モュのの゚ \\
\hline$\sum_{\substack{a \\
\underline{a}}}^{\omega}$ & & 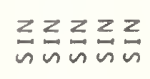 & 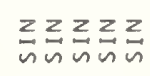 & 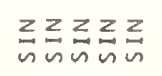 & 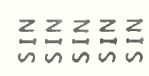 & 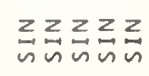 & 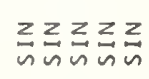 & 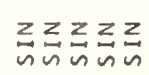 & 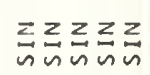 \\
\hline$\underset{z}{\substack{2 \\
x}}$ & & 出出出出出出 & 乔出出出出 & 㟧岕出岕岕 & 虫出岕出出出 & 出出出出出 & 岕出出出出出 & 岕出出出出出 & 岕出出出出出 \\
\hline 岁 & & 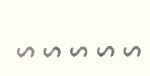 & $n n$ & $n^{+}$ & & $n$ & & $\dot{n}$ & $n n$ \\
\hline 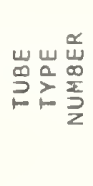 & 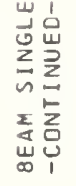 & 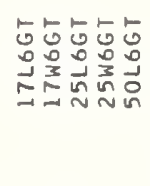 & 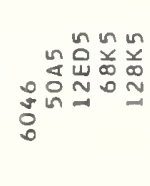 & 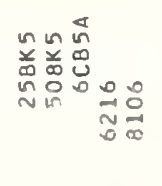 & 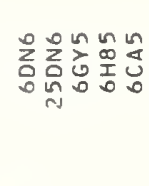 & 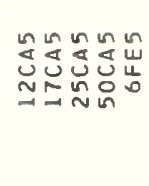 & 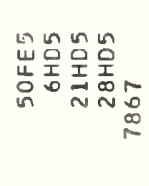 & 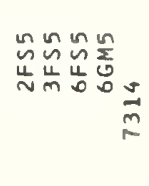 & 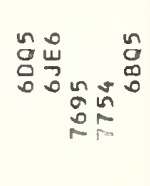 \\
\hline
\end{tabular}




\begin{tabular}{|c|c|c|c|c|c|c|c|c|c|}
\hline 岀岩号 & & 己ૂપૂ心ئ & & 罾品品 & & 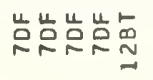 & 형햐영 & & 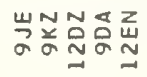 \\
\hline 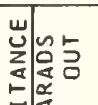 & & $\ddot{\circ} \dot{\circ} \dot{m} \dot{m} \dot{m}$ & & $\stackrel{0}{\dot{n}}$ & & & $\dot{0} \dot{0}$ & & $\ddot{\infty}: \stackrel{n}{\circ}$ \\
\hline $\begin{array}{l}0 \\
0 \\
0\end{array}$ & & 舟品品 & & $\stackrel{0}{\circ}$ & & $\begin{array}{l}\sim \sim \sim 0 \\
\dot{j}: \dot{j}\end{array}$ & & & $\because \because \quad \stackrel{0}{\beth}$ \\
\hline$=\sqrt[0]{\frac{n}{x}}$ & & 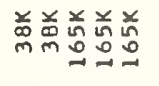 & & $\stackrel{\times}{\stackrel{x}{\sim}}$ & & & & & $\stackrel{ }{\simeq}$ \\
\hline 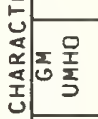 & & 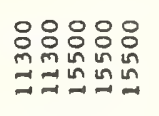 & & 웅유 & & & 造品 & & 웅요 \\
\hline 可迹 & & 운용ㅇㅇㅇㅡ & & $\simeq$ 용 & & 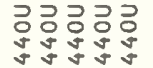 & 도무 & & Nㅜㅇ웡의 \\
\hline 昰 $>$ & & 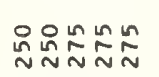 & 1 & $\stackrel{\infty}{\sim} \stackrel{0}{\sim} \stackrel{0}{N}$ & & 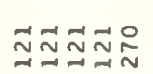 & 品员怘 & & 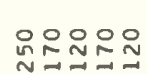 \\
\hline 氙|= & & 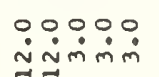 & & 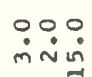 & & & $\dot{m} \dot{\sim} \dot{\sim}$ & & 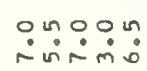 \\
\hline 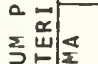 & & 농융유 & & & & $\simeq \simeq \simeq \cong$ & 풀욤 & & $\stackrel{n}{\sim} \stackrel{n}{\sim}$ \\
\hline $\begin{array}{l}x \\
x \\
x\end{array}$ & & & & & & & & & \\
\hline 这竞紊|> & & 임욤욤요 & & 용요 & & :일욤요 & 율윰요 & & 品芯怘怘怘 \\
\hline$-\sum_{u=\frac{\pi}{2}}$ & & 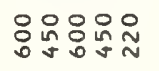 & & :용 & & 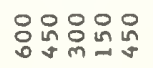 & 임용 & & 일입 \\
\hline $\begin{array}{ll}2 & 5 \\
2 & =\end{array} \mid>$ & & 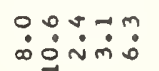 & & $\ddot{\infty} \dot{0}$ & & 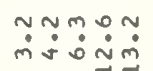 & mm & & 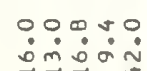 \\
\hline 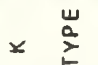 & & エエエエエ & & III & & エエエエI & III & & IエエエI \\
\hline$\underset{\sim}{\Psi}$ & & 㐫え゙岁岁出 & & えむえ & & 嵌岕岁え岕 & Шّ山 & & 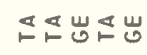 \\
\hline 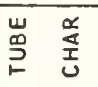 & & 范品号号怘 & & 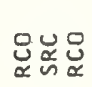 & & & 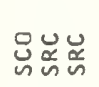 & & $\underset{\&}{S}$ \\
\hline$\stackrel{w}{ٌ}$ & & 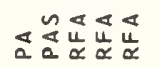 & & $a \leq a$ & & 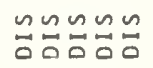 & 岀岁出 & & 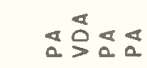 \\
\hline$\stackrel{\infty}{3}$ & & คำณn & & の๐こ & & 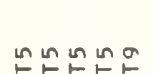 & ㅇํ요 & & ํ๐ロ。 \\
\hline$\frac{u}{\frac{1}{2}}$ & & 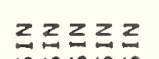 & & $\frac{2}{3} \frac{2}{3}$ & & zaz $z \leq 0$ & $z \geq z$ & & $\vec{x} \vec{\alpha} \vec{\alpha} \vec{\alpha} \vec{x}$ \\
\hline$\underset{\underline{z}}{\underline{\underline{z}}}$ & & 出出岕出出 & & 岀㟒峞 & & 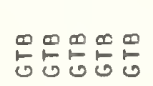 & 署罢罢 & & 出出出出 \\
\hline 㟔 & & & & + & & & $n n$ & & \\
\hline 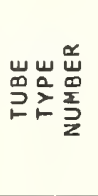 & 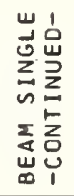 & 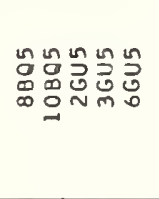 & $\begin{array}{l}\frac{z}{3} \\
\vdots \\
\sum \\
\vdots \\
w \\
0\end{array}$ & 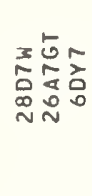 & 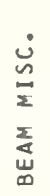 & 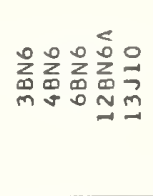 & 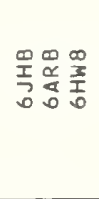 & 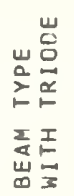 & 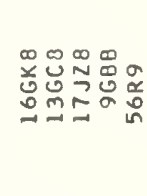 \\
\hline
\end{tabular}




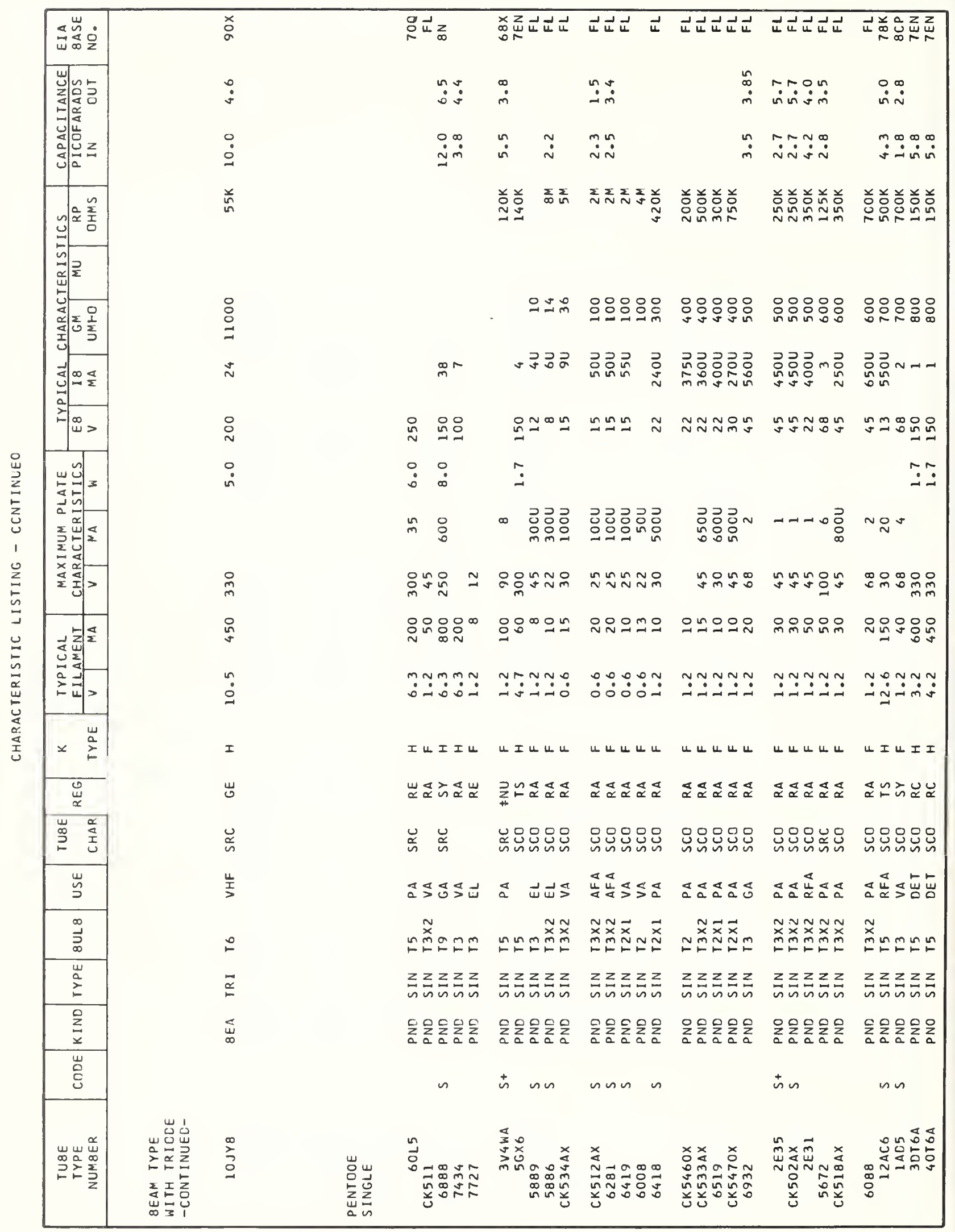




\begin{tabular}{|c|c|c|c|c|c|c|c|c|c|}
\hline 这崖咞 & & 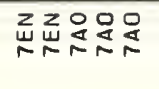 & 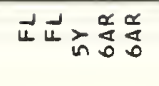 & 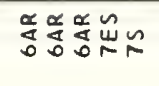 & 山旽星山㒸 & แ & 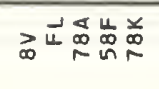 & 㒸品山这的 & 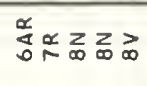 \\
\hline 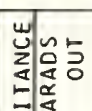 & & $\stackrel{\circ}{\sim} \therefore \dot{0}$ & 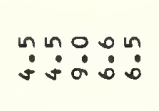 & 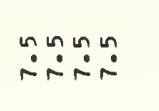 & $\dot{j} \dot{\sim} \dot{\sim}^{\infty} \dot{s}$ & 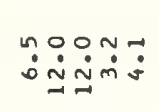 & 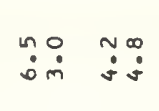 & $\stackrel{\infty}{\dot{0}} \dot{0}$ & 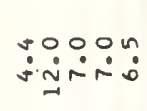 \\
\hline 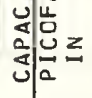 & & ம் & $\ddot{m} \ddot{n} \dot{n} \dot{\sim} \dot{\sim} \dot{m} \dot{m} \dot{m}$ & $\ddot{m} \dot{m} \dot{m} \dot{m} \dot{m}$ & 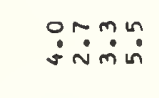 & 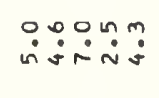 & 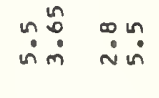 & $\ddot{n} \dot{0} \dot{0}$ & : : : : : \\
\hline 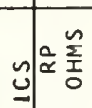 & & 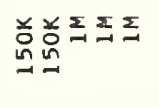 & Nָえ & 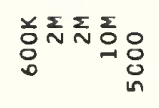 & 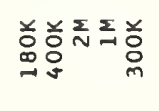 & $\sum \sum \sum \sum \sum$ & 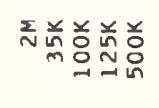 & 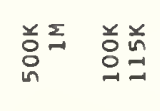 & 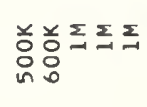 \\
\hline 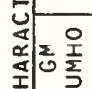 & & 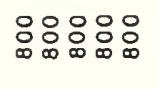 & :ㅇচㅁ용ㅇㅇㅁ & 응응용요 & 용임엄엄 & 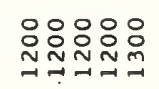 & 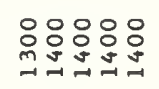 & 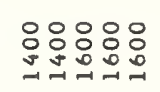 & 응ㅇㅇㅇㅇ \\
\hline $\int_{-\infty}^{\infty}$ & & $\rightarrow-I N N$ & 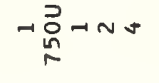 & $m \rightarrow N N \vec{n}$ & $N-N \sim \stackrel{D_{n}}{\sim}$ & $\sim \sim \sim{ }_{0}{ }_{\infty} N$ & NoOR- & $\rightarrow n a n$ & $S O M m N$ \\
\hline $7 \omega_{w}^{\infty}>$ & & 윰윰영ㅇㅇㅇ & 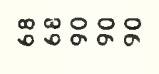 & 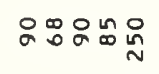 & 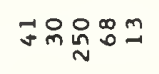 & 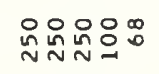 & 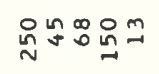 & 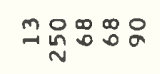 & 옸윳ํํํำ \\
\hline = & & $\because$ & $\because \dot{0}$ & บo & $\because \stackrel{\sim}{-}$ & $\begin{array}{lll}\infty & \infty & \text { un } \\
0 & 0 & 0\end{array}$ & $\stackrel{5}{-0}$ & $\begin{array}{l}n \infty \\
\dot{0} 0\end{array}$ & $\begin{array}{l}\infty \ln \sim 0 \\
\dot{\sim} \dot{N} \dot{\sim}\end{array}$ \\
\hline 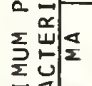 & & in in & $N \rightarrow \operatorname{Nn}$ & OMONO & sN & & $\cong$ & $\stackrel{\sim}{\sim} \approx \cong$ & $\Xi$ \\
\hline 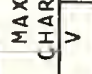 & & 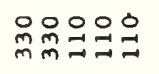 & 오ㅇㅛㅛ & 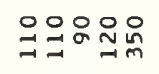 & 욤유용 & 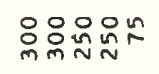 & : & 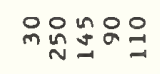 & 욤임잉이 \\
\hline बड & & 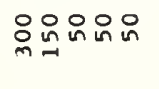 & 옹유응요 in & ㅁำ $\sim$ ํㅛ $\sim$ & 웅욤욤요 & 品品品望: & 욱응요욤요 & 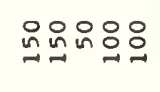 & 웅임윰욤요 \\
\hline 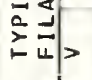 & & $\ddot{m} \dot{0} \dot{q} \dot{\sim}$ & 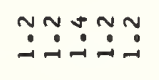 & 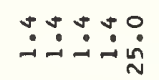 & 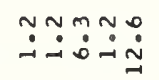 & 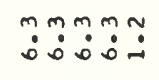 & 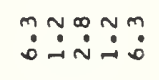 & $\dot{\sim} \ddot{\sim} \dot{\sim} \dot{\sim} \dot{\sim}$ & 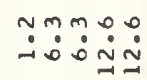 \\
\hline$\times \sum_{i}^{0}$ & & IエレUル & レேレルレ & レレレルI & $\sqcup レ I ル I$ & エエエエル & IレயレI & IエயபИ & $U I I I I$ \\
\hline$\underset{\Psi}{\overleftrightarrow{\Psi}}$ & & 凹ニえうらす & 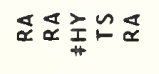 & 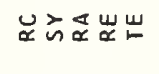 & 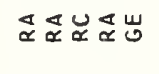 & 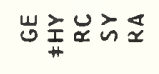 & 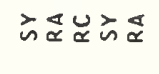 & 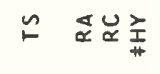 & ※) \\
\hline 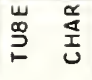 & & 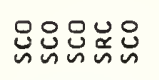 & 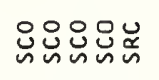 & 勇导 & 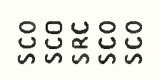 & 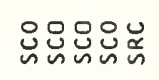 & 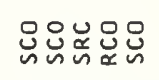 & 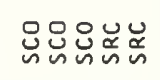 & 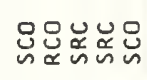 \\
\hline 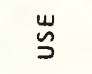 & & 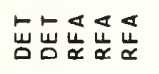 & 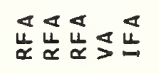 & 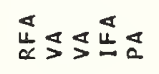 & 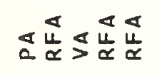 & 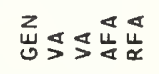 & 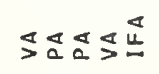 & 造㟔むむむ & 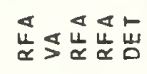 \\
\hline$\stackrel{D}{\infty}_{\infty}^{\infty}$ & & คேレロにの & 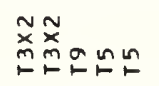 & 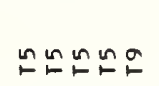 & 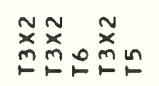 & 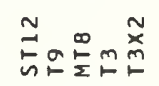 & 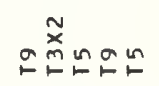 & 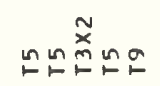 & ๓の昂のの \\
\hline$\underset{\frac{1}{2}}{\frac{\omega}{2}}$ & & 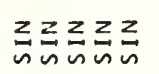 & 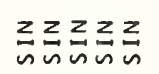 & 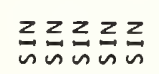 & 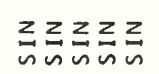 & $\frac{z}{n} \frac{z}{n} \underset{n}{n} \frac{2}{n}$ & 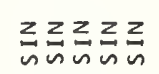 & 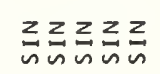 & 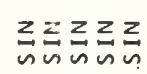 \\
\hline 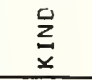 & & 只只只只只只 & 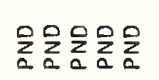 & 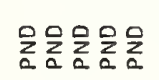 & 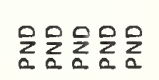 & 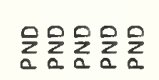 & 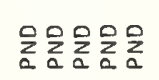 & 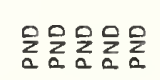 & 呈员员员员 \\
\hline 음 & & $n \backsim n$ & n市市 & $\sim n$ & $n n$ & $\sin \dot{s}^{+}$ & is & & $\dot{s} n$ \\
\hline 出 & 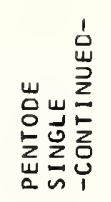 & 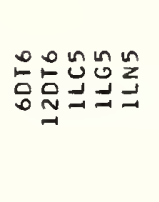 & 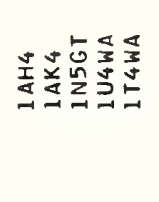 & 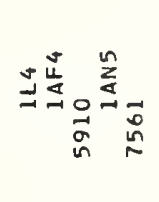 & 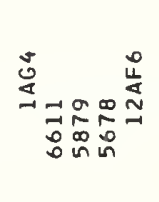 & 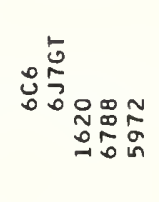 & 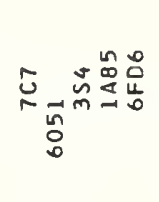 & 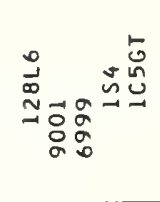 & 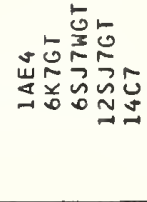 \\
\hline
\end{tabular}









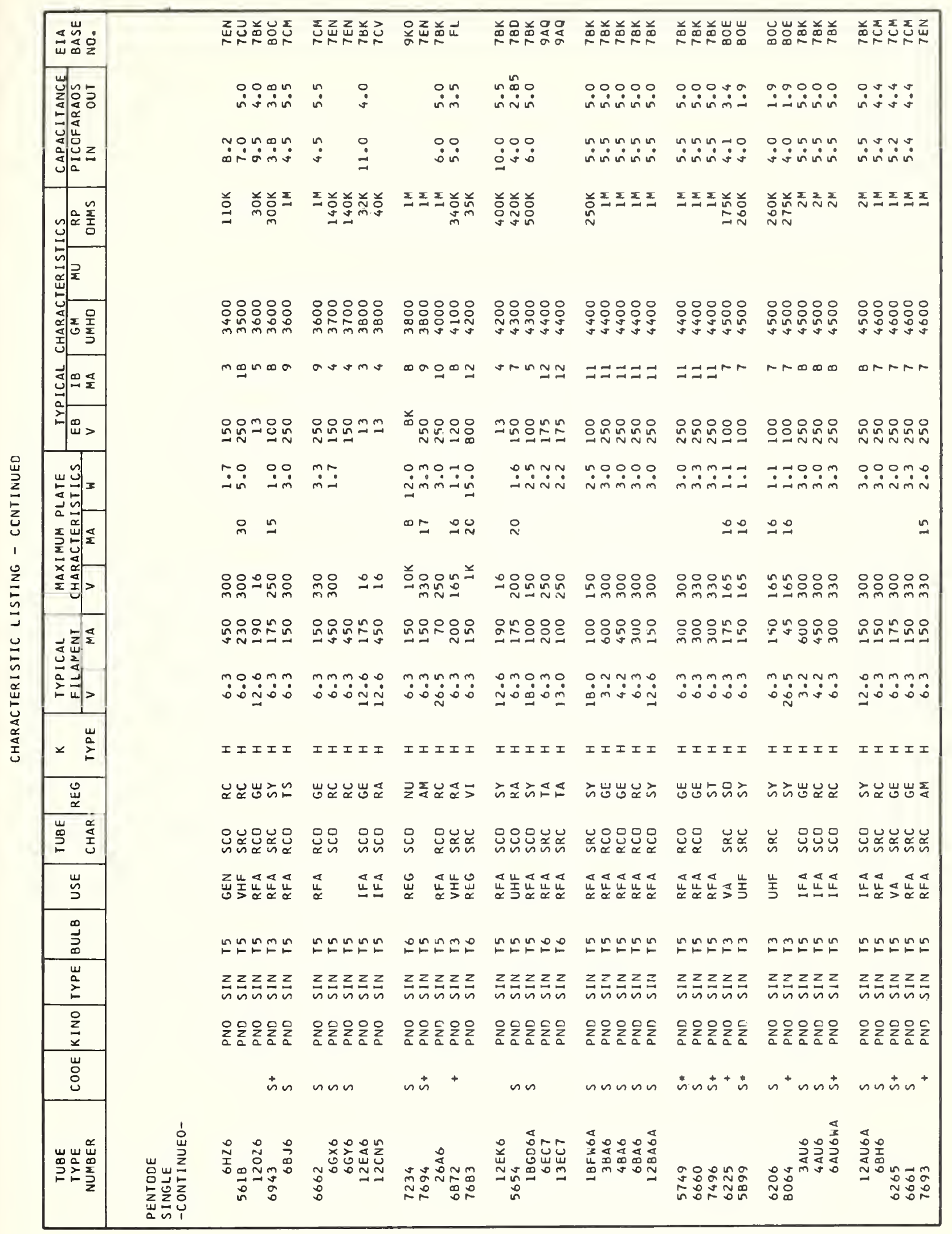




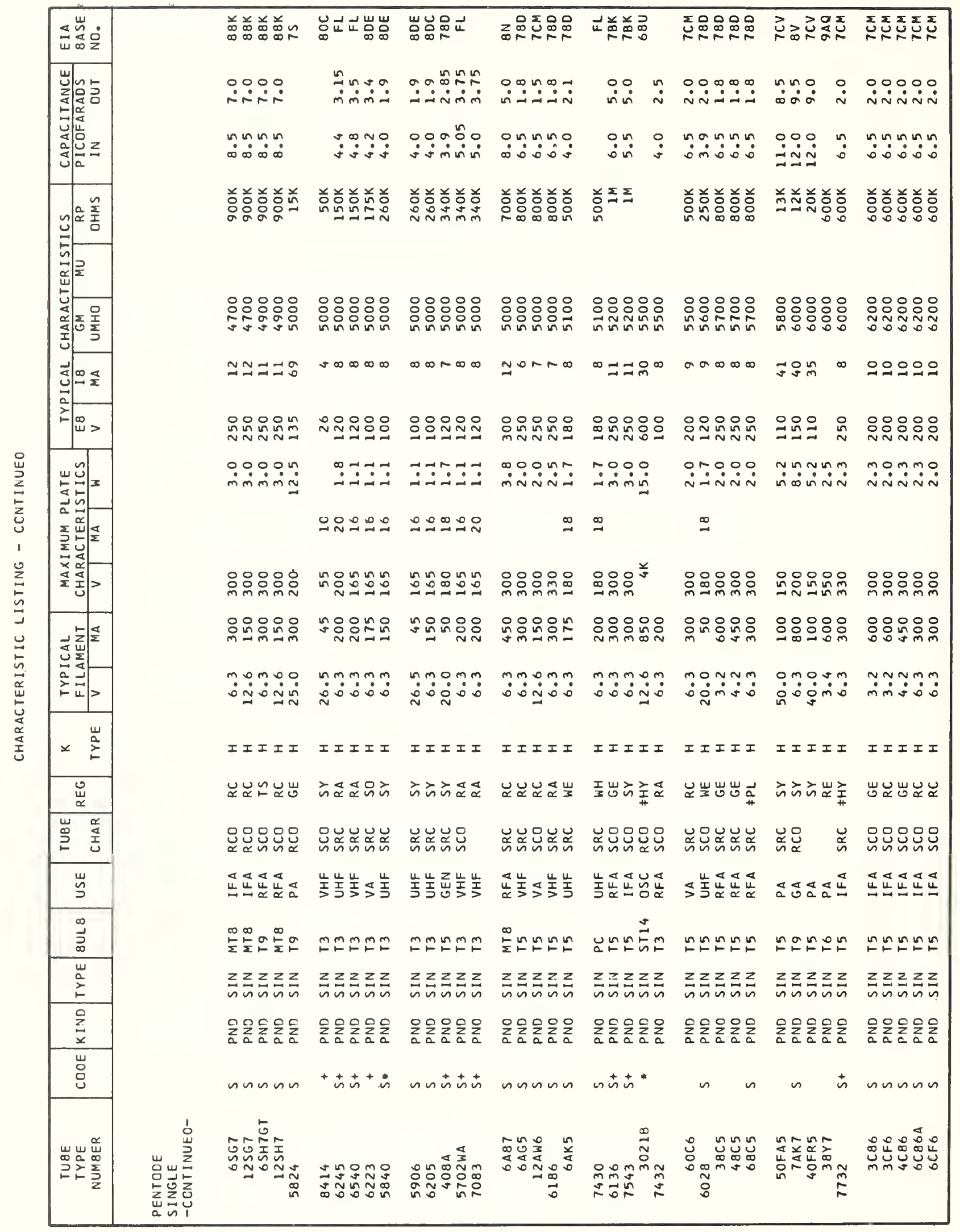




\begin{tabular}{|c|c|c|c|c|c|c|c|c|c|}
\hline 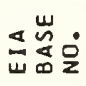 & & 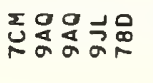 & 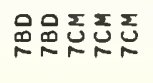 & 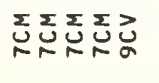 & 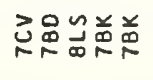 & 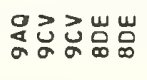 & 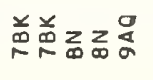 & 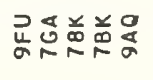 & 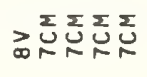 \\
\hline 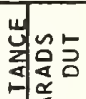 & & $\dot{\sim} \dot{m} \dot{m} \dot{m} \operatorname{m} \tilde{m}$ & 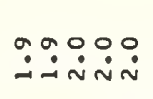 & $\dot{\sim} \dot{\sim} \dot{\sim} \dot{\sim}$ & 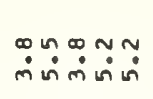 & $\because:$ & 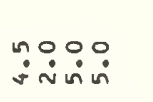 & 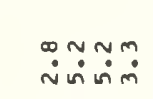 & $\stackrel{\sim}{\sim} \dot{\sim} \sigma \sigma \sigma$ \\
\hline 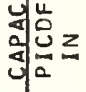 & & 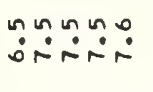 & $\ddot{n}$ & 品品品 & $\ddot{\infty}$ & $\ddot{\circ}:$ & :용이 & 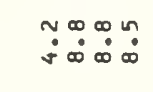 & 过: \\
\hline$\sqrt{4} \frac{\frac{n}{2}}{\frac{2}{\partial}}$ & & 关圐兑 & 兑弟总总兑兑 & 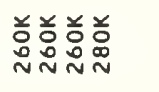 & 弟 差兑兑 & 前弟总兑 & 号兑品 & 兑弟兑兑兑兑 & 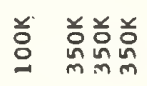 \\
\hline 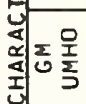 & & 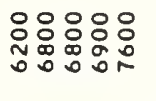 & 영ㅇㅇㅇㅛ & 음욤욤 & 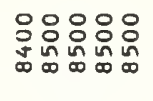 & 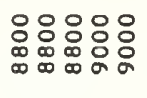 & 응용ㅇㅁㅇㅇㅇㅇ & 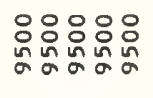 & 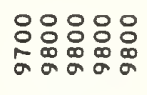 \\
\hline 矛回东 & & 응ㅇ음으 & ニニュささ & $\Xi \pm \unlhd コ \vec{m}$ & $\stackrel{m \infty}{\sim} \underset{m}{ }=$ & 요뮤 & 으오엄ㅇㅇㅇㅗ & 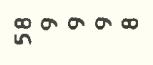 & $\stackrel{m}{ } \approx \simeq \simeq \cong$ \\
\hline 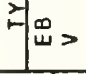 & & 윳ํํํํํํำ & 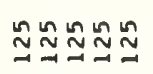 & $\stackrel{\cong}{\cong} \cong \cong$ & 옥응ㅇㅁ윰 & 옹융욤요 & 임윰융요 & 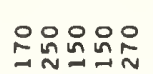 & 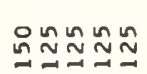 \\
\hline 列 & & 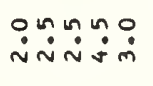 & 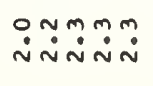 & 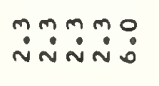 & 过苗宜品 & 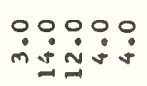 & 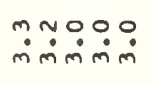 & 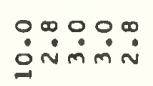 & 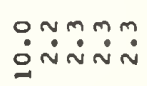 \\
\hline 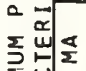 & & 요 & & 品 & nี & 읭ㅇㅁ웅 & $\stackrel{\infty}{N} \stackrel{n}{\sim}$ & $\stackrel{\sim}{\sim}$ & \\
\hline 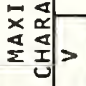 & & 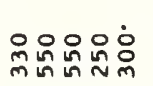 & 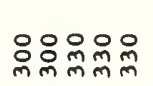 & 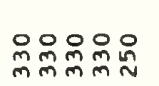 & 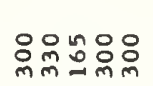 & 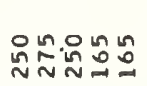 & 잍윰유욤요 & 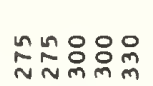 & 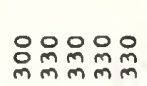 \\
\hline , 昰要 & & 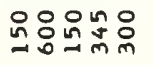 & 용윰용요 & 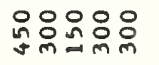 & 啹品品品 & 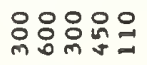 & 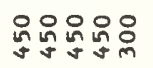 & 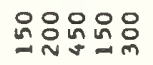 & 品品品品品 \\
\hline 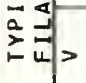 & & $\ddot{n} \dot{\sim} \dot{\sim} \dot{\sim} \dot{\sim}$ & $\dddot{m} \ddot{\dot{m}} \because \dot{m} \dot{m}$ & 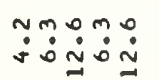 & $\because \because \because \ddot{\circ}: \dot{0}$ & 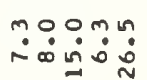 & 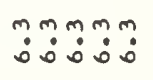 & $\ddot{n}: \dot{m} \dot{0} \dot{0}$ & 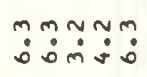 \\
\hline$\times \quad \frac{a}{2}$ & & IエエルI & IIIII & IIIII & IIIII & IIIII & IIIII & IIIII & IIIII \\
\hline$\underset{\sim}{\stackrel{\Psi}{\alpha}}$ & & 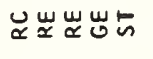 & a & 岕ええ゙せ。 & 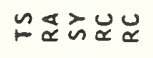 & 『岕ひえう & 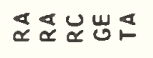 & 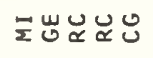 & 方岕榃 $\frac{T}{3} \propto$ \\
\hline 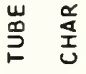 & & 总总总品 & 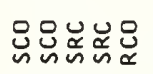 & 足总总导 & 号导若 & 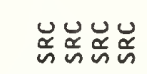 & 号总导品 & 品总导怘 & 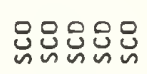 \\
\hline 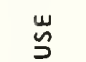 & & 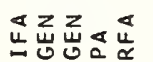 & 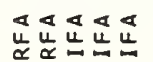 & 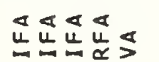 & 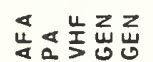 & 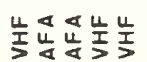 & 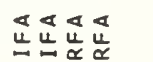 & 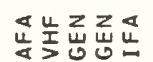 & 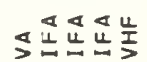 \\
\hline$\sum_{0}^{\infty}$ & & ロ゚ロロロ & ロロロロロロ & ロேロロேロ & ロேロロロロ & ロロロ゚ロ & 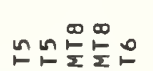 & ロேロロロ & 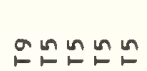 \\
\hline$\frac{a}{a}$ & & 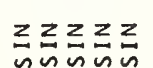 & 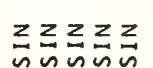 & 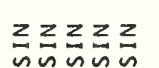 & 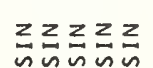 & $\begin{array}{l}z \geq z z \\
n\end{array}$ & 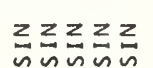 & 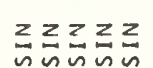 & $\begin{array}{l}z z \\
n \\
n\end{array}$ \\
\hline$\frac{O}{z}$ & & 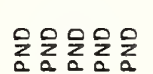 & 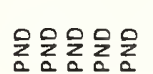 & 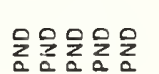 & 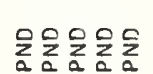 & $\sum_{0} \sum_{0} \sum_{a} \sum_{0} \sum_{0}$ & 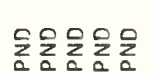 & 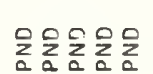 & $\sum_{a} \sum_{a} \sum_{a} \sum_{a} z_{0}$ \\
\hline 岁 & & & $n n n$ & nnun & $n^{+} n$ & + & シ்ッn் & $n$ & $n$ \\
\hline 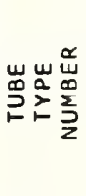 & 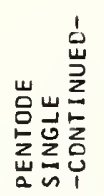 & 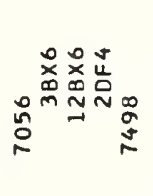 & 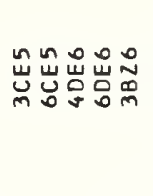 & 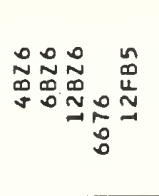 & 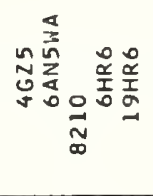 & 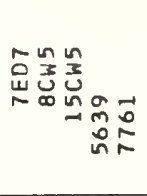 & 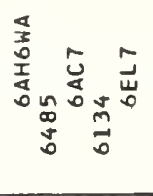 & 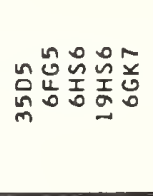 & 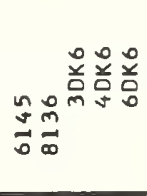 \\
\hline
\end{tabular}




\begin{tabular}{|c|c|c|c|c|c|c|c|c|c|}
\hline 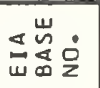 & & 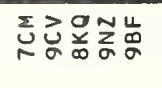 & 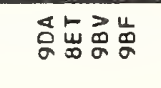 & 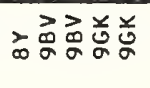 & 弟芯句弟 & 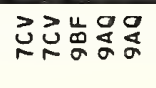 & 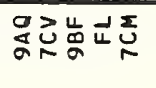 & 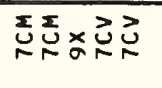 & 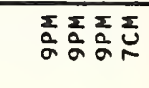 \\
\hline 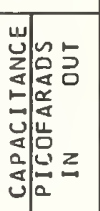 & & 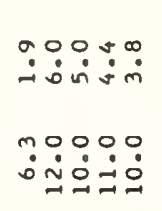 & 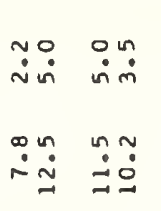 & 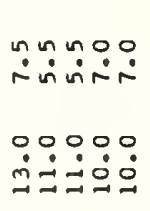 & 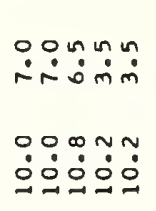 & 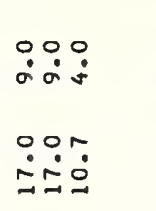 & 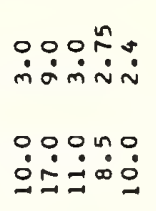 & 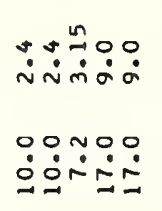 & 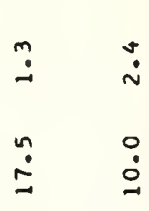 \\
\hline 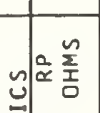 & & 弟酋总㒸首 & 兑 吕兑前 & 总总总酋酋 & 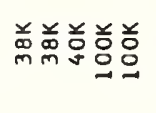 & 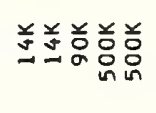 & 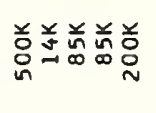 & 弟兑兑㒸弟 & 盖惫弟兑 \\
\hline \begin{tabular}{l|l}
10 \\
0
\end{tabular} & & 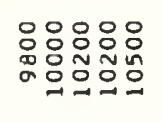 & 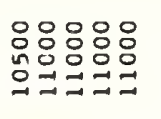 & 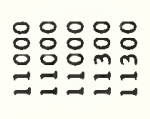 & 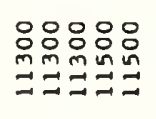 & 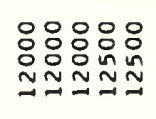 & 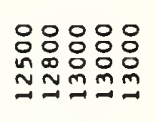 & 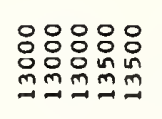 & 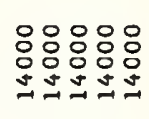 \\
\hline ⿹弋工्) & & 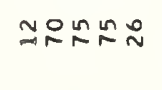 & 늠용요 & $\stackrel{m}{m} \vec{m} \vec{m} \quad \stackrel{\infty}{v}$ & 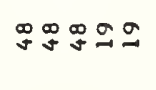 & $\tilde{N} \underset{m}{N}$ & $\simeq \tilde{m} \tilde{N}^{\infty} \pm$ & $\Xi \pm \pm \stackrel{n}{m} \stackrel{n}{m}$ & 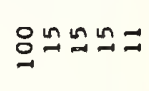 \\
\hline w > & & 폭윰윰유 & 识怘怘怘品 & 品品品怘怘 & 虽怘怘怘怘怘 & 을요 & 定呈怘品 & $\stackrel{n}{\cong} \cong 0$ & 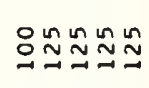 \\
\hline 点氙| & & $\begin{array}{l}m \circ: 0 \backsim \\
\dot{\sim} \dot{\sigma} \sigma \dot{\sigma}\end{array}$ & 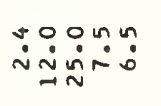 & 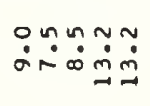 & 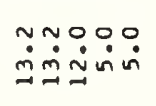 & 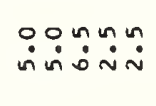 & 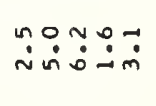 & 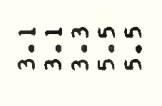 & 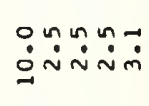 \\
\hline 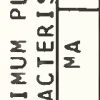 & & 용요 & 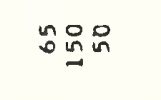 & $n$ & n & & 욜 & \& & $\underset{N}{0} \underset{\sim}{\sim} \stackrel{n}{N}$ \\
\hline 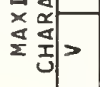 & & 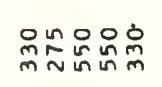 & 㗐品: & 品品品品定 & 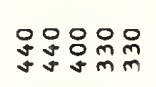 & 品品尊总品 & 真品品只品 & 衇品品品 & 品品品怘品 \\
\hline 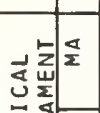 & & 咒品: & 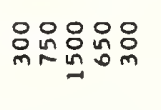 & 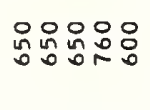 & 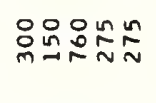 & 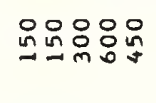 & 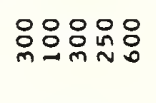 & 品号号品品品 & 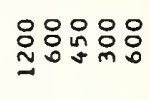 \\
\hline 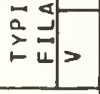 & & 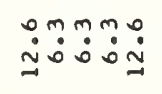 & 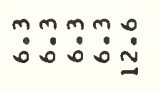 & : & 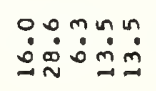 & 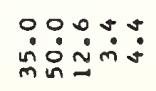 & 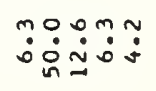 & $\dot{m}: \ddot{m}: 0$ & : \\
\hline 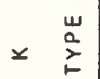 & & IエエエI & Iエエエエ & IIIII & エエエエエ & エエエエエ & エエエエエ & IIIII & IIIII \\
\hline$\underset{\sim}{\stackrel{u}{\alpha}}$ & & & 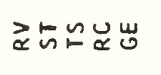 & ひ岑えむる & 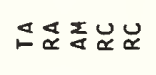 & 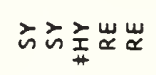 & 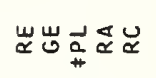 & 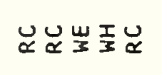 & 文孚孚孚嵌 \\
\hline 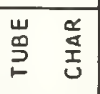 & & 号品 完品 & 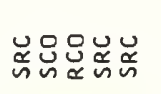 & 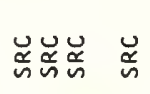 & 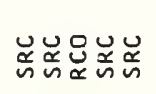 & 造兑号 & 苂怘怘 & 造造号 品 & 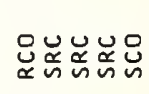 \\
\hline 岁 & & 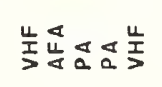 & 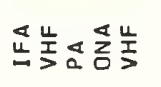 & 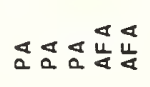 & 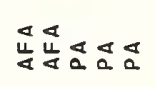 & 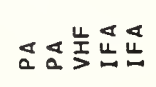 & 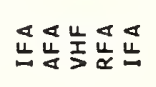 & 选选造造区 & 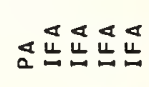 \\
\hline 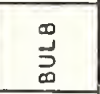 & & セロのの゚ & ピロロレ゚ & 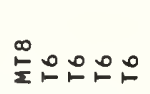 & レ요요 & セロュ゚゚゚ & レレロュ & 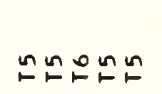 & ロ゚゚゚゚ロ \\
\hline$\frac{\omega}{2}$ & & 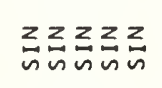 & 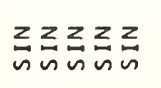 & 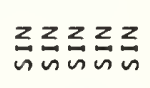 & 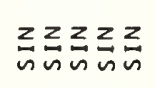 & 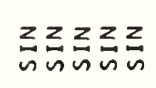 & 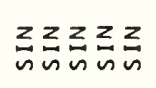 & 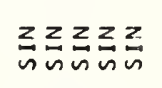 & 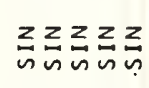 \\
\hline$\frac{0}{2}$ & & 只员员员员员 & 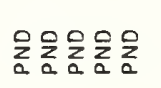 & 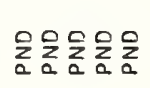 & 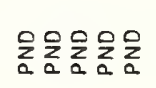 & 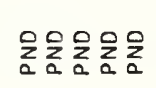 & 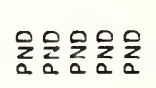 & 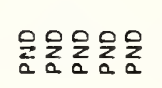 & 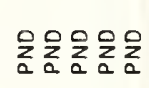 \\
\hline 岑 & & $\sim$ & $+n n$ & nnn & $n n$ & & $n n$ & $n$ & + \\
\hline 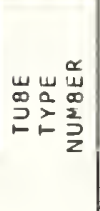 & 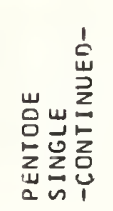 & 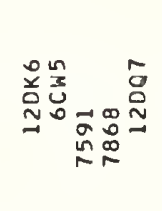 & 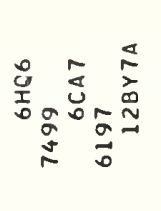 & 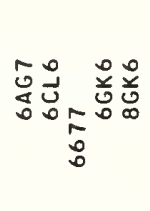 & 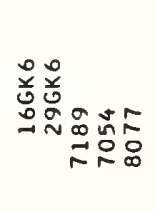 & 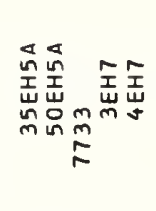 & 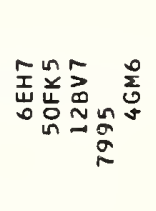 & 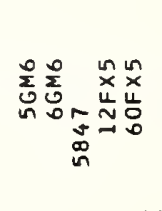 & 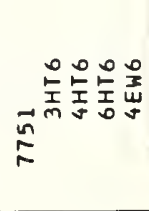 \\
\hline
\end{tabular}




\begin{tabular}{|c|c|c|c|c|c|c|c|c|c|}
\hline 造岕完 & & 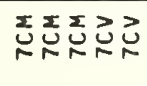 & 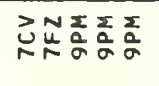 & 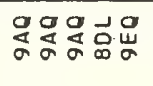 & 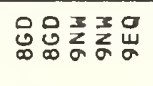 & 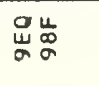 & & 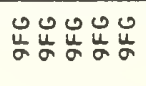 & 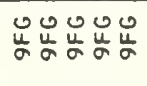 \\
\hline 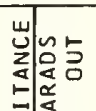 & & $\dot{\sim} \dot{\sim} \dot{\sim} \dot{\alpha} \dot{0} \dot{0}$ & 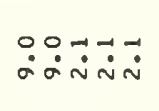 & 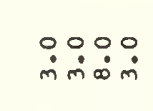 & 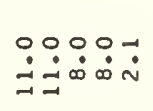 & $\dot{\sim} \dot{\sim} \dot{0}$ & & $\dddot{n} \sim$ & $\ddot{m} \dot{m} \dot{m} \dot{m} \dot{m} \dot{m}$ \\
\hline \begin{tabular}{l|l}
0 \\
$\vdots$ \\
0
\end{tabular} & & $\begin{array}{l}\circ 0 \\
\dot{0} \\
0\end{array}$ & $\because \because \because \because \because \dot{\infty}$ & 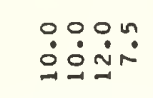 & 우요. & 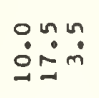 & & $\because: 0$ & : $: \because: 0:$ \\
\hline 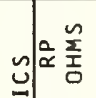 & & 哾兑兑兑 & 兰兰总兑兑 & 兑兑总占兑 & 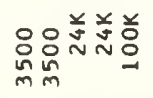 & 兑弟 & & & \\
\hline 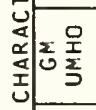 & & 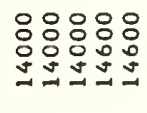 & 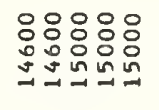 & 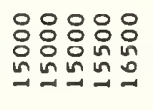 & $\begin{array}{l}\text { ㅇ:ㅇㅇㅇ } \\
\text { ㅇㅇㅁ융유 }\end{array}$ & 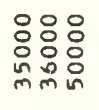 & & 음웜옥 & 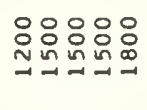 \\
\hline$\underbrace{a}_{n=\frac{\pi}{2}}$ & & 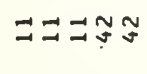 & 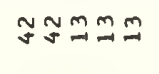 & 으으ำ & 웍요 & 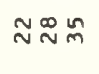 & & $\sim \sim N \infty \infty$ & $\infty N N N m$ \\
\hline W & & 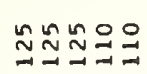 & 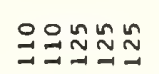 & 융욤요 & 음용ํํ요 & 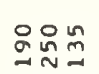 & & ㅇㅇㅇㅇㅇㅁㅇ & 응ㅇㅁㅇㅇㅁ \\
\hline 氙 & & 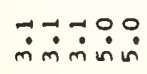 & 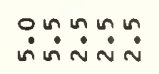 & 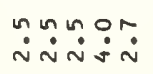 & :0000 & 萿㶽 & & 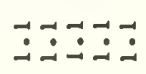 & 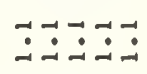 \\
\hline 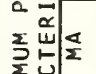 & & & $\stackrel{\sim}{N} \approx$ & $\stackrel{n}{\sim} \stackrel{n}{\sim} \stackrel{n}{N}$ & 욤욤 & $\stackrel{2}{\sim}$ & & $\simeq \simeq \simeq \simeq \simeq$ & $\simeq \simeq \simeq \simeq$ \\
\hline 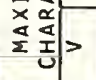 & & 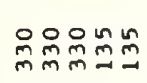 & 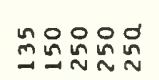 & 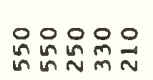 & 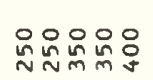 & 웅요욤 & & 임임윰요 & 임임임임이 \\
\hline-5 & & 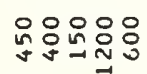 & 윰욤용요 & 啹品品品品 & 욤윰욤요 & 윰요 & & 윰욤욤요 & 윰용용요 \\
\hline 竞幽> & & 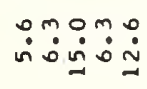 & 品 & 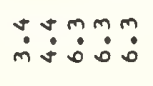 & mom & ن̊ & & ヘ & $\ddot{\dot{m}} \dot{m} \mathfrak{i} \dot{m}$ \\
\hline 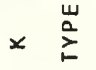 & & IIIII & エエエエエ & エエエエエ & エエエエエ & III & & IIIII & IIIII \\
\hline$\underset{\sim}{\sim}$ & & بِ بِ & 岁出 $\frac{I}{3} \frac{I}{3}$ & 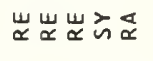 & 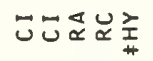 & 主公衣 & & 嵌嵌岕方六 & 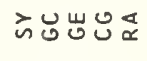 \\
\hline 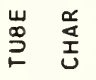 & & 总号号品品 & 号怘怘怘怘 & 怘怘 & 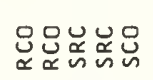 & $\stackrel{D}{n}_{n}$ & & 总号怘怘怘品 & 号怘怘怘怘 \\
\hline$\stackrel{w}{\leftrightharpoons}$ & & 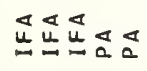 & 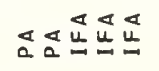 & 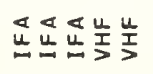 & 埕浛す & 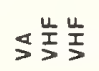 & & & 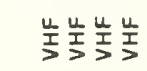 \\
\hline$\stackrel{D}{\infty}_{\infty}^{\infty}$ & & 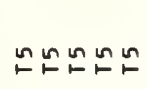 & ペロレ゚ロ & ゚゚ロロレ & モュュ゚ュ & ゚゚ & & ト゚゚ロ゚゚ & ゚゚゚゚゚ \\
\hline$\sum_{2}^{\omega}$ & & 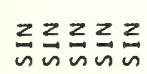 & 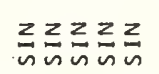 & 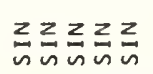 & 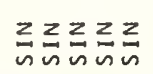 & 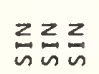 & & 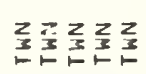 & 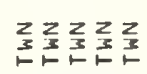 \\
\hline$\underset{z}{2}$ & & 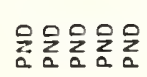 & 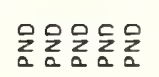 & 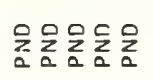 & 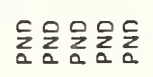 & 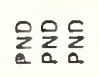 & & 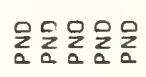 & 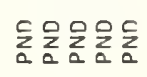 \\
\hline 岁 & & $n$ & & $\backsim++$ & $n$ & $n+$ & & 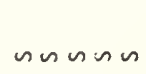 & 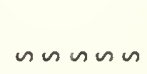 \\
\hline 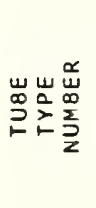 & 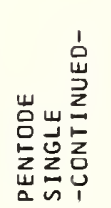 & 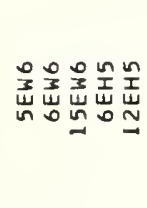 & 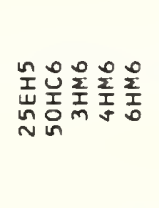 & 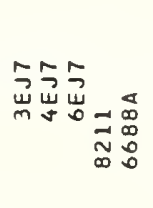 & 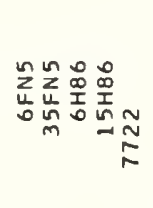 & 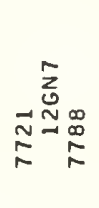 & 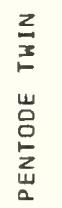 & 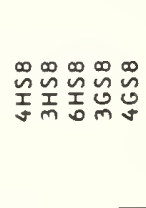 & 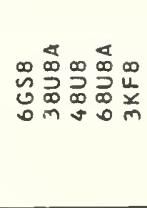 \\
\hline
\end{tabular}




\begin{tabular}{|c|c|c|c|c|c|c|c|c|c|}
\hline 造崖号 & & 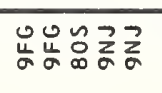 & 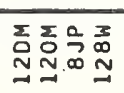 & & 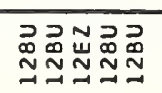 & 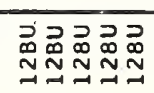 & 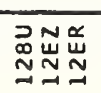 & & 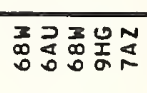 \\
\hline 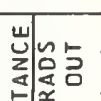 & & 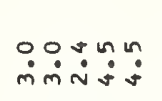 & 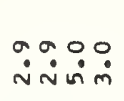 & & & 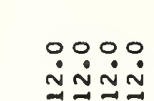 & 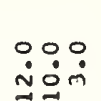 & & $\dot{\sim} \dot{\sim} \dot{0}$ \\
\hline 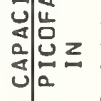 & & 品前品足 & 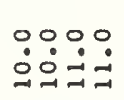 & & & 号号号 & $\begin{array}{l}0 \\
\dot{1}\end{array}$ & & 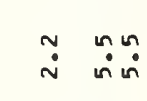 \\
\hline$\sqrt[3]{\approx} \approx \frac{n}{z_{0}^{2}}$ & & 总曾酋 & 总兑总总总 & & 总总总总总总 & 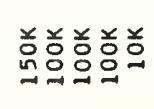 & 烂鬲 & & 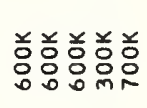 \\
\hline 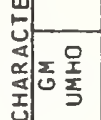 & & 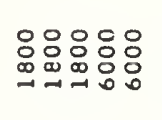 & 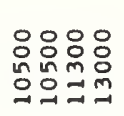 & & 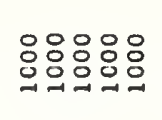 & 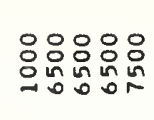 & 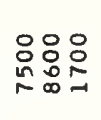 & & 영:욤윰유 \\
\hline 我里 & & MmM & $\underset{⿱ 乛 小}{\infty}=$ & & Aara- & 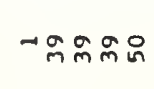 & 윰ำ & & $N \sim N-N$ \\
\hline w & & 品政品怘 & 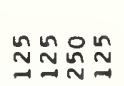 & & 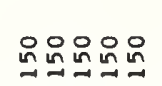 & 品品品品曷 & 웜웜 & & : \\
\hline 幽氙= & & 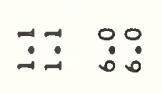 & 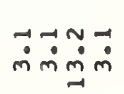 & & 莽芒 & 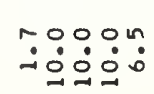 & 品: & & $\stackrel{n}{m}$ \\
\hline 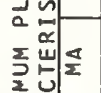 & & $\cong \simeq \backsim g_{q} q_{j}$ & $\Rightarrow z$ & & & ก & 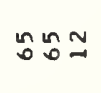 & & $m m m o$ \\
\hline 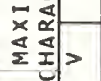 & & : & 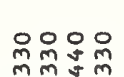 & & 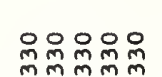 & 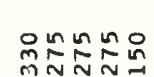 & 윰유 & & 영용유 \\
\hline 昰这 & & 哟品总品品 & 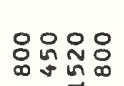 & & 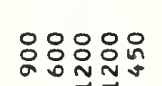 & 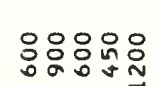 & 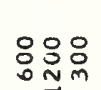 & & 윰요윰유 \\
\hline 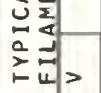 & & NMْ & : & & 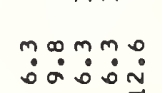 & 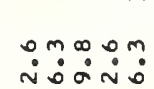 & :m: & & 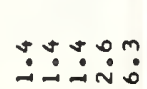 \\
\hline$\simeq \sum_{\Sigma}^{m}$ & & エエルエエ & エエエエ & & エエエエエ & エエエエエ & エエI & & ルルルエエ \\
\hline$\stackrel{u}{\sim}$ & & 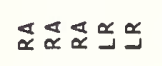 & U山ّ & & سّ & تّ ثّ سّة & 岕吃 & & 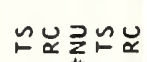 \\
\hline 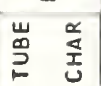 & & 品品芯 & 递岕号号 & & 吕虽品品品 & 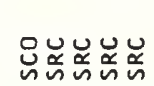 & $\stackrel{u}{\sim}$ & & 少号品品品 \\
\hline$\stackrel{\breve{s}}{s}$ & & 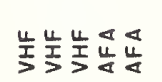 & 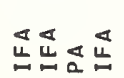 & & 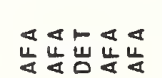 & 侥凯凯出 & 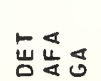 & & 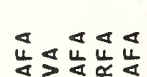 \\
\hline$\stackrel{\infty}{3}$ & & 온요용 & $\sigma \sigma 2$ & & araga & agago & $\sigma a \sigma$ & & 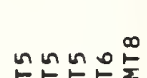 \\
\hline$\stackrel{u}{a}$ & & 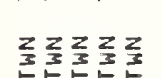 & 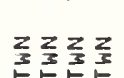 & & こュュュニ & ๓ュュニュ & $\cong \simeq \bar{a}$ & & 응믕믕응응 \\
\hline$\sum_{3}^{0}$ & & 울울울을운 & 울울울운 & & 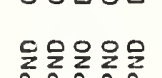 & 을율일을 & 울울 & & 울을융융 \\
\hline 亗 & & & & & & & & & \\
\hline 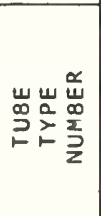 & 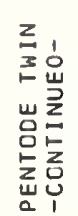 & 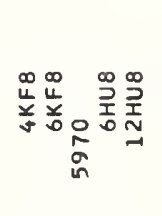 & 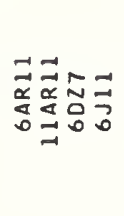 & 总密 & 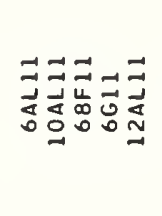 & 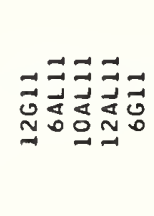 & 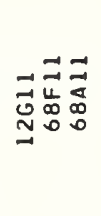 & $\begin{array}{l}\frac{I}{3} \\
3 \\
\text { 品 } \\
\text { 点㟧 } \\
\text { a }\end{array}$ & 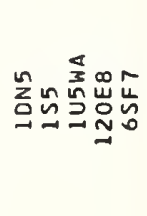 \\
\hline
\end{tabular}




\begin{tabular}{|c|c|c|c|c|c|c|c|c|}
\hline 岕岕岕 & & 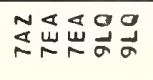 & 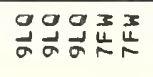 & 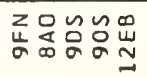 & 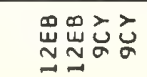 & ৫ゔす志岕 & 崖岩崖美美美 & 岕る \\
\hline 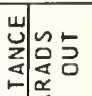 & & $\begin{array}{ll}\circ & 0 \\
\dot{0} & \dot{n}\end{array}$ & ம் & $\dot{n} \dot{\sim} \dot{\sim}$ & $\dot{\sim} \dot{\sim}$ & 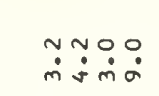 & $\dot{m} \sim \dot{\sim} \dot{\sim} \dot{\sim} \dot{\sim}$ & $\ddot{\sim} \dot{\sim}$ \\
\hline 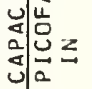 & & $\because \quad \stackrel{n}{n} \quad \stackrel{n}{n}$ & 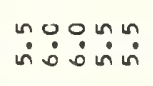 & in $\stackrel{0}{i} \stackrel{0}{r}$ & $\because: 0$ & 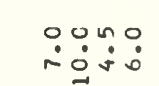 & 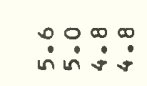 & 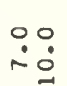 \\
\hline ป & & 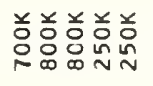 & 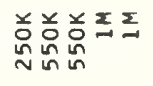 & 跰兑兑兑 & 엉어잉ㅇㅇㅇㅁㅇ & 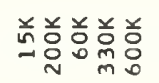 & 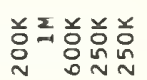 & ․ㅇㅇㅁㅇ \\
\hline 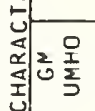 & & 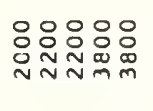 & 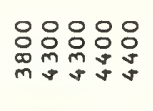 & 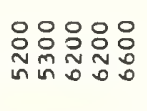 & $\begin{array}{l}\text { 응요 } \\
: 0000 \\
\circ: 00\end{array}$ & 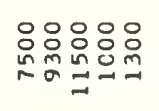 & 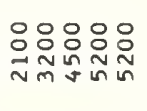 & $\begin{array}{l}\text { 웅 } \\
\text { 웅 } \\
\text { 足 }\end{array}$ \\
\hline 我 & & 응ㅇㅁ & $000=$ & $=$ m음우 & 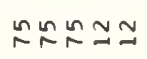 & 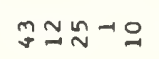 & $N 0=0$ 잉 & $9 \stackrel{2}{\sim}$ \\
\hline 每 & & 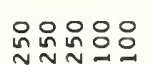 & 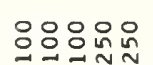 & 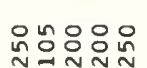 & 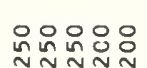 & 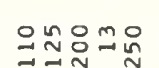 & బ呈: & 웅우 \\
\hline 岕氙 & & $\ddot{\sim} \dot{\sim} \dot{\sim} \dot{\sim} \dot{\sim} \dot{m} \dot{m}$ & 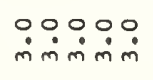 & 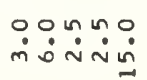 & 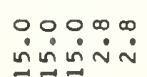 & 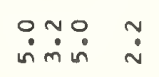 & ஸ் ஸ்ํ் & : \\
\hline 졸연] & & & & $\cong$ & 운욤요 & & $n \stackrel{0}{n}$ & \\
\hline ×x & & & & & & & & \\
\hline 2 I & & 임임임이 & 잉이용이이 & 율임임 & 욧ㅇㅇㅇㅇㅇㅁㅇ & =일잉요 & 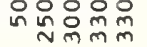 & 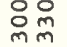 \\
\hline$-\frac{z_{w}}{2}$ & & 욤을욤욤 & 음윰윰요 & 응영용요 & 号品品品品 & 욤욤욤욤요 & 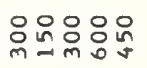 & 용 \\
\hline $\begin{array}{ll}\vec{a} & 4 \\
1 & 4\end{array}$ & & 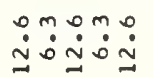 & 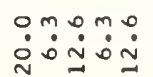 & mơmm & mơn: & 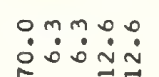 & : & $\because \dot{0}$ \\
\hline$\times \frac{a}{2}$ & & $I I I I I$ & IIIII & $I I I I I$ & エエエエエ & IIIII & IIIII & $I I$ \\
\hline$\underset{\sim}{\sim}$ & & 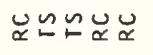 & $\bigcup_{\propto} \cup_{\propto} \underset{\propto}{ } \underset{\propto}{ }$ & 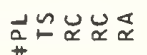 & 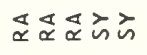 & 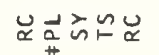 & 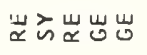 & $\frac{T}{3}$ 公 \\
\hline 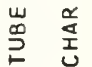 & & 엄엄엄 & 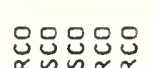 & 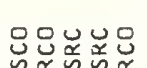 & 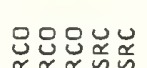 & 品 & 足 & ب् \\
\hline$\ddot{w}$ & & 造造造造 & 造造造出 & 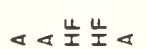 & 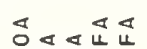 & 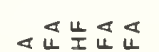 & $\mathbb{L}_{4} \mathbb{E}_{4}$ & 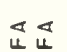 \\
\hline & & & & & & & & \\
\hline క్ర & & 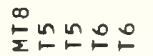 & 욘욛ำ & 요ำ & エュュュ゚。 & の゚゚゚゚占 & ロ゚ロェ゚ュ & $\stackrel{2}{2}$ \\
\hline$\frac{w}{2}$ & & 듬응ㅇㅇㅇ응 & 음음음응으 & 응으응ㅇㅇㅇ & 으응ㅇㅇㅇㅡ & 으응ㅇㅇㅇ웅 & 웅오옹옹오 & 욿 \\
\hline 2 & & & & & & & & \\
\hline$\underline{x}$ & & zzzana & 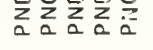 & $z_{a} z_{a} z_{a} z_{a}$ & $\begin{array}{l}z_{a} \\
a \\
a\end{array} z_{a} z_{a}$ & zazzzza & 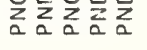 & $z_{a} z_{a}$ \\
\hline u & & & & $n$ & & & & \\
\hline 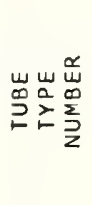 & 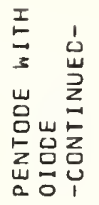 & 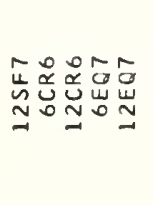 & 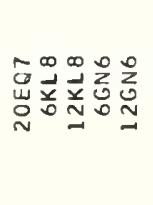 & 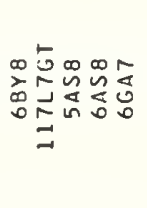 & 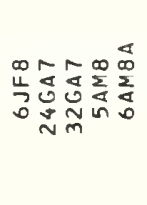 & 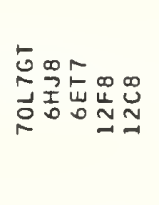 & 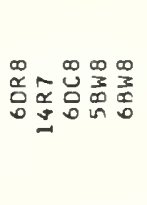 & 思点 \\
\hline
\end{tabular}




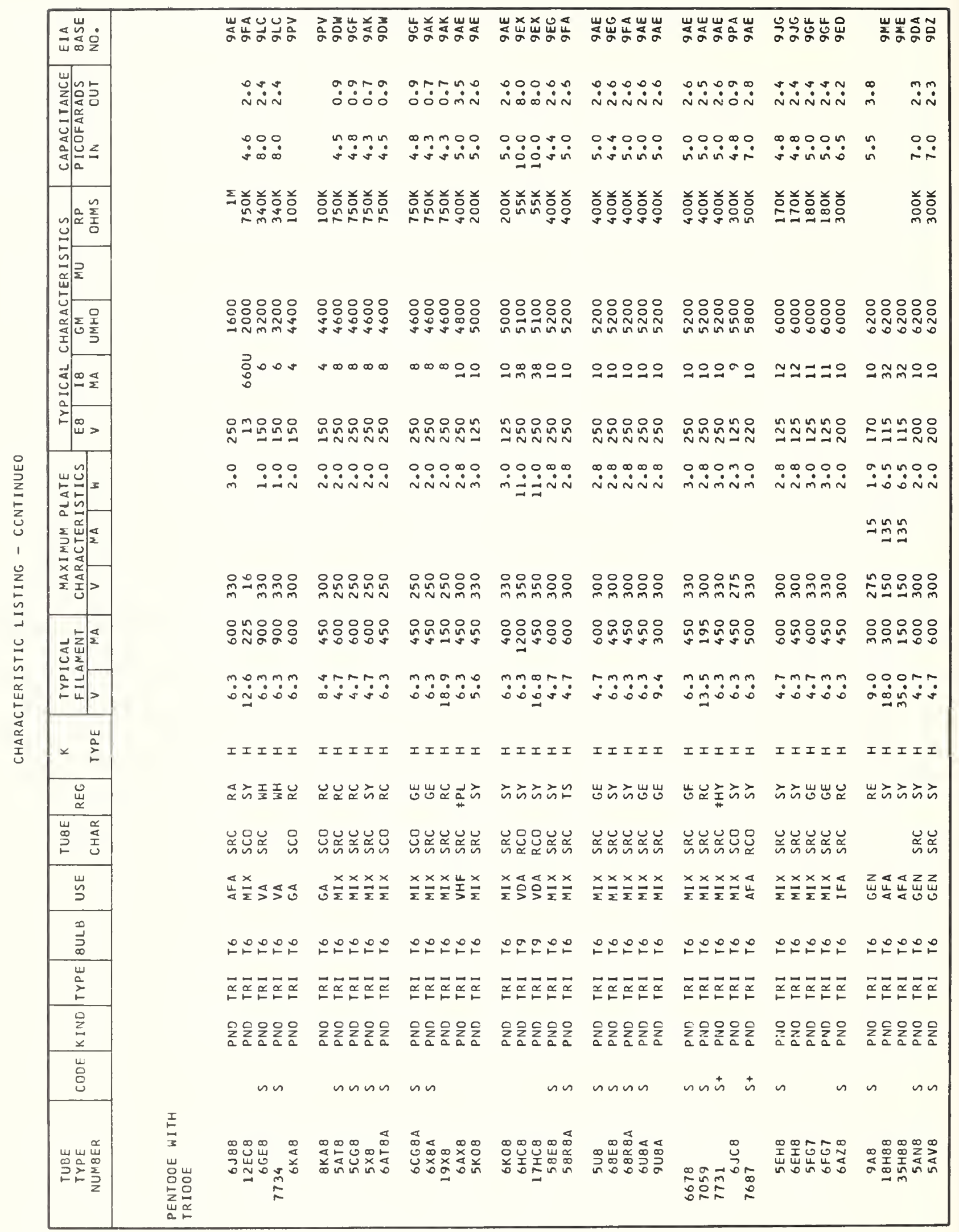




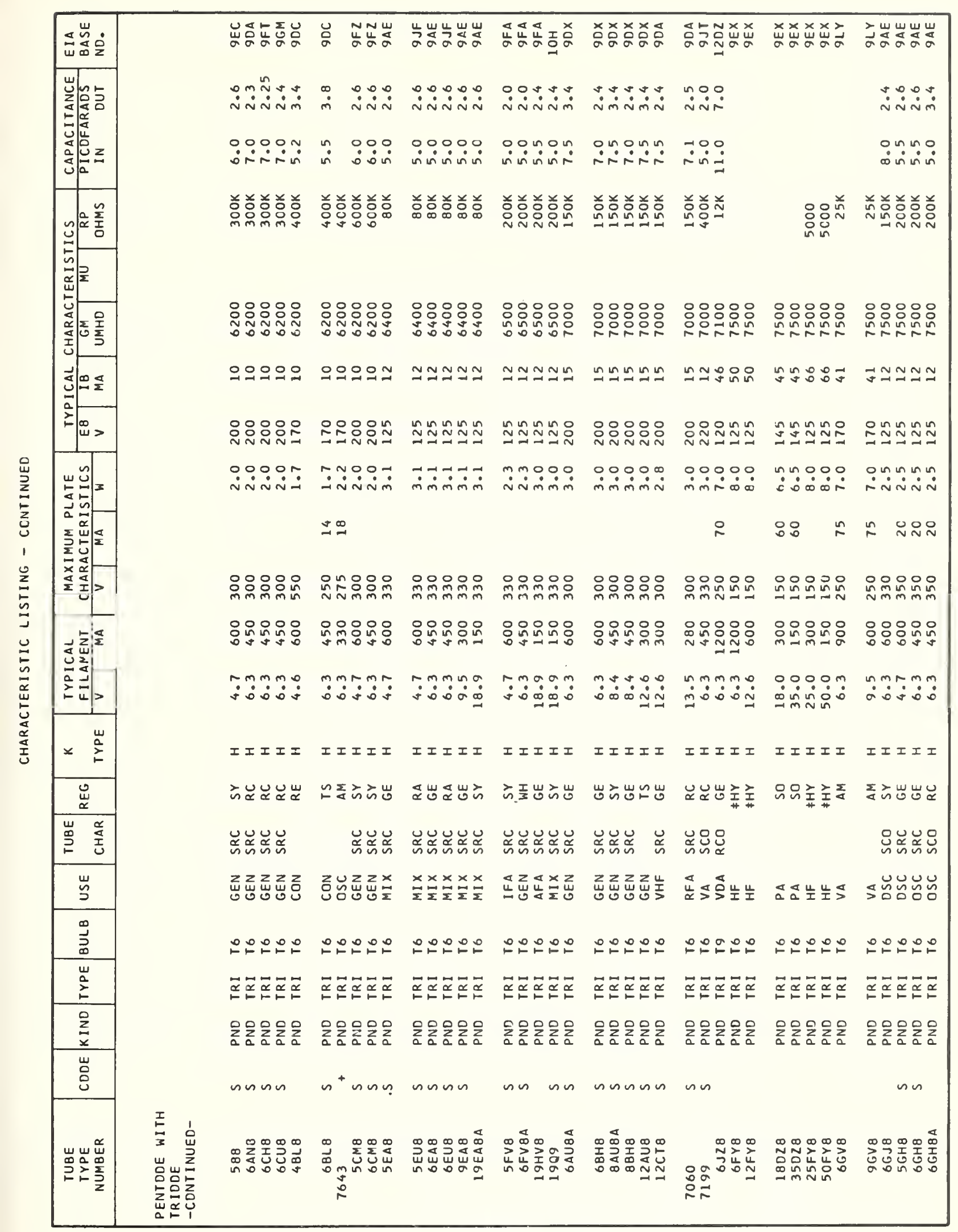




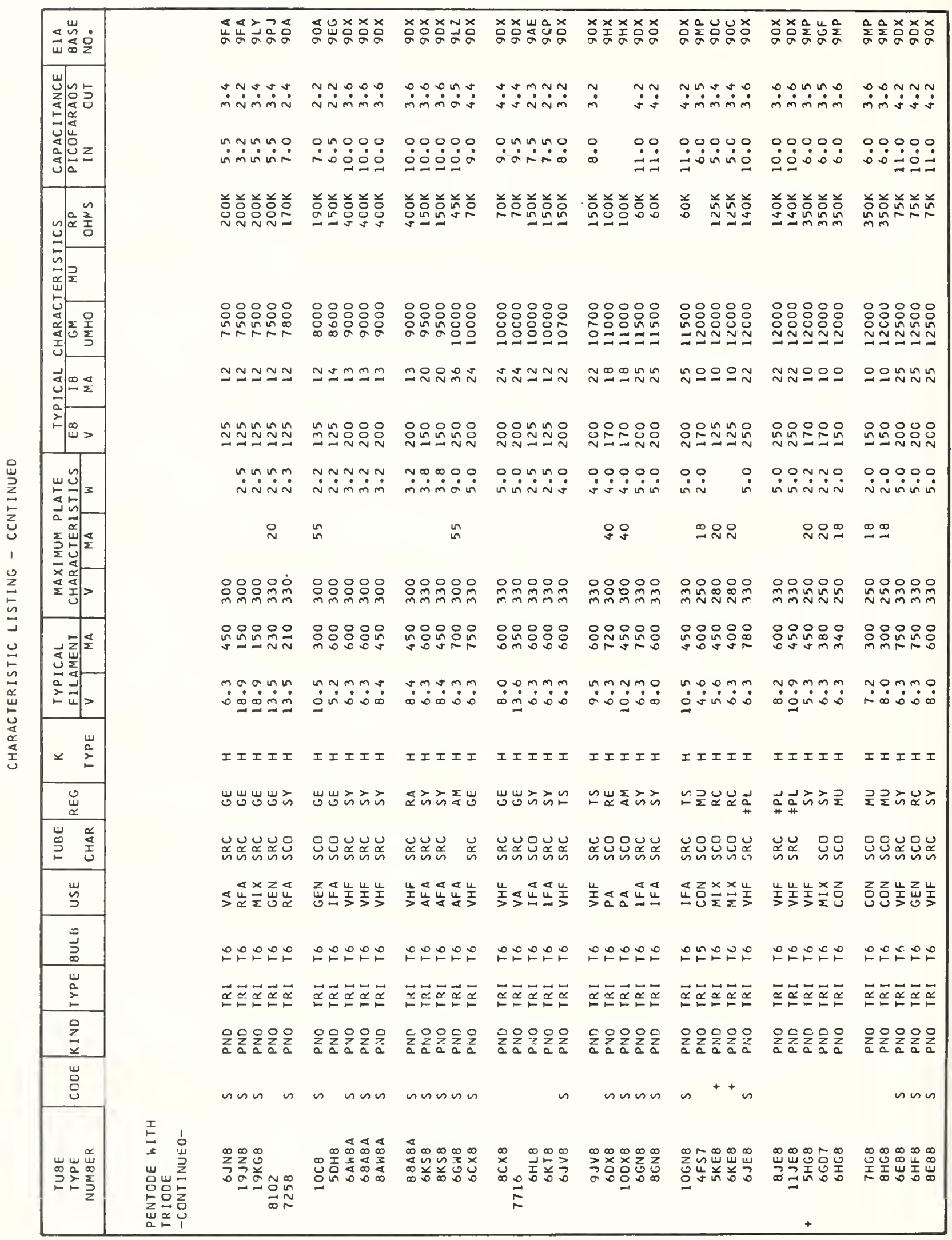




\begin{tabular}{|c|c|c|c|c|c|c|c|c|c|}
\hline 岕岕宫 & & 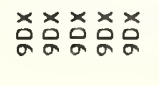 & 芯虽克克怘 & 旁哭 & & 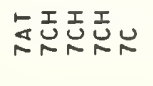 & 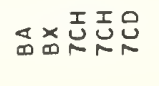 & N䇗道忈忈 & 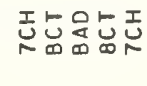 \\
\hline 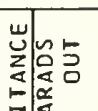 & & 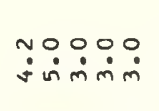 & $\dot{\sim} \dot{\sim}: \dot{s}$ & $\ddot{n} \dot{0}$ & & 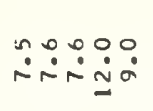 & 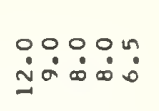 & ño: & 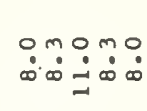 \\
\hline 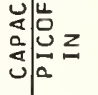 & & 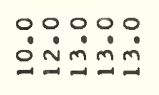 & 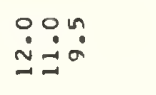 & $\stackrel{\infty}{\infty} \stackrel{0}{\square}$ & & n் & ơn & $\operatorname{nn} n$ & 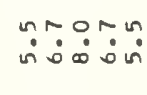 \\
\hline$\leadsto \mid \frac{n}{\alpha} \sum_{0}^{\frac{n}{2}}$ & & 总关关兑兑 & 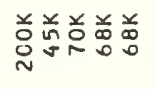 & 응 & & 㒸兑弟 & 总兑兑兑兑 & 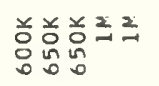 & こ少江 \\
\hline \begin{tabular}{l|l}
0 \\
ân
\end{tabular} & & 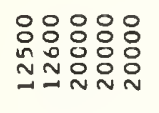 & 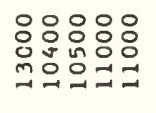 & $\begin{array}{l}\text { 웅 } \\
\text { 옹 } \\
\text { N }\end{array}$ & & & & & \\
\hline$\infty$ & & ヘัヘニニニ & ニュミ゙ & $N g$ & & 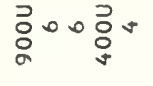 & and & 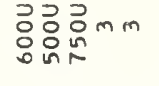 & $m s t a m$ \\
\hline$\stackrel{D}{\sim}$ & & 유욤융유 & 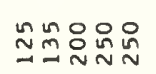 & $=\stackrel{m}{N}$ & & 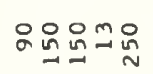 & 오N오승ㅇㅇㅇㅇㅇ & 음응으욧요 & 怘品员虽怘 \\
\hline 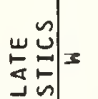 & & 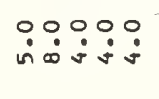 & 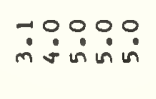 & $\dot{0}$ & & $\because \because 0 \stackrel{-}{\circ}$ & $\stackrel{\circ}{\circ} \stackrel{\circ}{-}$ & $\stackrel{\circ}{\square}$ & 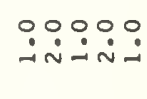 \\
\hline 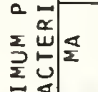 & & & & & & 里유시 & ป゚ & $\checkmark v m \unlhd \unlhd$ & $\Xi \approx \Xi N \Xi$ \\
\hline 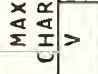 & & 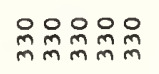 & 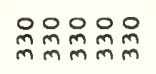 & $\stackrel{\sim}{\sim}$ & & 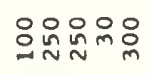 & 임윰요 & 읔을윰유 & 임윰임윰 \\
\hline - & & 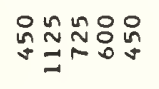 & 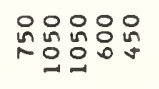 & 윰 & & 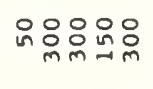 & 을욤요 & 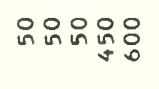 & 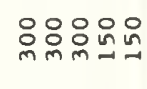 \\
\hline $\begin{array}{ll}2 & 5 \\
2 & =\end{array}$ & & 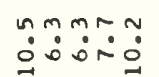 & 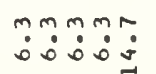 & $\dot{\dot{q}}$ & & 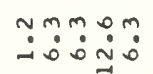 & 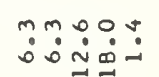 & 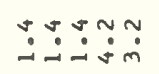 & $\ddot{\dot{0}} \dot{m} \dot{0} \dot{\sim} \dot{\sim}$ \\
\hline$\times \stackrel{\substack{\omega \\
\vdots}}{2}$ & & IIIII & IIIII & II & & ルエエエエ & エエエエル & レレレII & エエエエエ \\
\hline$\underset{\sim}{\stackrel{u}{\alpha}}$ & & 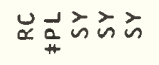 & 岕岕岕岕 & $\approx$ 岃 & & ひ岕え゙ぇ゙ & 主๙へええ & 主ええう崫岕 & \\
\hline 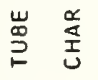 & & 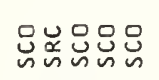 & 号怘芯芯芯 & $\begin{array}{l}\text { 号莒 } \\
\text { n }\end{array}$ & & 亗 & 号芯 & & \\
\hline$\stackrel{w}{\leftrightharpoons}$ & & 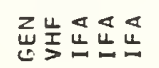 & 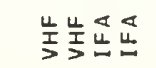 & 造过 & & 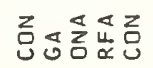 & 品品硈号 & żzz己z & 品吋吋吋号 \\
\hline$\stackrel{D}{a}_{a}^{\infty}$ & & 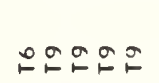 & คำค & 우 & & 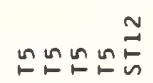 & 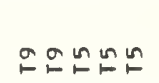 & のேロロッ & ロே゚ロレッ \\
\hline $\begin{array}{l}u \\
a \\
\vdots\end{array}$ & & 吕吕吕品品 & 路吃吕吕 & 㫣号 & & 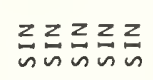 & 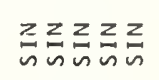 & 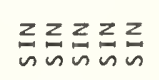 & 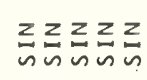 \\
\hline$\frac{0}{x}$ & & 只只员员员员 & 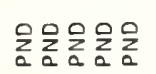 & 음음 & & 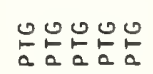 & 눈연 & 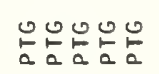 & 놈년연 \\
\hline 㟔 & & & & & & + nnunn & $n n$ & $n$ & 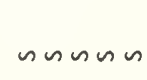 \\
\hline 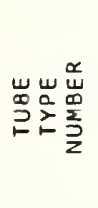 & 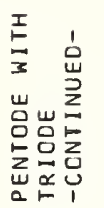 & 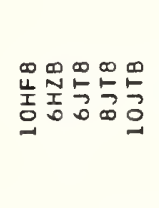 & 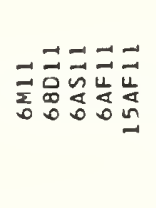 & 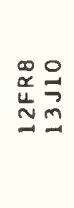 & 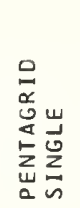 & 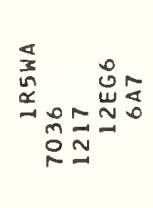 & 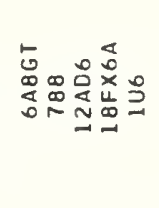 & 怘。莡出出 & 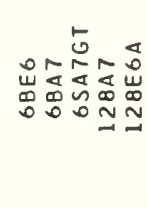 \\
\hline
\end{tabular}




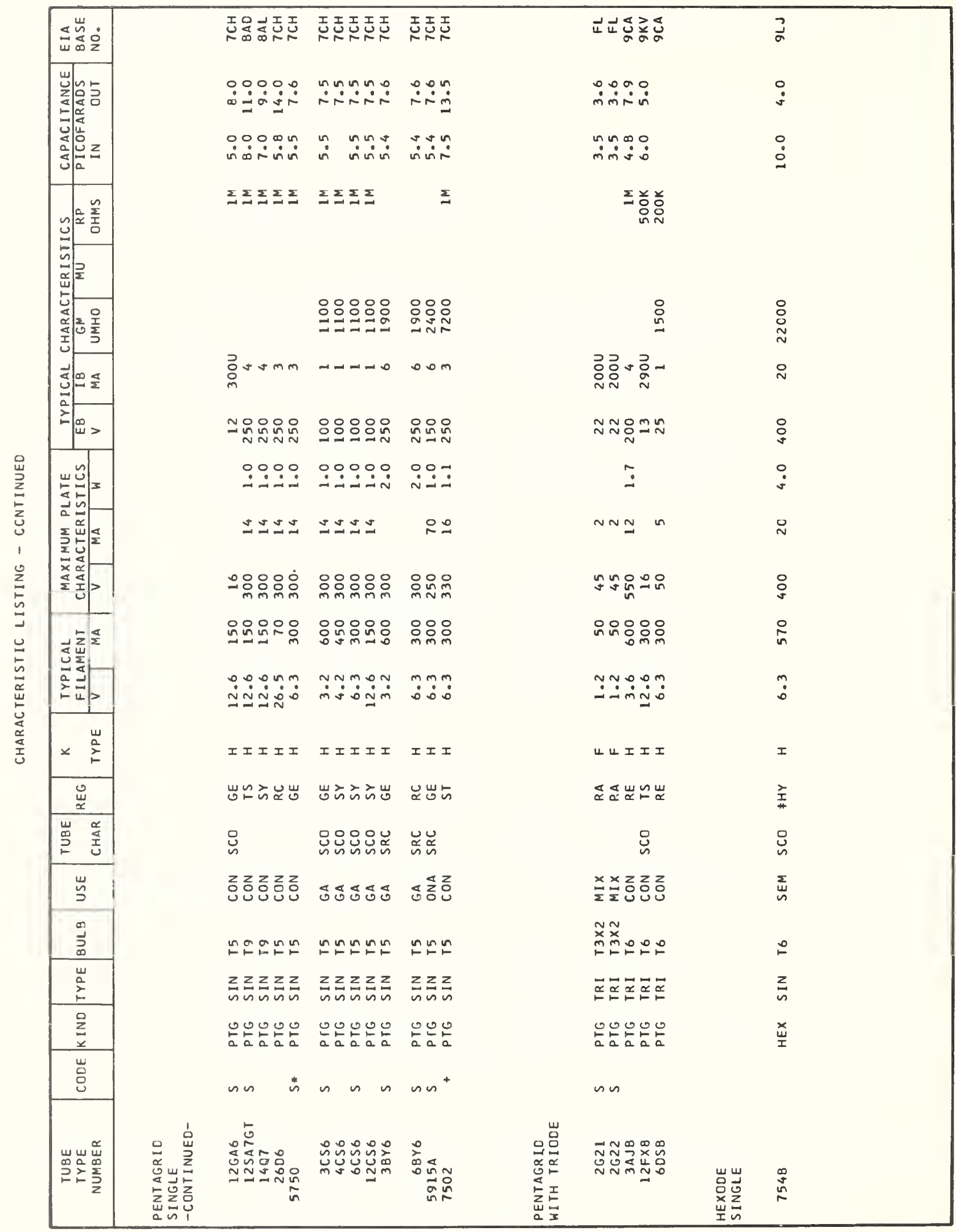




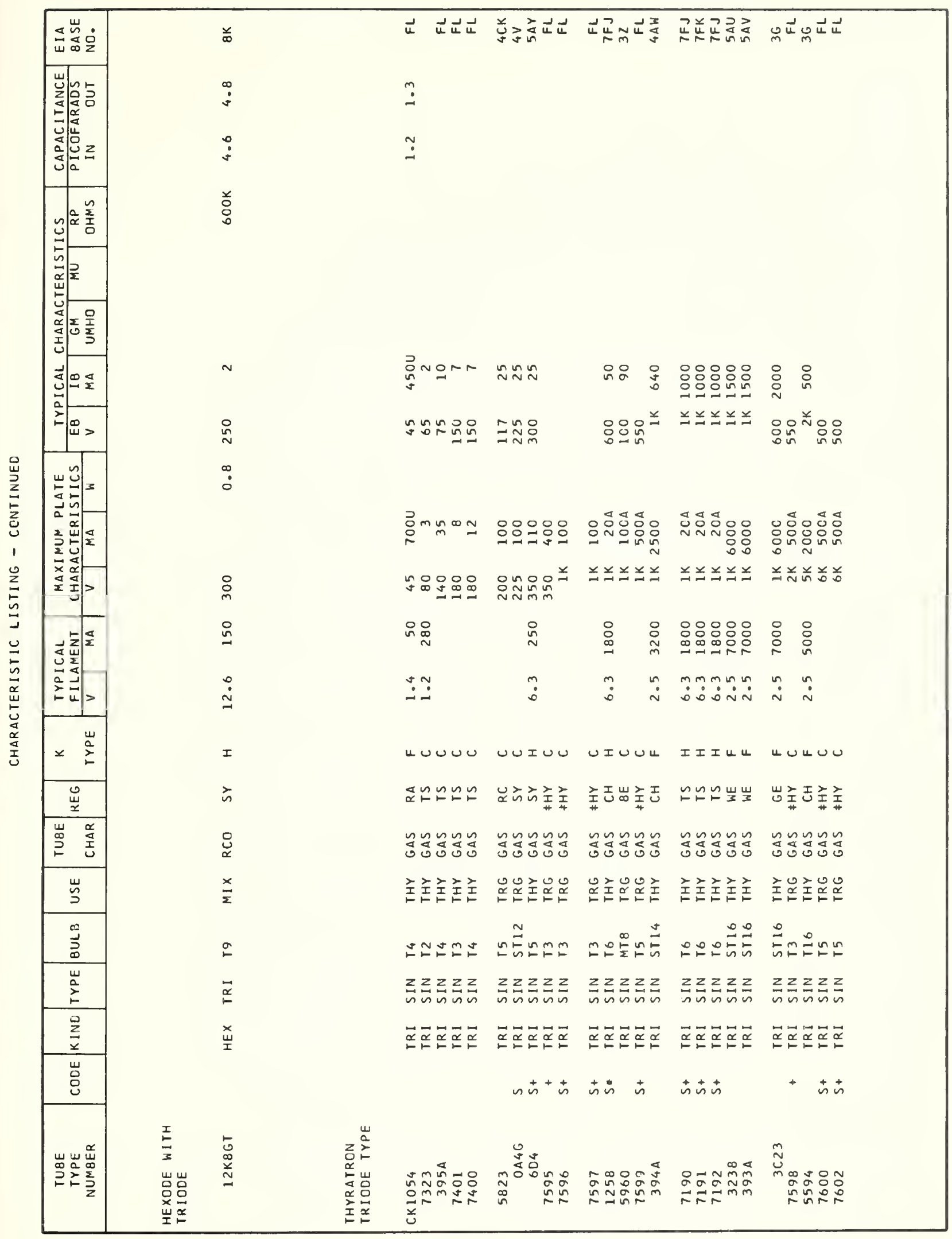




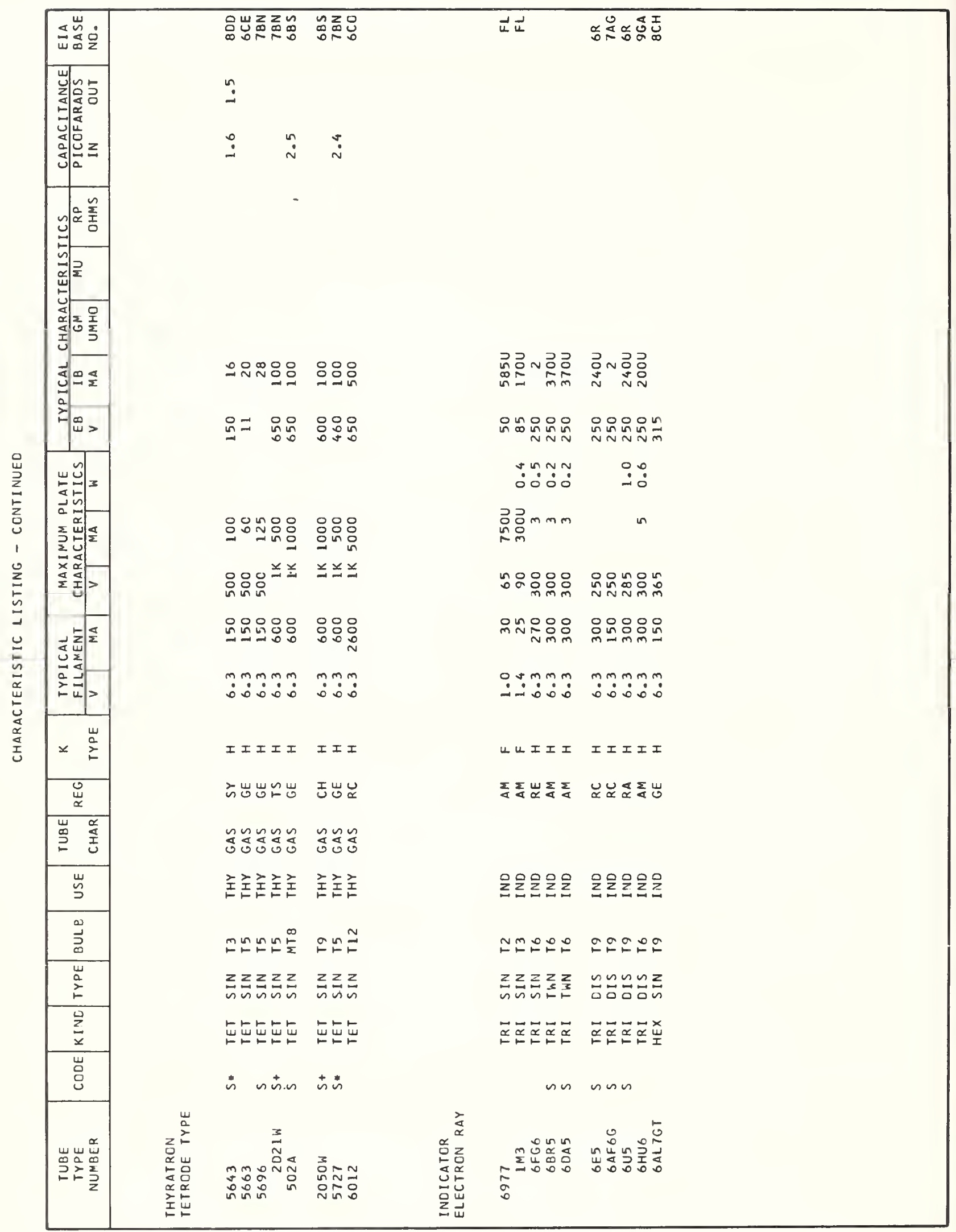




\section{List of Similar Types of Receiving Tubes}




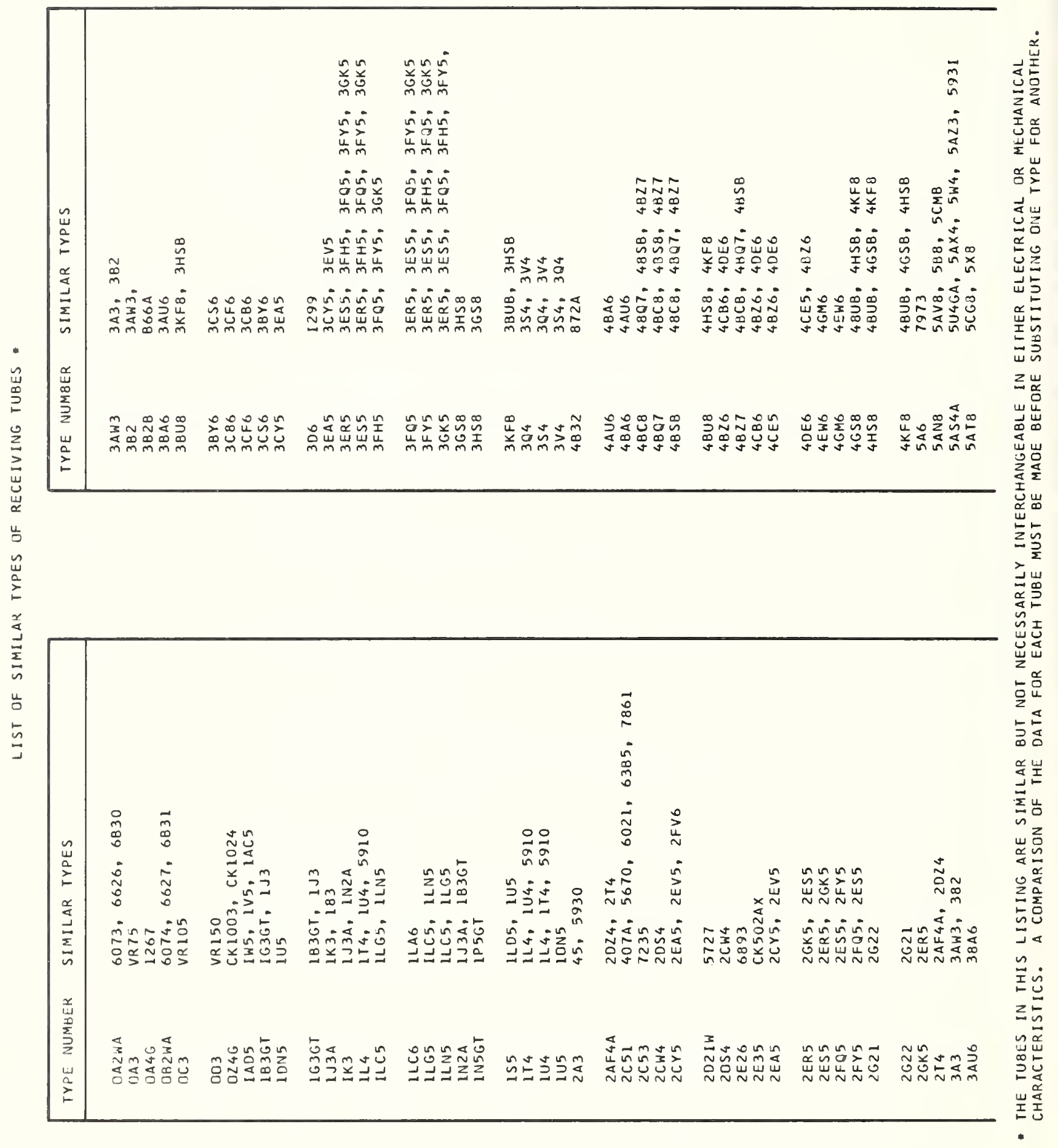




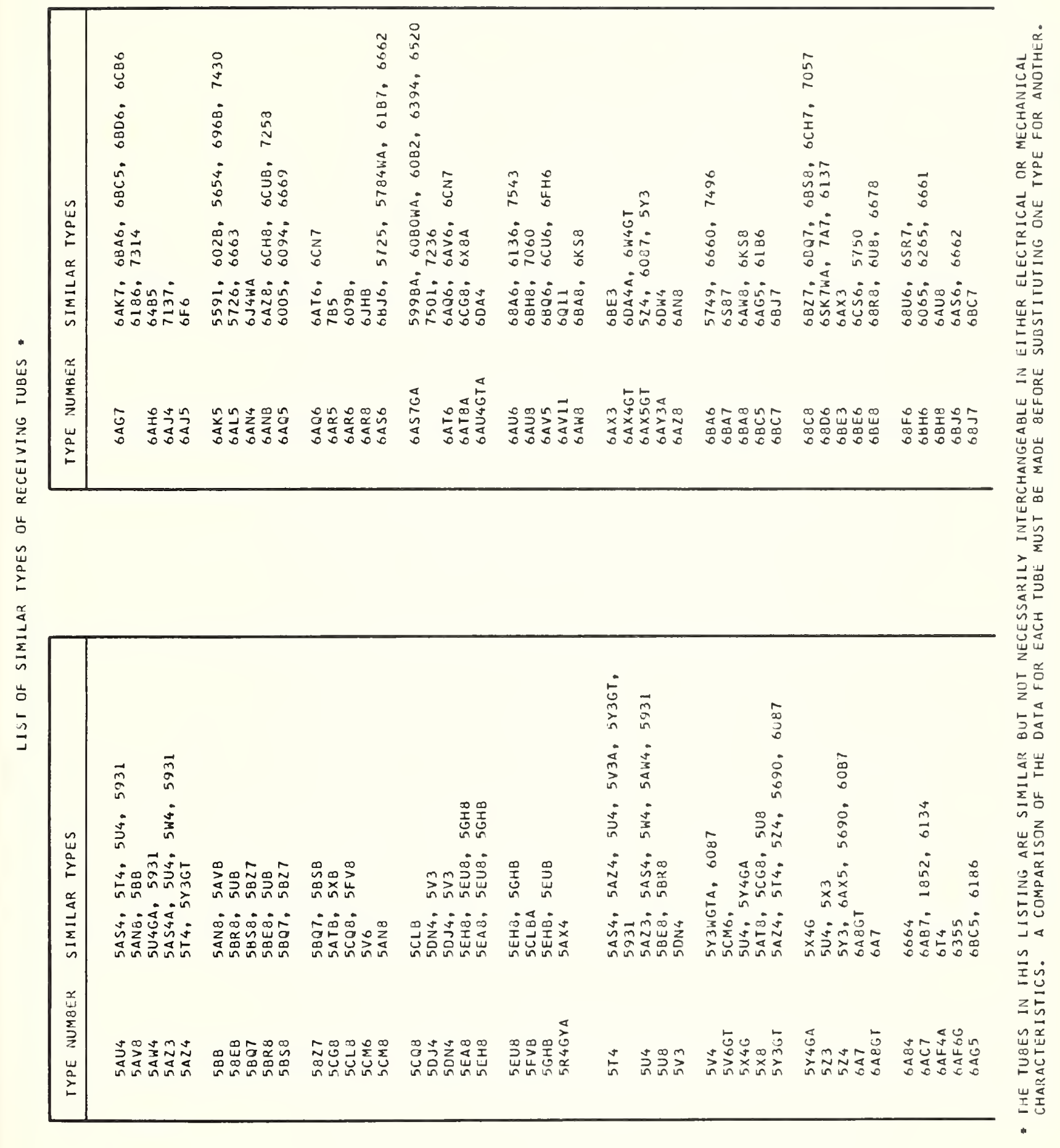




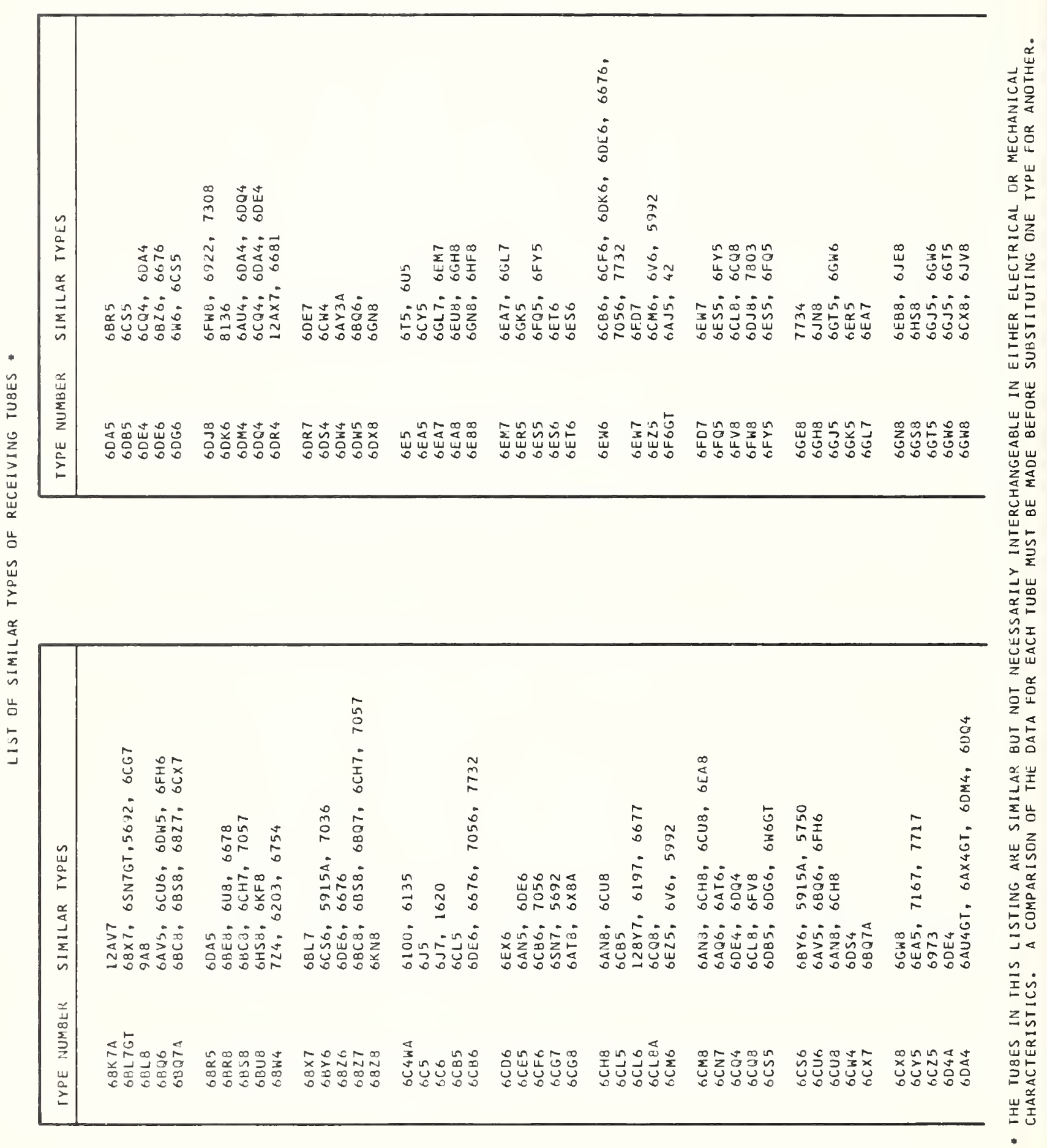




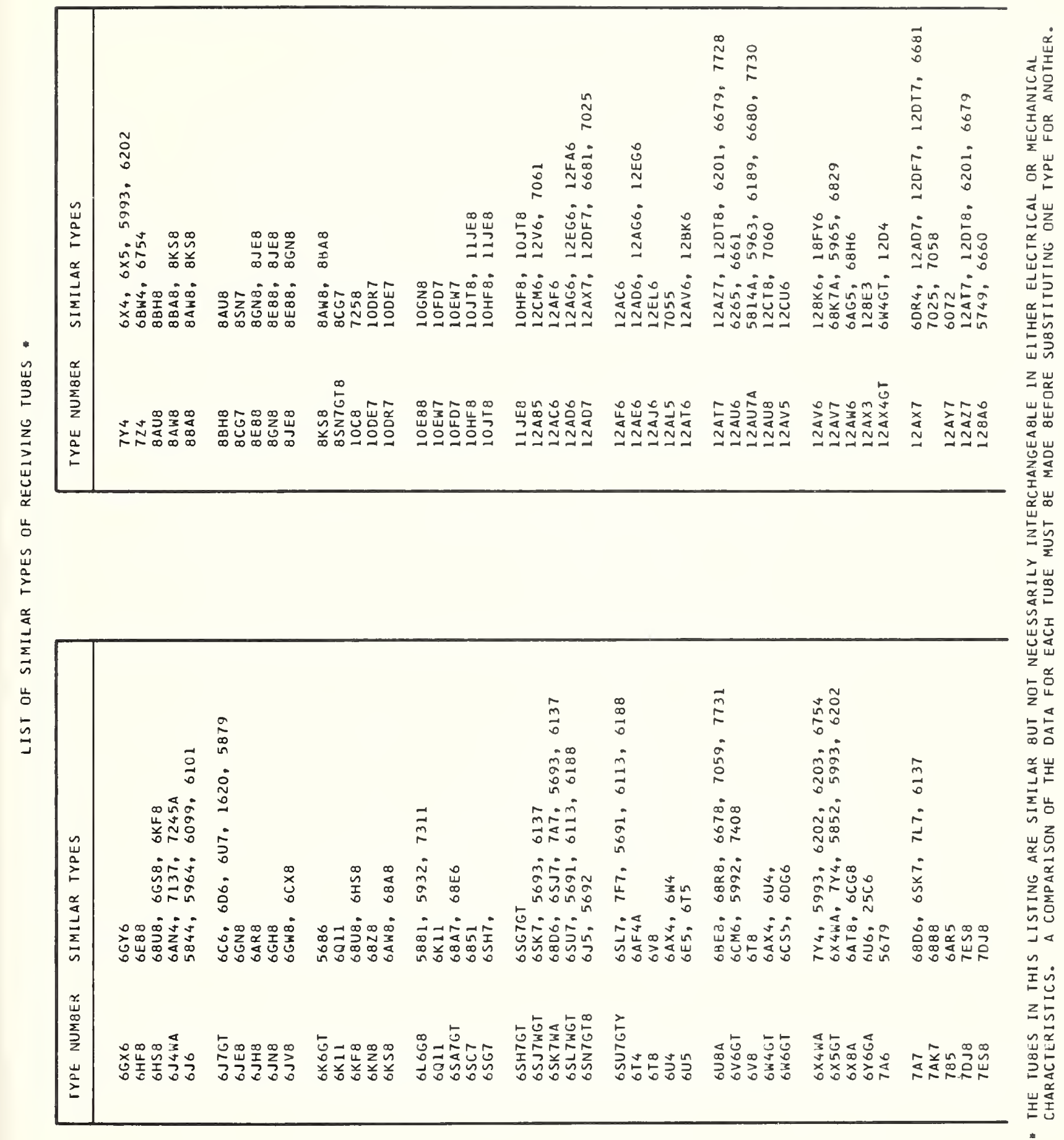




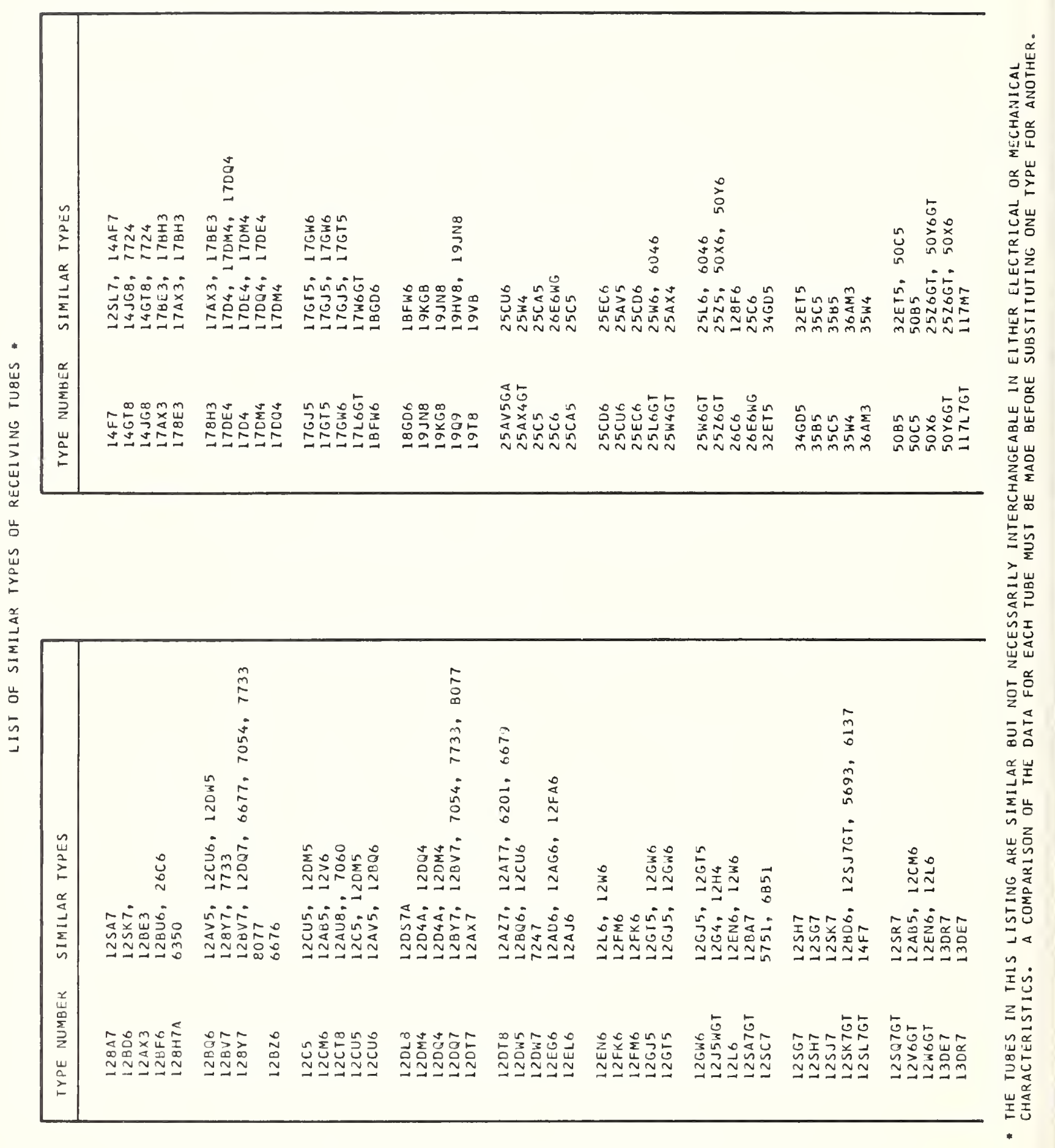




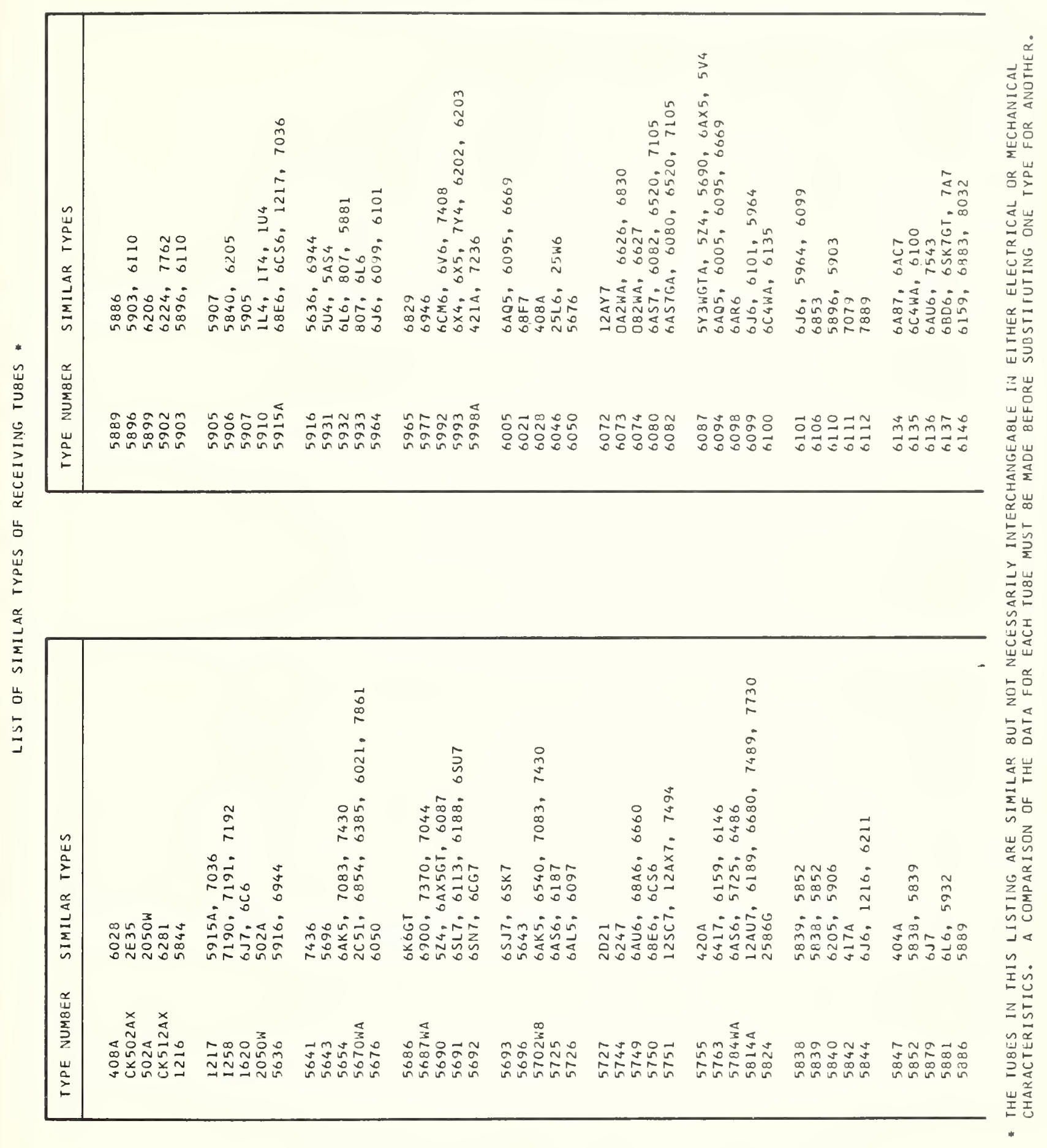




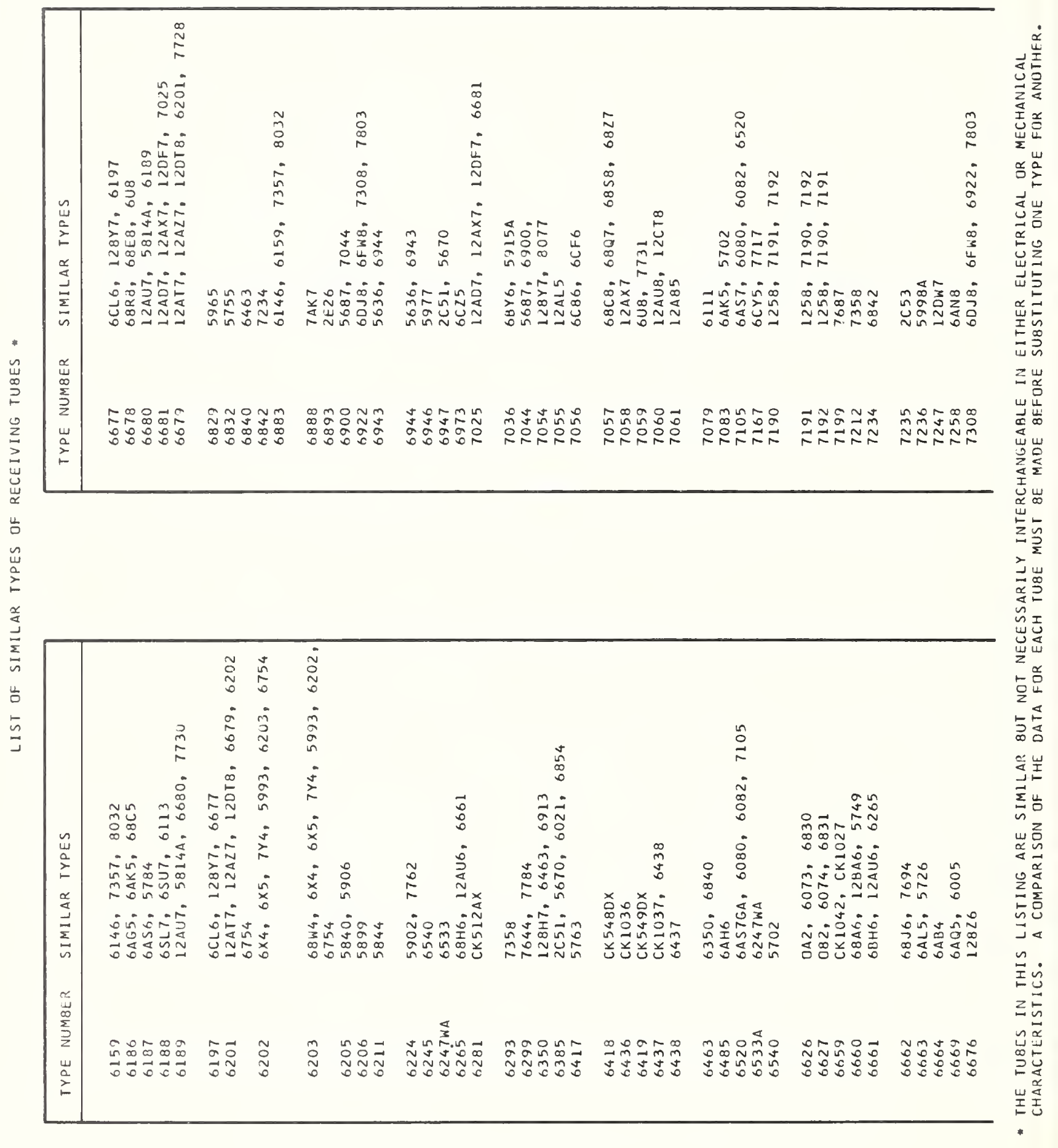



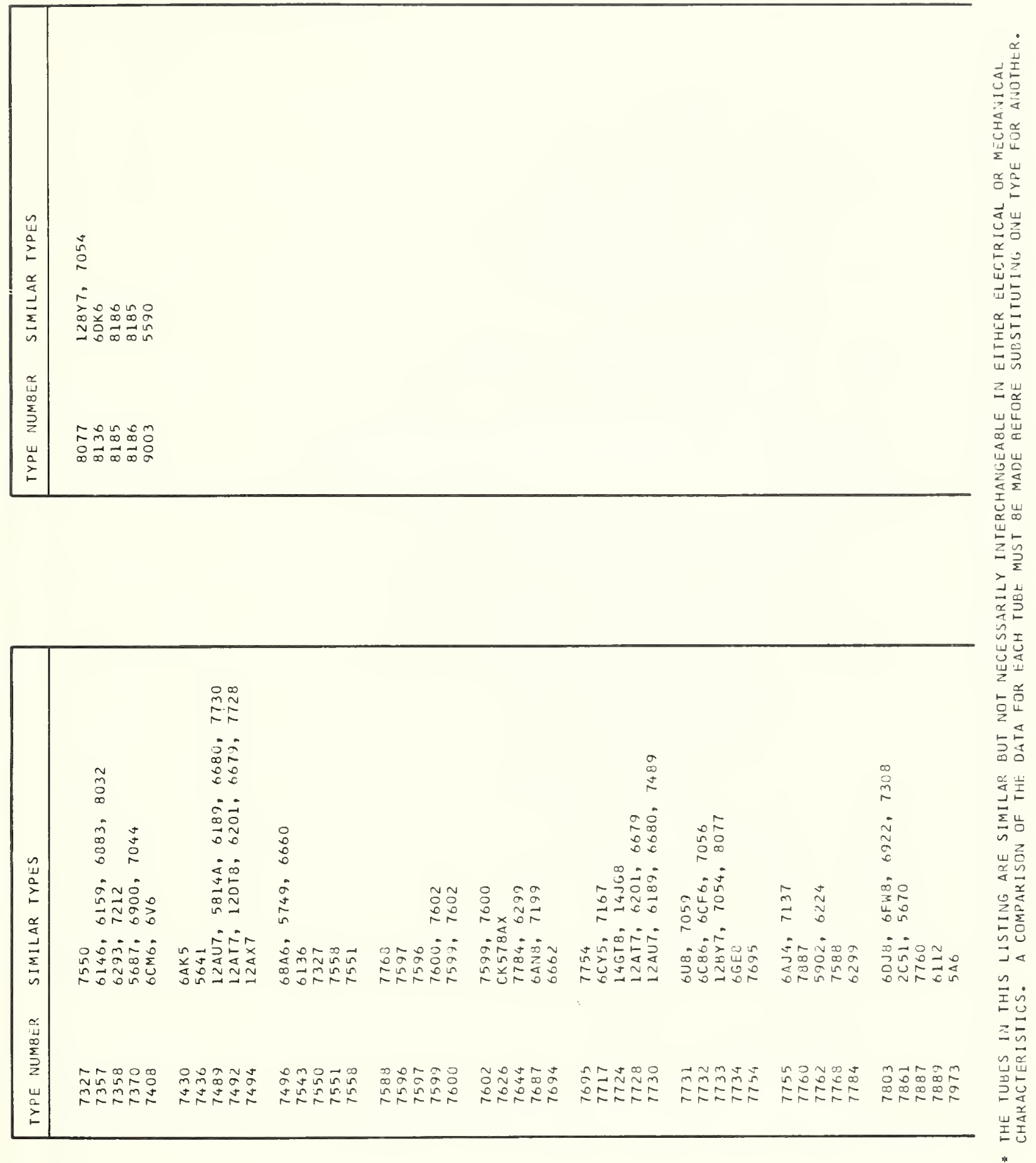


\section{EIA Basing Connections}




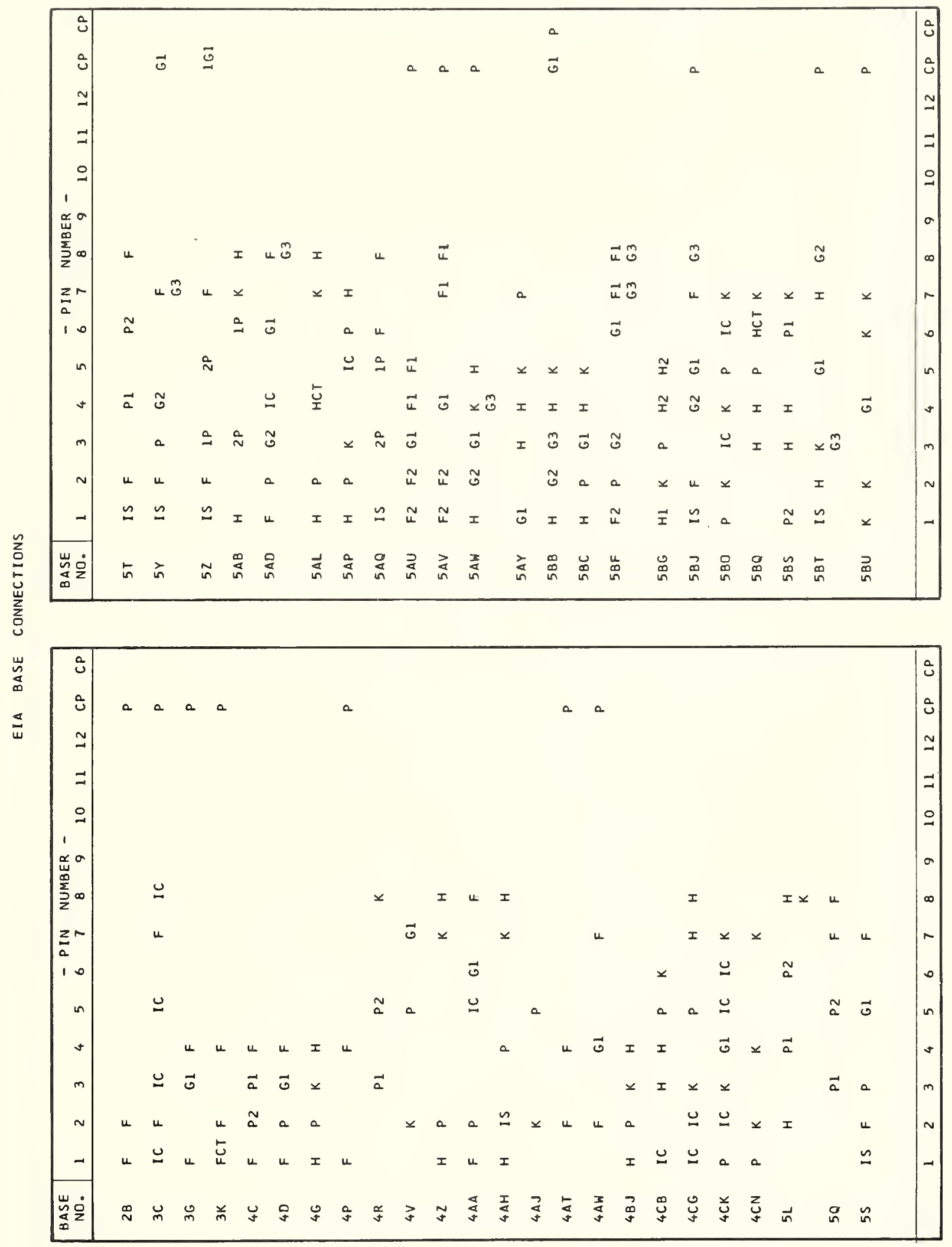




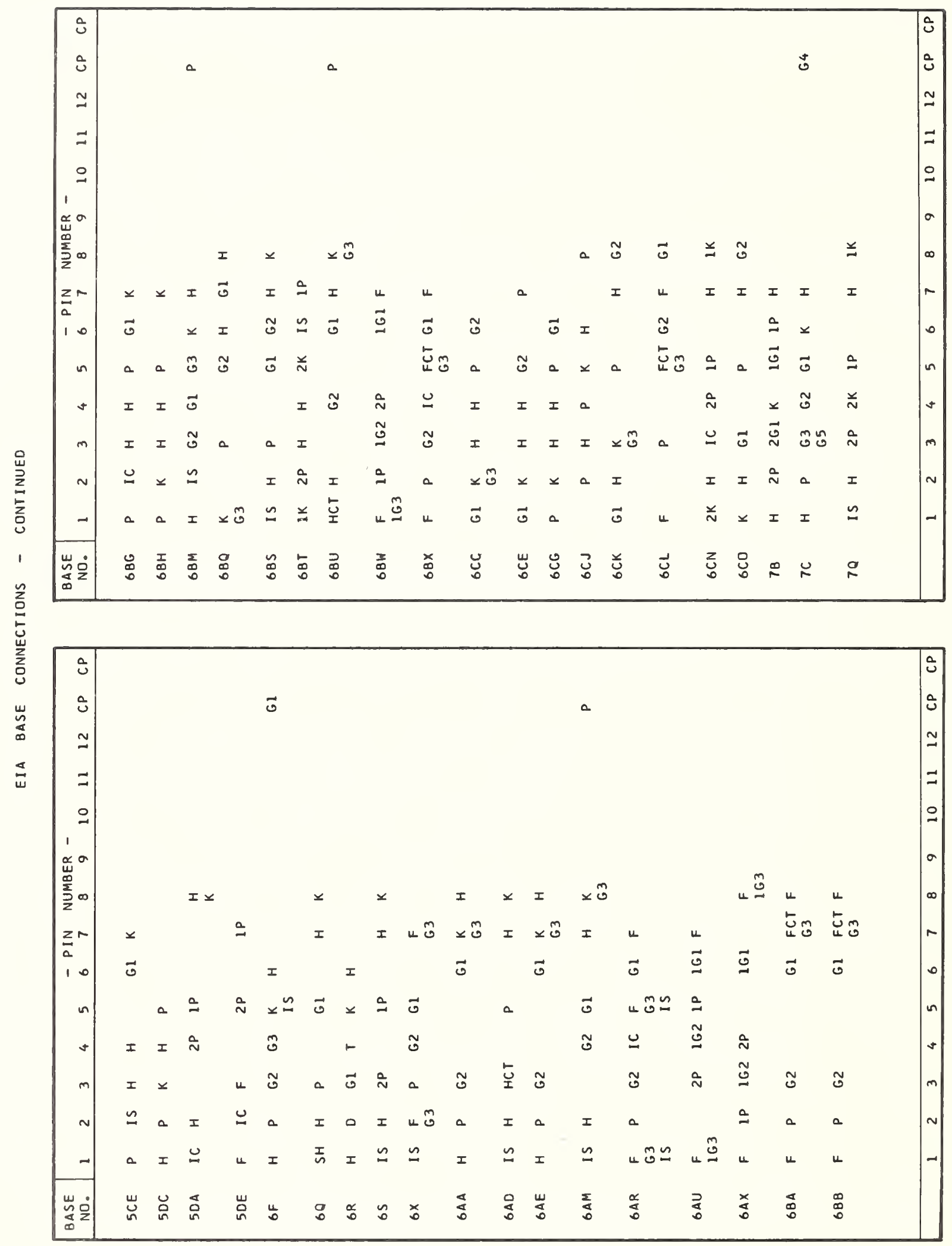




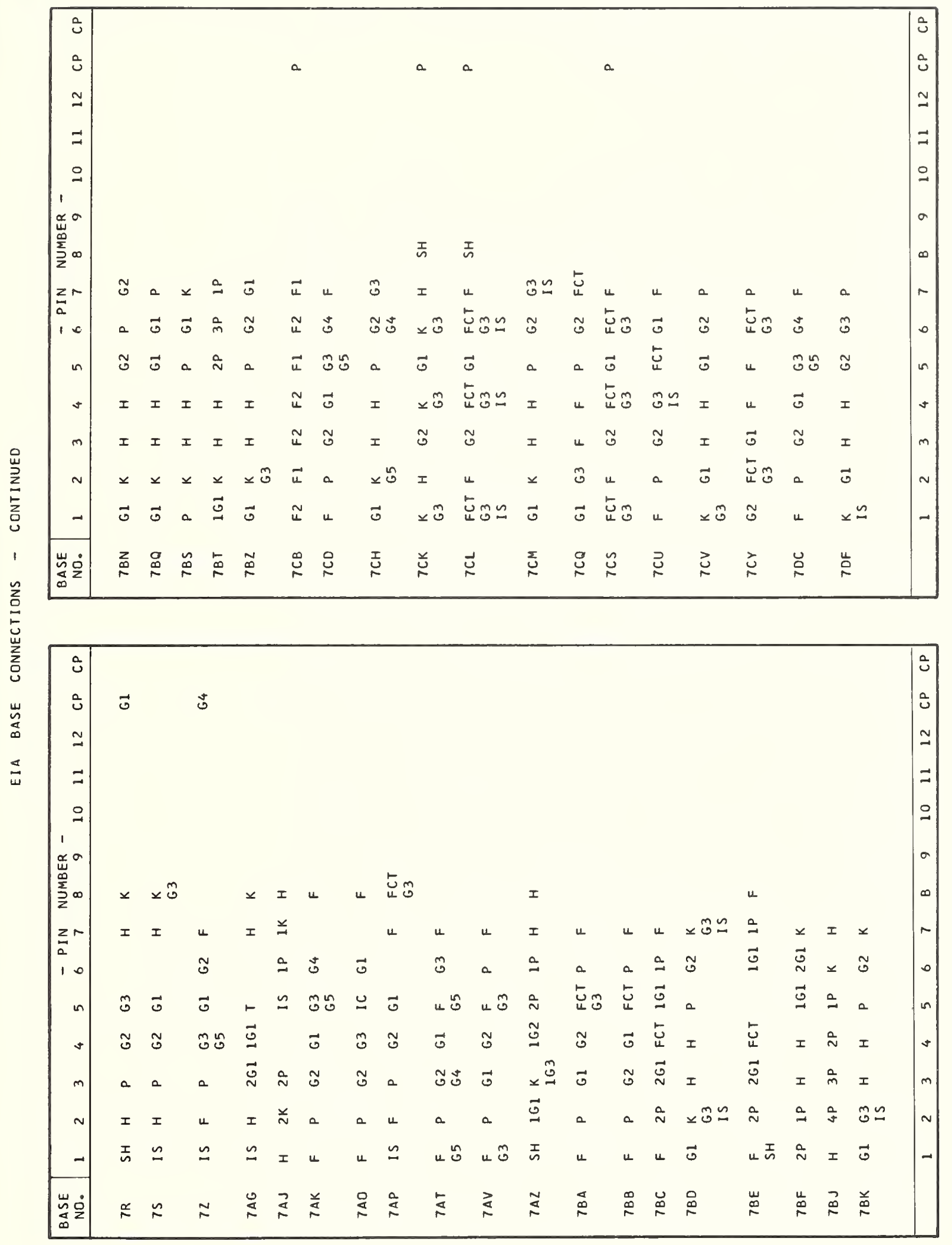




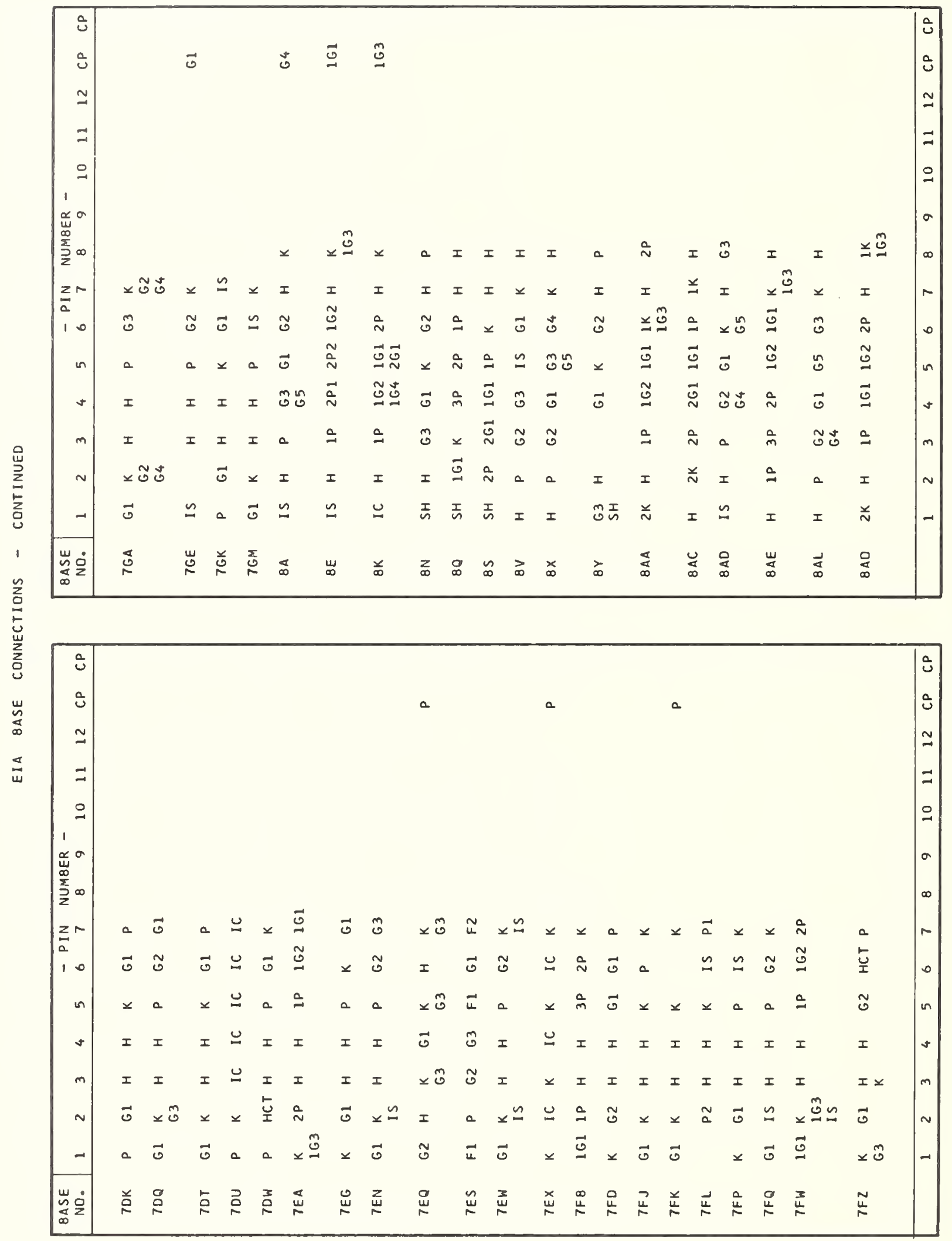




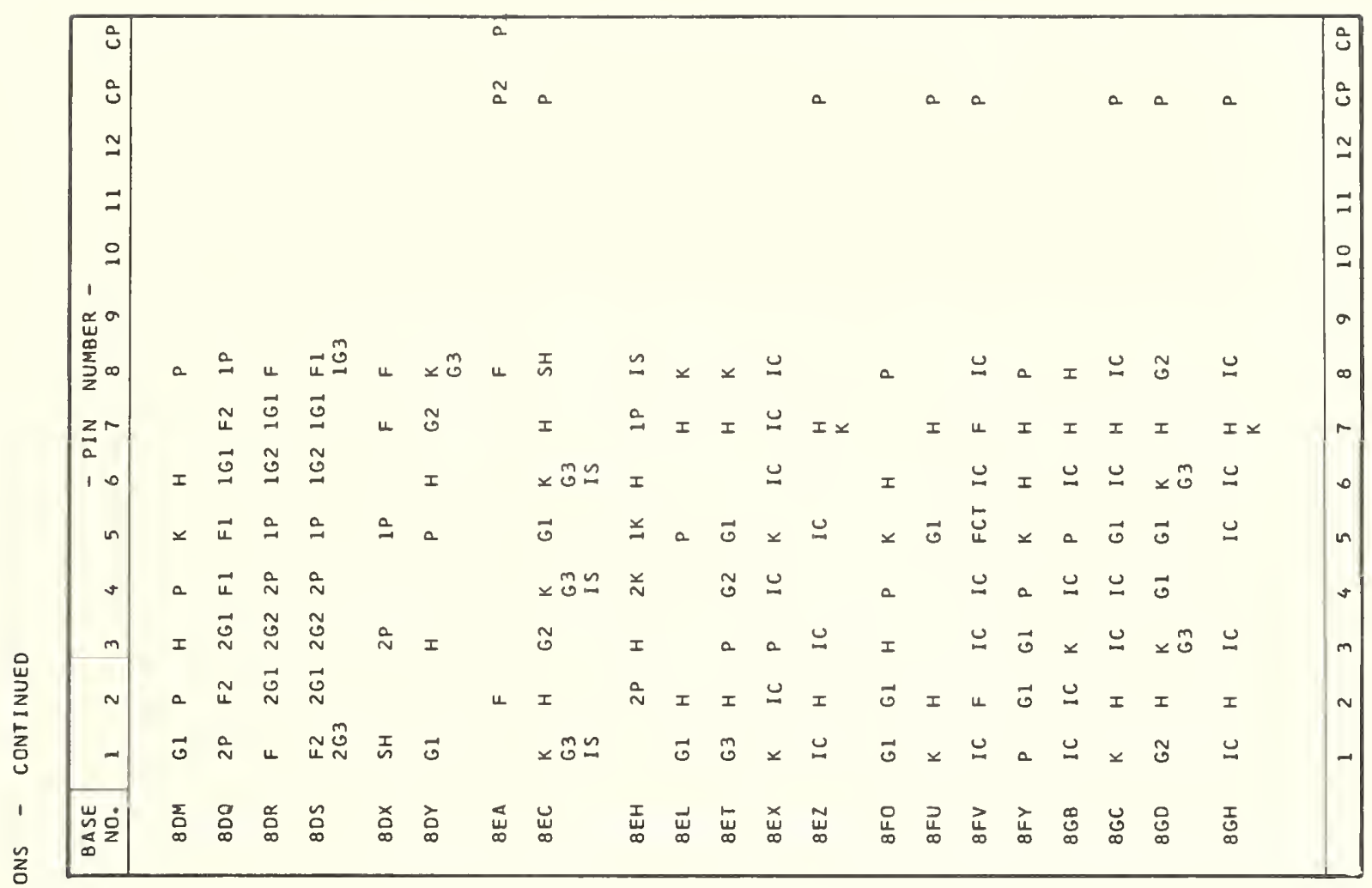

을

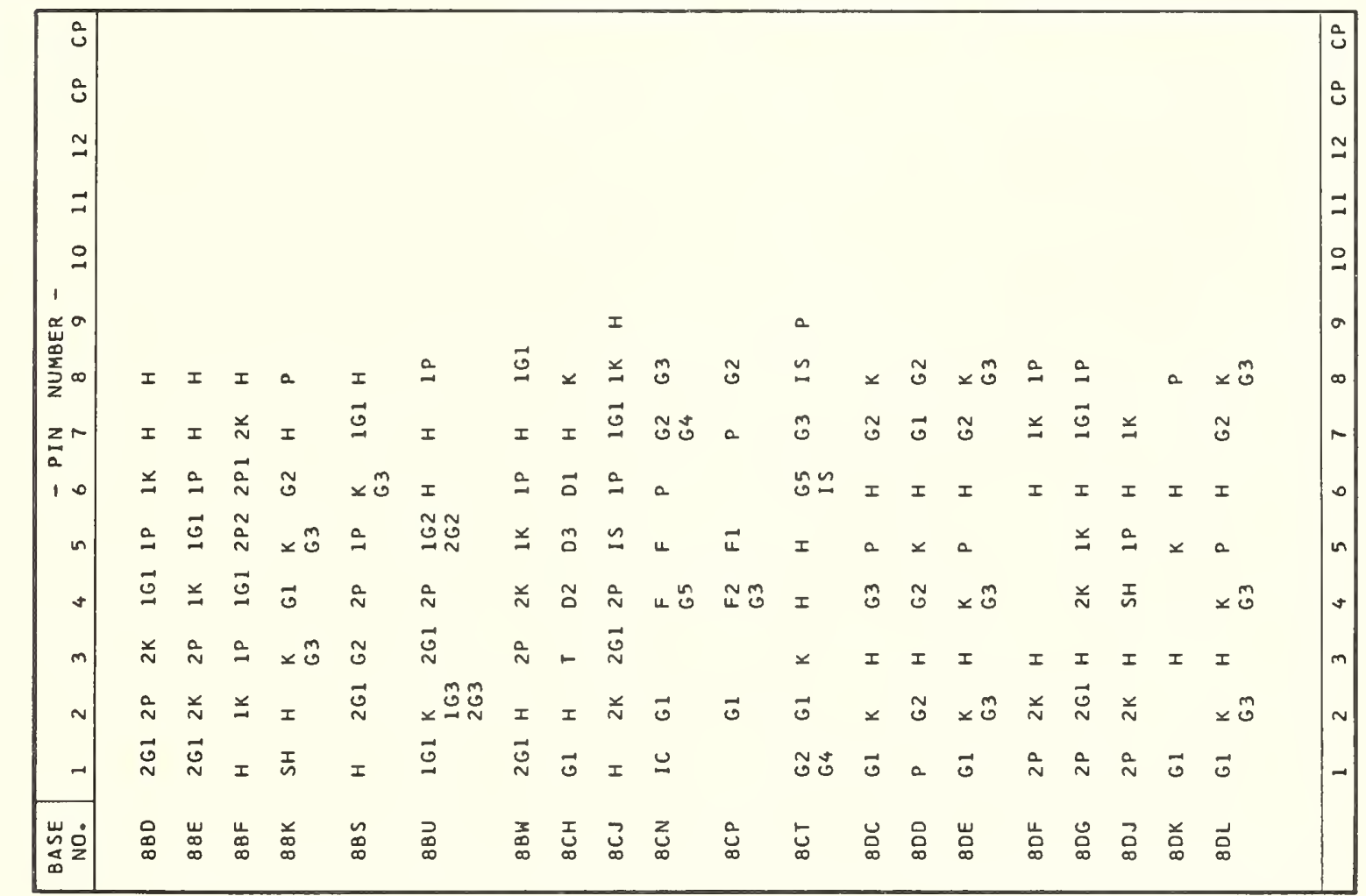




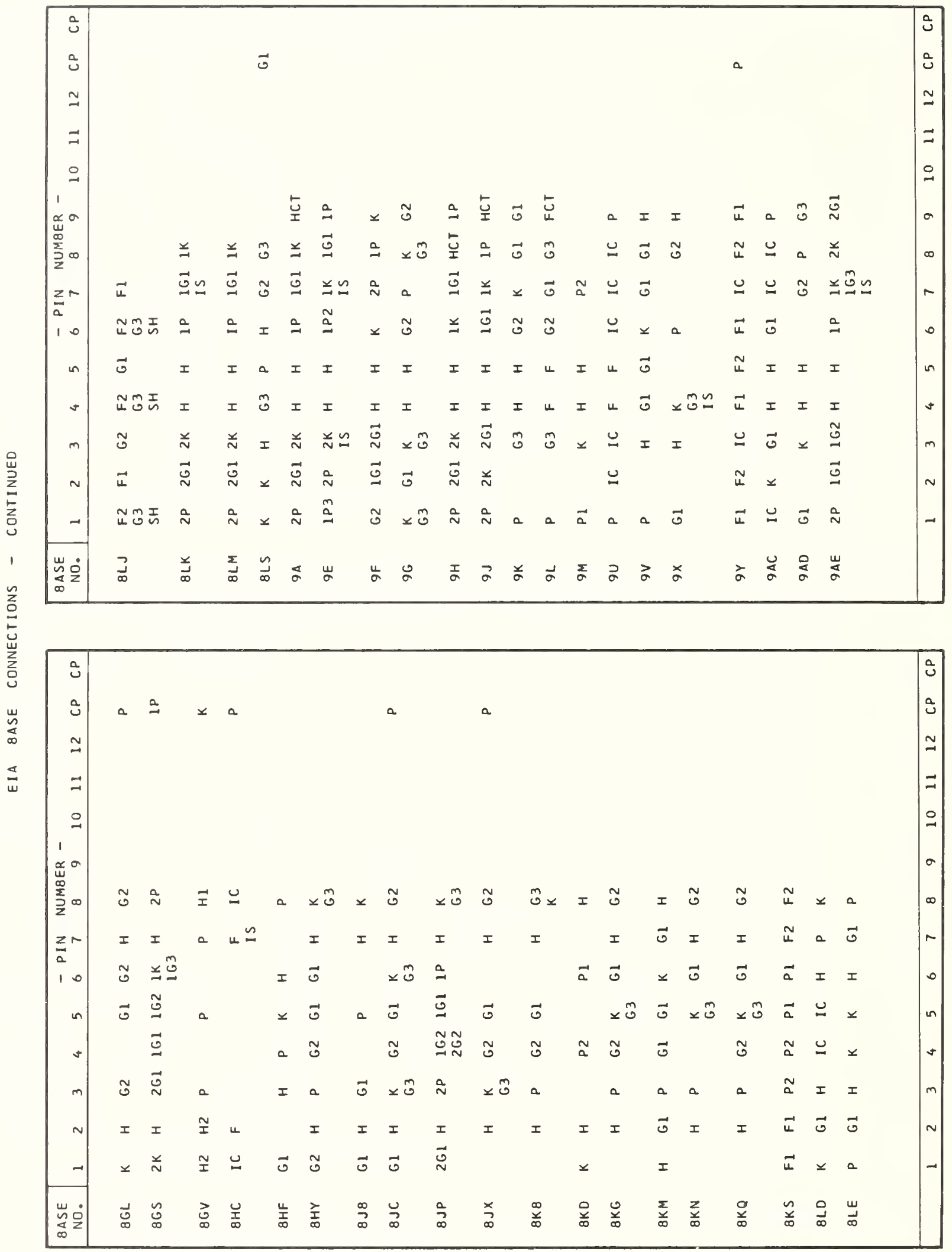




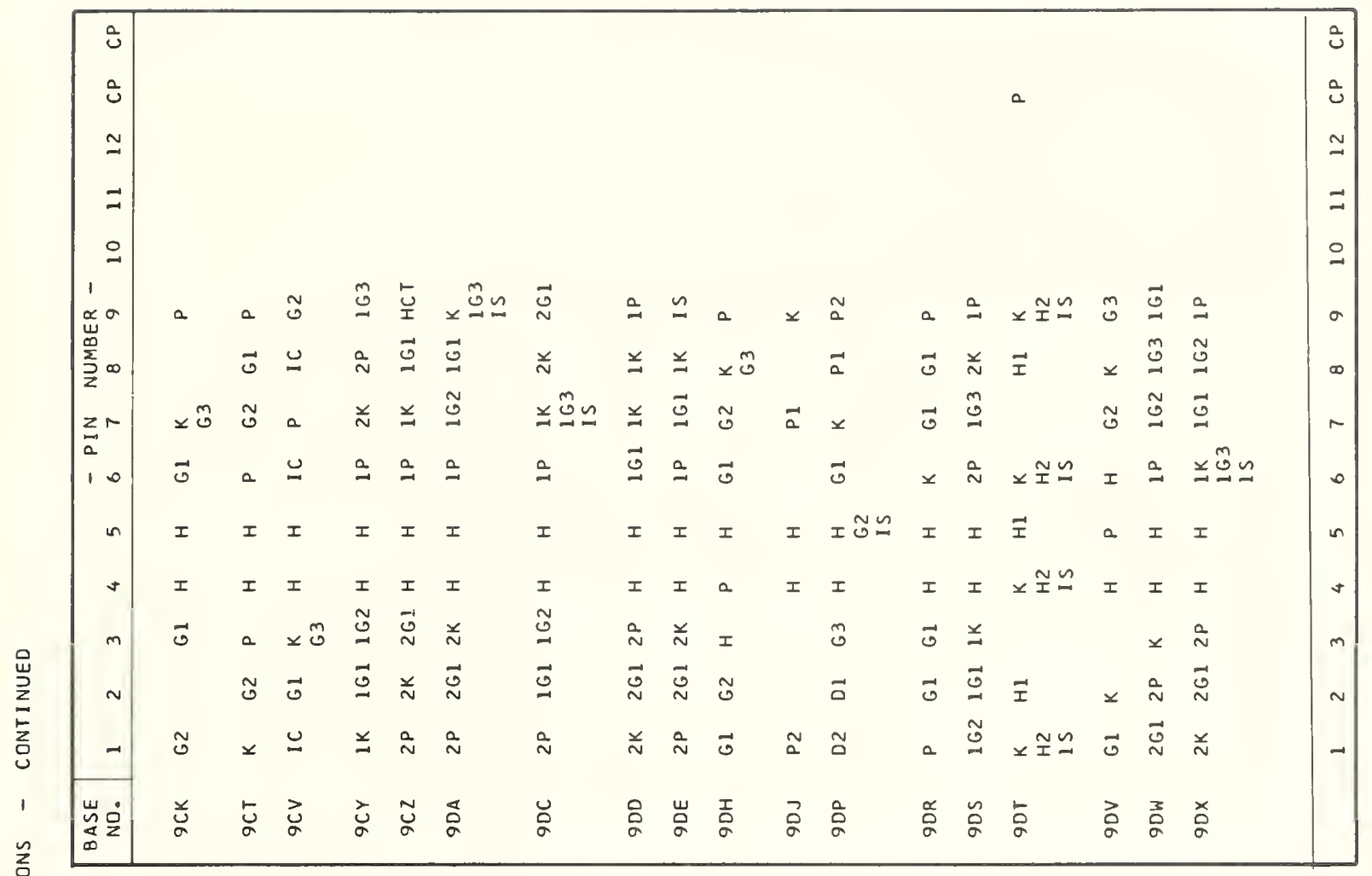

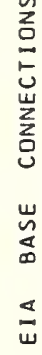

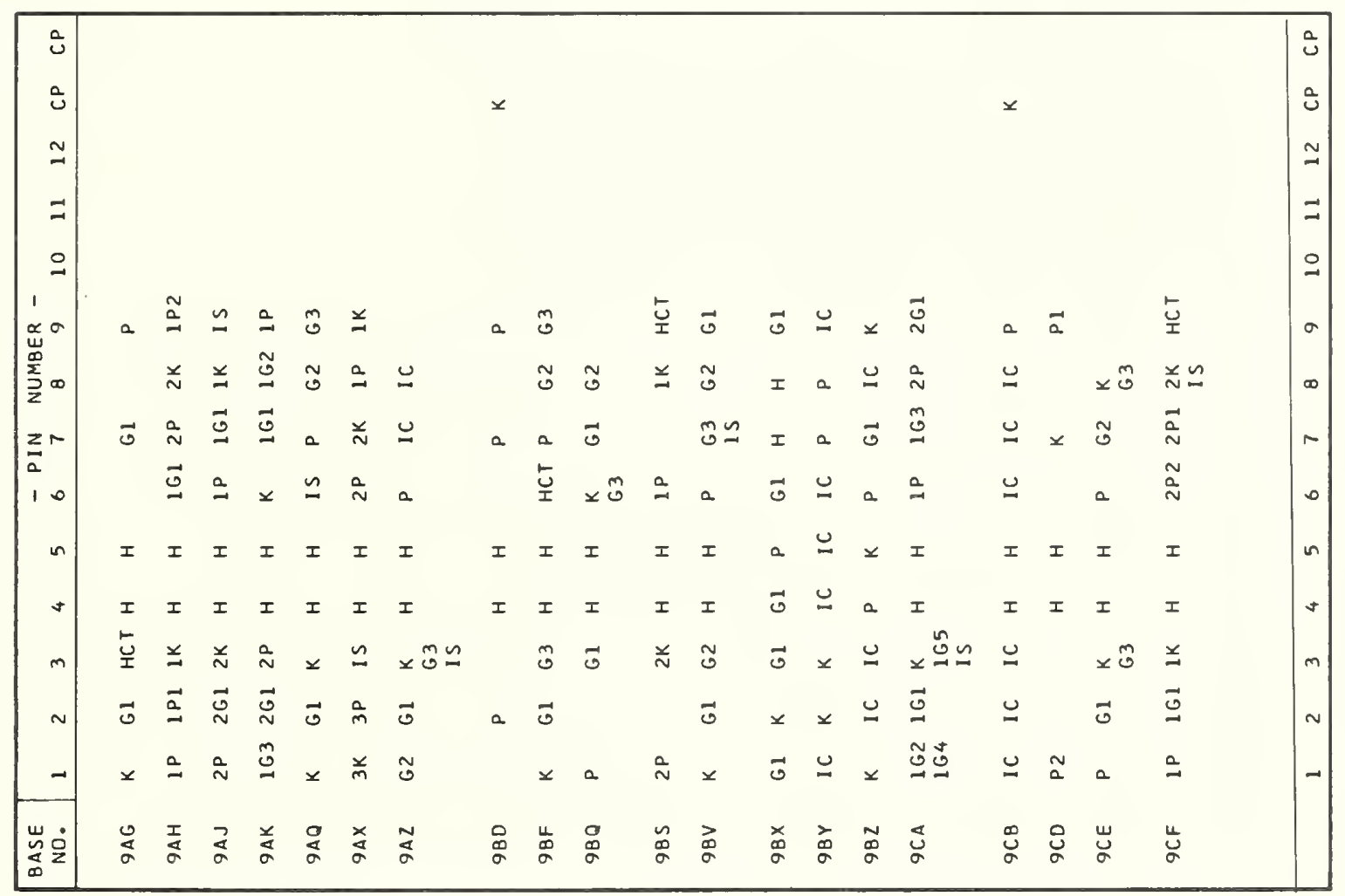




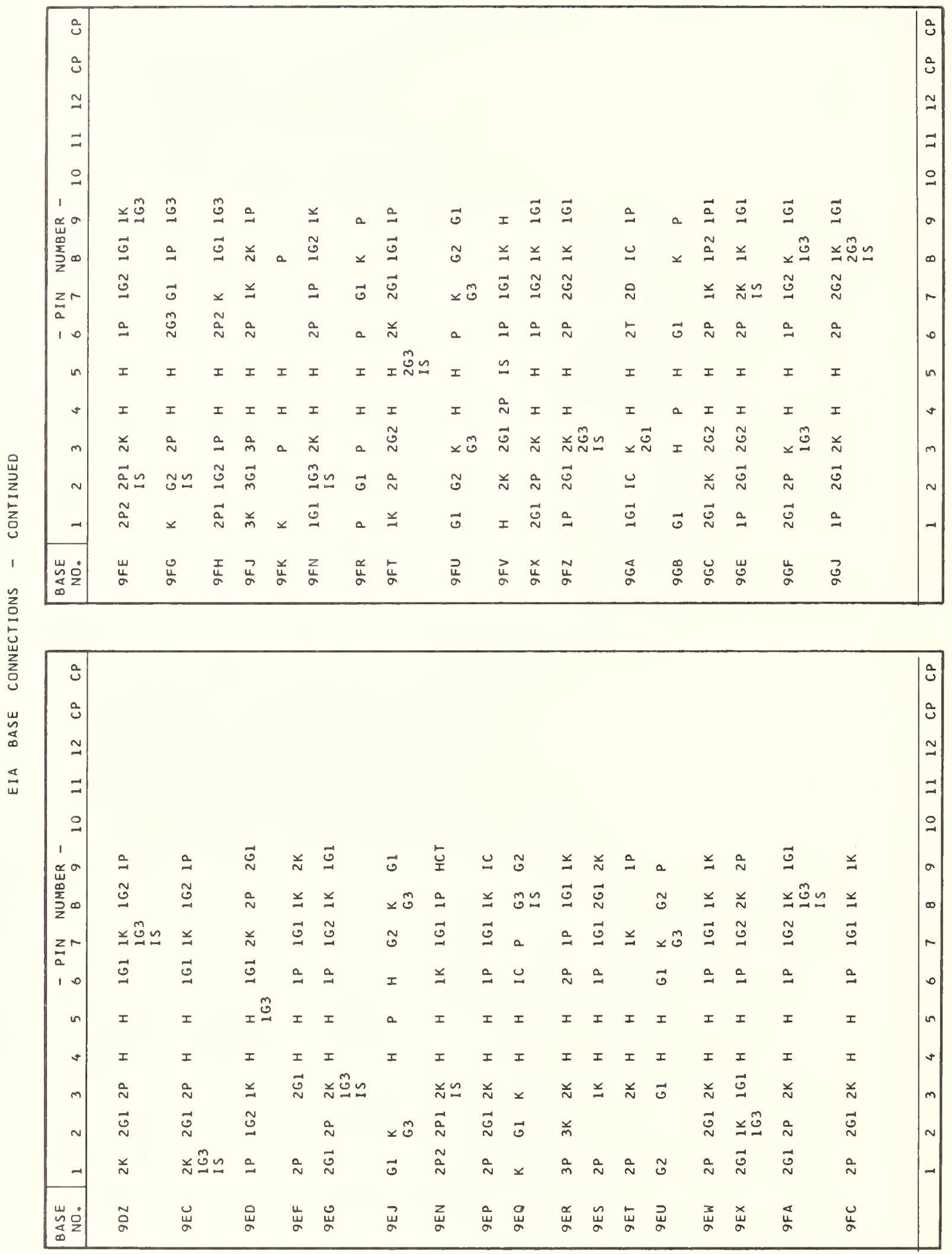



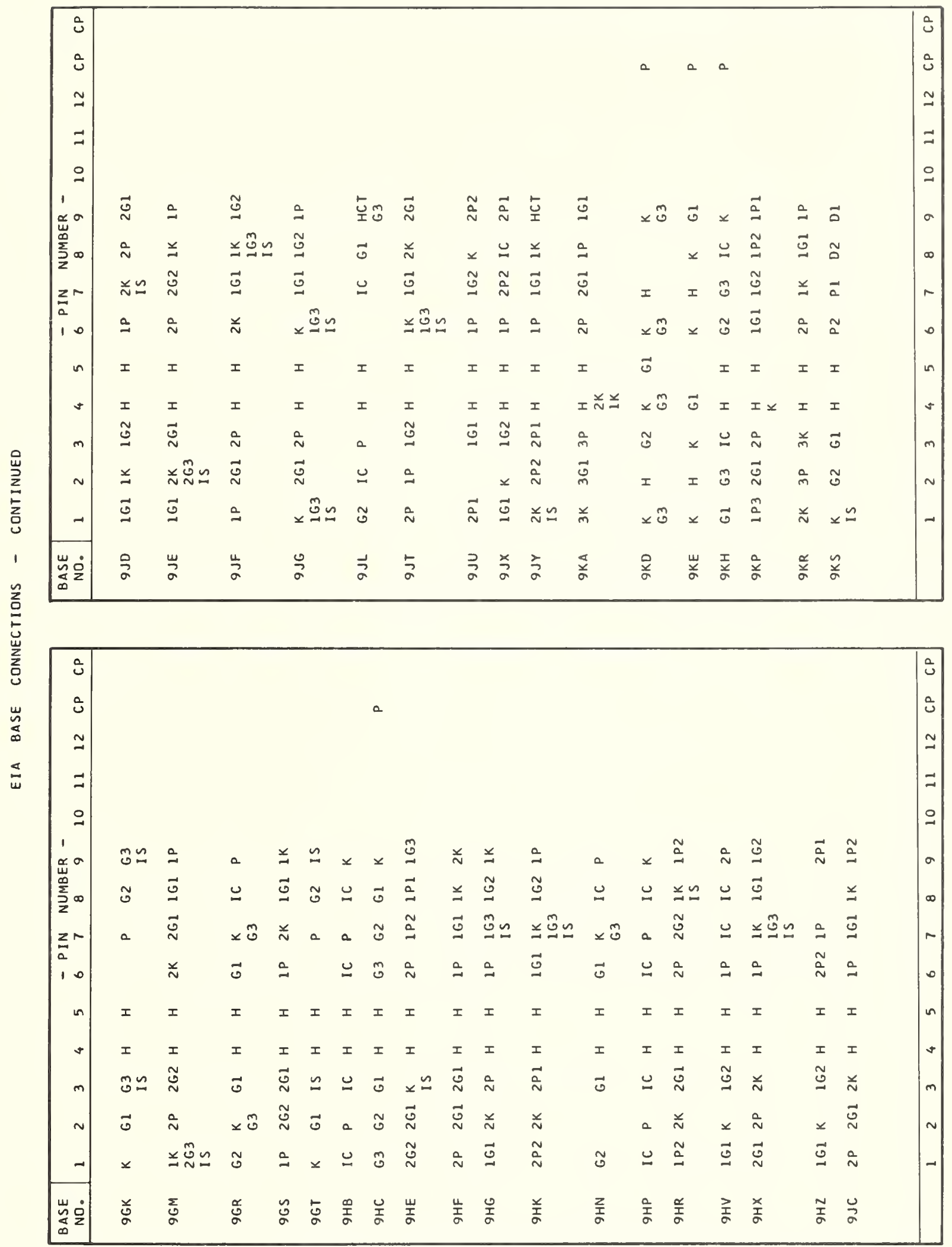


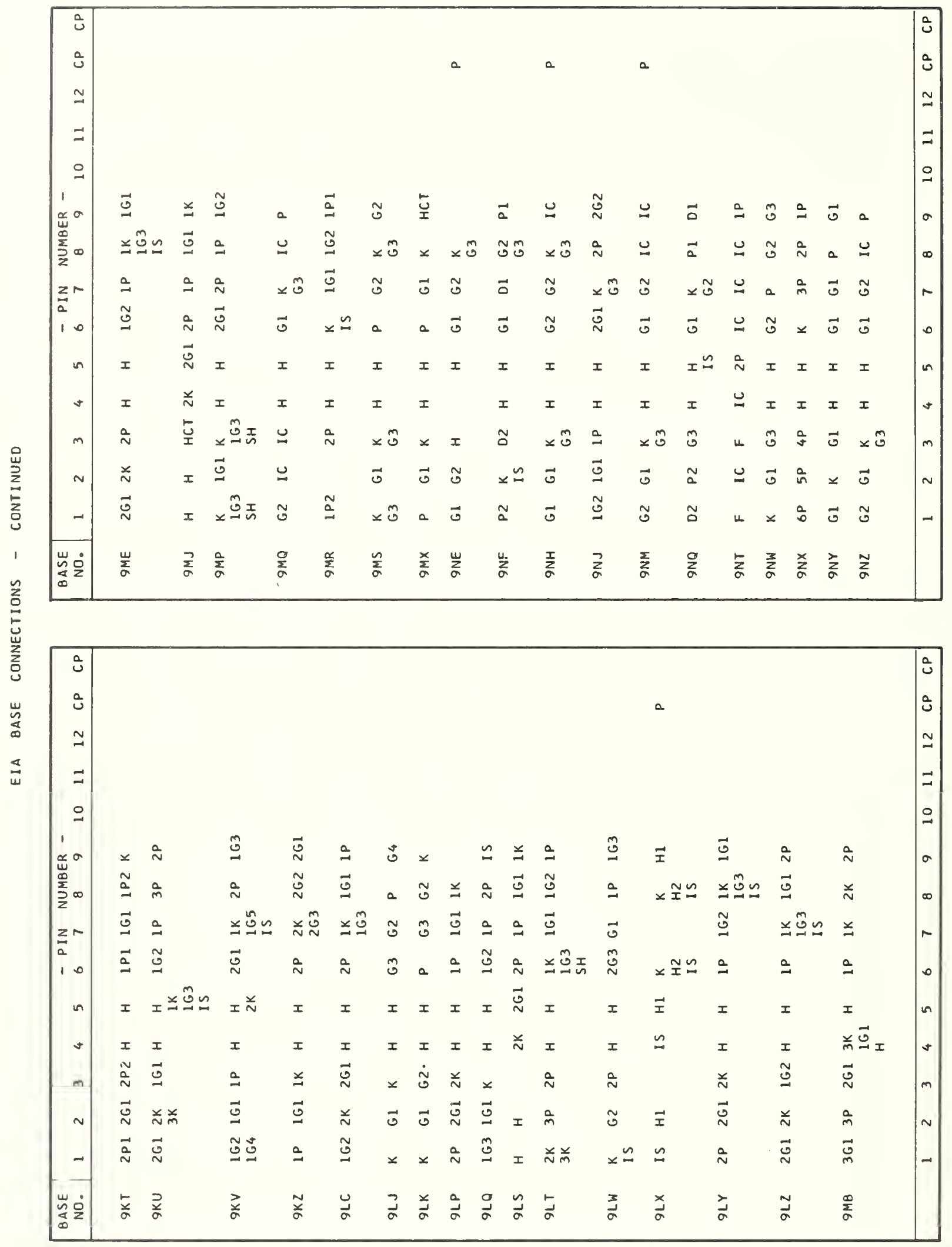




\begin{tabular}{|c|c|c|c|c|c|c|c|c|c|c|c|c|c|c|c|c|c|c|c|c|c|}
\hline i & & & & & & & & & & & & & & & & & & $\overrightarrow{0}$ & & & i \\
\hline i & & & & & a & & & & & & & & & & & & & $a$ & & a & s \\
\hline$\simeq$ & & & & $I$ & $I$ & m & $I$ & $I$ & $I$ & $I$ & $I$ & $\vec{u}$ & $I$ & $I$ & $I$ & $I$ & $I$ & $I$ & $I$ & I & $\simeq$ \\
\hline$=$ & & & & & & & $\approx$ & जे & & $\cong$ & $\vec{j}$ & $\vec{a}$ & $\vec{N}$ & $\cong$ & $\overrightarrow{0}$ & $\vec{D}$ & in & & 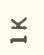 & $\stackrel{\cup}{ }$ & $=$ \\
\hline ㅇ & $\stackrel{\approx}{\sim} \simeq$ & $\stackrel{\sim}{\sim}$ & $\underline{z}$ & $I$ & $I$ & $\grave{\sim}$ & $\stackrel{N}{\varrho}$ & $\times \mathscr{G}$ & a & $\overrightarrow{0}$ & $\cong$ & $\vec{a}$ & & ્ِ & $\hat{\theta}=$ & $\cong$ & 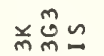 & I & $\cong$ & & 옹 \\
\hline 1 & $a$ & $\overrightarrow{0}$ & $\stackrel{\circ}{\sim}$ & 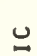 & 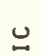 & $\vec{N}$ & $\underline{\sim}$ & 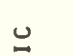 & 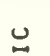 & $\underline{\underline{I}}$ & $\overrightarrow{0}$ & 5 & $\stackrel{2}{N}$ & $\simeq \stackrel{\mathscr{G}}{=}$ & $a$ & $\overrightarrow{0}$ & $\underline{I}$ & & $\stackrel{x}{N}$ & 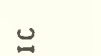 & $\sigma$ \\
\hline$\sum_{\substack{\infty \\
\Sigma}}$ & S & $a$ & $\vec{N}$ & $x$ & $x$ & $\cong$ & $\vec{a}$ & 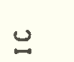 & 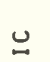 & & $\underline{\Xi}$ & $\vec{a}$ & $\underline{\simeq} \cong$ & $\overrightarrow{0}$ & $\underline{\exists}$ & $\simeq$ & $\overline{0}$ & $x$ & $\overrightarrow{0}$ & 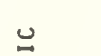 & $\infty$ \\
\hline 2 & J & $\overrightarrow{0}$ & $\stackrel{\text { N }}{ }$ & $\varrho$ & $\underline{\underline{U}}$ & $I$ & N & a & $x$ & $\underset{N}{x}$ & $\vec{N}$ & $\vec{a}$ & $\overline{0}$ & ్ָ & క్త & $\vec{N}$ & $a$ & $\underline{\simeq}$ & $\stackrel{2}{\sim}$ & 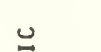 & r \\
\hline 0 & 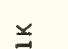 & $\stackrel{2}{\sim}$ & $\tilde{G} \simeq$ & 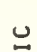 & u & $T$ & $\approx$ & $\underline{u}$ & & $u$ & $\stackrel{丷}{0}$ & $\approx$ & ษ & 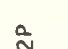 & $\stackrel{x}{\sim}$ & & $\stackrel{a}{a}$ & & a & u & 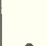 \\
\hline & & & & & & & 7 & & & & & & $m$ & & $\overrightarrow{0}$ & & - & & - & & \\
\hline in & $I$ & $I$ & $I$ & 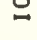 & 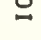 & $\simeq$ & $\stackrel{D}{N}$ & $\approx$ & & $\hat{\sim}$ & $\hat{\sim}$ & $\tilde{\alpha}$ & 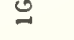 & $\approx$ & $\stackrel{\sim}{\sim}$ & $\hat{\sim}$ & $\stackrel{\vec{N}}{\sim}$ & & in & $\stackrel{\varrho}{0}$ & in \\
\hline a & $I$ & $I$ & $I$ & ज] & 0 & $\overrightarrow{0}$ & m & $\times \hat{0}$ & a & & 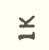 & ¿ & $\cong$ & N & $\stackrel{N}{N} \cong$ & 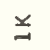 & $\stackrel{x}{N}$ & $x$ & 弚 & & a \\
\hline$m$ & $\stackrel{i}{\sim}$ & 弚 & 0 & $\stackrel{\sim}{\sim}$ & 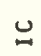 & $\stackrel{\text { 次 }}{ }$ & $\vec{~}$ & $\overrightarrow{0}$ & & $\vec{N}$ & 弚 & $\stackrel{\sim}{a}$ & 웜 & $\vec{N}$ & $\stackrel{a}{N}$ & 前 & W & & g & $\underline{0}$ & $m$ \\
\hline$\sim$ & $\underset{\sim}{\sim}$ & j & 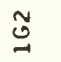 & a & ช & $\vec{j}$ & m & บ & & & $\stackrel{a}{m}$ & $\stackrel{\sim}{a}$ & ڤ & 弚 & Õ & ले & $\overrightarrow{0}$ & $x$ & 弟 & 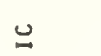 & $\sim$ \\
\hline- & $\vec{N}$ & m & $\overrightarrow{0}$ & 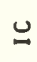 & 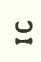 & 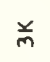 & $I$ & $I$ & $I$ & $I$ & $I$ & N & $I$ & $I$ & $I$ & $I$ & $I$ & & $I$ & $I_{x} \simeq$ & - \\
\hline 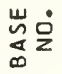 & $\stackrel{4}{0}$ & $\stackrel{0}{\circ}$ & I & $\stackrel{g}{\stackrel{a}{N}}$ & $\stackrel{n}{\underline{J}}$ & 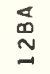 & $\stackrel{\stackrel{u}{ \pm}}{\stackrel{\sim}{\sim}}$ & $\stackrel{\vec{D}}{\stackrel{(}{N}}$ & $\stackrel{\vec{D}}{\underset{\sim}{\sim}}$ & $\stackrel{\Sigma}{\stackrel{\Sigma}{N}}$ & $\stackrel{g}{\stackrel{g}{N}}$ & 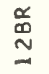 & $\stackrel{\mathfrak{D}}{\stackrel{D}{=}}$ & $\stackrel{\vec{D}}{\stackrel{D}{\sim}}$ & 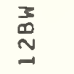 & 总 & 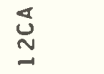 & 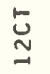 & $\stackrel{\Xi}{\text { I }}$ & $\stackrel{\text { I }}{\text { I }}$ & \\
\hline
\end{tabular}

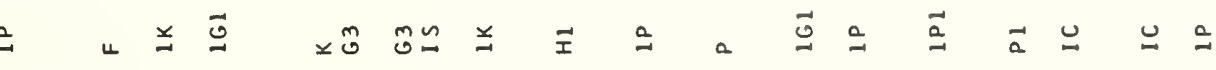

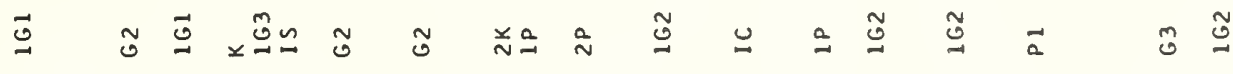

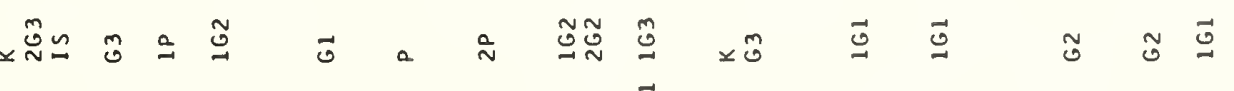

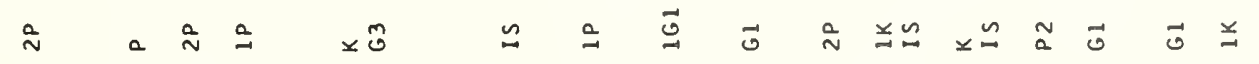

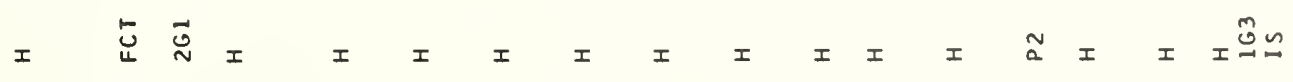
I

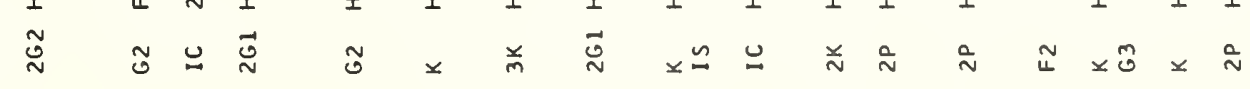

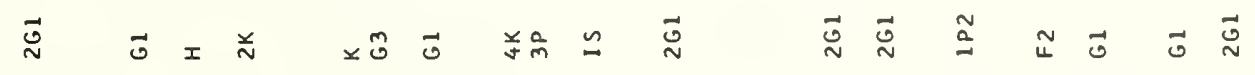

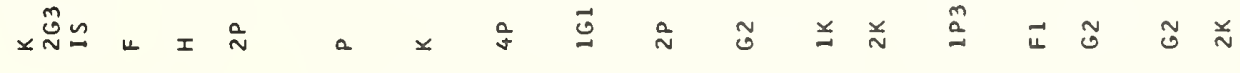

岁家 范 







\section{THE NATIONAL BUREAU OF STANDARDS}

\section{Functions and Activities}

The functions of the National Bureau of Standards are set forth in the Act of Congress, March 3, 1901, as amended by Congress in Public Law 619, 1950. These include the development and maintenance of the national standards of measurement and the provision of means and methods for making measurements consistent with these standards; the determination of physical constants and properties of materials; the development of methods and instruments for testing materials, devices, and structures; advisory services to government agencies on scientific and technical problems; invention and development of devices to serve special needs of the Government; and the development of standard practices, codes, and specifications. The work includes basic and applied research, development, engineering, instrumentation, testing, evaluation, calibration services, and various consultation and information services. Research projects are also performed for other government agencies when the work relates to and supplements the basic program of the Bureau or when the Bureau's unique competence is required. The scope of activities is suggested by the listing of divisions and sections on the inside of the back cover.

\section{Publications}

The results of the Bureau's research are published either in the Bureau's own series of publications or in the journals of professional and scientific societies. The Bureau itself publishes three periodicals available from the Government Printing Office: The Journal of Research, published in four separate sections, presents complete scientific and technical papers; the Technical News Bulletin presents summary and preliminary reports on work in progress; and Basic Radio Propagation Predictions provides data for determining the best frequencies to use for radio communications throughout the world. There are also five series of nonperiodical publications: Monographs, Applied Mathematics Series, Handbooks, Miscellaneous Publications, and Technical Notes.

A complete listing of the Bureau's publications can be found in National Bureau of Standards Circular 460, Publications of the National Bureau of Standards, 1901 to June 1947 (\$1.25), and the Supplement to National Bureau of Standards Circular 460, July 1947 to June 1957 (\$1.50), and Miscellaneous Publication 240, July 1957 to June 1960 (Includes Titles of Papers Published in Outside Journals 1950 to 1959 ) (\$2.25); available from the Superintendent of Documents, Government Printing Office, Washington, D.C. 


\section{THE NATIONAL BUREAU OF STANDARDS}

The scope of activities of the National Bureau of Standards at its major laboratories in Washington, D.C., and Boulder, Colorado, is suggested in the following listing of the divisions and sections engaged in technical work. In general, each section carries out specialized research, development, and engineering in the field indicated by its title. A brief description of the activities, and of the resultant publications, appears on the inside of the front cover.

\section{WASHINGTON, D.C.}

Electricity. Resistance and Reactance. Electrochemistry. Electrical Instruments. Magnetic Measurements. Dielectrics. High Voltage.

Metrology. Photometry and Colorimetry. Refractometry. Photographic Research. Length. Engineering Metrology. Mass and Scale. Volumetry and Densimetry.

Heat. Temperature Physics. Heat Measurements. Cryogenic Physics. Equation of State. Statistical Physics. Radiation Physics. X-ray. Radioactivity. Radiation Theory. High Energy Radiation. Radiological Equipment. Nucleonic Instrumentation. Neutron Physies.

Analytical and Inorganic Chemistry. Pure Substances. Spectrochemistry. Solution Chemistry. Standard Reference Materials. Applied Analytical Research. Crystal Chemistry.

Mechanics. Sound. Pressure and Vacuum. Fluid Mechanics. Engineering Mechanics. Rheology. Combustion Controls.

Polymers. Macromolecules: Synthesis and Structure. Polymer Chemistry. Polymer Physics: Polymer Characterization. Polymer Evaluation and Testing. Applied Polymer Standards and Research. Dental Research.

Metallurgy. Engineering Metallurgy. Microscopy and Diffraction. Metal Reactions. Metal Physics. Electrolysis and Metal Deposition.

Inorganic Solids. Engineering Ceramics. Glass. Solid State Chemistry. Crystal Growth. Physicál Properties. Crystallography.

Building Research. Structural Engineering. Fire Research. Mechanical Systems. Organic Building Materials. Codes and Safety Standards. Heat Transfer. Inorganic Building Materials. Metallic Building Materials.

Applied Mathematics. Numerical Analysis. Computation. Statistical Engineering. Mathematical Physics. Operations Research.

Data Processing Systems. Components and Techniques. Computer Technology. Measurements Automation. Engineering Applications. Systems Analysis.

Atomic Physics. Spectroscopy. Infrared Spectroscopy. Far Ultraviolet Physics. Solid State Physics. Electron Physics. Atomic Physics. Plasma Spectroscopy.

Instrumentation. Engineering Electronics. Electron Devices. Electronic Instrumentation. Mechanical Instruments. Basic Instrumentation.

Physical Chemistry. Thermochemistry. Surface Chemistry. Organic Chemistry. Molecular Spectroscopy. Elementary Processes. Mass Spectrometry. Photochemistry and Radiation Chemistry.

Office of Weights and Measures.

\section{BOULDER, COLO.}

Cryogenic Engineering Laboratory. Cryogenic Equipment. Cryogenic Processes. Properties of Materials. Cryogenic Technical Services.

\section{CENTRAL RADIO PROPAGATION LABORATORY}

Ionosphere Research and Propagation. Low Frequency and Very Low Frequency Research. Ionosphere Research. Predietion Services. Sun-Earth Relationships. Field Engineering. Radio Warning Services. Vertical Soundings Research.

Radio Propagation Engineering. Data Reduction Instrumentation. Radio Noise. Tropospheric Measurements. Tropospheric Analysis. Propagation-Terrain Effects. Radio-Meteorology. Lower Atmosphere Physics.

Radio Systems. Applied Electromagnetic Theory. High Frequency and Very High Frequency Research. Frequency Utilization. Modulation Research. Antenna Research. Radiodetermination.

Upper Atmosphere and Space Physics. Upper Atmosphere and Plasma Physics. High Latitude Ionosphere Physics. Ionosphere and Exosphere Scatter. Airglow and Aurora. Ionospheric Radio Astronomy.

\section{RADIO STANDARDS LABORATORY}

,

Radio Physics. Radio Broadcast Service. Radio and Microwave Materials. Atomic Frequency and Time-Interval Standards. Radio Plasma. Millimeter-Wave Research.

Circuit Standards. High Frequency Electrical Standards. High Frequency Calibration Services. High Frequency Impedance Standards. Microwave Calibration Services. Microwave Circuit Standards. Low Frequency Calibration Services. 

